\title{
Prader-Willi syndrome : genotype and phenotype at adult age
}

Citation for published version (APA):

Sinnema, M. (2011). Prader-Willi syndrome : genotype and phenotype at adult age. [Doctoral Thesis, Maastricht University]. Universitaire Pers Maastricht. https://doi.org/10.26481/dis.20111209ms

Document status and date:

Published: 01/01/2011

DOI:

10.26481/dis.20111209ms

Document Version:

Publisher's PDF, also known as Version of record

\section{Please check the document version of this publication:}

- A submitted manuscript is the version of the article upon submission and before peer-review. There can be important differences between the submitted version and the official published version of record.

People interested in the research are advised to contact the author for the final version of the publication, or visit the DOI to the publisher's website.

- The final author version and the galley proof are versions of the publication after peer review.

- The final published version features the final layout of the paper including the volume, issue and page numbers.

Link to publication

\footnotetext{
General rights rights.

- You may freely distribute the URL identifying the publication in the public portal. please follow below link for the End User Agreement:

www.umlib.nl/taverne-license

Take down policy

If you believe that this document breaches copyright please contact us at:

repository@maastrichtuniversity.nl

providing details and we will investigate your claim.
}

Copyright and moral rights for the publications made accessible in the public portal are retained by the authors and/or other copyright owners and it is a condition of accessing publications that users recognise and abide by the legal requirements associated with these

- Users may download and print one copy of any publication from the public portal for the purpose of private study or research.

- You may not further distribute the material or use it for any profit-making activity or commercial gain

If the publication is distributed under the terms of Article $25 \mathrm{fa}$ of the Dutch Copyright Act, indicated by the "Taverne" license above, 


\section{PRADER-WILLI SYNDROME:}

\section{GENOTYPE AND PHENOTYPE AT ADULT AGE}


The research presented in this thesis was conducted at the Governor Kremers Centre (GKC)- Department of Clinical Genetics of the Maastricht University Medical Centre (MUMC ${ }^{+}$).

\section{GKC| caphri GROШ Maastricht UMC+}

The studies presented in this dissertation were funded by the Prader-Willi fund (www.prader-willi-fonds.nl) and the Netherlands Organisation for Health Research and Development (ZonMw; project "Participatory research into quality of life of adults with intellectual disabilities", grant number 57000005).

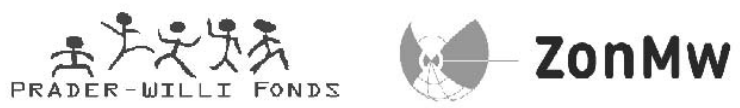

(C) 2011 Margje Sinnema, Maastricht

Cover design: Datawyse | Universitaire Pers Maastricht

Layout: Tiny Wouters

Production: Datawyse | Universitaire Pers Maastricht

ISBN: 9789461590930

Financial support for the printing of this thesis was kindly provided by:

The Prader-Willi fund (www.prader-willi-fonds.nl) 


\title{
PRADER-WILLI SYNDROME:
}

\section{GENOTYPE AND PHENOTYPE AT ADULT AGE}

\author{
PROEFSCHRIFT \\ ter verkrijging van de graad van doctor \\ aan de Universiteit Maastricht, \\ op gezag van de Rector Magnificus, Prof. mr. G.P.M.F. Mols, \\ volgens het besluit van het College van Decanen, \\ in het openbaar te verdedigen \\ op vrijdag 9 december 2011 om 12.00 uur \\ door
}

Margje Sinnema

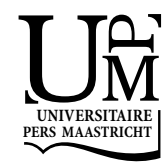




\section{Promotores:}

Prof. dr. L.M.G. Curfs

Prof. dr. C.T.R.M. Schrander-Stumpel

\section{Beoordelingscommissie:}

Prof. dr. J.J. van Os (voorzitter)

Prof. dr. J.P.M. Geraedts

Prof. dr. A.J. Holland (University of Cambridge, UK)

Prof. dr. G.D.E.M. van der Weijden 
Voor opapa en opa 


\section{CONTENTS}

Chapter 1 General introduction 9

1.1 Introduction 11

1.2 Research questions and outline of the thesis 20

1.3 Methods and study population 22

Chapter 2 Different distribution of genetic subtypes of Prader-Willi 33 syndrome in elderly

Eur J Hum Genet 2010;18:993-998

Chapter $3 \quad 3.1$ Physical health problems in adults with Prader-Willi syndrome Am J Med Genet Part A 2011;155:2112-2124

3.2 The use of medical care and prevalence of serious illness in a Dutch adult Prader-Willi syndrome cohort Submitted

Chapter 4 Behavioural phenotype in adults with Prader-Willi syndrome Res Dev Dis 2011;32:604-612

Chapter 5 Psychiatric illness in a cohort of adults with Prader-Willi 107 syndrome

Res Dev Dis 2011;32:1729-1735

Chapter 6 Dementia in a woman with Prader-Willi syndrome

Eur J Med Genet 2010;53:145-148

Chapter 7 Ageing in Prader-Willi syndrome: Twelve persons over the age of 50 years

Submitted

Chapter 8 General discussion

8.1 Results in a broader perspective

8.2 Clinical implications

8.3 Methodological considerations

8.4 Future research opportunities 
Summary

Samenvatting

List of publications

Appendix 1 Checklist for clinical follow-up of adults with

Prader-Willi syndrome

Appendix 2 Medical Alerts

Medical Alerts; aandachtspunten in spoedsituaties voor mensen met Prader-Willi syndroom. Utrecht/Maastricht, April 2009.

Appendix 3 Acute gastric dilatation as a cause of death in

Prader-Willi syndrome: two cases

Submitted

Appendix 4 Lymphoedema in Prader-Willi syndrome Int J Dermatol 2008; 47(Suppl.1):42-44

Appendix 5 Sleep disturbances and behavioural problems in adults with Prader-Willi syndrome J Intellect Disabil Res 2010;54:906-917

Appendix 6 Urinary incontinence in persons with Prader-Willi syndrome

BJU Int 2010;106:1758-1762

Appendix 7 The GH/IGF-I axis and pituitary function and size in adults with Prader-Willi syndrome Horm Res Paediatr 2011;75:403-404

Dankwoord 

CHAPTER 1

\section{GENERAL INTRODUCTION}


CHAPTER 1 


\subsection{INTRODUCTION}

Prader-Willi syndrome (PWS) was first described in 1956 by the three Swiss pediatricians Prader, Labhart and Willi ${ }^{1}$. The syndrome is a genetic disorder that originates from lack of expression of the PWS region of the paternally derived chromosome 15. The estimated birth incidence in PWS varies from 1:25 000 to 1:29 500 live births ${ }^{2-4}$. The reported overall population prevalence, based on epidemiologic studies, varies from 1:52 000 to $1: 76574^{3,4}$. Clinical characteristics of PWS include hypotonia, short stature, hypogonadism, intellectual disabilities, behavioral problems and hyperphagia ${ }^{5}$.

Research in PWS has mainly focused on clinical characteristics in childhood and early adulthood. Little is known about persons with PWS at older age. The aim of this thesis is to contribute towards better understanding of PWS at adult age. This chapter starts with an introduction into ageing in people with intellectual disabilities (ID) in general, followed by the age specific characteristics in PWS, the genetic mechanisms, the role of the hypothalamus, overeating behaviour, body-composition and obesity. In section 1.2 the research questions and outline of the thesis are presented. Finally, the methods and study population are described in section 1.3.

\section{Ageing in people with intellectual disabilities}

Life expectancy for individuals with ID has markedly increased in recent decades $^{6-8}$. Among others, this is due to improvements in nutrition, mastering the control of infectious diseases and early intervention in illness management ${ }^{6,8}$. Life expectancy of adults with mild ID is rapidly approaching near-parity with the general population ${ }^{7}$. Persons with moderate ID now routinely live into their late $60 \mathrm{~s}$ and those with severe ID to their late $50 \mathrm{~s}^{7}$.

Ageing in persons with ID presents significant challenges ${ }^{9}$. Like other people, older individuals with ID may have significant health needs. They may face age related physical changes and chronic morbidity common in the general older population ${ }^{10}$. Moreover, higher rates of morbidity and early mortality in adults with ID are found. Health conditions such as sensory impairments, obesity, epilepsy, mental health problems and gastro-intestinal conditions are common but frequently unrecognized and poorly managed ${ }^{10}$.

Appropriate surveillance of medical care is complicated by the diversity of the population of adults with ID as a whole ${ }^{11}$. There is a need to determine unique health status characteristics and morbidity risks relating to the underlying etiology. Ageing in Down syndrome for example is characterized by increased rates of cataract, hearing loss, hypothyroidism, osteoporosis, epilepsy and an 
elevated risk to develop Alzheimer disease ${ }^{12,13}$. Persons with Down syndrome are also suggested to age prematurely ${ }^{12}$. Little is known about the ageing characteristics of other genetic syndromes, such as PWS.

\section{Age related clinical characteristics in Prader-Willi syndrome}

It is possible to distinguish a fetal phenotype in PWS, although this is very variable in nature and extent. The fetal phenotype comprises decreased fetal movements, polyhydramnios and an abnormal posture on an ultrasonogram ${ }^{14,15}$. There is an increase in incidence of breech delivery and delivery by caesarian section. Pre- or post term deliveries are frequently seen ${ }^{15}$. At birth, neonates with PWS have severe hypotonia mainly affecting the neck and they have a weak or absent cry ${ }^{16,17}$. Due to the severe hypotonia and poor sucking reflex, feeding via a nasogastric tube is usually required ${ }^{16}$. Hypoplasia of the external genitalia is common in both sexes; however this is more obvious in boys ${ }^{5}$. Almost all boys have cryptorchidism, a hypoplastic scrotum and a decreased penile length ${ }^{18}$. Girls may have hypoplastic labia. Neonates often have temperature instability, little spontaneous movements and mild dysmorphic features ${ }^{19}$. Nowadays, the diagnosis of PWS is usually confirmed in the neonatal period ${ }^{20}$. Several weeks or months after birth, the infants become more responsive and are capable of more spontaneous movements. However, they continue to suffer from hypotonia, muscle weakness and as a result severely delayed motor development ${ }^{21-23}$. Facial dysmorphic features become more pronounced: a narrow bifrontal diameter, almond shaped eyes, a thin downturned upperlip and a narrow nose ${ }^{5}$.

Between the age of two and five, the original feeding problems improve and excessive appetite with hyperphagia develops. Without dietary restrictions this may result in extreme obesity. Persons with PWS have a short stature and abnormal body composition, characterized by a relatively high body fat percentage and low lean body mass ${ }^{24}$. A characteristic posture, including sloping shoulders, heavy mid-section, genu valgum and scoliosis often develops during childhood ${ }^{25}$. By school age, intellectual and social difficulties become more apparent. A typical behavioural pattern, including temper tantrums, stubbornness, hoarding, skinpicking, emotional lability and difficulty in changing routines, may become more pronounced during childhood ${ }^{26,27,28}$.

Puberty is incomplete or delayed in both males and females with PWS, although some have precocious puberty ${ }^{29}$. Traditionally, hypogonadism in PWS was mainly attributed to a central hypothalamic dysfunction characterized by deficiency of gonadotropins, oestrogen and testosterone ${ }^{30}$. Recent studies however, have also documented a variable contribution of primary gonadal defect in male and female to the hypogonadism ${ }^{31,32}$. The pubertal growth spurt 
may be lacking, and development of beard and body hair occurs later than normal or is absent. Menarche is often late or does not occur in women and menses are mostly irregular ${ }^{33}$. Approximately $90 \%$ of individuals with PWS have, without growth hormone treatment, short stature by adulthood ${ }^{34}$. Small hands with thin, tapering fingers and small feet become more pronounced ${ }^{5}$. Typical adolescent rebelliousness and behavioural problems are more noticeable in those with PWS; this is particularly food related ${ }^{35}$.

The specific characteristics of PWS during adult life are not well known. In childhood, once the diagnosis is made and the parents have been helped to understand the problem of overeating associated with the syndrome, parents usually manage the food environment and limit the access to food ${ }^{36}$. In adult life, increasing independence and more unsupervised access to food results in a risk of developing obesity ${ }^{37}$. There is a tension between respect for an adult's autonomy to make decisions for him/herself and the severe obesity that is likely to follow with all the health and social consequences ${ }^{38}$. Most people with PWS have intellectual disabilities. IQ in PWS is usually in the range of 50-85, with $25 \%$ having an IQ over $70^{39,40}$. People with PWS have poor short-term memory, deficits in sequential processing, perform better on visuo-spatial tasks and are more likely to have exceptional skills with jigsaw puzzles ${ }^{41,42}$. It has been suggested that physical morbidity, including diabetes mellitus, respiratory problems, obstructive sleep apnoea, hypertension and cardiovascular problems, is secondary to obesity ${ }^{3,36,43-46}$. Psychiatric symptoms are frequent in adults with PWS and are associated with psychosis and affective disorders ${ }^{47-50}$. These symptoms usually start in early adulthood ${ }^{46}$.

The mean mortality rate was estimated to be $3 \%$ per year across the age range of about $7 \%$ per year above the age $30^{4}$. Another large study suggested a 6 fold relative risk of death in PWS versus other individuals with $I D^{51}$. Common causes of death in PWS adults are obesity related cardiovascular and respiratory failure ${ }^{52}$, while unexpected sudden death in childhood is associated with acute respiratory failure and/or high fever ${ }^{53}$.

\section{Genetic mechanisms causing Prader-Willi syndrome}

Since the late 1970s, occasional reports in the literature have suggested that there is an association between PWS and a chromosomal rearrangement affecting a certain part of one of the chromosomes 15. In 1981 Ledbetter et al. ${ }^{54}$, using high resolution chromosome banding analysis, first reported the cause of PWS as an interstitional deletion of the long arm of chromosome 15 at region q11-q13 in the majority of subjects studied. The origin of the deletion was de novo and not present in either parent ${ }^{55}$. In all cases the chromosome 15 with the deletion was of paternal origin. A paternal deletion is the most 
common chromosomal defect in PWS and is present in about $70 \%$ of the subjects $^{42,56}$. The defect occurs either as a large type I deletion, spanning from breakpoint 1 (BP1) to breakpoint 3 (BP3), or as a smaller type II deletion, spanning from breakpoint 2 (BP2) to BP3 (see Figure 1.1). In about $10 \%$ of the cases deletions are atypical in size ${ }^{57}$. The recurrence risk of a 15q11-q13 deletion is very low if the parents have normal chromosomes ${ }^{58}$.

In 1989, Nicholls et al. ${ }^{59}$ described a molecular cause for PWS in the individuals without a deletion of 15q11-q13. They found that most of the remaining subjects lacked a paternal chromosome 15 and had two maternal chromosome 15s. Subsequent studies have revealed that maternal uniparental disomy (mUPD) is the second most frequent finding in PWS $(25 \%$ of the cases). mUPD arises in most cases from the postzygotic correction of a meiotic error $^{60}$. During meiosis the diploid set of chromosomes $(n=46)$ is reduced to a haploid set $(n=23)$. Nondisjunction of one of the homologous chromosome $15 \mathrm{~s}$ during female meiosis I or nondisjunction of the two sister chromatids during meisosis II results in an oocyte with two or none chromosome 15s. Fertilization of an oocyte containing two maternal chromosome 15 copies by a normal sperm with one paternal chromosome 15, leads to a zygote trisomic for chromosome 15. Many trisomies are non-viable and result in spontaneous abortions or in early postnatal death. If one of the chromosome $15 \mathrm{~s}$ can be rejected in early dividing cells, the fetus can be "rescued". In two thirds of the cases one of the maternal chromosome $15 \mathrm{~s}$ will be lost. However, if the paternal chromosome 15 is lost, the zygote is left with two maternal chromosome 15s. As in other non-disjunction cases, the risk of mUPD increases with maternal age ${ }^{61}$.

The discovery that only a deletion of $15 q 11-q 13$ of paternal origin and only maternal UPD 15 result in PWS, was an important clue that imprinting should play a role in the PWS region on chromosome $15^{62}$.

The chromosomal region $15 q 11-q 13$ is called the PWS region. PWS and Angelman Syndrome (AS) were the first examples of genomic imprinting in humans ${ }^{62}$. Gene imprinting is a mechanism by which part of a chromosome is "imprinted" or silenced during gametogenesis, which leads to a different expression according to the parent of origin. In healthy subjects the region of the maternally inherited chromosome 15 is silenced by the imprinting process, whereas this region of the paternally derived chromosome is expressed. Abnormal or absent expression of paternally expressed genes on the 15q11q13 region causes Prader-Willi syndrome. A deletion, a disomy or an imprinting defect in the same region on the maternal chromosome results in a completely different syndrome, $\mathrm{AS}^{62}$. 
In rare cases (1-5\%), PWS results from an imprinting defect. These individuals have apparently normal chromosome $15 \mathrm{~s}$ of biparental inheritance, but the paternal chromosome carries a maternal imprint. This leads to a complete loss of the paternally expressed genes in 15q11-q13. The functional consequences are identical to that of the mUPD. The imprinting centre (IC) regulates DNA methylation, gene expression and chromatin structure of the whole imprinted domain. In approximately $15 \%$ of the individuals with PWS due to an imprinting defect, the incorrect imprint is the result of a microdeletion affecting the $I C^{63-65}$. Most of the IC deletions are familial mutations and are associated with a $50 \%$ recurrence risk $^{66}$. The majority of people with PWS and an imprinting defect $(85 \%)$ do not have a IC deletion ${ }^{66,67}$. The imprinting defect in these persons occurs spontaneously in the absence of a DNA sequence change. In these cases, the paternal grandmother's imprint fails to reset ${ }^{66,67}$. The recurrence risk for siblings is very low ${ }^{66}$.

Until 1981 the diagnosis of PWS was solely based on a combination of clinical characteristics listed in the consensus diagnostic criteria ${ }^{5}$. However, these were published before comprehensive laboratory testing was available. Diagnosis should nowadays not be made on clinical grounds alone, but should be confirmed by genetic tests. The diagnosis of PWS can be confirmed or rejected by DNA methylation analyses, most commonly performed by using DNAspecific techniques at the SNURF/SNRPN locus ${ }^{36,58}$. In case of PWS, only a maternally methylated allele can be detected. Multiplex ligation-dependent probe amplification (MLPA) of the chromosome 15q11-q13 or fluorescence in situ hybridization (FISH) analysis, provides additional information on the presence of a deletion of the PWS region. DNA polymorphism analysis should be performed in the PWS subjects without deletion and the parents, to distinguish mUPD from an imprinting defect. An imprinting defect warrants further investigations in a specialized laboratory to determine whether a imprinting centre mutation is present ${ }^{65}$.

\section{The Prader-Willi region on chromosome 15}

Whether PWS is caused by the loss of function of a single gene or of several genes, is not yet clear. Hypotheses have ranged from the absence of expression of a single gene for each PWS phenotypic characteristic, through the absence of expression of a gene for a group of characteristics, to the absence of expression of a single gene for all common "core" characteristics.

Candidate genes for PWS, on the basis of their location and being maternally imprinted, include MKRN3, MAGEL2, NDN, PWRN1, C15orf2, SNURF-SNRPN and several C/D box small nucleolar RNA (snoRNA) genes. There have now been three reports that abnormalities in the SNORD116C/D box snoRNA cluster HBII-85 are sufficient for the core features of PWS to be present. 
SnoRNA's are important in the splicing and editing of messenger RNA. The observation suggests that the absence of expression of this snoRNA may be crucial $^{69-71}$ and is associated with several aspects of the syndrome including the abnormal eating behaviour. However, this genetic abnormality may not account for the full phenotype of PWS.

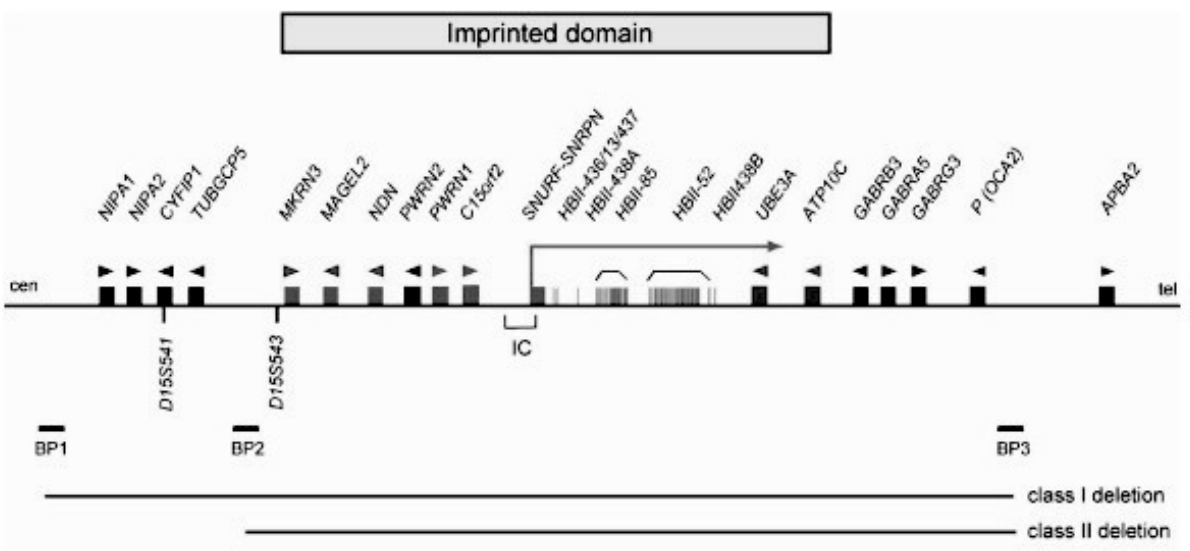

Figure 1.1 Genes within the PWS critical region. "Adapted from Ramsden et al. $2010^{68}$ Genes within the PWS and AS critical region. IC, imprinting centre; BP, common breakpoint cluster region."

The use of mouse models is one of the promising approaches to understanding the genetic basis of PWS. Several mouse models of PWS have been developed, with paternal deletions or mUPD of the PWS region, or with mutations in the imprinting centre. These mice have a consistent phenotype of failure to thrive, hypotonia, neonatal lethality, and growth retardation, but not of hyperphagia and obesity ${ }^{72}$. However, because these animals do not thrive, they do not live long enough for a full PWS phenotype to develop. Knock-out mouse models suggest that loss of MAGEL2 contributes to the reproductive deficits ${ }^{73}$ and lack of Necdin expression contributes to breathing deficits in $\mathrm{PWS}^{74}$.

\section{The role of the hypothalamus}

Many of the manifestations of PWS are attributable to insufficient functioning of the hypothalamus ${ }^{75}$. One of the most important functions of the hypothalamus is to link the nervous system to the endocrine system. The hypothalamus secretes neurohormones, which stimulate or inhibit the secretion of hormones by the pituitary gland. The pituitary hormones include growth hormone $(G H)$, 
the gonadotropins luteinizing and follicle stimulating hormones (LH/FSH), thyroid stimulating hormone (TSH) and adrenocorticotropic hormone (ACTH) ${ }^{30}$.

The often abnormal position of the baby in the uterus at the onset of labour, the high percentage of infants with asphyxia and the high proportion of children born prematurely or post-maturely may all be related to abnormal fetal hypothalamic systems in PWS, as the fetal hypothalamus plays a crucial role in labour $^{75}$. In addition, typical PWS characteristics such as abnormal temperature control, excessive daytime sleepiness, sleep-related breathing disorders, abnormalities of sleep architecture, insatiable appetite, decreased activity level and energy expenditure, temper tantrums, hypogonadotropic hypogonadism, cryptorchidism and growth hormone deficiency may result from hypothalamic disturbances ${ }^{18,36,72,75-78}$.

\section{Over-eating behaviour}

One of the most striking characteristics in individuals with PWS is the overeating behaviour, which, in the absence of dietary restrictions, leads to severe obesity $^{79}$. This propensity to overeat is not present from birth, but usually starts around the age of two years. There is evidence that the propensity to obesity may develop before the onset of hyperphagia ${ }^{80}$. It has been suggested that eating behaviour is more consistent with an abnormal satiety response, rather than with an abnormal hunger ${ }^{81}$. In experimental settings, people with PWS have been observed to consume around three to six times more than the normal caloric intake at a given meal ${ }^{82,83}$. Moreover, their hunger, desire to eat and fullness returned towards those of the pre-meal state very shortly after food was no longer available ${ }^{82}$. Several mechanisms have been proposed to play a role in the overeating behaviour.

Investigations of the brain support a delayed satiety response ${ }^{81}$. Recent neuroimaging studies show an irregular post-meal response with atypical brain activation post meal ${ }^{84}$, delayed activation of satiety centres following glucose administration ${ }^{85}$ and an abnormal activation in areas associated with satiety post-meal ${ }^{81}$. Swaab et al. ${ }^{75}$ showed that the number of oxytocin neurones (the putative satiety neurones) in the hypothalamic paraventricular nucleus is markedly decreased in PWS.

Recently, studies investigated neuropeptide or endocrine factors contributing to the eating behaviour. In PWS, leptin levels are high, which is in line with the excess fat mass ${ }^{86}$. Anabolic neural circuits appear to be repressed ${ }^{87}$. Therefore, eating less would be expected. However, unlike in obese controls, fasting and postprandial plasma levels of the orexigenic stomach-derived hormone ghrelin are greatly elevated in PWS, although they do fall after food 
intake $e^{88-91}$. The cause of the apparent overproduction of ghrelin in PWS is not known and may only be a phenomenon reflecting the presence of a fundamental deficit elsewhere in the feedback mechanism. The role of other gut hormones, such as peptide $Y Y$, an anorexigenic hormone known to affect satiety $^{92}$, is not fully determined ${ }^{93}$. It remains unproven whether the hyperghrelinemia or other gut-hormone abnormalities contribute to the hyperphagia in PWS, in addition to brain defects ${ }^{93}$.

More models are proposed to explain the over-eating behaviour in PWS. It is possible that the delayed satiety response is the result of a disturbance in the perception of inner physiological states ${ }^{79}$. A high pain threshold, which has often been noted in $\mathrm{PWS}^{94}$, might refer to this mechanism.

An abnormal reward response is one of the most discussed behavioural theories of obesity. This theory considers eating in PWS to be an addictive behaviour, with food being the substance of dependence or abuse ${ }^{95,96}$. Holland et al. ${ }^{97}$ proposed that the syndrome should be redefined as starvation that manifests as obesity in a food-rich environment. Because of the postulated interruption of the normal hypothalamic pathways (caused by the genetic abnormality), the body incorrectly perceives itself to be in a state of starvation.

\section{Body composition and obesity}

The overeating behaviour, the short stature, abnormal body composition, reduced physical activity and reduced energy-use, contribute to the physical appearance in PWS. The short stature has been attributed primarily to the decreased levels of growth hormone ${ }^{98}$. Growth hormone deficiency, however, has also major effects on body composition. Compared with normal weight or obese individuals, people with PWS have a lower lean body mass and higher fat mass due to this deficiency ${ }^{99}$. Therefore, supplementation with growth hormone decreases body fat percentage and increases lean body mass ${ }^{24,100-103}$. Furthermore, it improves psychomotor development in young children with PWS and has psychological and behavioural benefits ${ }^{22,104}$. Nowadays, most children with PWS in the Netherlands are treated with growth hormone ${ }^{24,100}$.

Obesity related problems, such as respiratory difficulties and cardiovascular disease, are the most common reported causes of death in PWS ${ }^{3,51,53}$. Death related to eating itself has also been reported including choking ${ }^{105}$ and gastric dilatation whilst binging ${ }^{106}$. However, compared to non-PWS obese individuals, persons with PWS have significantly reduced visceral adiposity ${ }^{107}$. Visceral fat is positively correlated with glucose and triglyceride levels and contributes to insulin resistance ${ }^{108}$. In addition, insulin resistance is generally less in PWS individuals compared with non-PWS obese individuals ${ }^{109}$. 
Stomach surgery, such as gastric bypass operations and intra-gastric balloons, has been used to try to reduce the obesity. However, none of these methods were successful in the long term and some were associated with severe complications ${ }^{110,111}$. Moreover, stomach rupture has been reported as a cause of death in PWS due to overeating ${ }^{106,112}$. A surgically reduced size of the stomach, without decrease of the overeating behaviour, may further increase the risk of a ruptured stomach. Pharmacological treatment, including available anorexigenic agents, has not been of benefit in treating hyperphagia, although only a few placebo-controlled studies have been published ${ }^{113,114}$.

Obesity management in people with PWS still involves environmental control with early institution of a low-calorie, well-balanced diet, with regular exercise, rigorous supervision, restriction of access to food and money to buy food $^{36,115-118}$. 


\subsection{RESEARCH QUESTIONS AND OUTLINE OF THE THESIS}

The aim of this thesis is to contribute towards better understanding of PWS at adult age.

The following main research questions were formulated:

1. What is the distribution of genetic subtypes in a PWS cohort at adult age? How is this related to age?

2. What are the physical characteristics in adults with PWS? How are these characteristics related to age, genetic subtype and BMI?

3. What are the behavioural characteristics in adults with PWS? How are these characteristics related to age, genetic subtype and BMI?

4. What are the psychiatric characteristics in adults with PWS?

5. What are the characteristics of PWS at older age?

\section{Distribution of genetic subtypes in PWS at adult age}

The frequencies of genetic subtypes in PWS are usually given in literature as $70 \%$ deletion, $25-30 \%$ mUPD and $3-5 \%$ others (IC defects and translocations $)^{2-4,56}$. However, these studies have mainly described relatively young cohorts of people with PWS. Little is known about the distribution of genetic subtypes in adult PWS populations.

Our first study aimed to describe the distribution of genetic subtypes in a representative PWS cohort at adult age. The results of this study are presented in Chapter 2.

\section{Physical characteristics of PWS at adult age}

Numerous medical conditions have been associated with PWS, with varying degrees of published documentation. Most of the morbidity is reported to be secondary to obesity, including diabetes mellitus, respiratory problems, obstructive sleep apnoea, hypertension and cardiovascular problems ${ }^{36}$. This morbidity results in a higher mortality rate in all age-groups, compared to people with ID in general, resulting in a lower life expectancy ${ }^{4,51}$.

Previous studies on physical health problems in PWS were restricted by small sample sizes, limited age range and lack of genetically confirmed diagnoses ${ }^{3,43-45,119}$. We describe a large-scale, systematic study investigating morbidity in a cohort of adults with PWS. The results of this study are reported in Chapter 3.

\section{Behavioural characteristics of PWS at adult age}

Previous studies on behaviour in PWS have often been limited by sample size, age range, a lack of genetically confirmed diagnosis of PWS and inconsistent 
assessment of behaviour. We systematically explored the relation between behavioural problems and age groups, genetic subtypes and BMI in an adult PWS population. The results of this study are presented in Chapter 4.

\section{Psychiatric characteristics of PWS at adult age}

Besides the behavioural problems, an association between PWS and comorbid psychiatric illnesses has been suggested for many years. The first reports on psychotic episodes consisted of individual case reports ${ }^{124,128-132,133,134}$. In 2002, Boer et al. ${ }^{46}$ first indicated that the risk of developing psychotic episodes with increasing age was associated with the mUPD subtype of PWS. Of those aged over 27 years, $100 \%$ had developed at least one psychotic episode. These findings were supported by subsequent studies $^{50,135}$. The first systematical study on psychiatric illness in a large cohort was performed by Soni et al. ${ }^{47}$ within the UK in 2007.

Prevalence rates of psychiatric illness in PWS from this UK study have not been confirmed in other large PWS cohorts or in any other country than the UK. We describe a large-scale, systematic study investigating the prevalence of psychiatric illness in adults with PWS in Chapter 5.

\section{Dementia}

Compared to people without ID, ageing specific conditions occur more often and, in general, they appear earlier in life for people with $I D^{136-141}$. Persons with Down syndrome are known to have an increased risk to develop dementia of Alzheimer's type ${ }^{139,142-145}$. Little is known about the prevalence of dementia in PWS. We report a case of an older woman with PWS who presented with findings highly suggestive of dementia in Chapter 6.

\section{Characteristics of PWS at older age}

Clinical research in PWS mainly focused on child- and early adulthood until now. Little is known about the older adults with PWS. Reports on people with Prader-Willi syndrome above the age of 50 years in the literature are scarce $^{43,146-148}$. In Chapter 7 we focus in detail on the oldest individuals of the study population. Ageing characteristics are described by combining data on functional decline, physical health status, behaviour and psychiatric illness.

In Chapter 8, the general discussion, the results of the studies described in this thesis are discussed. Recommendations for further research as well as clinical implications for preventive management are addressed. Specific topics related to this thesis are presented in the Appendices 3-7. 


\subsection{METHODS AND STUDY POPULATION}

This thesis describes studies embedded in the study "Ageing in Prader-Willi syndrome". The presented studies were carried out at The Governor Kremers Centre and Department of Clinical Genetics, Maastricht University Medical Centre, the Netherlands. The study population consisted of adult (18+) persons with PWS in the Netherlands.

\section{Procedure}

Nominees with possible PWS were contacted via the Dutch Prader-Willi Parent Association and through intellectual disability physicians. In total 149 nominees with a (possible) diagnosis of PWS were notified to us. Two nominees had died and two parents informed us that PWS was excluded by genetic testing. Hence, 145 possible participants were left. Of these, 108 agreed to participate in the study (response rate $75 \%$ ). Results of genetic testing before $(n=68)$ or during the study $(n=40)$ were used to confirm the diagnosis and determine the genetic subtype. For 102 out of 108 persons, the genetic diagnosis of PWS was confirmed. Genetic testing revealed that the six remaining persons did not have PWS. Consequently, this study is based on these 102 individuals. The characteristics of the study population are summarized in table 1.1.

\section{Data collection}

The individuals with PWS and their main caregivers (family and/or professional carers), were visited at home for a semi-structured interview. The interview included questions about physical health problems experienced over the participants' lifetime. A number of questionnaires were used for additional information on behavioural and psychiatric symptoms including the Developmental Behaviour Checklist for Adults (DBC-A) (Einfeld et al. 2002) and the Psychiatric Assessment Schedule for Adults with Developmental Disabilities (PAS-ADD) checklist (Moss et al. 1996).

The questionnaire of the interview was divided in the following sections:

- General data: demographic, diagnostic characteristics, early development

- Context: family, occupation, living circumstances

- Physical health: diagnosed illness, physical measurements

- Psychiatric illness and behaviour

- Cognition and function

- Investigations and treatment

Medical files were retrieved from general practitioners, intellectual disability physicians, psychiatrists and other medical specialists. Participants, and if possible their parents, were requested to give blood samples for genetic 
testing. For a detailed description of the data collection used in the different sub-studies, we refer to the method sections of the chapters 3,4 and 5 .

\section{Genetic diagnosis}

During the interviews, parents were asked whether genetic tests on PWS including genetic subtype were undertaken previously. Written confirmations on genetic diagnoses were retrieved from genetic centres, with permission of the legal representatives. Genetic testing was undertaken in participants who did not have a confirmed genetic diagnosis $(n=40)$. Cytogenetic analysis and molecular analysis using the SALSA MLPA kit P245 (MRC Holland, Amsterdam) was performed to establish whether deletions were present. Diagnosis of PWS was confirmed by DNA methylation studies on the SNURF/SNRPN locus and mUPD was confirmed with microsatellite analysis at various loci on chromosome 15 , when blood of parents was available.

Table 1.1 The characteristics of the study population.

\begin{tabular}{lcc}
\hline Characteristic & $\mathrm{n}$ & $\%$ \\
\hline Gender & & \\
Male & 49 & 58 \\
Female & 53 & \\
Age & & 22 \\
18-24 yrs & 22 & 28 \\
$25-34$ yrs & 28 & 25 \\
$35-44$ yrs & 26 & 25 \\
45+ yrs & 26 & \\
Genetic subtype & & 54 \\
Deletion & 55 & 43 \\
mUPD & 44 & 3 \\
Imprinting defect & 3 & \\
BMI & & 1 \\
<18,5 & 1 & 17 \\
18,5-25 & 17 & 26 \\
$25-30$ & 27 & 56 \\
30+ & 57 & 5 \\
Level of ID & & 8 \\
No ID & 5 & 51 \\
Borderline ID & 8 & 28 \\
Mild & 52 & 8 \\
Moderate & 29 & 21 \\
Severe & 8 & 79 \\
Residential setting & & 100 \\
Home* & 21 & \\
Community-based facilities $\ddagger$ & 81 & \\
Total & 102 & \\
\hline
\end{tabular}

* Including living with family members and relatives, or living independently

$\ddagger$ Community-based facilities include group homes and supervised staff apartments 


\section{References}

1. Prader A, Labhart A, Willi H: Ein syndrom von adipositas, kleinwuchs, kryptorchismus and oligophrenie nach myotonicartigen zustand im neugeborenenalter. Schweizerische Medizinische Wochenschrift 1956; 86: 1260-1261.

2. Smith A, Egan J, Ridley G, Haan E, Montgomery P, Williams K, Elliott E: Birth prevalence of Prader-Willi syndrome in Australia. Arch Dis Child 2003; 88: 263-264.

3. Vogels A, Van Den Ende J, Keymolen K, Mortier G, Devriendt K, Legius E, Fryns JP: Minimum prevalence, birth incidence and cause of death for Prader-Willi syndrome in Flanders. Eur J Hum Genet 2004; 12: 238-240.

4. Whittington JE, Holland AJ, Webb T, Butler J, Clarke D, Boer H: Population prevalence and estimated birth incidence and mortality rate for people with PraderWilli syndrome in one UK Health Region. J Med Genet 2001; 38: 792-798.

5. Holm VA, Cassidy SB, Butler MG, Hanchett JM, Greenswag LR, Whitman BY, Greenberg F: Prader-Willi syndrome: consensus diagnostic criteria. Pediatrics 1993; 91: 398-402.

6. World Health Organization. Ageing and intellectual disability: improving longevity and promoting healthy ageing: summative report Geneva, WHO, 2000.

7. Bittles AH, Petterson BA, Sullivan SG, Hussain R, Glasson EJ, Montgomery PD: The influence of intellectual disability on life expectancy. J Gerontol A Biol Sci Med Sci 2002; 57: M470-472.

8. Haveman M, Heller T, Lee L, Maaskant M, Shooshtari S, Strydom A: Ageing and Health risks in Persons with Intellectual Disabilities: An overview of recent studies. Journal of Policy and Practice in Intellectual Disabilities 2010; 7: 59-69.

9. Holland AJ: Ageing and learning disability. Br J Psychiatry 2000; 176: 26-31.

10. Haveman MJ, Heller T, Lee LA, Maaskant MA, Shooshtari S, Strydom A. Report on the State of Science on Health Risks and Ageing in People with Intellectual Disabilities. IASSID Special Interest Research Group on Ageing and Intellectual Disabilities/Faculty Rehabilitation Sciences, University of Dortmund, 2009.

11. van Schrojenstein Lantman-de Valk HM, Walsh PN: Managing health problems in people with intellectual disabilities. BMJ 2008; 337: a2507.

12. Devenny DA, Silverman WP, Hill AL, Jenkins E, Sersen EA, Wisniewski KE: Normal ageing in adults with Down's syndrome: a longitudinal study. J Intellect Disabil Res 1996; 40: 208-221.

13. Oliver C, Holland AJ: Down's syndrome and Alzheimer's disease: a review. Psychol Med 1986; 16: 307-322.

14. Bigi N, Faure JM, Coubes C, Puechberty J, Lefort G, Sarda P, Blanchet P: PraderWilli syndrome: is there a recognizable fetal phenotype? Prenat Diagn 2008; 28: 796-799.

15. Whittington JE, Butler JV, Holland AJ: Pre-, peri- and postnatal complications in Prader-Willi syndrome in a UK sample. Early Hum Dev 2008; 84: 331-336.

16. Stephenson JB: Neonatal presentation of Prader-Willi syndrome. Am J Dis Child 1992; 146: 151-152.

17. McSweeney N, Cowan F, Manzur A, Robb S, Muntoni F: Perinatal dyskinesia as a presenting feature in Prader Willi syndrome. Eur $J$ Paediatr Neurol 2009; 13: 350-355. 
18. Crino A, Schiaffini R, Ciampalini P, Spera S, Beccaria L, Benzi F, Bosio L, Corrias A, Gargantini L, Salvatoni A, Tonini G, Trifiro G, Livieri C: Hypogonadism and pubertal development in Prader-Willi syndrome. Eur J Pediatr 2003; 162: 327-333.

19. Miller SP, Riley P, Shevell MI: The neonatal presentation of Prader-Willi syndrome revisited. J Pediatr 1999; 134: 226-228.

20. Gunay-Aygun M, Schwartz S, Heeger S, O'Riordan MA, Cassidy SB: The changing purpose of Prader-Willi syndrome clinical diagnostic criteria and proposed revised criteria. Pediatrics 2001; 108: E92.

21. Reus L, Zwarts M, van Vlimmeren LA, Willemsen MA, Otten BJ, Nijhuis-van der Sanden MW: Motor problems in Prader-Willi syndrome: A systematic review on body composition and neuromuscular functioning. Neurosci Biobehav Rev 2010; 35: 956-69.

22. Festen DA, Wevers M, Lindgren AC, Bohm B, Otten BJ, Wit JM, Duivenvoorden $\mathrm{HJ}$, Hokken-Koelega AC: Mental and motor development before and during growth hormone treatment in infants and toddlers with Prader-Willi syndrome. Clin Endocrinol (Oxf) 2008; 68: 919-925.

23. Eiholzer U, Schlumpf M, Nordmann Y, l'Allemand D: Early manifestations of Prader-Willi syndrome: influence of growth hormone. J Pediatr Endocrinol Metab 2001; 14: 1441-1444.

24. Festen DA, de Lind van Wijngaarden $R$, van Eekelen $M$, Otten BJ, Wit JM, Duivenvoorden HJ, Hokken-Koelega AC: Randomized controlled GH trial: effects on anthropometry, body composition and body proportions in a large group of children with Prader-Willi syndrome. Clin Endocrinol (Oxf) 2008; 69: 443-451.

25. Greggi T, Martikos K, Lolli F, Bakaloudis G, Di Silvestre M, Cioni A, Barbanti Brodano G, Giacomini S: Treatment of scoliosis in patients affected with PraderWilli syndrome using various different techniques. Scoliosis 2010; 5: 11.

26. Dimitropoulos A, Feurer ID, Butler MG, Thompson T: Emergence of compulsive behavior and tantrums in children with Prader-Willi syndrome. Am J Ment Retard 2001; 106: 39-51.

27. Dykens EM, Kasari C: Maladaptive behavior in children with Prader-Willi syndrome, Down syndrome, and nonspecific mental retardation. Am J Ment Retard 1997; 102: 228-237.

28. van Lieshout CF, de Meyer RE, Curfs LM, Koot HM, Fryns JP: Problem behaviors and personality of children and adolescents with Prader-Willi syndrome. J Pediatr Psychol 1998; 23: 111-120.

29. Tauber M, Barbeau C, Jouret B, Pienkowski C, Malzac P, Moncla A, Rochiccioli P: Auxological and endocrine evolution of 28 children with Prader-Willi syndrome: effect of GH therapy in 14 children. Horm Res 2000; 53: 279-287.

30. Burman P, Ritzen EM, Lindgren AC: Endocrine dysfunction in Prader-Willi syndrome: a review with special reference to GH. Endocr Rev 2001; 22: 787-799.

31. Eldar-Geva T, Hirsch HJ, Benarroch $F$, Rubinstein O, Gross-Tsur V: Hypogonadism in females with Prader-Willi syndrome from infancy to adulthood: variable combinations of a primary gonadal defect and hypothalamic dysfunction. Eur J Endocrinol 2010; 162: 377-384.

32. Hirsch HJ, Eldar-Geva T, Benarroch F, Rubinstein O, Gross-Tsur V: Primary testicular dysfunction is a major contributor to abnormal pubertal development in males with Prader-Willi syndrome. J Clin Endocrinol Metab 2009; 94: 2262-2268.

33. Butler MG: Prader-Willi syndrome: current understanding of cause and diagnosis. Am J Med Genet 1990; 35: 319-332. 
34. Butler MG, Meaney FJ: Standards for selected anthropometric measurements in Prader-Willi syndrome. Pediatrics 1991; 88: 853-860.

35. Butler MG, Lee PDK, Whitman BY: Management of Prader-Willi syndrome, Third edition edn, New York: Springer, 2006.

36. Goldstone AP, Holland AJ, Hauffa BP, Hokken-Koelega AC, Tauber M: Recommendations for the diagnosis and management of Prader-Willi syndrome. $J$ Clin Endocrinol Metab 2008; 93: 4183-4197.

37. Holland AJ, Wong J: Genetically determined obesity in Prader-Willi syndrome: the ethics and legality of treatment. J Med Ethics 1999; 25: 230-236.

38. van Hooren $\mathrm{RH}$, Widdershoven $\mathrm{GA}$, van der Bruggen $\mathrm{H}$, van den Borne HW, Curfs LM: Values in the care for young persons with Prader-Willi syndrome: creating a meaningful life together. Child Care Health Dev 2005; 31: 309-319.

39. Curfs LM, Fryns JP: Prader-Willi syndrome: a review with special attention to the cognitive and behavioral profile. Birth Defects Orig Artic Ser 1992; 28: 99-104.

40. Curfs LM, Verhulst FC, Fryns JP: Behavioral and emotional problems in youngsters with Prader-Willi syndrome. Genet Couns 1991; 2: 33-41.

41. Dykens EM, Hodapp RM, Walsh K, Nash LJ: Profiles, correlates, and trajectories of intelligence in Prader-Willi syndrome. J Am Acad Child Adolesc Psychiatry 1992; 31: 1125-1130.

42. Cassidy SB: Prader-Willi syndrome. J Med Genet 1997; 34: 917-923.

43. Greenswag LR: Adults with Prader-Willi syndrome: a survey of 232 cases. Dev Med Child Neurol 1987; 29: 145-152.

44. Laurance BM, Brito A, Wilkinson J: Prader-Willi Syndrome after age 15 years. Arch Dis Child 1981; 56: 181-186.

45. Thomson AK, Glasson EJ, Bittles AH: A long-term population-based clinical and morbidity review of Prader-Willi syndrome in Western Australia. J Intellect Disabil Res 2006; 50: 69-78.

46. Boer H, Holland A, Whittington J, Butler J, Webb T, Clarke D: Psychotic illness in people with Prader Willi syndrome due to chromosome 15 maternal uniparental disomy. Lancet 2002; 359: 135-136.

47. Soni S, Whittington J, Holland AJ, Webb T, Maina E, Boer H, Clarke D: The course and outcome of psychiatric illness in people with Prader-Willi syndrome: implications for management and treatment. J Intellect Disabil Res 2007; 51: 32-42.

48. Soni S, Whittington J, Holland AJ, Webb T, Maina EN, Boer H, Clarke D: The phenomenology and diagnosis of psychiatric illness in people with Prader-Willi syndrome. Psychol Med 2008; 38: 1505-1514.

49. Vogels A, De Hert M, Descheemaeker MJ, Govers V, Devriendt K, Legius E, Prinzie P, Fryns JP: Psychotic disorders in Prader-Willi syndrome. Am J Med Genet A 2004; 127A: 238-243.

50. Verhoeven WM, Tuinier S, Curfs LM: Prader-Willi syndrome: the psychopathological phenotype in uniparental disomy. J Med Genet 2003; 40: e112.

51. Einfeld SL, Kavanagh SJ, Smith A, Evans EJ, Tonge BJ, Taffe J: Mortality in Prader-Willi syndrome. Am J Ment Retard 2006; 111: 193-198.

52. Stevenson DA, Anaya TM, Clayton-Smith J, Hall BD, Van Allen MI, Zori RT, Zackai EH, Frank G, Clericuzio CL: Unexpected death and critical illness in Prader-Willi syndrome: report of ten individuals. Am J Med Genet A 2004; 124: 158-164.

53. Schrander-Stumpel CT, Curfs LM, Sastrowijoto P, Cassidy SB, Schrander JJ, Fryns JP: Prader-Willi syndrome: causes of death in an international series of 27 cases. Am J Med Genet A 2004; 124: 333-338. 
54. Ledbetter DH, Riccardi VM, Airhart SD, Strobel RJ, Keenan BS, Crawford JD: Deletions of chromosome 15 as a cause of the Prader-Willi syndrome. $N$ Engl $J$ Med 1981; 304: 325-329.

55. Butler MG, Palmer CG: Parental origin of chromosome 15 deletion in Prader-Willi syndrome. Lancet 1983; 1: 1285-1286.

56. Whittington JE, Butler JV, Holland AJ: Changing rates of genetic subtypes of Prader-Willi syndrome in the UK. Eur J Hum Genet 2007; 15: 127-130.

57. Sahoo T, Bacino CA, German JR, Shaw CA, Bird LM, Kimonis V, Anselm I, Waisbren S, Beaudet AL, Peters SU: Identification of novel deletions of 15q11q13 in Angelman syndrome by array-CGH: molecular characterization and genotypephenotype correlations. Eur J Hum Genet 2007; 15: 943-949.

58. Buiting K: Prader-Willi syndrome and Angelman syndrome. Am J Med Genet $C$ Semin Med Genet 2010; 154C: 365-376.

59. Nicholls RD, Knoll JH, Butler MG, Karam S, Lalande M: Genetic imprinting suggested by maternal heterodisomy in nondeletion Prader-Willi syndrome. Nature 1989; 342: 281-285.

60. Fridman C, Koiffmann CP: Origin of uniparental disomy 15 in patients with PraderWilli or Angelman syndrome. Am J Med Genet 2000; 94: 249-253.

61. Ginsburg C, Fokstuen S, Schinzel A: The contribution of uniparental disomy to congenital development defects in children born to mothers at advanced childbearing age. Am J Med Genet 2000; 95: 454-460.

62. Cassidy SB, Schwartz S: Prader-Willi and Angelman syndromes. Disorders of genomic imprinting. Medicine (Baltimore) 1998; 77: 140-151.

63. Buiting K, Saitoh S, Gross S, Dittrich B, Schwartz S, Nicholls RD, Horsthemke B: Inherited microdeletions in the Angelman and Prader-Willi syndromes define an imprinting centre on human chromosome 15. Nat Genet 1995; 9: 395-400.

64. Ohta T, Gray TA, Rogan PK, Buiting K, Gabriel JM, Saitoh S, Muralidhar B, Bilienska B, Krajewska-Walasek M, Driscoll DJ, Horsthemke B, Butler MG, Nicholls $\mathrm{RD}$ : Imprinting-mutation mechanisms in Prader-Willi syndrome. Am J Hum Genet 1999; 64: 397-413.

65. Buiting K, Farber C, Kroisel P, Wagner K, Brueton L, Robertson ME, Lich C, Horsthemke B: Imprinting centre deletions in two PWS families: implications for diagnostic testing and genetic counseling. Clin Genet 2000; 58: 284-290.

66. Buiting K, Dittrich B, Gross S, Lich C, Farber C, Buchholz T, Smith E, Reis A, Burger J, Nothen MM, Barth-Witte U, Janssen B, Abeliovich D, Lerer I, van den Ouweland AM, Halley DJ, Schrander-Stumpel C, Smeets H, Meinecke P, Malcolm S, Gardner A, Lalande M, Nicholls RD, Friend K, Schulze A, Matthijs G, Kokkonen H, Hilbert P, Van Maldergem L, Glover G, Carbonell P, Willems P, GillessenKaesbach G, Horsthemke B: Sporadic imprinting defects in Prader-Willi syndrome and Angelman syndrome: implications for imprint-switch models, genetic counseling, and prenatal diagnosis. Am J Hum Genet 1998; 63: 170-180.

67. Buiting K, Gross S, Lich C, Gillessen-Kaesbach G, el-Maarri O, Horsthemke B: Epimutations in Prader-Willi and Angelman syndromes: a molecular study of 136 patients with an imprinting defect. Am J Hum Genet 2003; 72: 571-577.

68. Ramsden SC, Clayton-Smith J, Birch R, Buiting K: Practice guidelines for the molecular analysis of Prader-Willi and Angelman syndromes. BMC Med Genet 2010; 11: 70.

69. Sahoo T, del Gaudio D, German JR, Shinawi M, Peters SU, Person RE, Garnica A, Cheung SW, Beaudet AL: Prader-Willi phenotype caused by paternal deficiency for the HBII-85 C/D box small nucleolar RNA cluster. Nat Genet 2008; 40: 719-721. 
70. de Smith AJ, Purmann C, Walters RG, Ellis RJ, Holder SE, Van Haelst MM, Brady AF, Fairbrother UL, Dattani M, Keogh JM, Henning E, Yeo GS, O'Rahilly S, Froguel P, Farooqi IS, Blakemore Al: A deletion of the HBII-85 class of small nucleolar RNAs (snoRNAs) is associated with hyperphagia, obesity and hypogonadism. Hum Mol Genet 2009; 18: 3257-3265.

71. Duker AL, Ballif BC, Bawle EV, Person RE, Mahadevan S, Alliman S, Thompson R, Traylor R, Bejjani BA, Shaffer LG, Rosenfeld JA, Lamb AN, Sahoo T: Paternally inherited microdeletion at 15q11.2 confirms a significant role for the SNORD116 C/D box snoRNA cluster in Prader-Willi syndrome. Eur J Hum Genet 2010; 18: 1196-1201.

72. Goldstone AP: Prader-Willi syndrome: advances in genetics, pathophysiology and treatment. Trends Endocrinol Metab 2004; 15: 12-20.

73. Mercer RE, Wevrick R: Loss of magel2, a candidate gene for features of PraderWilli syndrome, impairs reproductive function in mice. PLoS One 2009; 4: e4291.

74. Zanella S, Watrin F, Mebarek S, Marly F, Roussel M, Gire C, Diene G, Tauber M, Muscatelli F, Hilaire G: Necdin plays a role in the serotonergic modulation of the mouse respiratory network: implication for Prader-Willi syndrome. J Neurosci 2008; 28: 1745-1755.

75. Swaab DF: Prader-Willi syndrome and the hypothalamus. Acta Paediatr Suppl 1997; 423: 50-54.

76. Swaab DF, Purba JS, Hofman MA: Alterations in the hypothalamic paraventricular nucleus and its oxytocin neurons (putative satiety cells) in Prader-Willi syndrome: a study of five cases. J Clin Endocrinol Metab 1995; 80: 573-579.

77. Lindgren AC, Hellstrom LG, Ritzen EM, Milerad J: Growth hormone treatment increases $\mathrm{CO}(2)$ response, ventilation and central inspiratory drive in children with Prader-Willi syndrome. Eur J Pediatr 1999; 158: 936-940.

78. Vela-Bueno A, Kales A, Soldatos CR, Dobladez-Blanco B, Campos-Castello J, Espino-Hurtado P, Olivan-Palacios J: Sleep in the Prader-Willi syndrome. Clinical and polygraphic findings. Arch Neurol 1984; 41: 294-296.

79. McAllister CJ, Whittington JE, Holland AJ: Development of the eating behaviour in Prader-Willi Syndrome: advances in our understanding. Int $J$ Obes 2010; 35: 188-197.

80. Butler JV, Whittington JE, Holland AJ, McAllister CJ, Goldstone AP: The transition between the phenotypes of Prader-Willi syndrome during infancy and early childhood. Dev Med Child Neurol 2010; 52: e88-93.

81. Hinton EC, Holland AJ, Gellatly MS, Soni S, Patterson M, Ghatei MA, Owen AM: Neural representations of hunger and satiety in Prader-Willi syndrome. Int $J$ Obes 2006; 30: 313-321.

82. Holland AJ, Treasure J, Coskeran P, Dallow J, Milton N, Hillhouse E: Measurement of excessive appetite and metabolic changes in Prader-Willi syndrome. Int $J$ Obes Relat Metab Disord 1993; 17: 527-532.

83. Lindgren AC, Barkeling B, Hagg A, Ritzen EM, Marcus C, Rossner S: Eating behavior in Prader-Willi syndrome, normal weight, and obese control groups. $J$ Pediatr 2000; 137: 50-55.

84. Holsen LM, Zarcone JR, Brooks WM, Butler MG, Thompson TI, Ahluwalia JS, Nollen NL, Savage CR: Neural mechanisms underlying hyperphagia in Prader-Willi syndrome. Obesity 2006; 14: 1028-1037.

85. Shapira NA, Lessig MC, He AG, James GA, Driscoll DJ, Liu Y: Satiety dysfunction in Prader-Willi syndrome demonstrated by fMRI. J Neurol Neurosurg Psychiatry 2005; 76: 260-262. 
86. Goldstone AP, Brynes AE, Thomas EL, Bell JD, Frost G, Holland A, Ghatei MA, Bloom SR: Resting metabolic rate, plasma leptin concentrations, leptin receptor expression, and adipose tissue measured by whole-body magnetic resonance imaging in women with Prader-Willi syndrome. Am J Clin Nutr 2002; 75: 468-475.

87. Goldstone AP, Unmehopa UA, Bloom SR, Swaab DF: Hypothalamic NPY and agouti-related protein are increased in human illness but not in Prader-Willi syndrome and other obese subjects. J Clin Endocrinol Metab 2002; 87: 927-937.

88. Cummings DE, Clement K, Purnell JQ, Vaisse C, Foster KE, Frayo RS, Schwartz MW, Basdevant A, Weigle DS: Elevated plasma ghrelin levels in Prader Willi syndrome. Nat Med 2002; 8: 643-644.

89. DelParigi A, Tschop M, Heiman ML, Salbe AD, Vozarova B, Sell SM, Bunt JC, Tataranni PA: High circulating ghrelin: a potential cause for hyperphagia and obesity in prader-willi syndrome. J Clin Endocrinol Metab 2002; 87: 5461-5464.

90. Tauber M, Conte Auriol F, Moulin P, Molinas C, Delagnes V, Salles JP: Hyperghrelinemia is a common feature of Prader-Willi syndrome and pituitary stalk interruption: a pathophysiological hypothesis. Horm Res 2004; 62: 49-54.

91. Goldstone AP, Patterson M, Kalingag N, Ghatei MA, Brynes AE, Bloom SR, Grossman $A B$, Korbonits $M$ : Fasting and postprandial hyperghrelinemia in PraderWilli syndrome is partially explained by hypoinsulinemia, and is not due to peptide YY3-36 deficiency or seen in hypothalamic obesity due to craniopharyngioma. $J$ Clin Endocrinol Metab 2005; 90: 2681-2690.

92. Batterham RL, Cowley MA, Small CJ, Herzog H, Cohen MA, Dakin CL, Wren AM, Brynes AE, Low MJ, Ghatei MA, Cone RD, Bloom SR: Gut hormone PYY(3-36) physiologically inhibits food intake. Nature 2002; 418: 650-654.

93. Goldstone AP: The hypothalamus, hormones, and hunger: alterations in human obesity and illness. Prog Brain Res 2006; 153: 57-73.

94. Priano L, Miscio G, Grugni G, Milano E, Baudo S, Sellitti L, Picconi R, Mauro A: On the origin of sensory impairment and altered pain perception in Prader-Willi syndrome: a neurophysiological study. Eur J Pain 2009; 13: 829-835.

95. von Deneen KM, Gold MS, Liu Y: Food Addiction and Cues in Prader-Willi Syndrome. Journal of Addiction Medicine 2009; 3: 19-25.

96. Siep N, Roefs A, Roebroeck A, Havermans R, Bonte ML, Jansen A: Hunger is the best spice: an fMRI study of the effects of attention, hunger and calorie content on food reward processing in the amygdala and orbitofrontal cortex. Behav Brain Res 2009; 198: 149-158.

97. Holland A, Whittington J, Hinton E: The paradox of Prader-Willi syndrome: a genetic model of starvation. Lancet 2003; 362: 989-991.

98. Grugni G, Guzzaloni G, Moro D, Bettio D, De Medici C, Morabito F: Reduced growth hormone $(\mathrm{GH})$ responsiveness to combined $\mathrm{GH}$-releasing hormone and pyridostigmine administration in the Prader-Willi syndrome. Clin Endocrinol 1998; 48: 769-775.

99. Carrel AL, Allen DB: Prader-Willi syndrome: how does growth hormone affect body composition and physical function? J Pediatr Endocrinol Metab 2001; 14 Suppl 6: 1445-1451.

100. de Lind van Wijngaarden RF, Siemensma EP, Festen DA, Otten BJ, van Mil EG, Rotteveel J, Odink RJ, Bindels-de Heus GC, van Leeuwen M, Haring DA, Bocca G, Houdijk EC, Hoorweg-Nijman JJ, Vreuls RC, Jira PE, van Trotsenburg AS, Bakker B, Schroor EJ, Pilon JW, Wit JM, Drop SL, Hokken-Koelega AC: Efficacy and safety of long-term continuous growth hormone treatment in children with PraderWilli syndrome. J Clin Endocrinol Metab 2009; 94: 4205-4215. 
101. Lindgren AC, Hagenas L, Muller J, Blichfeldt S, Rosenborg M, Brismar T, Ritzen EM: Growth hormone treatment of children with Prader-Willi syndrome affects linear growth and body composition favourably. Acta Paediatr 1998; 87: 28-31.

102. Eiholzer U, Gisin R, Weinmann C, Kriemler S, Steinert H, Torresani T, Zachmann M, Prader A: Treatment with human growth hormone in patients with PraderLabhart-Willi syndrome reduces body fat and increases muscle mass and physical performance. Eur J Pediatr 1998; 157: 368-377.

103. Davies PS, Evans S, Broomhead S, Clough H, Day JM, Laidlaw A, Barnes ND: Effect of growth hormone on height, weight, and body composition in Prader-Willi syndrome. Arch Dis Child 1998; 78: 474-476.

104. Whitman B, Carrel A, Bekx T, Weber C, Allen D, Myers S: Growth hormone improves body composition and motor development in infants with Prader-Willi syndrome after six months. J Pediatr Endocrinol Metab 2004; 17: 591-600.

105. Stevenson DA, Heinemann J, Angulo M, Butler MG, Loker J, Rupe N, Kendell P, Clericuzio CL, Scheimann AO: Deaths due to choking in Prader-Willi syndrome. Am J Med Genet A 2007; 143: 484-487.

106. Stevenson DA, Heinemann J, Angulo M, Butler MG, Loker J, Rupe N, Kendell P, Cassidy SB, Scheimann A: Gastric rupture and necrosis in Prader-Willi syndrome. $J$ Pediatr Gastroenterol Nutr 2007; 45: 272-274.

107. Goldstone AP, Thomas EL, Brynes AE, Bell JD, Frost G, Saeed N, Hajnal JV, Howard JK, Holland A, Bloom SR: Visceral adipose tissue and metabolic complications of obesity are reduced in Prader-Willi syndrome female adults: evidence for novel influences on body fat distribution. J Clin Endocrinol Metab 2001; 86: 4330-4338.

108. Usui C, Asaka M, Kawano H, Aoyama T, Ishijima T, Sakamoto S, Higuchi M: Visceral fat is a strong predictor of insulin resistance regardless of cardiorespiratory fitness in non-diabetic people. J Nutr Sci Vitaminol 2010; 56: 109-116.

109. Kennedy L, Bittel DC, Kibiryeva N, Kalra SP, Torto R, Butler MG: Circulating adiponectin levels, body composition and obesity-related variables in Prader-Willi syndrome: comparison with obese subjects. Int J Obes 2006; 30: 382-387.

110. De Peppo F, Di Giorgio G, Germani M, Ceriati E, Marchetti P, Galli C, Ubertini MG, Spera S, Ferrante G, Cuttini M, Cappa M, Castelli Gattinara G, Rivosecchi M, Crino A: BioEnterics intragastric balloon for treatment of morbid obesity in Prader-Willi syndrome: specific risks and benefits. Obes Surg 2008; 18: 1443-1449.

111. Scheimann AO, Butler MG, Gourash L, Cuffari C, Klish W: Critical analysis of bariatric procedures in Prader-Willi syndrome. J Pediatr Gastroenterol Nutr 2008; 46: 80-83.

112. Wharton RH, Wang T, Graeme-Cook F, Briggs S, Cole RE: Acute idiopathic gastric dilation with gastric necrosis in individuals with Prader-Willi syndrome. Am J Med Genet 1997; 73: 437-441.

113. Shapira NA, Lessig MC, Lewis MH, Goodman WK, Driscoll DJ: Effects of topiramate in adults with Prader-Willi syndrome. Am J Ment Retard 2004; 109: 301-309.

114. Kohn Y, Weizman A, Apter A: Aggravation of food-related behavior in an adolescent with Prader-Willi syndrome treated with fluvoxamine and fluoxetine. Int J Eat Disord 2001; 30: 113-117.

115. Bachere N, Diene G, Delagnes V, Molinas C, Moulin P, Tauber M: Early diagnosis and multidisciplinary care reduce the hospitalization time and duration of tube feeding and prevent early obesity in PWS infants. Horm Res 2008; 69: 45-52. 
116. Grolla E, Andrighetto G, Parmigiani P, Hladnik U, Ferrari G, Bernardelle R, Dal Lago M, Albarello A, Baschirotto G, Filippi G, Lovato R, Dolcetta D: Specific treatment of Prader-Willi syndrome through cyclical rehabilitation programmes. Disabil Rehabil 2011; 33: 1837-1847.

117. Kaufman H, Overton G, Leggott J, Clericuzio C: Prader-Willi syndrome: effect of group home placement on obese patients with diabetes. South Med J 1995; 88: 182-184.

118. Descheemaeker MJ, Swillen A, Plissart L, Borghgraef M, Rasenberg S, Curfs LM, Fryns JP: The Prader-Willi syndrome: a self supporting program for children, youngsters and adults. Genet Couns 1994; 5: 199-205.

119. Butler JV, Whittington JE, Holland AJ, Boer H, Clarke D, Webb T: Prevalence of, and risk factors for, physical ill-health in people with Prader-Willi syndrome: a population-based study. Dev Med Child Neurol 2002; 44: 248-255.

120. Einfeld SL, Smith A, Durvasula S, Florio T, Tonge BJ: Behavior and emotional disturbance in Prader-Willi syndrome. Am J Med Genet 1999; 82: 123-127.

121. Clarke DJ, Boer H, Whittington J, Holland A, Butler J, Webb T: Prader-Willi syndrome, compulsive and ritualistic behaviours: the first population-based survey. Br J Psychiatry 2002; 180: 358-362.

122. Dykens EM, Leckman JF, Cassidy SB: Obsessions and compulsions in PraderWilli syndrome. J Child Psychol Psychiatry 1996; 37: 995-1002.

123. Dykens EM: Maladaptive and compulsive behavior in Prader-Willi syndrome: new insights from older adults. Am J Ment Retard 2004; 109: 142-153.

124. Beardsmore A, Dorman T, Cooper SA, Webb T: Affective psychosis and PraderWilli syndrome. J Intellect Disabil Res 1998; 42: 463-471.

125. Clarke DJ, Boer H, Chung MC, Sturmey P, Webb T: Maladaptive behaviour in Prader-Willi syndrome in adult life. J Intellect Disabil Res 1996; 40: 159-165.

126. Dykens EM, Cassidy SB: Correlates of maladaptive behavior in children and adults with Prader-Willi syndrome. Am J Med Genet 1995; 60: 546-549.

127. Whittington J, Holland A: Neurobehavioral phenotype in Prader-Willi syndrome. Am J Med Genet C Semin Med Genet 2010; 154C: 438-447.

128. Clarke DJ: Prader-Willi syndrome and psychoses. Br J Psychiatry 1993; 163: 680684.

129. Kollrack HW, Wolff D: Paranoid-hallucinatory psychosis in the Prader-Labhart-WilliFanconi syndrome. Acta Paedopsychiatr 1966; 33: 309-314.

130. Descheemaeker MJ, Vogels A, Govers V, Borghgraef M, Willekens D, Swillen A, Verhoeven W, Fryns JP: Prader-Willi syndrome: new insights in the behavioural and psychiatric spectrum. J Intellect Disabil Res 2002; 46: 41-50.

131. Clarke D, Boer H, Webb T, Scott P, Frazer S, Vogels A, Borghgraef M, Curfs LM: Prader-Willi syndrome and psychotic symptoms: 1. Case descriptions and genetic studies. J Intellect Disabil Res 1998; 42: 440-450.

132. Verhoeven WM, Curfs LM, Tuinier S: Prader-Willi syndrome and cycloid psychoses. J Intellect Disabil Res 1998; 42: 455-462.

133. Whitman BY, Accardo P: Emotional symptoms in Prader-Willi syndrome adolescents. Am J Med Genet 1987; 28: 897-905.

134. Clarke D: Prader-Willi syndrome and psychotic symptoms: 2. A preliminary study of prevalence using the Psychopathology Assessment Schedule for Adults with Developmental Disability checklist. J Intellect Disabil Res 1998; 42: 451-454.

135. Vogels A, Matthijs G, Legius E, Devriendt K, Fryns JP: Chromosome 15 maternal uniparental disomy and psychosis in Prader-Willi syndrome. J Med Genet 2003; 40: 72-73. 
136. Maaskant MA: Mental handicap and ageing. Thesis Maastricht University. Dwingeloo: Kavanah. 1993.

137. Van Schrojenstein Lantman-de Valk HM, Metsemakers JF, Haveman MJ, Crebolder HF: Health problems in people with intellectual disability in general practice: a comparative study. Fam Pract 2000; 17: 405-407.

138. Van Schrojenstein Lantman-de Valk HMJ: Health problems in people with intellectual disability. Aspects of morbidity in residential settings and in primary health care. Thesis Maastricht University. Maastricht: UPM. 1998.

139. Strydom A, Shooshtari S, Lee L, Raykar V, Torr J, Tsiouris J, Jokinen N, Courtenay K, Bass N, Sinnema M, Maaskant M: Dementia in older adults with Intellectual Disabilities - epidemiology, presentation and diagnosis. JPPID 2010; 7: 96-110.

140. Janicki MP, Davidson PW, Henderson CM, McCallion P, Taets JD, Force LT, Sulkes SB, Frangenberg E, Ladrigan PM: Health characteristics and health services utilization in older adults with intellectual disability living in community residences. J Intellect Disabil Res 2002; 46: 287-298.

141. Lifshitz H, Merrick J: Aging among persons with intellectual disability in Israel in relation to type of residence, age, and etiology. Res Dev Disabil 2004; 25 : 193-205.

142. Schupf N, Sergievsky GH: Genetic and host factors for dementia in Down's syndrome. Br J Psychiatry 2002; 180: 405-410.

143. Tyrrell J, Cosgrave M, McCarron M, McPherson J, Calvert J, Kelly A, McLaughlin M, Gill M, Lawlor BA: Dementia in people with Down's syndrome. Int J Geriatr Psychiatry 2001; 16: 1168-1174.

144. Burt DB, Loveland KA, Primeaux-Hart S, Chen YW, Phillips NB, Cleveland LA, Lewis KR, Lesser J, Cummings E: Dementia in adults with Down syndrome: diagnostic challenges. Am J Ment Retard 1998; 103: 130-145.

145. Zigman WB, Schupf N, Devenny DA, Miezejeski C, Ryan R, Urv TK, Schubert R, Silverman W: Incidence and prevalence of dementia in elderly adults with mental retardation without down syndrome. Am J Ment Retard 2004; 109: 126-141.

146. Goldman JJ: Prader-Willi syndrome in two institutionalized older adults. Ment Retard 1988; 26: 97-102.

147. Carpenter PK: Prader-Willi syndrome in old age. J Intellect Disabil Res 1994; 38: 529-531.

148. Butler MG: A 68-year-old white female with Prader-Willi syndrome. Clin Dysmorphol 2000; 9: 65-67. 


\title{
CHAPTER 2
}

\author{
DIFFERENT DISTRIBUTION OF \\ GENETIC SUBTYPES OF \\ PRADER-WILLI SYNDROME IN ELDERLY
}

Sinnema M, van Roozendaal KEP, Maaskant MA, Smeets HJM, Engelen JJM, Jonker-Houben N, Schrander-Stumpel CTRM, Curfs LMG.

Eur J Hum Genet 2010;18:993-8. 


\section{ABSTRACT}

Prader-Willi syndrome (PWS) is a genetic disorder caused by the absent expression of the paternal copy of maternally imprinted genes in chromosome region 15q11-13. The frequencies of different subtypes in PWS are usually given in literature as $70 \%$ deletion, $25-30 \%$ mUPD and $3-5 \%$ others (imprinting centre (IC) defects and translocations). Little is known about factors that influence the frequency of genetic subtypes in PWS. The study sample comprised 102 adults with clinically and genetically confirmed PWS, contacted through the Dutch Prader-Willi Parent Association and physicians specialized in persons with intellectual disabilities. Genetic testing showed 55 persons $(54 \%)$ with a paternal deletion, 44 persons $(43 \%)$ with a mUPD and 3 persons (3\%) with a defect of the imprinting center. The observed distribution in our study differed from literature $(70 \%$ deletion, 30\% mUPD), which was statistically significant $(z$-score: $p<0.05)$. This was mainly caused by a higher proportion of mUPD in the advanced age groups. Differences in maternal age and BMI of the persons with PWS could not explain the differences in distribution across the age groups. Our study population had a much broader age range, compared with other studies, because of a predominance of elderly people $(40+)$ with PWS. In other studies, these elderly persons might have been undiagnosed and/or underreported, because of a lack of genetic diagnosis. The results underline both the need for correct genetic diagnosis in all persons with PWS and adjustment of the guidelines for preventive management in adulthood. 


\subsection{INTRODUCTION}

The Prader-Willi syndrome (PWS) is a genetic disorder caused by the absent expression of the paternal copy of maternally imprinted genes in chromosome region 15q11-13. PWS is characterized by neonatal hypotonia and feeding problems, childhood onset hyperphagia and obesity, short stature, hypogonadism, intellectual disabilities (ID) and behavioral problems ${ }^{1-3}$. In population studies ${ }^{4-6}$ birth incidence rates have been revised from one in 15000 to one in $22000-25000$. There are two main genetic subtypes causing PWS: paternal interstitial deletion of the 15q11-13 region ${ }^{7}$ and maternal uniparental disomy (mUPD) of chromosome $15^{8}$. Less commonly, PWS arises from an imprinting centre (IC) defect $^{9}$ or unbalanced chromosomal translocation. The frequencies of different subtypes in PWS are usually given in literature as $70 \%$ deletion, $25-30 \%$ mUPD and $3-5 \%$ others (IC defects and translocations) ${ }^{10}$.

At present, little is known about factors that influence the distribution of genetic subtypes in PWS. Most prominent is the association of mUPD with increased maternal age. Whittington et al. ${ }^{10}$ reported a higher frequency of mUPD subtype of PWS in children under 5 years of age living in the United Kingdom compared with the frequencies reported in the literature. They suggested an increasing maternal age at conception in this generation of mothers, as a likely explanation of this change. Cassidy et al. ${ }^{1}$ also postulated a relationship between mUPD and advanced maternal age. This relation has been ascribed to the mechanism of non-dysjunction during meiosis, forming a trisomic zygote and the subsequent loss of the paternal homologue, resulting in $\mathrm{MUPD}^{11}$.

In recent years, assisted reproductive technologies (ART) have been studied extensively as a potential factor involved in the molecular cause of genetic abnormalities. One report suggested an elevated risk of birth defects and genetic abnormalities associated with infertility and treatment with $A R T^{12}$. Other reports on increased numbers of children with Beckwith-Wiedemann syndrome and Angelman syndrome after ART suggested also a potential association between ART and an increased rate of imprinting abnormalities ${ }^{13}$. Finally, a relationship between the etiology of PWS and paternal exposure to hydrocarbons has been reported in one study ${ }^{14}$, but this has never been supported by other studies.

We report the different distribution of genetic subtypes across age groups in the adult PWS population in The Netherlands and the differences with the frequencies in literature. Possible explanations for this different distribution have been examined. 
The aim of this study was threefold: (1) to explore the relationship between the distribution of genetic subtypes and age in an adult PWS population in The Netherlands (2) to explore the relationship between the distribution of genetic subtypes and maternal age (3) to explore the relationship between the distribution of genetic subtypes and BMI, as a possible indicator of selective survival of a certain genetic subtype.

\subsection{METHODS}

\section{Participants}

This study is part of a larger study in The Netherlands on "Ageing in PWS". Nominees with possible PWS were contacted through the Dutch Prader-Willi Parent Association and through physicians specialized in persons with ID (Figure 2.1). The individuals with PWS and their main carers (family and/or professional carers), were visited at home. Through semistructured interviews, data were collected on demographics, physical, behavioural and psychiatric conditions and adaptive skills. Some physical measurements, such as height and weight, were taken. The study was approved by the Medical Ethics Committee of the academic hospital Maastricht in The Netherlands and written informed consent to participate in the study was given by the legal representatives (mostly parents) of the adults with PWS.

\section{Genetic diagnosis}

During the interviews, parents were asked whether genetic tests on PWS, including genetic subtype, had been undertaken previously. Written confirmation on genetic diagnoses was retrieved from genetic centres, with permission from the legal representatives. Genetic testing was undertaken in participants who did not have a confirmed genetic diagnosis $(n=40)$. Cytogenetic and molecular analyses using the SALSA MLPA kit P245 (MRC Holland, Amsterdam) was performed to establish whether deletions were present. Diagnosis of PWS was confirmed by DNA methylation studies on the SNURF/SNRPN locus and mUPD was confirmed with microsatellite analysis at various loci on chromosome 15 , when blood of parents were available. 


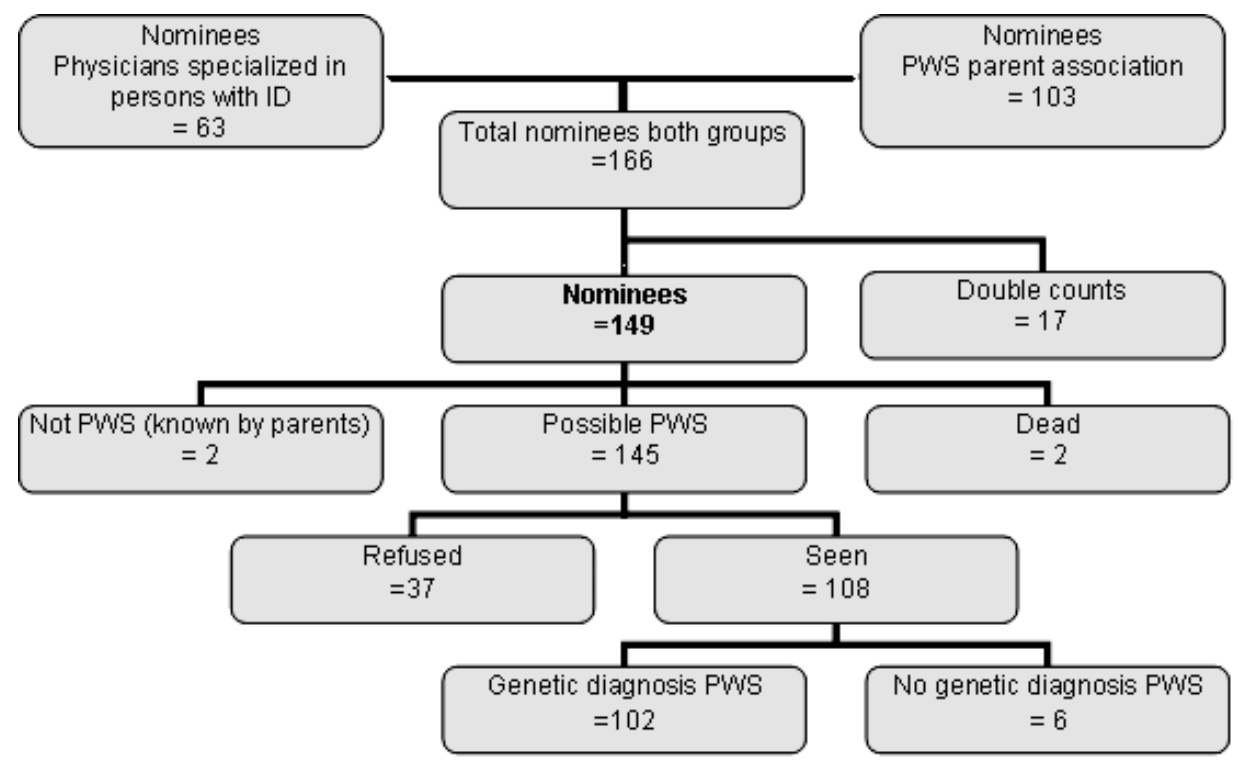

Figure 2.1 Background of the study population

\subsection{RESULTS}

\section{The study population}

Participants of the study were recruited through the Dutch Prader-Willi Parent Association and trough physicians specialized in persons with ID (Figure 2.1). In total, 149 nominees with (possible) diagnoses of PWS were notified to us. After eliminating those nominees who had died and whose parents told that PWS was excluded by genetic testing, we were left with 145 possible participants. Of them, 108 actually agreed to participate in the study (response rate $74.5 \%)$. The participants underwent genetic laboratory testing before $(n=68)$ or during the study $(n=40)$ to confirm the diagnosis and determine the genetic subtype. For 102 persons, the genetic diagnosis of PWS was confirmed and, consequently, this report is based on these 102 individuals. Of these 102 individuals, 32 were recruited trough physicians specialized in persons with ID, 18 of these persons underwent genetic testing during the study. 


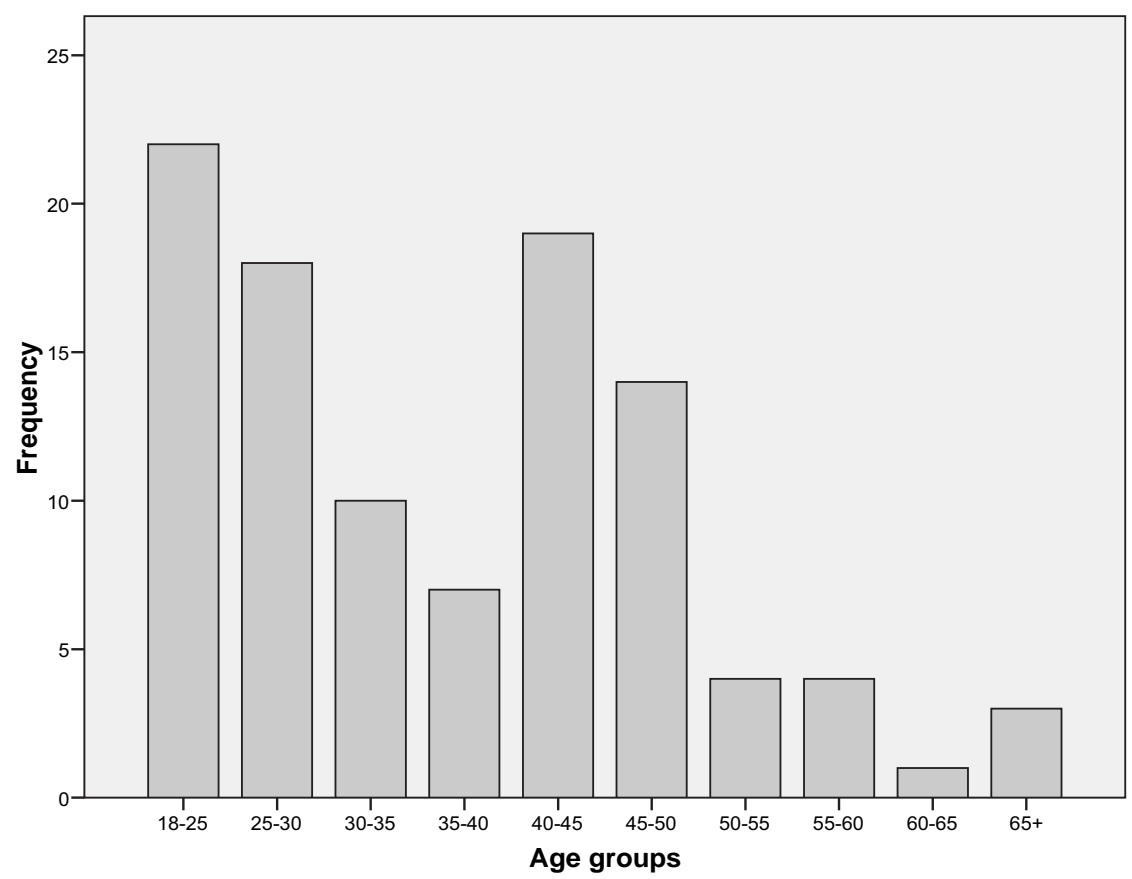

Figure 2.2 Frequencies by age group

Figure 2.2 shows the age-distribution of the study group (standardized to 1 March 12009$)$. A substantial proportion of the study population $(44 \%, n=45)$ was $\geq 40$ years of age. The oldest participant was 66 years old (Figure 2.2). Of the persons above the age of 40 years, 56\% (25/45) underwent genetic testing because of an unconfirmed clinical diagnosis in the past.

The level of ID was mild $(49 \%, n=50)$ or moderate $(28 \%, n=29)$ in most participants. Eight (8\%) participants had a severe ID. The other participants were functioning on a borderline ID level $(10 \%, n=10)$ or did not have an ID $(5 \%, n=5)$. The great majority of the individuals were ambulant (86 of 97$)$. Five persons needed minor adjustments for walking and five other persons needed major adjustments. One person was not ambulant anymore. Intellectual disability and mobility did not differ between genetic subtypes.

In total 37 persons decided not to participate in the study. The mean age of the participants did not differ from the mean age of the non-participants, 36.2 versus 37.1 years (T-test: $t=-0.413, p=0.68)$. 


\section{(1) Relationship between distribution of genetic subtypes and age}

Genetic testing showed 55 persons (54\%) with a paternal deletion, 44 persons $(43 \%)$ with a mUPD and 3 persons $(3 \%)$ with a defect of the imprinting center (Table 2.1). The observed distribution in our study differed from that in the literature $(70 \%$ deletion, $30 \%$ mUPD), which was statistically significant (z-score: $p<0.05)$.

Table 2.1 also shows the distribution of persons per genetic subtype per age group. When comparing the deletion group and the mUPD group, the percentage of persons with the deletion subtype in the youngest age group $(<25)$ was significantly higher than in the older age-groups $\left(x^{2}=11.645, d f=3\right.$, $p=0.001$ ). In addition, the distribution ratio of deletion versus mUPD was 86:9 in the youngest versus 39:54 in the oldest age group.

Table 2.1 Distribution genetic subtypes by age groups

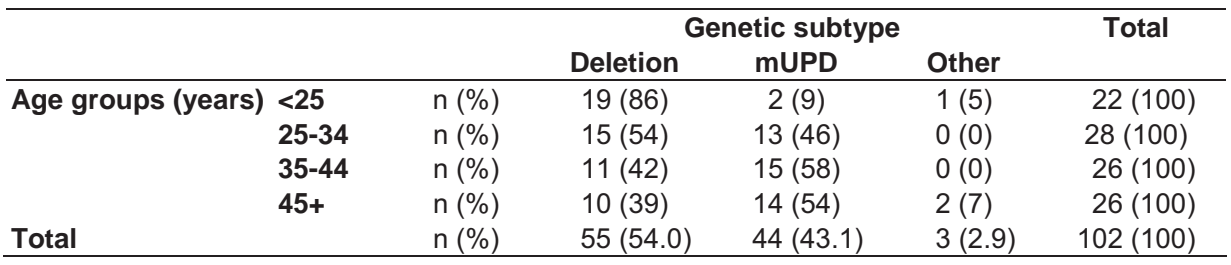

Comparing Deletion and mUPD: $x^{2}=11.645, d f=3, p=0.001$

(2) The relationship between distribution of genetic subtypes and maternal age at birth

Analysis of the distribution of genetic subtypes in relation to maternal age at birth of the persons with PWS showed that in all age groups, the mean age of the mothers at birth of mUPD persons was significantly higher than the mean age of the mothers at birth of deletion persons (Figure 2.3). The mean maternal age at birth of the persons with a deletion was 28.9 years, compared with 35.2 years in persons with a mUPD $(t=-5.451, p=<0.01)$.

To examine this effect of maternal age on genetic subtypes, we also analyzed the effect in the different age groups of persons with PWS. The mean age of mothers at birth of deletion persons, as well as the mean age of mothers at birth of mUPD persons, did not significantly differ across age groups. 

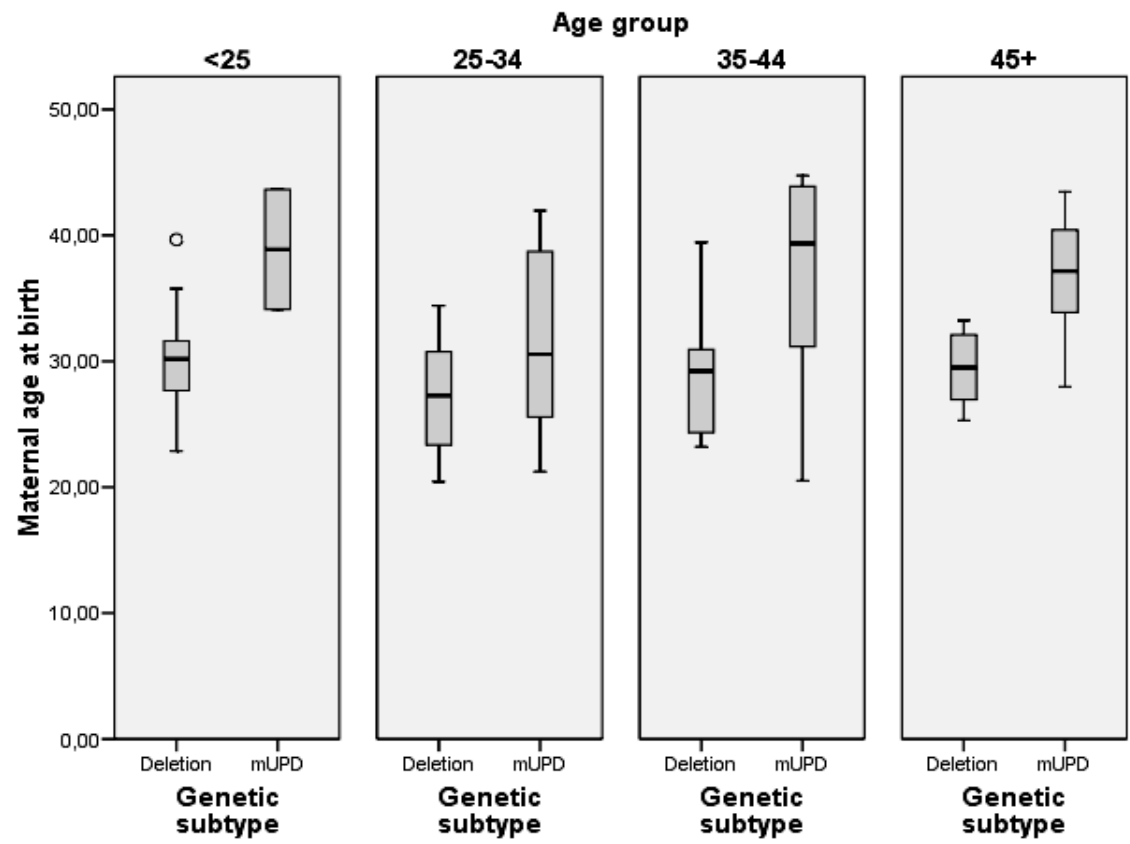

Figure 2.3 Maternal age at birth by genetic subtype and age group

\section{(3) Relationship between distribution of genetic subtypes and BMI}

An analysis of the distribution of genetic subtypes in relation to BMI (Figure 2.4) showed no difference between the mean BMl $\left(\mathrm{kg} / \mathrm{m}^{2}\right)$ of persons with a deletion versus persons with mUPD (32.3 versus $32.8, t=-0.265, p=0.791)$. A significant difference in mean BMI in the different age groups was observed for persons with a deletion, respectively 28.8, 31.5, 36.6, 35.7 (ANOVA: $p=0.024$ ). Observed differences were mainly due to the difference between age group $<25$ years and age group 35-44 years $(p=0.045)$

Moreover, a significant difference in mean BMI in the different age groups was observed for persons with a mUPD, respectively $27.2,37.8,31.3,30.3$ (ANOVA: $p=0.037$ ). Observed differences were mainly due to the differences between age group $25-34$ years and $>45$ years $(p=0.078)$.

Because the current BMI might not reflect weight status across life span, we also examined the reported maximum BMI levels of these persons. The mean maximum BMI in deletion persons was 36.1 , compared with 36.9 in mUPD persons $(t=-0.391, p=0.7)$. In deletion persons, differences in maximum BMI 
between age groups were statistically significant (ANOVA: $p<0.01$ ), mainly because of differences between age group $<25$ years versus age group 35-44 years and age group $<25$ years versus age group $>45$ years (both $p<0.01$ ). In persons with mUPD, BMI maximum differences were not statistically significant between age groups (ANOVA: $p=0.145$ ).
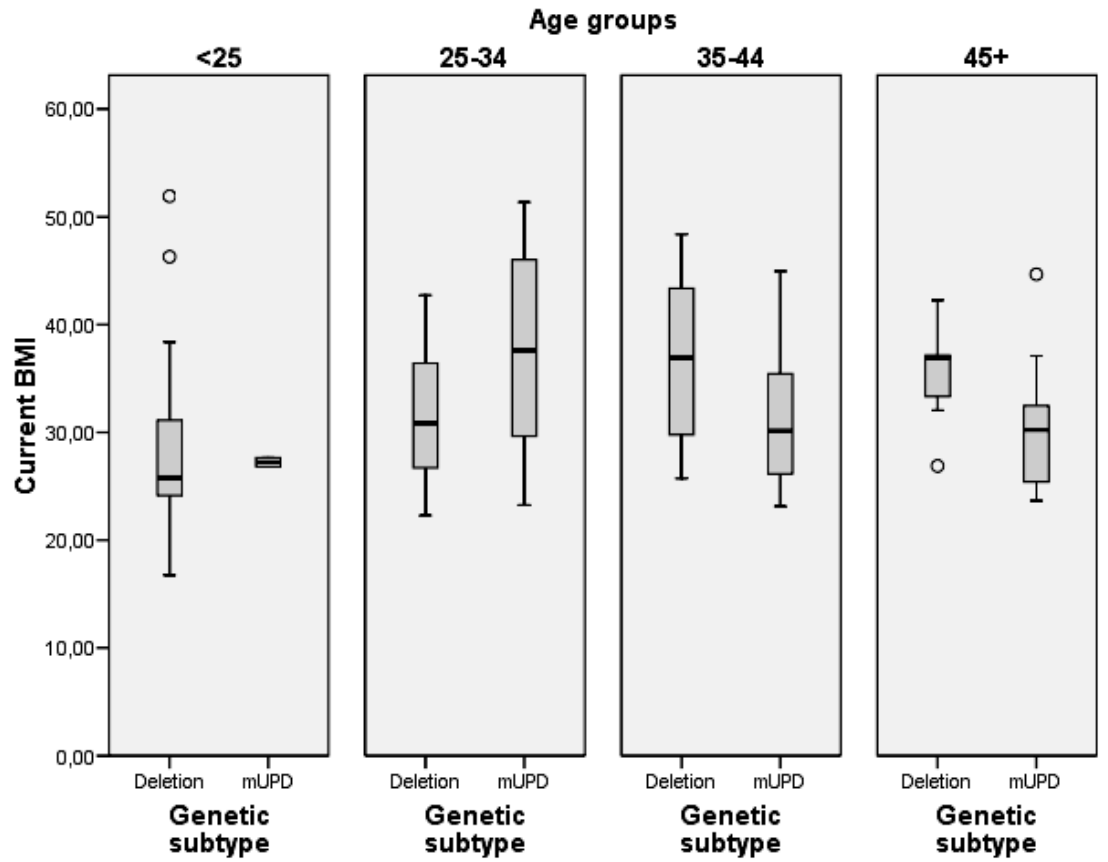

Figure 2.4 Current BMI by genetic subtype and age group

\subsection{DISCUSSION}

In our study population of 102 adults with PWS in The Netherlands, a different distribution of genetic subtypes across the different age groups was found when compared with previous population-based studies (Table 2.2$)^{4-6}$. In this study a relatively high proportion of mUPD in the older age groups was found. Possible explanations for the differences will be discussed. 
Table 2.2 Distribution of PWS genetic subtypes in recent population studies

\begin{tabular}{lccccccc}
\hline Location & $\begin{array}{c}\text { Sample } \\
\text { total }\end{array}$ & $\begin{array}{c}\text { Sample } \\
\text { ascertained }\end{array}$ & $\begin{array}{c}\text { Deletion } \\
(\%)\end{array}$ & $\begin{array}{c}\text { UPD } \\
(\%)\end{array}$ & $\begin{array}{c}\text { Other } \\
(\%)\end{array}$ & Age range & $\begin{array}{c}\text { Above 40 } \\
\text { yrs of age }\end{array}$ \\
\hline UK & & & & & & & \\
Flanders & 96 & 58 & 74 & 22 & 3 & $0-47$ & 7 \\
Australia & 78 & 73 & 69 & 19 & 5 & $0-56$ & 23 \\
\hline
\end{tabular}

\section{Bias of study population}

The differences in distribution of the genetic subtypes across the age groups could be attributed to a selection bias. Bias of the study group may include one of the following: sampling error in our study or selective diagnosing in our study and/or in previous literature.

\section{Sampling error}

Participants of our study were recruited through the Dutch Prader-Willi Parent Association and physicians specialized in treating persons with ID. The response rate of the study was $75 \%$. We have no reason to assume a sampling error in our study, by neither the non-response or by the selection of cases. However, we did not analyze the genetic PWS subtypes in the non-response group nor did we perform a population study in which all possible cases of PWS were included.

\section{Selective diagnosing}

Selective diagnosing (that is, undiagnosed deletion cases in our study or undiagnosed mUPD cases in other studies) is unlikely, as most studies used broad inclusion criteria. Major clinical criteria (such as obesity, hyperphagia, intellectual disabilities, hypogonadism) are common to both deletion and mUPD subtypes and are not likely to be missed. However, in the elderly, information on hypotonia and feeding problems at young age is not always known by professional caregivers or siblings. In our study, we found a wide age range; in particular relatively many elderly (40+ years) with PWS compared to other studies (Table 2.1). More than half of these elderly (56\%) did not have a confirmed genetic diagnosis in the past. In other studies, these elderly might have been undiagnosed and/or underreported. This may especially be the case in the studies that collaborated only with a PWS parent association as source for their participants. This kind of study should be done in other populations over different countries in order to increase the number of patients and to reduce a probable way of recruitment. 


\section{Additional factors reported in the literature}

Additional factors that might influence the distribution of genetic subtypes comprise maternal age, environmental variables causing genetic errors and the use of reproductive technologies ${ }^{10,12,14,15}$. Although the age of the mUPD mothers at birth of the PWS baby is significantly higher than the age of the deletion mothers in the present study, this does not explain the differences in distribution across the age groups. Reproductive technologies were not used in our study population and so cannot have influenced these results. Furthermore we have no indications of environmental factors to affect the relatively high proportion MUPD in our study.

\section{Selective mortality}

A possible explanation for the observed differences in distribution of genetic subtypes across age groups may be differences in survival of the genetic subtypes. As causes of death in adults with PWS are usually stated as "obesity related" ${ }^{5,16,17}$, we compared the BMI rates of the individuals by subtypes across the different age groups. We found no statistically significant differences indicating a difference in survival between the genetic subtypes. In contrast with our results, a possible relationship between higher death rates in the young adult age range and the mUPD subtype has been stated by Smith et $\mathrm{al}^{18}$. However, in other studies, no significant differences in mortality rates in relation to the genetic subtype were found. Most studies are limited by sample size or report on highly selective cases ${ }^{16,17}$ and thus these data in the literature may be insufficient to compare differences in survival. Further studies on survival in relation to genetic subtypes of PWS are highly recommended.

\section{Psychiatry}

The most striking difference between the deletion and mUPD subtypes in adulthood is the occurrence of psychotic episodes, which are more associated with the mUPD subtype ${ }^{19-21}$. In the general population, psychotic illnesses result in a substantially increased risk of death at relatively young age. Overall, people with schizophrenia have a two- to threefold increased risk of premature dying $^{22}$. Suicide contributes to this increased premature mortality. Moreover, people with schizophrenia are thought to be less inclined to seek health care, to consume less medical care, to engage in high-risk behaviors, and to be less compliant with their treatments. Combined, these lifestyle factors elevate the risk of a wide range of somatic conditions and consequently increase the risk of early death ${ }^{22}$. However, in our adult PWS population, the proportion of mUPD in the elderly is higher than in younger age groups. Although psychotic illness attributes to an elevated a risk of premature death in the general population, this may not hold true for the PWS population. Suicide is probably rare in 
people with PWS. Practically all adults with PWS live under close supervision of their parents or professional caregivers. Lifestyle factors such as smoking, alcohol consumption, access to food and compliance to therapy are usually carefully monitored by parents and professional caregivers and might therefore not influence the life expectancy, as observed in psychiatric persons in the general population.

\section{Differences in gene expression}

Phenotypical differences that exist between genetic subtypes might arise from a variety of proposed genetic mechanisms. The PWS phenotype results from the absence of expression of a set of genes in the 15q11-q13 region, which are paternally expressed and maternally imprinted. Although no single gene alteration has been found that accounts for all key PWS characteristics, several unique translocation and deletion persons have narrowed a "key" region to explain much of the PWS phenotype to the HBII-85 snoRNA gene ${ }^{24}$. Persons with PWS either have no inherited copy of the paternally expressed genes (deletion) or two maternal gene copies due to a maternal disomy (mUPD). In addition, imprinting of the respective genes may be aberrant as a result of an imprinting defect in the $15 q$ region.

The phenotypic differences between persons with either the deletion or mUPD subtype may be related to the underlying differences in gene expression of the genetic subtypes. In the deletion subtype, haploinsufficiency of non-imprinted genes in the PWS region may contribute to phenotypic differences between the deletion and mUPD subtype ${ }^{25}$. Conversely, maternally expressed genes, such as UBE3A, show an elevated expression in the mUPD subtype and have been suggested to contribute to specific phenotypic characteristics ${ }^{26,27}$.

Furthermore, any imprinted genes distal to $15 q 11-13$ would be affected in persons with UPD but not in persons with a deletion ${ }^{25}$. In addition, differences in expression have been reported due to parental biased expression of nonimprinted genes outside the deletion region ${ }^{27}$. Consequently, persons with mUPD have a lower level of expression from both chromosomes 15, compared with individuals without PWS and those with a deletion subtype. A more severe phenotype may be associated with a reduced life expectancy. A milder clinical phenotype in persons with Angelman syndrome due to paternal UPD compared with persons with a deletion has been reported ${ }^{28}$.

\section{Conclusion}

We did not find a proper explanation for differences in distribution of genetic subtypes across age groups. Further research on morbidity and causes of death in relation to the genetic subtypes is required. 
The increasing number of elderly people with PWS and the different distribution of genetic subtypes across age groups raise some important issues. Our findings underline the need for correct genetic diagnosis in persons with PWS. Over the last 10 years, the age of diagnosis has fallen significantly and the majority of cases are now diagnosed during the first months of life. The results of this study show a substantial number $(n=45)$ of persons above the age of 40 and even up to the age of 66 years. We noticed that 25 of these elderly persons had not had a confirmed genetic diagnosis prior to the study. The clinical diagnosis of PWS is based on core features like hypotonia, failure to thrive and undescended testes in boys. However, this clinical information is not always available later in life. Genetic testing for PWS in adults should also be considered in case of a less marked phenotype, characterized by behavioural and psychological problems in addition to obesity and delayed or incomplete puberty ${ }^{29}$.

The results also underline the need for adjustment of the guidelines for preventive management in adulthood. For example, special attention should be given to psychiatric problems, because of the high proportion of mUPD persons among elderly people with PWS. A correct genetic diagnosis followed by efficient use of preventive management programs, should allow the ageing PWS population to enjoy a longer and healthier life. 


\section{REFERENCES}

1. Cassidy SB: Prader-Willi syndrome. J Med Genet 1997; 34: 917-923.

2. Holm VA, Cassidy SB, Butler MG, Hanchett JM, Greenswag LR, Whitman BY, Greenberg F: Prader-Willi syndrome: consensus diagnostic criteria. Pediatrics 1993; 91: 398-402.

3. Cassidy SB, Driscoll DJ: Prader-Willi syndrome. Eur J Hum Genet 2009; 17: 3-13.

4. Smith A, Egan J, Ridley G, Haan E, Montgomery P, Williams K, Elliott E: Birth prevalence of Prader-Willi syndrome in Australia. Arch Dis Child 2003; 88: 263-264.

5. Vogels A, Van Den Ende J, Keymolen K, Mortier G, Devriendt K, Legius E, Fryns JP: Minimum prevalence, birth incidence and cause of death for Prader-Willi syndrome in Flanders. Eur J Hum Genet 2004; 12: 238-240.

6. Whittington JE, Holland AJ, Webb T, Butler J, Clarke D, Boer H: Population prevalence and estimated birth incidence and mortality rate for people with PraderWilli syndrome in one UK Health Region. J Med Genet 2001; 38: 792-798.

7. Ledbetter DH, Riccardi VM, Airhart SD, Strobel RJ, Keenan BS, Crawford JD: Deletions of chromosome 15 as a cause of the Prader-Willi syndrome. N Engl J Med 1981; 304: 325-329.

8. Nicholls RD, Knoll JH, Butler MG, Karam S, Lalande M: Genetic imprinting suggested by maternal heterodisomy in nondeletion Prader-Willi syndrome. Nature 1989; 342: 281-285.

9. Buiting K, Saitoh S, Gross S, Dittrich B, Schwartz S, Nicholls RD, Horsthemke B: Inherited microdeletions in the Angelman and Prader-Willi syndromes define an imprinting centre on human chromosome 15. Nat Genet 1995; 9: 395-400.

10. Whittington JE, Butler JV, Holland AJ: Changing rates of genetic subtypes of Prader-Willi syndrome in the UK. Eur J Hum Genet 2007; 15: 127-130.

11. Ginsburg C, Fokstuen S, Schinzel A: The contribution of uniparental disomy to congenital development defects in children born to mothers at advanced childbearing age. Am J Med Genet 2000; 95: 454-460.

12. Bukulmez O: Does assisted reproductive technology cause birth defects? Curr Opin Obstet Gynecol 2009; 21: 260-264.

13. Manipalviratn S, DeCherney A, Segars J: Imprinting disorders and assisted reproductive technology. Fertil Steril 2009; 91: 305-315.

14. Akefeldt A, Anvret M, Grandell U, Nordlinder R, Gillberg C: Parental exposure to hydrocarbons in Prader-Willi syndrome. Dev Med Child Neurol 1995; 37: 1101-1109.

15. Cassidy SB, Forsythe M, Heeger S, Nicholls RD, Schork N, Benn P, Schwartz S: Comparison of phenotype between patients with Prader-Willi syndrome due to deletion 15q and uniparental disomy 15. Am J Med Genet 1997; 68: 433-440.

16. Schrander-Stumpel CT, Curfs LM, Sastrowijoto P, Cassidy SB, Schrander JJ, Fryns JP: Prader-Willi syndrome: causes of death in an international series of 27 cases. Am J Med Genet A 2004; 124: 333-338.

17. Einfeld SL, Kavanagh SJ, Smith A, Evans EJ, Tonge BJ, Taffe J: Mortality in Prader-Willi syndrome. Am J Ment Retard 2006; 111: 193-198.

18. Smith A, Loughnan $G$, Steinbeck K: Death in adults with Prader-Willi syndrome may be correlated with maternal uniparental disomy. J Med Genet 2003; 40: e63.

19. Descheemaeker MJ, Vogels A, Govers V, Borghgraef M, Willekens D, Swillen A, Verhoeven W, Fryns JP: Prader-Willi syndrome: new insights in the behavioural and psychiatric spectrum. J Intellect Disabil Res 2002; 46: 41-50. 
20. Boer H, Holland A, Whittington J, Butler J, Webb T, Clarke D: Psychotic illness in people with Prader Willi syndrome due to chromosome 15 maternal uniparental disomy. Lancet 2002; 359: 135-136.

21. Vogels A, De Hert M, Descheemaeker MJ, Govers V, Devriendt K, Legius E, Prinzie P, Fryns JP: Psychotic disorders in Prader-Willi syndrome. Am J Med Genet A 2004; 127A: 238-243.

22. Saha S, Chant D, McGrath J: A systematic review of mortality in schizophrenia: is the differential mortality gap worsening over time? Arch Gen Psychiatry 2007; 64: 1123-1131.

23. Maina EN, Webb T, Soni S, Whittington J, Boer H, Clarke D, Holland A: Analysis of candidate imprinted genes in PWS subjects with atypical genetics: a possible inactivating mutation in the SNURF/SNRPN minimal promoter. J Hum Genet 2007; 52: 297-307.

24. Sahoo T, del Gaudio D, German JR, Shinawi M, Peters SU, Person RE, Garnica A, Cheung SW, Beaudet AL: Prader-Willi phenotype caused by paternal deficiency for the HBII-85 C/D box small nucleolar RNA cluster. Nat Genet 2008; 40: 719-721.

25. Holsen LM, Zarcone JR, Brooks WM, Butler MG, Thompson TI, Ahluwalia JS, Nollen NL, Savage CR: Neural mechanisms underlying hyperphagia in Prader-Willi syndrome. Obesity 2006; 14: 1028-1037.

26. Joseph B, Egli M, Sutcliffe JS, Thompson T: Possible dosage effect of maternally expressed genes on visual recognition memory in Prader-Willi syndrome. Am J Med Genet 2001; 105: 71-75.

27. Bittel DC, Kibiryeva N, Sell SM, Strong TV, Butler MG: Whole genome microarray analysis of gene expression in Prader-Willi syndrome. Am J Med Genet A 2007; 143: $430-442$.

28. Bottani A, Robinson WP, DeLozier-Blanchet CD, Engel E, Morris MA, Schmitt B, Thun-Hohenstein L, Schinzel A: Angelman syndrome due to paternal uniparental disomy of chromosome 15: a milder phenotype? Am J Med Genet 1994; 51: 35-40.

29. Goldstone AP, Holland AJ, Hauffa BP, Hokken-Koelega AC, Tauber M: Recommendations for the diagnosis and management of Prader-Willi syndrome. $J$ Clin Endocrinol Metab 2008; 93: 4183-4197. 



\section{CHAPTER 3.1}

\section{PHYSICAL HEALTH PROBLEMS IN ADULTS WITH PRADER-WILLI SYNDROME}

Sinnema M, Maaskant MA, van Schrojenstein Lantman-de Valk HMJ, van Nieuwpoort IC, Drent ML, Curfs LMG ${ }^{\S}$, Schrander-Stumpel CTRM ${ }^{\S}$.

Am J Med Genet A 2011;155:2112-2124

$\S$ authors share senior authorship 


\section{ABSTRACT}

\section{Introduction}

Prader-Willi syndrome (PWS) is a genetic disorder which is characterized by severe hypotonia and feeding problems in early infancy. In later childhood and adolescence, this is followed by hyperphagia and extreme obesity if the diet is not strictly controlled. Data on physical health problems in adults with PWS is scarce. We report on the prevalence of physical health problems in a Dutch cohort of adults with PWS in relation to age, BMI and genetic subtype.

\section{Method}

Participants $(n=102)$ were retrieved via the Dutch Prader-Willi Parent Association and through physicians specializing in persons with Intellectual Disabilities (ID). Details regarding physical health problem spanning the participants' lifespan were collected through semi-structured interviews.

\section{Results}

Cardiovascular problems included diabetes mellitus, hypertension and cerebrovascular accidents. Respiratory infections were frequent in adulthood. In males, cryptorchidism was almost universal, for which 28/48 males had a history of surgery, mostly orchidopexy. None of the women had a regular menstrual cycle. Sixteen individuals had a diagnosis of osteoporosis. Spinal deformation, hip dysplasia and foot abnormalities were common. Skin-picking, leg edema and erysipelas were frequent dermatological problems.

\section{Discussion}

The findings in our group support the notion that the prevalence of physical health problems is underestimated. This underscores the importance of developing monitoring programs which would help to recognize physical health problems at an early stage. 


\subsubsection{INTRODUCTION}

Prader-Willi syndrome (PWS) is characterized by severe hypotonia and feeding problems in early infancy. In childhood and adolescence, this is followed by hyperphagia and, without strict dietary control, extreme obesity. People with PWS tend to have a short stature, facial dysmorphisms, hypogonadism, intellectual disabilities and behavioural difficulties ${ }^{1-3}$. PWS is a genetic disorder which results from loss of function of paternally expressed genes in the chromosome $15 q 11-q 13$ region. About $75 \%$ of the people with PWS have a deletion in the paternally derived $15 q 11-q 13$ region $^{4}$ and most of the remaining subjects have a maternal uniparental disomy (mUPD; $20 \%)^{5}$ or an imprinting defect $(5 \%)^{6}$.

In recent years, research on adults with PWS has largely focused on behavioural and psychiatric problems ${ }^{7-10}$. Information on physical health problems however, is scarce. Most of the physical health problems are reported to be secondary to obesity, including diabetes mellitus, respiratory problems, obstructive sleep apnoea, hypertension and cardiovascular problems ${ }^{3}$. This physical health problems result in a higher mortality rate in all age-groups, compared to people with ID in general and a lower life expectancy ${ }^{11,12}$. The mean annual mortality rate for persons with PWS is estimated to be $3 \%$ in general and about $7 \%$ in those older than 30 years ${ }^{11}$. This is substantially higher than the overall death rate of $0.82 \%$ and $0.79 \%$ in the general population of the Netherlands (2008) and UK (2007), resepectively (adults 15-59 years) $)^{13,14}$.

In this report, we describe the prevalence of physical health problems in a Dutch cohort of adults with PWS in relation to age, BMI and genetic subtype. Studies in the literature that focused on physical health problems were restricted by relatively small sample sizes, limited age ranges or lack of genetically confirmed diagnoses ${ }^{15-19}$ (see Table 3.1.1). This article describes a large-scale, systematic study investigating physical health problems in a Dutch cohort of adults with PWS. The study population we describe is unique because of two reasons. Firstly, it is the largest cohort of adults with PWS $(n=102)$, with a genetically confirmed diagnosis described in the literature. Secondly, our study population had a broad age range and a high number of older people (over the age of 40 years). Therefore, the results provide more insight in the natural history of physical health problems and lifespan development in the syndrome (Figure 3.1.1, 3.1.2). 
CHAPTER 3.1

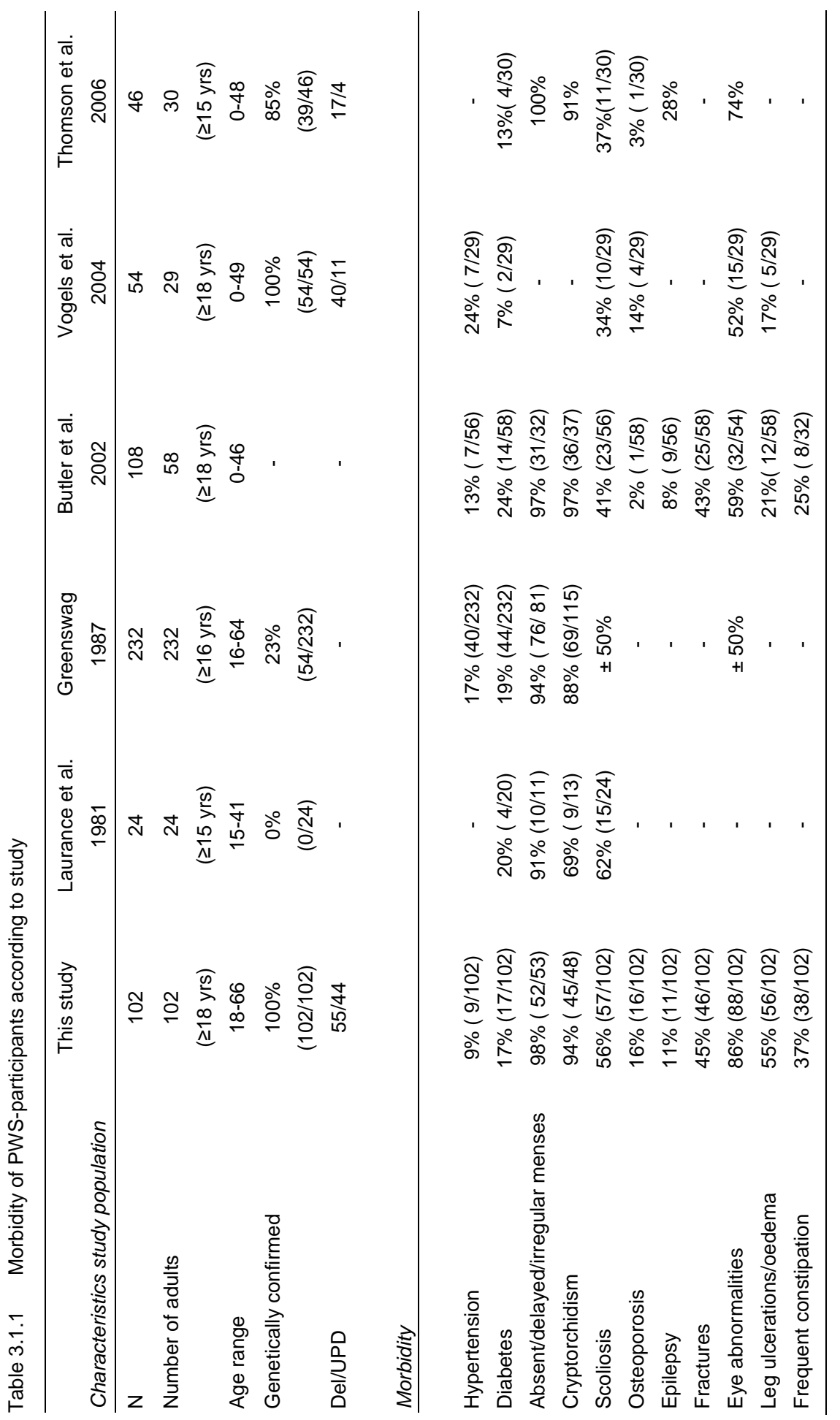



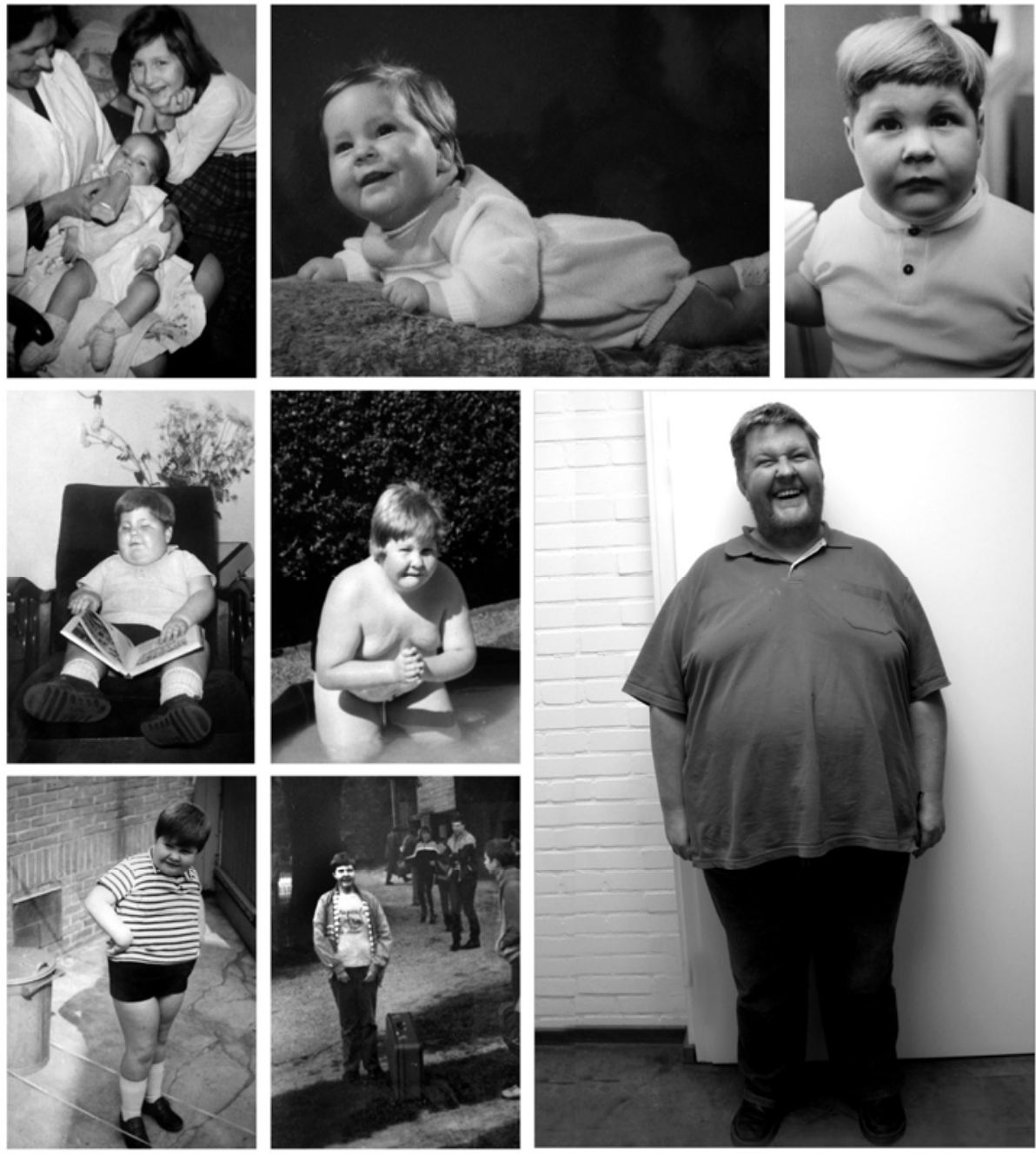

Figure 3.1.1 Lifespan of a 45 year old man with Prader-Willi syndrome

\subsubsection{METHODS}

\section{Procedure}

This study was approved by the Medical Ethics Committee of Maastricht University Medical Centre. Adult nominees (18 years and older) with possible PWS were contacted via the Dutch Prader-Willi Parent Association and through physicians specializing in persons with ID. The individuals with PWS and their 
main caretakers (family and/or professional carers), were visited at home. They were interviewed by the first author (MS) using a semi-structured interview that included questions about physical health problems experienced over the participants' lifetime. Reports of health problems led to further inquiries as to age at onset and treatment. Due to the setting of home visits, no further physical examinations could be carried out, apart from recordings of current height and weight. The medical files of all subjects were retrieved from physicians.

\section{Co-morbidity}

Co-morbidity was classified by the Charlson index ${ }^{20}$. This index predicts the 1 -year mortality for a patient. The range of co-morbid conditions may include for instance heart disease, diabetes, or cancer (a total of 17 conditions) ${ }^{21}$. Each condition is assigned a score of 1,2,3 or 6 depending on the risk of dying associated with this condition. The scores are summed up and given a total score which reflects the cumulative increased likelihood of 1-year mortality.

\section{Genetic diagnosis}

We performed genetic testing in participants $(n=40)$ who did not have a previously confirmed genetic diagnosis. Cytogenetic analysis and molecular analysis using the SALSA MLPA kit P245 (MRC Holland, Amsterdam) were performed to establish whether deletions were present. A diagnosis of PWS was confirmed by DNA methylation studies on the SNURF/SNRPN locus. mUPD was confirmed with microsatellite analysis at various loci on chromosome 15, when blood of parents was available. If mUPD was rejected by microsatellite analysis, an imprinting defect was assumed.

\section{Participants}

In total 149 nominees with a (possible) diagnosis of PWS were notified to us. Two nominees had died and two parents informed us that PWS was excluded by genetic testing. Hence, 145 possible participants were left. Of these, 108 agreed to participate in the study (a response rate of $75 \%$ ). Results of genetic testing before $(n=68)$ or during the study $(n=40)$ were used to confirm the diagnosis and determine the genetic subtype. For 102 out of 108 persons, the genetic diagnosis of PWS was confirmed; the 6 remaining persons did not suffer from PWS. Consequently, this report is based on these 102 individuals. The characteristics of the study population are summarized in Table 3.1.2. The mean age of the participants did not differ significantly from the mean age of the non-participants, 36.2 versus 37.1 years (T-test: $t=-0.413, p=0.68$ ). 
Table 3.1.2 Characteristics of the study population

\begin{tabular}{|c|c|c|}
\hline Characteristic & $\mathrm{n}$ & $\%$ \\
\hline \multicolumn{3}{|l|}{ Gender } \\
\hline Male & 49 & 48 \\
\hline Female & 53 & 52 \\
\hline \multicolumn{3}{|l|}{ Age } \\
\hline $18-24$ yrs & 22 & 22 \\
\hline $25-34$ yrs & 28 & 28 \\
\hline $35-44$ yrs & 26 & 25 \\
\hline $45+y r s$ & 26 & 25 \\
\hline \multicolumn{3}{|l|}{ Genetic subtype } \\
\hline Deletion & 55 & 54 \\
\hline mUPD & 44 & 43 \\
\hline Imprinting defect & 3 & 3 \\
\hline \multicolumn{3}{|l|}{$B M I$} \\
\hline$<18,5$ & 1 & 1 \\
\hline $18,5-25$ & 17 & 17 \\
\hline $25-30$ & 27 & 26 \\
\hline $30+$ & 57 & 56 \\
\hline \multicolumn{3}{|l|}{ Level of ID } \\
\hline No ID & 5 & 5 \\
\hline Borderline ID & 8 & 8 \\
\hline Mild & 52 & 51 \\
\hline Moderate & 29 & 28 \\
\hline Severe & 8 & 8 \\
\hline \multicolumn{3}{|l|}{ Residential setting } \\
\hline Home* $^{*}$ & 21 & 21 \\
\hline Community-based facilities $\ddagger$ & 81 & 79 \\
\hline Total & 102 & 100 \\
\hline
\end{tabular}

* Including living with family members and relatives, or living independently

‡ Community-based facilities include group homes and supervised staff apartments

\section{Statistical analyses}

The following statistical tests were used: ANOVA to compare means of three or more groups, independent sample t-tests to compare means of two independent groups, Chi-square to compare frequencies of nominal data, and Kendall's tau to compare frequencies of ordinal data. SPSS (version 16.0) was used to analyze the data. A p-value of 0.05 or less was taken as significance level for all statistical tests.

\subsubsection{RESULTS}

Tables 3.1.3, 3.1.4 and 3.1.5 show the results of the total reported physical health problems according to genetic subtypes, BMI category and age group respectively. Additional information is included in the next paragraphs. 
Table 3.1.3 Prevalence of physical health problems in PWS adults, total and per genetic subtype, and level of statistical significance

\begin{tabular}{|c|c|c|c|c|c|c|}
\hline \multirow[t]{2}{*}{ Tract } & \multirow[t]{2}{*}{ Physical health problems } & \multirow{2}{*}{$\begin{array}{c}\text { Total } \\
\mathrm{n}\end{array}$} & \multicolumn{3}{|c|}{ Prevalence per genetic subytpe } & \multirow{2}{*}{$\begin{array}{l}X^{2(*)} \\
p\end{array}$} \\
\hline & & & $\begin{array}{c}\text { Deletion } \\
(n=55)\end{array}$ & $\begin{array}{l}\text { mUPD } \\
(n=44)\end{array}$ & $\underset{(n=3)}{\operatorname{IM}}$ & \\
\hline \multirow[t]{3}{*}{ Cardiovascular } & Hypertension & 9 & 6 & 3 & 0 & n.s. \\
\hline & Stroke & 5 & 1 & 4 & 0 & n.s. \\
\hline & Coronary heart disease & 1 & 1 & 0 & 0 & n.s. \\
\hline Diabetes & NIDDM & 17 & 7 & 10 & 0 & n.s. \\
\hline \multirow{7}{*}{ Respiratory } & Pneumonia & 6 & 1 & 5 & 0 & 0.05 \\
\hline & Asthma & 10 & 6 & 4 & 0 & n.s. \\
\hline & Exessive daytime sleepiness & 73 & 35 & 36 & 2 & 0.05 \\
\hline & Sleep apnea & 10 & 7 & 3 & 0 & n.s. \\
\hline & Disturbed sleep & 20 & 6 & 13 & 1 & 0.02 \\
\hline & Snoring & 51 & 30 & 20 & 1 & n.s. \\
\hline & Narcolepsy & 5 & 3 & 1 & 1 & n.s \\
\hline \multirow[t]{5}{*}{ Gastro-intestinal } & Constipation & 38 & 24 & 13 & 1 & n.s. \\
\hline & Reflux & 10 & 4 & 5 & 1 & n.s. \\
\hline & Gallstones & 4 & 3 & 1 & 0 & n.s. \\
\hline & Rectal bleeding & 5 & 2 & 3 & 0 & n.s. \\
\hline & Anemia & 6 & 1 & 5 & 0 & 0.04 \\
\hline \multirow[t]{4}{*}{ Genito-urinary } & Cryptorchidism (in males) & $48 / 49$ & $27 / 27$ & $18 / 19$ & $3 / 3$ & n.s \\
\hline & Hernia inguinalis & 21 & 9 & 10 & 2 & n.s. \\
\hline & Urinary incontinence & 13 & 2 & 11 & 0 & $<0.01$ \\
\hline & Urinary tract/kidney problems & 6 & 3 & 3 & 0 & n.s. \\
\hline \multirow[t]{5}{*}{ Endocrine } & Osteoporosis & 16 & 13 & 2 & 1 & 0.02 \\
\hline & History of any fracture & 46 & 23 & 21 & 1 & n.s. \\
\hline & Primary amenorrhea (in female) & $28 / 53$ & $16 / 28$ & $12 / 25$ & $0 / 0$ & n.s \\
\hline & Adrenal insufficiency & 1 & 0 & 1 & 0 & n.s. \\
\hline & Hypothyroidism & 9 & 5 & 4 & 0 & n.s. \\
\hline \multirow[t]{2}{*}{ Neurologic } & Epilepsy & 14 & 5 & 9 & 0 & n.s. \\
\hline & Meningitis/encephalitis & 3 & 1 & 2 & 0 & n.s. \\
\hline \multirow[t]{4}{*}{ Orthopedic } & Scoliosis & 57 & 30 & 24 & 2 & n.s. \\
\hline & Foot problems & 81 & 47 & 31 & 1 & n.s. \\
\hline & Knee problems & 6 & 6 & 0 & 0 & 0.02 \\
\hline & Hip problems & 9 & 3 & 5 & 1 & n.s. \\
\hline \multirow[t]{5}{*}{ Dermatologic } & Skinpicking & 86 & 42 & 42 & 2 & n.s. \\
\hline & Oedema & 56 & 37 & 19 & 0 & 0.02 \\
\hline & Erysipelas & 38 & 20 & 16 & 1 & n.s. \\
\hline & Varices & 16 & 6 & 10 & 0 & n.s. \\
\hline & Thrombosis & 3 & 1 & 2 & 0 & n.s. \\
\hline Ophthalmologic & Eye problems & 88 & 47 & 38 & 1 & n.s. \\
\hline Otolaryngologic & Ear problems & 16 & 13 & 2 & 1 & $<0.01$ \\
\hline
\end{tabular}

$\left(^{*}\right)$ Due to the small numbers of IM, only differences between deletion and UPD were tested 
Table 3.1.4 Prevalence of physical health problems in PWS adults, total and per BMI category, and level of statistical significance

\begin{tabular}{|c|c|c|c|c|c|c|}
\hline \multirow[t]{2}{*}{ Tract } & \multirow[t]{2}{*}{ Physical health problems } & \multirow{2}{*}{$\begin{array}{c}\text { Total } \\
\mathrm{n}\end{array}$} & \multicolumn{3}{|c|}{ Prevalence per BMI category } & \multirow{2}{*}{$\begin{array}{l}X^{2} \\
p\end{array}$} \\
\hline & & & $\begin{array}{c}\mathrm{BMI}<25 \\
(\mathrm{n}=18)\end{array}$ & $\begin{array}{c}\text { BMI } 25-30 \\
\quad(n=27)\end{array}$ & $\begin{array}{c}\mathrm{BMI}>30 \\
(\mathrm{n}=57)\end{array}$ & \\
\hline \multirow[t]{3}{*}{ Cardiovascular } & Hypertension & 9 & 0 & 0 & 9 & 0.01 \\
\hline & Stroke & 5 & 3 & 1 & 1 & 0.03 \\
\hline & Coronary heart disease & 1 & 0 & 0 & 1 & n.s. \\
\hline Diabetes & NIDDM & 17 & 2 & 1 & 14 & 0.05 \\
\hline \multirow{7}{*}{ Respiratory } & Pneumonia & 6 & 2 & 2 & 2 & n.s. \\
\hline & Asthma & 10 & 3 & 2 & 5 & n.s. \\
\hline & Exessive daytime sleepiness & 73 & 9 & 18 & 46 & 0.03 \\
\hline & Disturbed sleep & 20 & 7 & 6 & 7 & n.s. \\
\hline & Snoring & 51 & 5 & 8 & 38 & $<0.01$ \\
\hline & Sleep apnea & 10 & 2 & 2 & 6 & n.s. \\
\hline & Narcolepsy & 5 & 1 & 1 & 3 & n.s. \\
\hline \multirow[t]{5}{*}{ Gastro-intestinal } & Constipation & 38 & 7 & 11 & 20 & n.s. \\
\hline & Reflux & 10 & 2 & 2 & 6 & n.s. \\
\hline & Gallstones & 4 & 1 & 1 & 2 & n.s. \\
\hline & Rectal bleeding & 5 & 1 & 2 & 2 & n.s. \\
\hline & Anemia & 6 & 2 & 1 & 3 & n.s. \\
\hline Genito-urinary & Cryptorchidism (in males) & $48 / 49$ & $12 / 12$ & $16 / 17$ & $20 / 20$ & n.s \\
\hline \multirow[t]{3}{*}{ Genito-urinary } & Hernia inguinalis & 21 & 6 & 5 & 10 & n.s. \\
\hline & Urinary incontinence & 13 & 2 & 1 & 10 & n.s. \\
\hline & Urinary tract/kidney problems & 6 & 3 & 0 & 3 & n.s. \\
\hline \multirow[t]{5}{*}{ Endocrine } & Osteoporosis & 16 & 4 & 2 & 10 & n.s. \\
\hline & History of any fracture & 46 & 9 & 12 & 25 & n.s. \\
\hline & Primary amenorrhea (in female) & $28 / 53$ & $5 / 6$ & $8 / 10$ & $15 / 37$ & 0.02 \\
\hline & Adrenal insufficiency & 1 & 0 & 0 & 1 & n.s. \\
\hline & Hypothyroidism & 9 & 1 & 4 & 4 & n.s. \\
\hline \multirow[t]{2}{*}{ Neurologic } & Epilepsy & 14 & 3 & 6 & 5 & n.s. \\
\hline & Meningitis/encephalitis & 3 & 1 & 1 & 1 & n.s. \\
\hline \multirow[t]{4}{*}{ Orthopedic } & Scoliosis & 57 & 12 & 14 & 30 & n.s. \\
\hline & Foot problems & 81 & 10 & 21 & 50 & n.s. \\
\hline & Knee problems & 6 & 0 & 3 & 3 & n.s. \\
\hline & Hip problems & 9 & 2 & 3 & 4 & n.s. \\
\hline \multirow[t]{5}{*}{ Dermatologic } & Skinpicking & 86 & 15 & 22 & 49 & n.s. \\
\hline & Oedema & 56 & 7 & 7 & 41 & $<0.01$ \\
\hline & Erysipelas & 38 & 7 & 4 & 27 & 0.03 \\
\hline & Varices & 16 & 1 & 2 & 13 & n.s. \\
\hline & Thrombosis & 3 & 0 & 0 & 3 & n.s. \\
\hline Ophthalmologic & Eye problems & 88 & 13 & 24 & 51 & n.s. \\
\hline Otolaryngologic & Ear problems & 16 & 2 & 7 & 7 & n.s. \\
\hline
\end{tabular}


Table 3.1.5 Prevalence of physical health problems in PWS adults, total and per age group, and level of statistical significance

\begin{tabular}{|c|c|c|c|c|c|c|c|}
\hline \multirow[t]{2}{*}{ Tract } & \multirow[t]{2}{*}{ Physical health problems } & \multirow{2}{*}{$\begin{array}{c}\text { Total } \\
\mathrm{n}\end{array}$} & \multicolumn{4}{|c|}{ Prevalence per age group } & \multirow{2}{*}{$\begin{array}{c}X^{2} \\
p\end{array}$} \\
\hline & & & $\begin{array}{c}<25 \\
(n=22)\end{array}$ & $\begin{array}{c}25-34 \\
(n=28)\end{array}$ & $\begin{array}{c}35-44 \\
(n=26)\end{array}$ & $\begin{array}{c}45+ \\
(n=26)\end{array}$ & \\
\hline \multirow[t]{3}{*}{ Cardiovascular } & Hypertension & 9 & 0 & 2 & 3 & 4 & n.s. \\
\hline & Stroke & 5 & 0 & 1 & 1 & 3 & n.s. \\
\hline & Coronary heart disease & 1 & 0 & 0 & 0 & 1 & n.s. \\
\hline Diabetes & NIDDM & 17 & 1 & 4 & 3 & 9 & 0.04 \\
\hline \multirow[t]{7}{*}{ Respiratory } & Pneumonia & 6 & 0 & 2 & 1 & 3 & n.s. \\
\hline & Asthma & 10 & 1 & 5 & 2 & 2 & n.s. \\
\hline & Exessive daytime sleepiness & 73 & 12 & 17 & 25 & 19 & $<0.01$ \\
\hline & Disturbed sleep & 20 & 3 & 6 & 5 & 6 & n.s \\
\hline & Snoring & 51 & 7 & 18 & 13 & 13 & n.s. \\
\hline & Sleep apnea & 10 & 1 & 4 & 4 & 1 & n.s. \\
\hline & Narcolepsy & 5 & 2 & 1 & 2 & 0 & n.s. \\
\hline \multirow[t]{5}{*}{ Gastro-intestinal } & Constipation & 38 & 9 & 8 & 11 & 10 & n.s. \\
\hline & Reflux & 10 & 1 & 4 & 1 & 4 & n.s. \\
\hline & Gallstones & 4 & 0 & 0 & 1 & 3 & n.s. \\
\hline & Rectal bleeding & 5 & 0 & 2 & 3 & 0 & n.s. \\
\hline & Anemia & 6 & 0 & 1 & 3 & 2 & n.s. \\
\hline \multirow[t]{4}{*}{ Genito-urinary } & Cryptorchidism (in males) & $48 / 49$ & $10 / 10$ & $12 / 12$ & $13 / 13$ & $13 / 14$ & n.s. \\
\hline & Hernia inguinalis & 21 & 4 & 3 & 7 & 7 & n.s. \\
\hline & Urinary incontinence & 13 & 1 & 1 & 5 & 6 & n.s. \\
\hline & Urinary tract/kidney problems & 6 & 1 & 2 & 2 & 1 & n.s. \\
\hline \multirow[t]{5}{*}{ Endocrine } & Osteoporosis & 16 & 5 & 2 & 5 & 4 & n.s. \\
\hline & History of any fracture & 46 & 7 & 11 & 15 & 13 & n.s. \\
\hline & Primary amenorrhea (in female) & $28 / 53$ & $11 / 12$ & $8 / 16$ & $7 / 13$ & $2 / 13$ & $<0.01$ \\
\hline & Adrenal insufficiency & 1 & 0 & 1 & 0 & 0 & n.s. \\
\hline & Hypothyroidism & 9 & 4 & 1 & 1 & 3 & n.s. \\
\hline \multirow[t]{2}{*}{ Neurologic } & Epilepsy & 14 & 4 & 4 & 0 & 3 & n.s. \\
\hline & Meningitis/encephalitis & 3 & 1 & 0 & 2 & 0 & n.s. \\
\hline \multirow[t]{4}{*}{ Orthopedic } & Scoliosis & 57 & 15 & 13 & 16 & 13 & n.s. \\
\hline & Foot problems & 81 & 19 & 22 & 21 & 19 & n.s. \\
\hline & Knee problems & 6 & 3 & 1 & 2 & 0 & n.s. \\
\hline & Hip problems & 9 & 2 & 4 & 0 & 3 & n.s. \\
\hline \multirow[t]{5}{*}{ Dermatologic } & Skinpicking & 86 & 15 & 28 & 22 & 21 & n.s. \\
\hline & Edema & 56 & 11 & 17 & 12 & 16 & n.s. \\
\hline & Erysipelas & 38 & 2 & 9 & 13 & 14 & 0.02 \\
\hline & Varices & 16 & 1 & 4 & 5 & 6 & n.s. \\
\hline & Thrombosis & 3 & 0 & 1 & 2 & 0 & n.s. \\
\hline Ophthalmologic & Eye problems & 88 & 18 & 25 & 24 & 21 & n.s. \\
\hline Otolaryngologic & Ear problems & 16 & 7 & 5 & 2 & 2 & n.s. \\
\hline
\end{tabular}

\section{BMI, smoking and alcohol use}

Mean body mass index $(\mathrm{BMl}=\mathrm{kg} / \mathrm{m} 2)$ was $32.2(S D=7.9$, range=16.8-51.9). Fifty-seven (56\%) participants were obese (BMI $\geq 30$ ) (Table 3.1.2). The mean BMI did not differ between the genetic subtypes. Twenty-six persons, mainly those in the older age groups, smoked cigarettes, cigars or pipes. Thirty-six 
persons drank alcohol occasionally. There were two anecdotal reports of individuals stealing and binging alcohol.

\section{Comorbidity}

The mean total score on the Charlson index was 0.39 (range 0-8, SD 1.05). Seventy-eight participants scored zero on the Charlson index and two persons scored $\geq 5$ on the Charlson index. The mean total score was higher in the older age groups (mean $=0.05$ in age group $<25$ years vs. mean=0.81 in age group $45+$ ). These differences were statistically significant (ANOVA p0.05; Kendall's tau, $p<0.01$ ). Persons with mUPD scored significantly (ANOVA $p=0.03$ ) higher on the Charlson index than persons with a deletion (mean $=0.66$ in mUPD vs. mean $=0.20$ in deletion).

\section{Cryptorchidism}

In males, a history of cryptorchidism or absent testicles was almost universal, occurring in 48 out of 49 males. In three persons the testicles descended spontaneously during childhood or after medication use. Twenty-eight males underwent surgery, mostly orchidopexy. Orchidectomy was performed in four persons because of atrophic testes. Those under 25 years were significantly more likely to have had surgery $(100 \%)$, than those of 45 years and older $(50 \%)\left(X^{2}, p<0.01\right)$. Inguinal hernia surgery was frequently combined with orchidopexy. One man had been diagnosed with a testicular carcinoma which was thought to have been caused by cryptorchidism which had not been surgically corrected.

\section{Menstrual cycles}

Nearly half the women (25/53) reported a history of at least one spontaneous vaginal bleeding. In general, menarche occurred later than in the general population (mean: 21.9 years, SD 7.1, range 14-43 years). None of the women had a regular menstrual cycle. Eight women were thought to have reached menopause (range 30-56 years). Five women experienced irregular periods. Seven women had previously had one or several menstrual cycles which stopped. Four women had secondary amenorrhea following medication use. Twenty-eight women had no menstrual cycles. There was no report of a pregnancy in the presently described cohort.

\section{Sexual interests}

Almost half of the participants $(n=47)$ were reported to have been engaged in some kind of sexually motivated activity, varying from falling in love, to masturbation and sexual relationships. Eleven persons stated to have had a relationship, an additional nine persons stated to have a relationship at time of 
the interview. A history of sexual abuse was reported by 22 individuals (of whom 16 women).

\section{Use of growth and sex hormones}

Five young adults had a current prescription of growth hormone; eight persons had used growth hormone in the past. Eight men and nine women had a current prescription of sex hormones. Additionally, seven men and five women had used sex hormones in the past.

\section{Relation between physical health problems and genetic subtype, BMI and age}

Differences between the prevalence of physical health problems in the genetic subtypes, BMI categories and age groups, were statistically significant (see Table 3.1.3, 3.1.4, 3.1.5). Persons with the mUPD subtype had more often been diagnosed with pneumonia (at adult age), excessive daytime sleepiness, disturbed sleep, anaemia (mostly due to rectal skin-picking), ear problems and urinary incontinence. The deletion subtype was associated with osteoporosis, knee problems and leg edema. A higher BMI was related to diabetes, hypertension, excessive daytime sleepiness, snoring and erysipelas. A lower $\mathrm{BMI}$ was associated with cerebrovascular accidents and primary amenorrhea. Diabetes and erysipelas were more common in the older age groups. Primary amenorrhea was less prevalent in the older women. Excessive daytime sleepiness was most prominent in the group aged between 35 and 44 years.

\subsubsection{DISCUSSION}

We report on physical health problems in the largest cohort of genetically confirmed adults with PWS. Adults with PWS have a considerable phenotypic variability. There is limited data on physical health problems of adults with PWS in the reported literature ${ }^{15-19,22}$.

\section{Risk factors for physical health problems}

Risk factors contributing to the development of health problems in adults with PWS include primarily hypotonia and obesity. Hypotonia, which is most prominent in the neonatal period, is a lifelong core feature of $\mathrm{PWS}^{1}$. Problems such as scoliosis, strabismus and susceptibility to respiratory infections may be related to the hypotonia ${ }^{19}$. Hyperphagia is another core feature of PWS ${ }^{1}$, leading to obesity if not controlled. However, the severity of obesity can be managed by early diagnosis, dietary restrictions, controlling access to food, regular exercise, appropriate behavioural counseling and hormonal 
replacement ${ }^{3}$. Obesity related problems could include diabetes, hypertension and cardiac problems. Finally, some disorders, like joint problems, could be caused by a combination of both risk factors.

The results on the Charlson index indicated that the risk of dying in adults with PWS was higher in the older age groups, which is obvious. However, the risk of dying was also higher in people with mUPD.

\section{Recognition of illness}

It is often not possible to recognise physical health problems in people with PWS until the advanced stages of disease. In general people with ID may not be able to understand the significance of their physical symptoms and may not report them at all or too late ${ }^{23}$. Typical PWS characteristics such as temperature instability, the lack of ability to vomit and a high pain threshold may also contribute to masking of the initial symptoms of illness ${ }^{1}$. This underlines the need for screening of physical health problems. The presence of systemic symptoms or acute onset of unusual behaviour, body temperature instability, respiratory problems or uncharacteristic body movements may signal the presence of a deep tissue infection or systemic infections, such as pneumonia.

We could not screen for unrevealed physical health problems in the setting of this study. The participants and their caregivers were visited at home. We collected as many as possible details on physical health problems, but extensive physical examinations and additional tests like blood analysis (e.g. glucose), blood pressure measurements, metyrapone stress tests for adrenal insufficiency, bone density measurements, polysomnography or ultrasound were not part of the current study. It is possible that this approach resulted in an underestimation of the prevalence of specific disorders. Based on the results of this study, it is important to focus more in detail on disorders such as sleep apnea, osteoporosis and cardiovascular diseases in this cohort in the future.

\section{Role of behaviour and psychiatry}

Behavioural and psychiatric problems are known to be very common in adults with $\mathrm{PWS}^{7,9,10,24,25}$. It is difficult however, to eliminate the effect of these problems on their physical conditions. Physical health problems can manifest as challenging behaviour or loss of daily function. Some challenging behaviour can be so intense that this adversely affects the physical health of persons. Physical disorders can also be a side effect of psychotropic medication, prescribed for challenging behaviour ${ }^{26}$.

Mental health problems may also occur as a response to physical disorders. It is not an uncommon clinical observation that such problems may improve or even disappear with medical treatment of physical disorders. In our experience, 
physical characteristics often occurred in the early stages of psychiatric episodes, such as the occurrence of urine incontinence, weight loss and skinpicking in the first phase of a psychosis. This is in line with the findings of Vogels et al. ${ }^{10}$.

\section{Cardio-vascular disease and diabetes mellitus}

The prevalence ratio (PR) of NIDDM in men with BMI 30-35 in the general population is 10, the PR of coronary heart disease (CHD) 16 and the PR of hypertension 49, (in women: diabetes 7, CHD 13, hypertension 48) ${ }^{27}$. NIDDM only occurred in a minority of adults with PWS, but the prevalence was higher than expected in comparison with the prevalence in the obese general population. The prevalence of hypertension and CHD was surprisingly low in our cohort. Only a few well-documented cases of coronary artery disease and cerebrovascular accidents in PWS have been reported in the literature ${ }^{28-30}$. Eight persons with NIDDM also suffered from hypertension and one person had a history of a cerebrovascular accident.

The prevalence of cerebrovascular accidents in individuals without obesity was surprising. One man also suffered from pseudoxanthoma elasticum (PXE), which may have contributed to his risk of ischaemic stroke. In the remaining cases there were no other predisposing factors (e.g. smoking or cancer).

There were no persons with a clear diagnosis of cor pulmonale in our study. Cor pulmonale is the most commonly reported cardiovascular complication in PWS and is often cited as cause of mortality ${ }^{16,31}$. However, in the literature, only few well-documented cases are described. In non-PWS patients, clinical signs are usually seen late in the course of disease. Peripheral edema, a common finding in PWS, might indicate a higher incidence of cor pulmonale than reported in this study. Future research should focus on unraveling the causes of the low prevalence of cardio-vascular diseases. Because underdiagnosis might also play a role, screening for these conditions may be advisable as a routine element of care.

\section{Respiratory and sleep problems}

Death and serious illness in the older age group was often triggered by acute or chronic pulmonary infections. Pneumonia at adult age was reported in six individuals, four of whom were over the age of 40 years. These episodes were not always recognized in an early stage, for instance because of lack of fever. Because of the risk of respiratory decompensation, close monitoring and judicious use of antibiotics should be considered if there is any evidence of infection $^{18,32}$, especially in older people with PWS.

Given the high incidence of symptoms such as excessive daytime sleepiness and snoring, the number of people with a diagnosis of sleep apnea in this 
cohort is likely to be an underestimate. Sleep studies (polysomnography) and ear, nose, and throat evaluation should be recommended to evaluate the true prevalence ${ }^{3}$.

\section{Constipation and rectal skinpicking}

Our results show that many of the adults with PWS suffer from constipation. Rectal bleedings was reported in five persons and in four of these rectal skinpicking was thought to be the cause. Three persons were diagnosed with rectal ulcers. The rectal bleeding could be significant and even caused anemia in four persons. Rectal skinpicking is associated with the behavioural phenotype in individuals with PWS due to $\mathrm{MUPD}^{8}$. Severe skinpicking behaviour has been described in some cases, including rectal picking, ulcers and bleeding have been described ${ }^{33-35}$. Such behaviour might be exacerbated by rectal irritation from constipation, diarrhea, or large stools. Early recognition of rectal skinpicking may help to avoid misdiagnosis.

\section{Cryptorchidism and risk of testicular carcinoma}

One man in our cohort was diagnosed with a testicular carcinoma at the age of 38 years. Studies in non-PWS populations indicate that cryptorchidism is associated with a relative risk for testicular cancer between 2.75 and $8^{36}$. Because testicular cancer is rare, the absolute numbers of affected persons remain small despite a high relative risk (especially in PWS cohorts). In our study, surgery was performed in 28 out of 48 males with cryptorchidism. Half of the men in the oldest age group did not undergo surgery. Including our case, only three cases of testicular cancer in PWS have been described in the literature ${ }^{37,38}$. This is possibly due to under-diagnosis or under-reporting. Surgical correction of cryptorchidism (orchidopexy) reduces the risk for cancer. However, the risk for malignancy after orchidopexy is still increased compared with normally descended testicles ${ }^{36}$. Testicular malignancy may be detected at an early stage only in those testicles that are completely intrascrotal (after surgery) and therefore amenable to self- and medical examination ${ }^{37,39}$. It is possible that the number of observed cases of testicular cancer in PWS in recent years is low due to early surgical correction. Males with PWS may also be at reduced risk of malignant degeneration compared to the general population.

\section{Use of sex hormones}

In the Netherlands, treatment with sex hormones is not common in adults with PWS. Suppletion of estrogen and testosterone has been recommended because of the potential positive effects on bone mineral density and improvement in secondary sex characteristics ${ }^{40,41}$. Low levels of sex hormones 
are also associated with age characteristics (e.g., alterations of the skin, coronary atherosclerosis, and risk of Alzheimer disease). The relatively low prevalence of primary amenorrhea in women in the oldest age group of our study and therefore presumably relately high levels of estrogen, may have contributed to reaching older age in these individuals. In our study, almost half of the persons ever treated with sex hormones discontinued this therapy because of adverse effects (e.g. behavioural difficulties, thrombosis and acne). Sex hormone treatment should be individualized through weighing of the risks and benefits and through discussions with the person with PWS and the parents or caregivers ${ }^{41,42}$.

\section{Sexual interest}

Sexual activity in adults with PWS is usually described as uncommon. Our results, however, do not confirm this assumption. A few cases of pregnancy in females with PWS have been described ${ }^{43,44}$. The ID, social and emotional immaturity of people with PWS, and the risk of Angelman syndrome in children of PWS deletion mothers, has prompted professionals to advise against pregnancy $^{3}$. More research on expectations and support in terms of sexual health needs to be done from the perspective of persons with PWS themselves and their families. Although normal sperm development has been reported in some orchidectomy specimens, there have been no reports of paternity in $\mathrm{PWS}^{45}$. The results on sexual interests from our study show that education about relationships and sexuality in persons with PWS is as important as in the general ID population ${ }^{46-48}$. Our data also indicate that adults with PWS are at risk of sexual abuse.

\section{Osteoporosis}

Decreased bone mineral density is common in individuals with $\mathrm{PWS}^{49}$. Butler et al. found low bone mass or osteopenia in four of the nine subjects with PWS over the age of 20 years ${ }^{40}$. In our study, a diagnosis of osteoporosis was reported by the caregivers in only 16 individuals. All diagnoses had been confirmed by bone density measurements. However, most of the participants in the study had not had bone density measurements, as it was not part of the current study. Therefore, we also assessed fracture rates. Almost half of the study population had at least one reported fracture. The fracture rate was the same in individuals with and without a diagnosis of osteoporosis.

The most important risk factors for osteoporosis in the general population are advanced age (in both men and women) and female gender. In PWS, low growth hormone levels, low sex hormone levels, hypotonia and inactivity contribute to low bone mineral density ${ }^{40}$. No significant differences were found in the prevalence of osteoporosis in the different age groups and genders in our cohort. We therefore hypothesize that young adults were more likely to 
have been screened for the presence of osteoporosis during follow-up by their own physicians. The prevalence of osteoporosis in our study was lower than expected ${ }^{40}$ and is likely to be an underestimate of the actual prevalence.

\section{Leg edema}

In our study, edema of the legs was a very frequent characteristic in adults with PWS and this was often exacerbated by skinpicking and erysipelas (Figure 3.1.2). The cause of the edema was mostly unknown. In previous reports, edema of the legs in people with PWS has frequently been attributed to obesity. A girl from the present study was reported with primary lymphedema ${ }^{50}$. Whether the diagnosis of primary lymphedema in this patient with PWS is a coincidental finding or a frequently overlooked and important clinical sign, needs to be studied in additional cases of adult individuals with PWS.
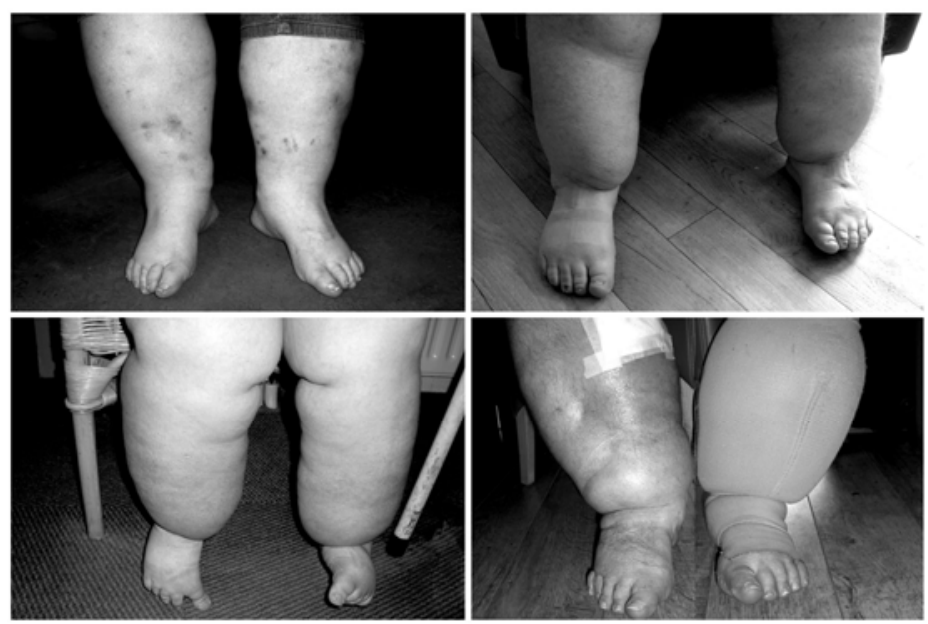

Figure 3.1.2 Severe leg edema in adults with Prader-Willi syndrome

\section{Conclusion and recommendations}

Some of the health problems in adults with PWS may be preventable by health promotion and optimized assessment and treatment of medical conditions. Strict management of weight may be the most important factor, as many of the common co-morbidities occur almost exclusively in persons with a BMI>30. However, weight loss does not seem to be a cure for all aspects of the disorder. Daily exercise, limiting the use of alcohol, prevention of starting to smoke and regular dental care are also important in the prevention of secondary health issues. Replacement therapy with growth hormone may help 
to reduce physical health problems and mortality by improving the body composition $^{3,51}$.

The results of this study should be interpreted in the context of the methodological shortcomings. The findings in this report relate to crosssectional data and there might be a selection bias towards survivors, with the most severely affected people with PWS having died earlier. Moreover, we had to rely on retrospective and self-reported data (mostly reported by the caregivers). In order to achieve a better understanding of the physical health problems, the ageing process and mortality in PWS, longitudinal research is of great importance. This data-set opens research opportunities for longitudinal follow up of this cohort in the future.
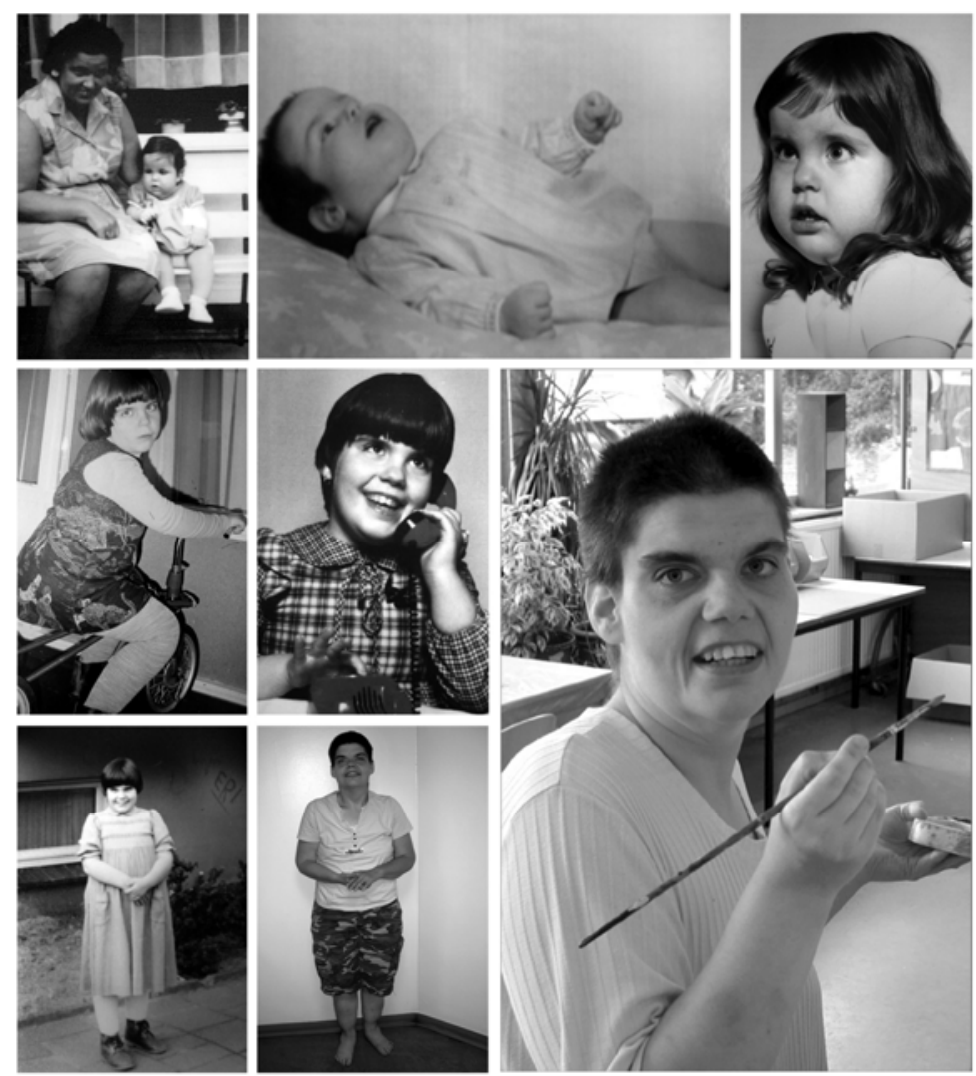

Figure 3.1.3 Lifespan of a 37 year old woman with Prader-Willi syndrome

The findings in our group support the idea that the prevalence of physical health problems is underestimated. This underscores the notion for guidelines for routine, preventive management, adjusted to the adult PWS population ${ }^{52}$. 
Such guidelines may help to recognize and treat physical health problems in an early stage. In Table 3.1.6 we suggest a checklist for preventive management in an adult with PWS. These recommendations for preventive management in adults with PWS are based on the results of our study, clinical experience and data from the literature. The results of this study are very important as a starting point for the development of evidence based guidelines.

Table 3.1.6 Checklist for preventive management in adults with PWS

\begin{tabular}{|c|c|}
\hline Category & Evaluation \\
\hline \multirow[t]{6}{*}{ General } & Evaluate general well-being \\
\hline & Evaluate working and living circumstances \\
\hline & Assess relationships and sexuality \\
\hline & Assess use of tobacco and alcohol \\
\hline & $\begin{array}{l}\text { Consider general (ID) population screening programmes (e.g. for } \\
\text { sensory impairment, PAP smear, breast cancer) }\end{array}$ \\
\hline & Evaluate medication use and possible side effects \\
\hline Genetics & Confirm clinical diagnosis of PWS by genetic tests* \\
\hline \multirow[t]{2}{*}{ Feeding and weight } & Measure and plot weight and body mass index \\
\hline & Assess diet, exercise and management for obesity prevention \\
\hline \multirow[t]{3}{*}{ Cardiovascular } & Assess for hypertension \\
\hline & Evaluate for type II diabetes mellitus \\
\hline & Assess for cardiac complaints. Consider ECG, cardiac ultrasound \\
\hline Respiratory & Evaluate history of respiratory infections \\
\hline \multirow[t]{2}{*}{ Gastro-intestinal } & Assess constipation \\
\hline & Assess rectal bleeding (and rectal picking) \\
\hline \multirow[t]{7}{*}{ Endocrine } & Assess menstrual cycle \\
\hline & Evaluate for osteoporosis and obtain bone densometry \\
\hline & Consider the need for vitamin D and calcium supplementation \\
\hline & Consider the need for sex hormone replacement \\
\hline & Consider the need and possibilities for growth hormone replacement \\
\hline & Consider evaluation of adrenal insufficiency \\
\hline & Assess thyroid function \\
\hline \multirow[t]{3}{*}{ Genito-urinary } & $\begin{array}{l}\text { Evaluate testicular descent. Consider referral for orchidopexy if } \\
\text { undescended }\end{array}$ \\
\hline & Assess for inguinal hernia \\
\hline & Assess urinary incontinence \\
\hline \multirow[t]{5}{*}{ Skeletal } & Assess scoliosis/kyphosis \\
\hline & Assess for arthrosis in any joint \\
\hline & Assess for hip dysplasia* \\
\hline & Assess for knee problems \\
\hline & Assess for feet abnormalities \\
\hline \multirow[t]{2}{*}{ Sleep } & Obtain sleep history \\
\hline & Consider referral for polysomnography \\
\hline Ophthalmologic & Opthalmologic evaluation for strabismus and visual acuity \\
\hline Skin & Evaluate the skin for signs of skinpicking, oedema and erysipelas \\
\hline Dental & Refer for dental care \\
\hline \multirow[t]{2}{*}{ Behaviour and psychiatric } & Assess behavioural problems, changes and management \\
\hline & $\begin{array}{l}\text { Assess for affective disorders and psychosis (and possible } \\
\text { precursors) }\end{array}$ \\
\hline \multirow[t]{3}{*}{ Development and function } & Evaluate physical fitness (physical therapy evaluation) \\
\hline & Perform IQ test \\
\hline & Assess functional decline and signs of dementia (50+ yrs) \\
\hline
\end{tabular}

\footnotetext{
* if not done previously
} 


\section{REFERENCES}

1. Holm VA, Cassidy SB, Butler MG, Hanchett JM, Greenswag LR, Whitman BY, Greenberg F: Prader-Willi syndrome: consensus diagnostic criteria. Pediatrics 1993; 91: 398-402.

2. Couper RT and Couper JJ: Prader-Willi syndrome. Lancet 2000; 356: 673-675.

3. Goldstone AP, Holland AJ, Hauffa BP, Hokken-Koelega AC, Tauber M: Recommendations for the diagnosis and management of Prader-Willi syndrome. $J$ Clin Endocrinol Metab 2008; 93: 4183-4197.

4. Ledbetter DH, Riccardi VM, Airhart SD, Strobel RJ, Keenan BS, Crawford JD: Deletions of chromosome 15 as a cause of the Prader-Willi syndrome. $N$ Engl $\mathrm{J}$ Med 1981; 304: 325-329.

5. Nicholls RD, Knoll JH, Butler MG, Karam S, Lalande M: Genetic imprinting suggested by maternal heterodisomy in nondeletion Prader-Willi syndrome. Nature 1989; 342: 281-285.

6. Buiting K, Saitoh S, Gross S, Dittrich B, Schwartz S, Nicholls RD, Horsthemke B: Inherited microdeletions in the Angelman and Prader-Willi syndromes define an imprinting centre on human chromosome 15. Nat Genet 1995; 9: 395-400.

7. Boer H, Holland A, Whittington J, Butler J, Webb T, Clarke D: Psychotic illness in people with Prader Willi syndrome due to chromosome 15 maternal uniparental disomy. Lancet 2002; 359: 135-136.

8. Dykens EM and Roof E: Behavior in Prader-Willi syndrome: relationship to genetic subtypes and age. J Child Psychol Psychiatry 2008; 49: 1001-1008.

9. Soni S, Whittington J, Holland AJ, Webb T, Maina E, Boer H, Clarke D: The course and outcome of psychiatric illness in people with Prader-Willi syndrome: implications for management and treatment. J Intellect Disabil Res 2007; 51: 32-42.

10. Vogels A, De Hert M, Descheemaeker MJ, Govers V, Devriendt K, Legius E, Prinzie P, Fryns JP: Psychotic disorders in Prader-Willi syndrome. Am J Med Genet A 2004; 127A: 238-243.

11. Whittington JE, Holland AJ, Webb T, Butler J, Clarke D, Boer H: Population prevalence and estimated birth incidence and mortality rate for people with PraderWilli syndrome in one UK Health Region. J Med Genet 2001; 38: 792-798.

12. Einfeld SL, Kavanagh SJ, Smith A, Evans EJ, Tonge BJ, Taffe J: Mortality in Prader-Willi syndrome. Am J Ment Retard 2006; 111: 193-198.

13. CBS. Sterfte; kerncijfers naar diverse kenmerken. www.statline.cbs.nl. 2009.

14. WHO. Health Status Statistics: Mortality; United Kingdom Health Profile. http://www.who.int/healthinfo/statistics/indneonatalmortality/en/. 2010.

15. Greenswag LR: Adults with Prader-Willi syndrome: a survey of 232 cases. Dev Med Child Neurol 1987; 29: 145-152.

16. Laurance BM, Brito A, Wilkinson J: Prader-Willi Syndrome after age 15 years. Arch Dis Child 1981; 56: 181-186.

17. Thomson AK, Glasson EJ, Bittles AH: A long-term population-based clinical and morbidity review of Prader-Willi syndrome in Western Australia. J Intellect Disabil Res 2006; 50: 69-78.

18. Vogels A, Frijns JP: Age at diagnosis, body mass index and physical morbidity in children and adults with the Prader-Willi syndrome. Genet Couns 2004; 15 : 397-404. 
19. Butler JV, Whittington JE, Holland AJ, Boer H, Clarke D, Webb T: Prevalence of, and risk factors for, physical ill-health in people with Prader-Willi syndrome: a population-based study. Dev Med Child Neurol 2002; 44: 248-255.

20. Charlson ME, Pompei P, Ales KL, MacKenzie CR: A new method of classifying prognostic comorbidity in longitudinal studies: development and validation. $J$ Chronic Dis 1987; 40: 373-383.

21. Sundararajan V, Henderson T, Perry C, Muggivan A, Quan H, Ghali WA: New ICD10 version of the Charlson comorbidity index predicted in-hospital mortality. J Clin Epidemiol 2004; 57: 1288-1294.

22. Carpenter PK: Prader-Willi syndrome in old age. J Intellect Disabil Res 1994; 38: 529-531.

23. van Schrojenstein Lantman-de Valk HM and Walsh PN: Managing health problems in people with intellectual disabilities. BMJ 2008; 337: a2507.

24. Sinnema M, Boer H, Collin P, Maaskant MA, van Roozendaal KEP, SchranderStumpel CTRM, Curfs LMG: Psychiatric illness in a cohort of adults with PraderWilli syndrome. Res Dev Disabil. 2011; 32: 1729-1735.

25. Sinnema M, Einfeld SL, Schrander-Stumpel CT, Maaskant MA, Boer H, Curfs LM: Behavioral phenotype in adults with Prader-Willi syndrome. Res Dev Disabil 2011; 32: 604-612.

26. Valdovinos MG, Caruso M, Roberts C, Kim G, Kennedy $\mathrm{CH}$ : Medical and behavioral symptoms as potential medication side effects in adults with developmental disabilities. Am J Ment Retard 2005; 110: 164-170.

27. Must A, Spadano J, Coakley EH, Field AE, Colditz G, Dietz WH: The disease burden associated with overweight and obesity. JAMA 1999; 282: 1523-1529.

28. Lamb AS and Johnson WM: Premature coronary artery atherosclerosis in a patient with Prader-Willi syndrome. Am J Med Genet 1987; 28: 873-880.

29. Page SR, Nussey SS, Haywood GA, Jenkins JS: Premature coronary artery disease and the Prader-Willi syndrome. Postgrad Med J 1990; 66: 232-234.

30. Kusuhara $T$, Ayabe $M$, Hino $H$, Shoji $H$, Neshige R: A case of Prader-Willi syndrome with bilateral middle cerebral artery occlusion and moyamoya phenomenon. Rinsho Shinkeigaku 1996; 36: 770-773.

31. Stevenson DA, Anaya TM, Clayton-Smith J, Hall BD, Van Allen MI, Zori RT, Zackai EH, Frank G, Clericuzio CL: Unexpected death and critical illness in Prader-Willi syndrome: report of ten individuals. Am J Med Genet A 2004; 124:158-164.

32. Eiholzer U: Deaths in children with Prader-Willi syndrome. A contribution to the debate about the safety of growth hormone treatment in children with PWS. Horm Res 2005; 63: 33-39.

33. Bhargava SA, Putnam PE, Kocoshis SA, Rowe M, Hanchett JM: Rectal bleeding in Prader-Willi syndrome. Pediatrics 1996; 97: 265-267.

34. Campeotto F, Naudin C, Viot G, Dupont C: [Rectal self-mutilation, rectal bleeding and Prader-Willi syndrome]. Arch Pediatr 2001; 8: 1075-1077.

35. Didden R, Korzilius H, Curfs L: Skin-picking in individuals with Prader-Willi syndrome: Prevalence, functional assessment, and its comorbidity with compulsive and self-injurious behaviours J Appl Res Intellect Disabil 2007; 20: 409-419.

36. Wood HM and Elder JS: Cryptorchidism and testicular cancer: separating fact from fiction. J Urol 2009; 181: 452-461.

37. Jaffray B, Moore L, Dickson AP: Prader-Willi syndrome and intratubular germ cell neoplasia. Med Pediatr Oncol 1999; 32: 73-74.

38. Robinson AC and Jones WG: Prader Willi syndrome and testicular tumour. Clin Oncol (R Coll Radiol) 1990; 2:117. 
39. Ashley RA, Barthold JS, Kolon TF: Cryptorchidism: pathogenesis, diagnosis, treatment and prognosis. Urol Clin North Am 2010; 37: 183-193.

40. Butler MG, Haber L, Mernaugh R, Carlson MG, Price R, Feurer ID: Decreased bone mineral density in Prader-Willi syndrome: comparison with obese subjects. Am J Med Genet 2001; 103: 216-222.

41. Crino A, Schiaffini R, Ciampalini P, Spera S, Beccaria L, Benzi F, Bosio L, Corrias A, Gargantini L, Salvatoni A, Tonini G, Trifiro G, Livieri C: Hypogonadism and pubertal development in Prader-Willi syndrome. Eur J Pediatr 2003; 162: 327-333.

42. Goldstone AP: Prader-Willi syndrome: advances in genetics, pathophysiology and treatment. Trends Endocrinol Metab 2004; 15: 12-20.

43. Akefeldt A, Tornhage CJ, Gillberg C: 'A woman with Prader-Willi syndrome gives birth to a healthy baby girl'. Dev Med Child Neurol 1999; 41: 789-790.

44. Schulze A, Mogensen H, Hamborg-Petersen B, Graem N, Ostergaard JR, Brondum-Nielsen K: Fertility in Prader-Willi syndrome: a case report with Angelman syndrome in the offspring. Acta Paediatr 2001; 90: 455-459.

45. Vogels A, Moerman P, Frijns JP, Bogaert GA: Testicular histology in boys with Prader-Willi syndrome: fertile or infertile? J Urol 2008; 180: 1800-1804.

46. Patel DR, Greydanus DE, Calles JL, Jr., Pratt HD: Developmental disabilities across the lifespan. Dis Mon 2010; 56: 304-397.

47. Clark LI and O'Toole M S: Intellectual impairment and sexual health: information needs. Br J Nurs 2007; 16: 154-156.

48. Servais L: Sexual health care in persons with intellectual disabilities. Ment Retard Dev Disabil Res Rev 2006; 12: 48-56.

49. Kroonen LT, Herman M, Pizzutillo PD, Macewen GD: Prader-Willi Syndrome: clinical concerns for the orthopaedic surgeon. J Pediatr Orthop 2006; 26: 673-679.

50. Heitink MV, Sinnema M, van Steensel MA, Schrander-Stumpel CT, Frank J, Curfs LM: Lymphedema in Prader-Willi syndrome. Int J Dermatol 2008; 47: 42-44.

51. Hoybye C: Five-years growth hormone $(\mathrm{GH})$ treatment in adults with Prader-Willi syndrome. Acta Paediatr 2007; 96: 410-413.

52. Grol R, Cluzeau FA, Burgers JS: Clinical practice guidelines: towards better quality guidelines and increased international collaboration. Br J Cancer 2003; 89: S4-S8. 


\section{CHAPTER 3.2}

\section{THE USE OF MEDICAL CARE AND PREVALENCE OF SERIOUS ILLNESS IN A DUTCH ADULT PRADER-WILLI SYNDROME COHORT}

Sinnema M, Maaskant MA, van Schrojenstein Lantman-de Valk HMJ, Boer H, Curfs LMG ${ }^{\S}$, Schrander-Stumpel CTRM ${ }^{\S}$

Submitted

${ }^{\S}$ Authors share senior authorship 


\section{ABSTRACT}

\section{Introduction}

Adults with Prader-Willi syndrome (PWS) have an increased occurrence of several medical conditions. We report on the consequences of high morbidity rates such as prevalence rate of hospital admissions, medication use and surgery in a Dutch cohort of adults with PWS. Special attention is paid to causes and symptoms of serious illness, and recovery from illness

\section{Method}

Participants were contacted via the Dutch Prader-Willi Parent Association and through physicians specializing in persons with ID. The persons with PWS and their main caregivers were visited at home. Information was collected through semi-structured interviews on 102 adults with PWS.

\section{Results}

The need for medical care in the neonatal period was associated with hypotonia and feeding problems. Hospital admissions for respiratory tract infections were frequent. During childhood most hospital admissions were due to PWS syndrome specific surgery. During adolescence hospital admissions occurred for scoliosis surgery and endocrine evaluations. At adult age, hospitalization was associated with inguinal hernia surgery, diabetes mellitus, psychosis, erysipelas, water and drug intoxications. In the older group, respiratory infections were again the main reason for hospital admissions. Frequently used medications at adult age included psychotropics, laxatives, anti-diabetics and dermatologic preparations. Abnormal drinking patterns, problems with anesthesia, decreased ability to vomit, abnormal pain awareness and unpredictable fever responses were frequent and often lead to delayed diagnoses of serious conditions.

\section{Discussion}

People with PWS are frequent users of medical-care. Reasons for hospitalization and medication use are age specific. Knowledge on the different presentation of symptoms in people with PWS is needed. In case of unexplained illness, disturbances of consciousness and behavioural changes in people with PWS, an infection should be ruled out in the first place. Information from this study may help in preventing conditions and recognizing conditions in an early stage. Adequate preventive management and treatment of PWS related morbidity, could reduce medical care use in the long term and could improve quality adjusted life years. 


\subsubsection{INTRODUCTION}

Prader-Willi syndrome (PWS) is a neurodevelopmental disorder due to a genetic abnormality on chromosome $15^{1,2,3}$. PWS is characterized by extreme neonatal hypotonia at birth with failure to thrive and a range of physical, behavioural, cognitive and psychiatric characteristics that become apparent during later life and give rise to often complex health and social needs ${ }^{4}$.

A number of studies have contributed to the knowledge on physical and psychiatric morbidity ${ }^{5-13}$. Adults with PWS have an increased occurrence of several medical conditions such as diabetes mellitus, hypertension, leg oedema, skin infections and respiratory infections, psychosis and mood disorders ${ }^{5-13}$. These physical health problems may be followed by an increased use of medical care. However, relatively few systematic studies on these characteristics are available ${ }^{7,14}$.

Signs and symptoms of illness are not always easy to interpret in people with PWS. A high pain threshold, decreased ability to vomit and temperature instability are frequently mentioned as characteristics of the syndrome ${ }^{4}$, and may mask signs and symptoms of illness. However, only little systematic data on these characteristics in a large cohort are available ${ }^{15,16}$.

We therefore focus on hospital admissions, medication use, undergone surgery, problems with anesthesia and recovery from illness in a Dutch cohort of adults with PWS. Special attention is paid to the causes and symptoms of serious illness. This information could provide clues about factors influencing life expectancy in PWS. We hope to find factors that contribute to the development of guidelines for preventive management.

\subsubsection{METHODS}

\section{Procedure}

Persons with possible PWS were contacted through the Dutch Prader-Willi Parent Association and through physicians specializing in ID. Information was collected through interviews with the individuals with PWS and their main carers (family and/or professional carers) at home. They were interviewed using semi-structured interviews that included questions about physical health problems experienced over the participants' lifetime. Detailed information on hospital admissions, medication use, surgery, serious illness and recovery from illness was also collected. Medical files were, with permission of those 
concerned, retrieved from attending physicians. The current study was approved by the Medical Ethics Committee Maastricht.

\section{Genetic diagnosis}

Parents were asked whether genetic tests on PWS including genetic subtype had been undertaken previously. Written confirmation on genetic diagnosis was requested from genetic centres, with permission of the legal representatives. In participants who did not have a confirmed genetic diagnosis $(n=40)$, genetic testing was undertaken. Cytogenetic and molecular analysis using the SALSA MLPA kit P245 (MRC Holland, Amsterdam) was performed to establish whether a deletions was present. Diagnosis of PWS was confirmed by DNA methylation studies on the SNURF/SNRPN locus and mUPD was confirmed with microsatellite analysis at various loci on chromosome 15, when blood of parents was available.

\section{Participants}

In total 149 nominees with a (possible) diagnoses of PWS were notified to us. After eliminating those nominees who had died and those whose parents informed us that PWS had been excluded by genetic testing, 145 possible participants were left. Of these, 108 agreed to participate in the study (response rate $75 \%$ ). The participants underwent genetic laboratory testing before $(n=68)$ or during the study $(n=40)$ to confirm the diagnosis and determine the genetic subtype. For 102 participants, the genetic diagnosis of PWS was confirmed and therefore this report is based on these 102 individuals.

Of the 102 adults with PWS who were included in this study, of whom 49 (48\%) were male. Their mean age was 36.2 years (SD 12.4, range 18-66 years). All participants were genetically confirmed as having PWS: 55 had paternal deletion (54\%), 44 had mUPD (43\%) and three participants had an imprinting centre defect (3\%). Eighty-one (79\%) participants lived in institutional residential or community residential facilities while $20(20 \%)$ participants lived at home with their parents or family, one (1\%) participant lived independently with some professional support. The level of ID was mild $(49 \%, n=50)$ or moderate $(28 \%, n=29)$ in most participants. Eight $(8 \%)$ participants had severe

ID. The other participants were functioning on a borderline ID level $(10 \%, n=10)$ or did not have ID $(5 \%, \mathrm{n}=5)$. Mean body mass index $\left(\mathrm{BMI}=\mathrm{kg} / \mathrm{m}^{3}\right)$ was 32.2 (SD 7.9, range 16.8-51.9). Fiftyseven (56\%) participants were obese (BMI $\geq 30$ ). Mean BMI did not differ statistically significant between genetic subtypes. 


\section{Statistical analyses}

To test whether differences between genetic subtypes, age(-groups), and BMI (-groups) were statistically significant, Chi-square tests and Independent Samples $t$-tests were performed. SPSS (version 16.0) was used to analyze the data. All tests were two-tailed, and p-values of 0.05 or less were considered statistically significant.

\subsubsection{RESULTS}

\section{Hospital admissions}

Most people with PWS were admitted to hospital in their first year $(n=95)$ (mean age 0.5 years, range $0-15$ years, SD 2.0). Neonatal hypotonia and feeding problems were reasons for stay in hospital in 87 out of 95 informative cases. In seven older individuals, whose parents had died, information regarding the neonatal period was lacking. The mean duration of this first hospital admission was 9.5 weeks (range 1-48 weeks, SD 8.6). In the remaining 7/95 cases, first hospital admissions were related to diagnostic tests, strabismus surgery, tonsillectomy, cerebrovascular accident incident and club foot surgery.

The mean number of total hospital admissions was 4.0 (range 0-12, SD 2.3). We did not find statistically significant relationships between number of hospital admissions on the one hand and age, genetic subtype and BMI on the other hand. The reasons for hospital admissions in the different life stages are summarized in Table 3.2.1. Fourteen persons had been admitted to general or psychiatric hospitals because of a psychotic disorder. However, although psychiatric episodes were common, they were mostly treated in the community.

\section{The use of medication}

Medication useage at the time of the study is described in Table 3.2.2. Twenty persons did not use any medication, 20 persons used one preparation, 46 used two to five different medications and 16 used five or more different medications. The Anatomical Therapeutic Chemical Classification System (ATC) was used to categorize different medication groups. Medication groups which were used most frequently included psychotropics $(n=30)$, laxatives $(n=23)$, anti-diabetics $(n=15)$, antiepileptics $(n=15)$ and dermatologic preparations $(n=14)$.

The use of sex hormones is summarized in Table 3.2.3. Of the men, 15 out of 49 had a history of sex hormone replacement. Medical reasons to start hormone replacement included the risk of osteoporosis, the possible effect on secondary sex characteristics, the possible effect on cryptorchidism and the possible effect on behaviour. Seven individuals discontinued replacement therapy because of either behavioural problems, having reached the desired 
effects, or development of skin problems (acne and skinpicking). Of the women, 14 had a history of sex hormone replacement. The medical reasons to start the therapy included the risk of osteoporosis, the regulation of menstrual cycle and/or contraception. Five individuals stopped replacement therapy because of the development of thrombosis, weight increase and/or behavioural problems. Seven of the women used progesterone in order to regulate their menstrual cycle and/or for contraception.

Table 3.2.1 Most frequent reasons for hospital admissions according to life stage (total $n=102$ )

\begin{tabular}{|c|c|c|c|c|c|}
\hline & $\begin{array}{l}0-2 \text { years } \\
(n=102)\end{array}$ & $\begin{array}{l}3-9 \text { years } \\
(n=102)\end{array}$ & $\begin{array}{l}10-19 \text { years } \\
(n=102)\end{array}$ & $20-39$ years & $\begin{array}{l}40+\text { years } \\
(n=45)\end{array}$ \\
\hline 1 & $\begin{array}{l}\text { Hypotonia, } \\
\text { feeding problems } \\
(\mathrm{n}=87)\end{array}$ & $\begin{array}{l}\text { Tonsillectomy } \\
(n=13)\end{array}$ & $\begin{array}{l}\text { Orchidopexia / } \\
\text { inguinal hernia } \\
(n=21)\end{array}$ & $\begin{array}{l}\text { Inguinal hernia } \\
(n=7)\end{array}$ & $\begin{array}{l}\text { Respiratory } \\
\text { infections } \\
(n=5)\end{array}$ \\
\hline 2 & $\begin{array}{l}\text { Respiratory } \\
\text { infections } \\
(n=13)\end{array}$ & $\begin{array}{l}\text { Orchidopexia / } \\
\text { inguinal hernia } \\
(n=12)\end{array}$ & $\begin{array}{l}\text { Scoliosis } \\
(n=10)\end{array}$ & $\begin{array}{l}\text { Diabetes mellitus } \\
(n=5)\end{array}$ & $\begin{array}{l}\text { Cerebrovascular } \\
\text { accidents } \\
(n=4)\end{array}$ \\
\hline 3 & $\begin{array}{l}\text { Other infections } \\
(n=11)\end{array}$ & $\begin{array}{l}\text { Strabismus } \\
\text { surgery } \\
(n=11)\end{array}$ & $\begin{array}{l}\text { Endocrine } \\
\text { investigations } \\
(n=8)\end{array}$ & $\begin{array}{l}\text { Psychiatry } \\
(n=5)\end{array}$ & $\begin{array}{l}\text { Inguinal hernia } \\
(n=3)\end{array}$ \\
\hline 4 & $\begin{array}{l}\text { Diagnostics } \\
(n=11)\end{array}$ & $\begin{array}{l}\text { Ear tube surgery } \\
(n=7)\end{array}$ & $\begin{array}{l}\text { Strabismus } \\
\text { surgery } \\
(n=5)\end{array}$ & $\begin{array}{l}\text { Intoxications } \\
\text { (water/medication) } \\
(n=4)\end{array}$ & $\begin{array}{l}\text { Water } \\
\text { intoxication } \\
(n=3)\end{array}$ \\
\hline 5 & $\begin{array}{l}\text { Strabismus } \\
\text { surgery } \\
(n=6)\end{array}$ & $\begin{array}{l}\text { Diagnostics } \\
(n=7)\end{array}$ & $\begin{array}{l}\text { Accidents } \\
(n=4)\end{array}$ & $\begin{array}{l}\text { Erysipelas } \\
(n=3)\end{array}$ & $\begin{array}{l}\text { Low body } \\
\text { temperature } \\
(n=2)\end{array}$ \\
\hline 6 & $\begin{array}{l}\text { Muscle biopsy } \\
(n=5)\end{array}$ & $\begin{array}{l}\text { Infections } \\
(n=5)\end{array}$ & $\begin{array}{l}\text { Tonsillectomy } \\
(n=4)\end{array}$ & $\begin{array}{l}\text { Cholecystitis } \\
(n=3)\end{array}$ & $\begin{array}{l}\text { Erysipelas } \\
(n=2)\end{array}$ \\
\hline 7 & $\begin{array}{l}\text { Orchidopexia / } \\
\text { inguinal hernia } \\
(n=5)\end{array}$ & $\begin{array}{l}{ }^{*} \text { Congenital } \\
\text { abnormalities } \\
(n=5)\end{array}$ & $\begin{array}{l}\text { Infections } \\
(n=4)\end{array}$ & $\begin{array}{l}\text { Fractures } \\
(n=3)\end{array}$ & $\begin{array}{l}\text { Dental care } \\
(n=2)\end{array}$ \\
\hline 8 & $\begin{array}{l}{ }^{*} \text { Congenital } \\
\text { abnormalities } \\
(n=4)\end{array}$ & $\begin{array}{l}\text { Accidents } \\
(n=3)\end{array}$ & $\begin{array}{l}\text { Appendicitis } \\
(n=3)\end{array}$ & $\begin{array}{l}\text { Accidents } \\
(n=3)\end{array}$ & $\begin{array}{l}\text { Diarrhea / } \\
\text { Obstipation } \\
(n=2)\end{array}$ \\
\hline 9 & $\begin{array}{l}\text { Convulsions } \\
(n=3)\end{array}$ & $\begin{array}{l}\text { Appendicitis } \\
(n=1)\end{array}$ & $\begin{array}{l}\text { Psychiatry } \\
(n=2)\end{array}$ & $\begin{array}{l}\text { Knee surgery } \\
(n=3)\end{array}$ & $\begin{array}{l}\text { Anemia } \\
(n=2)\end{array}$ \\
\hline 10 & $\begin{array}{l}\text { Tonsillectomy } \\
(n=2)\end{array}$ & $\begin{array}{l}\text { Convulsions } \\
(n=1)\end{array}$ & $\begin{array}{l}\text { Kidney surgery } \\
(n=2)\end{array}$ & $\begin{array}{l}\text { Sterilisation } \\
(n=1)\end{array}$ & $\begin{array}{l}\text { Trombosis/lung } \\
\text { embolism } \\
(n=1)\end{array}$ \\
\hline
\end{tabular}

${ }^{*}$ Congenital abnormalities include e.g. kidney abnormalities, cheiloschisis, club feet, lob ears, string of the tongue, phimosis, and hypospadias 
Table 3.2.2 Number of adults with PWS using medication according to ATC code, tract and medication group

\begin{tabular}{|c|c|c|c|c|}
\hline ATC & Tract & Medication group & $\mathrm{n}$ & \\
\hline \multirow[t]{9}{*}{ A } & Alimentary tract and metabolism & A02 Antacids & 12 & \\
\hline & & A06 Laxantives & 23 & \\
\hline & & A07 Intestinal antiinflammatory agents & 1 & \\
\hline & & A08 Anti-obesity preparations & 1 & \\
\hline & & A10 Drugs used in diabetes & 15 & \\
\hline & & A11 Vitamins (vitamin D) & 4 & \\
\hline & & A12 Mineral supplements (calcium) & 4 & \\
\hline & & $\begin{array}{l}\text { A16 Other alimentary tract and metabolism } \\
\text { products }\end{array}$ & 1 & \\
\hline & & Total & & 61 \\
\hline \multirow[t]{3}{*}{ B } & Blood & B01 Antithrombotic agents & 6 & \\
\hline & & B03 Antianemic preparations & 4 & \\
\hline & & Total & & 10 \\
\hline \multirow[t]{5}{*}{ C } & Cardiovascular system & C01 Cardiac therapy & 1 & \\
\hline & & C02 Antihypertensives & 8 & \\
\hline & & C03 Diuretics & 2 & \\
\hline & & C10 Lipid modifying agents & 12 & \\
\hline & & Total & & 23 \\
\hline \multirow[t]{2}{*}{ D } & Dermatologica & $\begin{array}{l}\text { D07 Corticosteroids, dermatological } \\
\text { preparations }\end{array}$ & 14 & \\
\hline & & Total & & 14 \\
\hline \multirow[t]{6}{*}{ G } & Genito urinary tract, sex hormones & G04 Urologicals & 1 & \\
\hline & & G03 Sex hormones & 8 & \\
\hline & & G03B Androgens & 7 & \\
\hline & & G03C Estrogens & 6 & \\
\hline & & G03D Progestogens & & \\
\hline & & Total & & 22 \\
\hline \multirow[t]{4}{*}{$\mathrm{H}$} & Systemic hormonal preparations & H01 Hypothalamic hormones & 7 & \\
\hline & & H02 Corticosteroids for systemic use & 1 & \\
\hline & & H03 Thyroid therapy & 7 & \\
\hline & & Total & & 15 \\
\hline \multirow[t]{2}{*}{$\mathrm{J}$} & Antiinfectives for systemic use & J01 Antibacterials & 6 & \\
\hline & & Total & & 6 \\
\hline M & Musculo-skeletal system & $\begin{array}{l}\text { M05 Drugs for treatment of bone diseases } \\
\text { Total }\end{array}$ & 3 & 3 \\
\hline \multirow[t]{9}{*}{$\mathrm{N}$} & Nervous system & N02 Analgesics & 5 & \\
\hline & & N03 Antiepileptics & $15^{*}$ & \\
\hline & & N04 Anti-parkinson drugs & 1 & \\
\hline & & N05 Psycholeptics & 30 & \\
\hline & & N05A Antipsychotics & 2 & \\
\hline & & N05B Anxiolytics & 8 & \\
\hline & & N05C Hypnotics and sedatives & & \\
\hline & & N06 Psychoanaleptics N06A Antidepressants & 15 & \\
\hline & & Total & & 76 \\
\hline \multirow[t]{5}{*}{$\mathrm{R}$} & Respiratory system & R01 Nasal preparations & 1 & \\
\hline & & R03 Drugs for obstructive airway diseases & 7 & \\
\hline & & R05 Cough and cold preparations & 2 & \\
\hline & & R06 Antihistamines for systemic use & 10 & \\
\hline & & Total & & 20 \\
\hline \multirow[t]{3}{*}{$\mathrm{s}$} & Sensory system & S01 Ophthalmologicals & 2 & \\
\hline & & S02 Otologicals & 2 & \\
\hline & & Total & & 4 \\
\hline
\end{tabular}

* 13 out of 15 persons used antiepileptics because of mood-stabilizing effects, not because of epilepsy 
Table 3.2.3 Number of persons who are taking (or had been taking) hormone replacement

\begin{tabular}{lc}
\hline & $\mathrm{n}$ \\
\hline Prescribed thyroid hormone & 9 \\
$\quad$ Lifetime history & 7 \\
$\quad$ Current prescription & 13 \\
Prescribed growth hormone & 5 \\
$\quad$ Lifetime history & \\
$\quad$ Current prescription & 15 \\
Prescribed sex hormone & 8 \\
Male & \\
$\quad$ Lifetime history & 14 \\
$\quad$ Current prescription & 9 \\
Female & \\
$\quad$ Lifetime history & 1 \\
$\quad$ Current prescription & 1 \\
Prescribed adrenal hormone & \\
$\quad$ Lifetime history & \\
$\quad$ Current prescription &
\end{tabular}

\section{Surgery}

Types of surgery are summarized in Table 3.2.4. Thirteen persons had no history of surgery. Twenty-seven persons had had one type of surgery, 32 persons two types, 21 persons three types and nine persons more than three types. Most frequent surgery was for orchidopexy $(n=32)$ and inguinal hernia surgery $(n=23)$ in men, strabismus $(n=21)$, tonsillectomy $(n=17)$, scoliosis $(n=11)$, ear tubes $(n=9)$ and dental problems $(n=6)$.

\section{Problems with anesthesia}

Thirteen persons had had problems relating to anesthesia. Most prominent $(n=6)$ was a delayed time to wake up after surgery as a prolonged and exaggerated response to sedatives. Other problems included cardiac events $(n=3)$, of whom two persons endured a cardiac arrest; unstable glucose levels $(n=2)$; pain sensation during surgery $(n=1)$; intubation problems because of anatomical abnormalities $(n=1)$; adrenal insuffiency $(n=1)$; and dyspnoea $(n=1)$.

\section{Serious illnesses}

In total, 38 out of 102 persons experienced at least one episode of serious or life threatening illness, as reported by the parents or caregivers. These events were not related to age, genetic subtype or BMI. The causes of these illnesses are described in Table 3.2.5. Table 3.2.6 shows factors which may be related to the recognition of illness such as an irregular drinking, vomiting, pain threshold and temperature instability. 
Table 3.2.4 Number of adults with PWS according to tract and reasons for surgery

\begin{tabular}{|c|c|c|c|}
\hline Tract & Surgery & $\mathrm{n}$ & \\
\hline \multirow[t]{2}{*}{ Cardio-vascular } & Varicose veins & 2 & \\
\hline & Total & & 2 \\
\hline \multirow[t]{3}{*}{ Endocrine } & Parathyroid & 1 & \\
\hline & Testicular carcinoma & 1 & \\
\hline & Total & & 2 \\
\hline \multirow[t]{8}{*}{ Gastro-intestinal } & Appendectomy & 5 & \\
\hline & Cholecystectomy & 3 & \\
\hline & Umbilical hernia & 2 & \\
\hline & Intestinal surgery & 1 & \\
\hline & Haemorrhoids & 1 & \\
\hline & Oesophagoscopy to remove a foreign body & 1 & \\
\hline & Gallstone crushing & 1 & \\
\hline & Total & & 14 \\
\hline \multirow[t]{10}{*}{ Uro-genital } & Orchidopexy (in males) & 32 & \\
\hline & Inguinal hernia & 23 & \\
\hline & Orchiectomy & 4 & \\
\hline & Sterilisation in woman & 3 & \\
\hline & Kidney / urinary tract surgery & 2 & \\
\hline & Circumcision & 2 & \\
\hline & Hypospadias & 1 & \\
\hline & Placement of testicular prosthesis & 1 & \\
\hline & Phimosis & 1 & \\
\hline & Total & & 69 \\
\hline \multirow[t]{7}{*}{ Musculo-skeletal } & Scoliosis & 11 & \\
\hline & Hip surgery & 4 & \\
\hline & Arthroscopy & 4 & \\
\hline & Knee surgery & 3 & \\
\hline & Osteosynthesis & 3 & \\
\hline & Foot surgery & 3 & \\
\hline & Total & & 28 \\
\hline \multirow[t]{4}{*}{ Eyes } & Strabismus & 21 & \\
\hline & Cataract & 2 & \\
\hline & Retinal detachment & 2 & \\
\hline & Total & & 25 \\
\hline \multirow[t]{8}{*}{ Ear, nose, throat } & Tonsillectomy & 17 & \\
\hline & Ear tubes & 9 & \\
\hline & Nasal septum & 2 & \\
\hline & Palate & 1 & \\
\hline & Cleft lip & 1 & \\
\hline & Acoustic duct & 1 & \\
\hline & Lop ears & 1 & \\
\hline & Total & & 32 \\
\hline \multirow[t]{5}{*}{ Dental } & Element extraction & 6 & \\
\hline & Wisdom teeth & 4 & \\
\hline & Total dental extraction & 3 & \\
\hline & Jaw surgery & 1 & \\
\hline & Total & & 14 \\
\hline \multirow[t]{8}{*}{ Other } & Muscle biopsy & 4 & \\
\hline & Burns & 1 & \\
\hline & Breast reduction & 1 & \\
\hline & String of the tongue & 1 & \\
\hline & Atheroma & 1 & \\
\hline & Ganglion cyst & 1 & \\
\hline & Abscess & 1 & \\
\hline & Total & & 10 \\
\hline
\end{tabular}


Table 3.2.5 Number of adults with PWS according to causes of serious illnesses

\begin{tabular}{lc}
\hline Cause of serious illness $(\mathrm{n}=40)$ & $\mathrm{n}$ \\
\hline Infection (mostly respiratory) & 10 \\
Intoxication/side effect medication & 3 \\
Diabetes mellitus & 3 \\
Apnea & 2 \\
Anemia & 2 \\
Kidney problems & 2 \\
Meningitis/encephalitis & 2 \\
Psychiatric problems & 2 \\
Adrenal insufficiency & 1 \\
Low body temperature & 1 \\
Near drowning & 1 \\
Cardiac arrest during anesthesia & 2 \\
Dehydration & 1 \\
Water intoxication & 3 \\
Bowel obstruction & 1 \\
Testicular carcinoma & 1 \\
Oedema & 1 \\
Unknown & 2 \\
\hline
\end{tabular}

Table 3.2.6 Factors in recognizing illness

\begin{tabular}{lc}
\hline Factors in recognizing illness & $\mathrm{n}$ \\
\hline Irregular drinking pattern & 13 \\
Yes & 89 \\
No & \\
Vomiting & 60 \\
$\quad$ Never & 41 \\
Once/rarely & 1 \\
Normal frequency & 3 \\
High Pain threshold & 99 \\
No & \\
Yes & 60 \\
No pain expressed in cases of & 49 \\
Toothache & 88 \\
Burns & 46 \\
Bruises & 25 \\
Sprains & \\
Fracture & 66 \\
Temperature regulation & 25 \\
Absence of fever during illness/infection & 9 \\
Fever above $40^{\circ} \mathrm{C}$ & \\
Low body temperature & 75 \\
Problems assessing temperature of the environment & 27 \\
Yes & \\
No &
\end{tabular}




\subsubsection{DISCUSSION}

In this report, results are presented regarding the use of medical care and the prevalence of serious illness in a Dutch adult PWS cohort. This mainly relates to hospitalization rates, medication use, surgery and visits to the emergency department. We discuss the implications for services providing medical care for people with PWS with regard to prevention and early recognition of serious illnesses.

\section{Hospital admissions}

With regard to hospital admissions, the results in this study highlight agespecific causes of morbidity and hospitalization. In recent years, severe neonatal hypotonia has continued to lead to hospital admissions and need for tube feeding ${ }^{17}$ and the diagnosis of PWS is often established within the first weeks of life. In the past, hypotonia during the neonatal period has often led to extensive medical evaluations including muscle biopsies and long term stay in hospital. Improved medical care has lead to much lower mortality rates in the first year of life ${ }^{8}$. A further decrease in early infancy hospitalization rates and duration may be achieved by preventing severe respiratory infections by, for example, rigorous treatments with antibiotics ${ }^{8,18}$. During childhood most hospital admissions were for PWS syndrome specific surgery such as orchidopexia, inguinal hernia, strabismus, tonsillectomy and the insertion of grommets. Scoliosis surgery and endocrine evaluation were common during adolescence. At adult age, hospitalization was associated with inguinal hernia surgery, diabetes mellitus, psychosis, water and drug intoxications and erysipelas. In older persons with PWS, respiratory infections were again the main reasons for hospital admissions. Cerebrovascular accidents and low body temperature may also play a role. Most hospital admissions could not be prevented. However, awareness of possible physical health problems (e.g. erysipelas, respiratory infections) may contribute to a diagnosis in an earlier stage and may shorten the length of stay in the hospital.

\section{Medication use}

The high prevalence the use of medication reflects the high morbidity in this group. Frequently used medications included laxatives, anti-diabetics and dermatologic preparations. Most striking, however, is the prescription of psychotropics. Psychiatric problems play an important role in the health status and quality of life in adults with PWS, especially in individuals with the mUPD subtype $^{10,12,13,19}$. Close supervision and documentation of the prescribed medication is essential because side effects and intoxication are frequent. Therefore, we recommend that consultant psychiatrists specializing in persons with PWS should be contacted when psychotropics are started. Sex hormone 
replacement was less commonly used than expected. Prescriptions easily add up and medication seeking by people with PWS is prominent in some individuals and can result in significant polypharmacy. In our experience, many people with PWS are inflexible regarding their medication regimes, at least partly because liquid medications tend to be sweet (e.g. laxatives and cough syrup) and they vigorously resist changes in routine. The possibility of this kind of behaviour should always be taken into account while prescribing medication. We recommend a yearly medication review to minimize side effects, prevent drug interactions or overmedication.

\section{Surgery}

Surgery was mostly associated with the main characteristics of the syndrome. This is in line with findings in the literature ${ }^{4,7}$. PWS is known to be associated with higher anesthesic risks, associated with obesity, hypotonia, temperature instability, thick saliva and post anesthesic drowsiness. Therefore, anesthesia should be carefully monitored. Food seeking and other behavioural problems during hospitalization and complications due to skinpicking should always be taken into consideration when planning surgery ${ }^{21-23}$. The surgical team should also be aware of osteopenia in case of orthopedic problems.

\section{Causes of serious illness}

This report documents the occurrence of critical illnesses during the entire lifespan of people with PWS. Certain medical causes should be considered in case of unexplained illness, disturbances of consciousness and behavioural changes. First of all, sources of infection (mostly respiratory, but also gastrointestinal or skin) should be ruled out, even in the absence of fever ${ }^{24}$. Besides, treating physicians should check for diabetic dysregulation, anemia (possibly due to rectal skinpicking), low body temperature, abnormal drinking patterns (water intoxication/ dehydration), cardiac problems, adrenal insufficiency and adverse reactions to medication ${ }^{9,25-28}$.

A possible weakness of the study is the cross-sectional design. Some causes of serious illnesses leading to death, such as cancer or gastric dilatation, might therefore have been overlooked. Behavioural and psychiatric problems are frequently associated with the development of crisis situations. Individuals with PWS appear to be more vulnerable to stress. Transitional periods such as family moves or changing schools can result in a loss of structure and consistency. Combined with limited coping mechanisms, such circumstances may result in extreme maladaptive behaviour such as aggression, destruction and self-harm. Life events appear to be a contributing factor in the onset of major psychiatric disorders such as mood disorders and psychoses ${ }^{12,13,19}$. Some presenting symptoms include mood lability, suicidality, aggression, increased irritability and automutilation. In addition, behaviour during 
psychiatric illness in this population sometimes leads to physical complications: water intoxication, attempts to swallow inedible things, severe self-harm, suicidal thoughts, coprophagia, rectal skinpicking and refusal to eat, drink or move. In case of physical complaints, psychiatric causes for the complaints should also be taken into account. However, the opposite also holds true: a physical decomposition could also be a trigger in the development of a psychiatric illnesses.

\section{Recognizing illness}

Complaints and symptoms are not always easy to interpret in persons with PWS. On the one hand, a decreased ability to vomit, abnormal pain awareness and unpredictable fever response can lead to underreporting of pain and missed diagnoses of serious conditions that would normally be expected to produce severe pain or fever. On the other hand, individuals with PWS frequently express somatic complaints for which objective evidence is lacking. When there is a marked discrepancy between objective findings and subjective stress, discomfort, or functional impairment, malingering should be considered, motivated by the possibility of obtaining food or avoiding tasks. Caregivers and physicians should be aware of these difficulties and should document which characteristics are medical alerts in a particular individual.

\section{Abnormal pattern of eating and drinking}

Hyperphagia is prominent in almost all adults with PWS. Therefore, individuals with PWS who show a decreased interest in food should also be suspected of suffering from a serious physical or psychiatric disorder. Thirteen persons in our cohort were reported to show an abnormal drinking pattern during certain periods. These episodes were related to diabetes $(n=7)$, lack of satiety $(n=3)$, behavioural problems $(n=2)$ and psychosis $(n=1)$. In three cases this led to water intoxication. Unusual water intake has not been researched in great detail in the literature. Akefeldt ${ }^{25}$ suggests that this might be part of the typical overeating behaviour or be a part of the hypothalamic impairment. Water intake in individuals with PWS should always be monitored because of the risk of developing hyponatraemia.

\section{Inability to vomit}

A commonly reported feature of PWS is a decreased ability to vomit with a complete absence of "natural" or induced vomiting noted in a large proportion of individuals ${ }^{16}$. The reasons for this are not completely known. The majority of the participants in our study had never vomited. The remaining individuals only vomited in rare circumstances, mostly only once during their life. Such circumstances included gastroenteritis, binge eating episodes, anesthesia, 
diabetic deregulation, alcohol consumption, psychiatric problems, serious infections and self generated vomiting. Caution is needed regarding reliance on emetic agents in the treatment of accidental poisoning for individuals with PWS since the response may be inadequate and higher doses of antiemetics could potentially be toxic. In case of complaints of nausea and/or vomiting, abdominal discomfort, dyspnea and distended abdomen, especially after a known episode of binge eating, the diagnosis of gastric dilatation should be considered ${ }^{29}$.

\section{Pain sensation}

Decreased peripheral and deep pain sensation is a commonly reported feature of PWS. However, published reports relating to pain sensation in PWS are remarkably scarce ${ }^{15}$. Our results show that almost all persons were reported to have high pain thresholds. Examples of this high pain threshold included skinpicking behaviour, other forms of self-harm, unrecognized fractures, bruises, burns, blood sampling, all without pain expressions. Serious illnesses such as cholecystitis, appendicitis, pneumonia or erysipelas, were frequently only recognized after some days because symptoms were mild and pain was hardly expressed. Easy bruising has also been anecdotally reported and could, in part, be related to decreased ability to sense pain; no other contributory factors of easy bruising have been identified so far. Therefore, any fever or a refusal to walk (after an injury or fall) should be taken seriously and a good clinical examination and close follow-up are indicated until serious illness or injury has been ruled out. It is important for caregivers to be vigilant for signs of infection and injury that might otherwise be signaled by pain or discomfort. Acute or unexpected changes in behaviour, mobility or gait may warrant further investigation ${ }^{23}$.

\section{Abnormal temperature regulation}

Temperature dysregulation may occur more frequently in individuals with PWS, perhaps related to a defect in thermogenesis ${ }^{30}$. In 66 out of 102 persons in our cohort, parents reported that fever was commonly absent during illnesses and infections. Bouts of fever may be absent during serious illnesses but hyperthermia is also reported in patients without an infectious cause and this may trigger medical investigations. Many parents stated that they do not rely on measuring body temperature during illness in staging the seriousness of illnesses. Physicians should also be careful in attaching to much importance to measuring body temperature in people with PWS.

A proportion of older people with PWS may be at risk of hypothermia. In our study this usually occurred when the outside temperature was cool, or for example after swimming ${ }^{31}$. Episodes of low body temperature were reported in nine persons in our study. This could be related to a diminished capacity for 
shivering or to the use of psychotropic medication. In view of the relative paucity of published data and the potentially serious nature of this condition, caregivers should be aware of the possible risks. Measurements of basal temperature in the absence of illness could give additional information on the "normal" temperature level in an individual. In persons at risk for hypothermia, a protocol for low body temperature may help to improve care. This protocol should include: when and how to measure the body temperature, how to warm the person up, when to alert a physician and how to prevent hypothermia.

Besides problems in regulating their own body temperature, 75 out of 102 persons in our study experienced problems in assessing temperature of the environment (e.g. estimating bath temperature, problems to adjust the amount and kind of clothes to the weather). This sometimes led to dangerous situations, such as burns caused by hot showers or standing too close to heaters.

\subsubsection{CONCLUSION}

Using the results of this study, expectations of parents and professionals on the use of medical care utilization by adults with PWS can be adjusted. Especially during emergency situations, in which symptoms are not always clear, it is important to be well informed about the possible health hazards. Information from this cohort may help in preventing conditions and recognizing others in an early stage by developing guidelines to monitor health. Adequate preventive management and treatment of PWS related morbidity, could reduce medical care use in the long term and could improve quality adjusted life years. 


\section{REFERENCES}

1. Ledbetter DH, Riccardi VM, Airhart SD, Strobel RJ, Keenan BS, Crawford JD: Deletions of chromosome 15 as a cause of the Prader-Willi syndrome. N Engl J Med 1981; 304: 325-329.

2. Nicholls RD, Knoll JH, Butler MG, Karam S, Lalande M: Genetic imprinting suggested by maternal heterodisomy in nondeletion Prader-Willi syndrome. Nature 1989; 342: 281-285.

3. Buiting K, Saitoh S, Gross S, Dittrich B, Schwartz S, Nicholls RD, Horsthemke B: Inherited microdeletions in the Angelman and Prader-Willi syndromes define an imprinting centre on human chromosome 15. Nat Genet 1995; 9: 395-400.

4. Holm VA, Cassidy SB, Butler MG, Hanchett JM, Greenswag LR, Whitman BY, Greenberg F: Prader-Willi syndrome: consensus diagnostic criteria. Pediatrics 1993; 91: 398-402.

5. Greenswag LR: Adults with Prader-Willi syndrome: a survey of 232 cases. Dev Med Child Neurol 1987; 29: 145-152.

6. Laurance BM, Brito A, Wilkinson J: Prader-Willi Syndrome after age 15 years. Arch Dis Child 1981; 56: 181-186.

7. Thomson AK, Glasson EJ, Bittles AH: A long-term population-based clinical and morbidity review of Prader-Willi syndrome in Western Australia. J Intellect Disabil Res 2006; 50: 69-78.

8. Vogels A, Van Den Ende J, Keymolen K, Mortier G, Devriendt K, Legius E, Fryns JP: Minimum prevalence, birth incidence and cause of death for Prader-Willi syndrome in Flanders. Eur J Hum Genet 2004; 12: 238-240.

9. Butler JV, Whittington JE, Holland AJ, Boer H, Clarke D, Webb T: Prevalence of, and risk factors for, physical ill-health in people with Prader-Willi syndrome: a population-based study. Dev Med Child Neurol 2002; 44: 248-255.

10. Boer H, Holland A, Whittington J, Butler J, Webb T, Clarke D: Psychotic illness in people with Prader Willi syndrome due to chromosome 15 maternal uniparental disomy. Lancet 2002; 359: 135-136.

11. Dykens EM, Roof E: Behavior in Prader-Willi syndrome: relationship to genetic subtypes and age. J Child Psychol Psychiatry 2008; 49: 1001-1008.

12. Soni S, Whittington J, Holland AJ, Webb T, Maina E, Boer H, Clarke D: The course and outcome of psychiatric illness in people with Prader-Willi syndrome: implications for management and treatment. J Intellect Disabil Res 2007; 51: 32-42.

13. Vogels A, De Hert M, Descheemaeker MJ, Govers V, Devriendt K, Legius E, Prinzie P, Fryns JP: Psychotic disorders in Prader-Willi syndrome. Am J Med Genet A 2004; 127A: 238-243.

14. Stevenson DA, Anaya TM, Clayton-Smith J, Hall BD, Van Allen MI, Zori RT, Zackai EH, Frank G, Clericuzio CL: Unexpected death and critical illness in Prader-Willi syndrome: report of ten individuals. Am J Med Genet A 2004; 124: 158-164.

15. Priano L, Miscio G, Grugni G, Milano E, Baudo S, Sellitti L, Picconi R, Mauro A: On the origin of sensory impairment and altered pain perception in Prader-Willi syndrome: a neurophysiological study. Eur J Pain 2009; 13: 829-835.

16. Alexander RC, Greenswag LR, Nowak AJ: Rumination and vomiting in Prader-Willi syndrome. Am J Med Genet 1987; 28: 889-895.

17. Whittington JE, Butler JV, Holland AJ: Pre-, peri- and postnatal complications in Prader-Willi syndrome in a UK sample. Early Hum Dev 2008; 84: 331-336. 
18. Eiholzer U: Deaths in children with Prader-Willi syndrome. A contribution to the debate about the safety of growth hormone treatment in children with PWS. Horm Res 2005; 63: 33-39.

19. Soni S, Whittington J, Holland AJ, Webb T, Maina EN, Boer H, Clarke D: The phenomenology and diagnosis of psychiatric illness in people with Prader-Willi syndrome. Psychol Med 2008; 38: 1505-1514.

20. Goldstone AP, Holland AJ, Hauffa BP, Hokken-Koelega AC, Tauber M: Recommendations for the diagnosis and management of Prader-Willi syndrome. $J$ Clin Endocrinol Metab 2008; 93: 4183-4197.

21. Legrand R, Tobias JD: Anesthesia and Prader-Willi syndrome: preliminary experience with regional anesthesia. Paediatr Anaesth 2006; 16: 712-722.

22. Morgan JR, Storch EA, Woods DW, Bodzin D, Lewin AB, Murphy TK: A preliminary analysis of the phenomenology of skin-picking in Prader-Willi syndrome. Child Psychiatry Hum Dev, 41: 448-463.

23. Kroonen LT, Herman M, Pizzutillo PD, Macewen GD: Prader-Willi Syndrome: clinical concerns for the orthopaedic surgeon. J Pediatr Orthop 2006; 26: 673-679.

24. Tauber M, Diene G, Molinas C, Hebert M: Review of 64 cases of death in children with Prader-Willi syndrome (PWS). Am J Med Genet A 2008; 146: 881-887.

25. Akefeldt A: Water intake and risk of hyponatraemia in Prader-Willi syndrome. $J$ Intellect Disabil Res 2009; 53: 521-528.

26. Bhargava SA, Putnam PE, Kocoshis SA, Rowe M, Hanchett JM: Rectal bleeding in Prader-Willi syndrome. Pediatrics 1996; 97: 265-267.

27. de Lind van Wijngaarden RF, Otten BJ, Festen DA, Joosten KF, de Jong FH, Sweep FC, Hokken-Koelega AC: High prevalence of central adrenal insufficiency in patients with Prader-Willi syndrome. J Clin Endocrinol Metab 2008; 93: 1649-1654.

28. Robson WL, Shashi V, Nagaraj S, Norgaard JP: Water intoxication in a patient with the Prader-Willi syndrome treated with desmopressin for nocturnal enuresis. $J$ Urol 1997; 157: 646-647.

29. Stevenson DA, Heinemann J, Angulo M, Butler MG, Loker J, Rupe N, Kendell P, Cassidy SB, Scheimann A: Gastric rupture and necrosis in Prader-Willi syndrome. J Pediatr Gastroenterol Nutr 2007; 45: 272-274.

30. Swaab DF: Prader-Willi syndrome and the hypothalamus. Acta Paediatr Suppl 1997; 423: 50-54.

31. Bray GA, Dahms WT, Swerdloff RS, Fiser RH, Atkinson RL, Carrel RE: The Prader-Willi syndrome: a study of 40 patients and a review of the literature. Medicine 1983; 62: 59-80. 



\section{CHAPTER 4}

\section{BEHAVIOURAL PHENOTYPE IN ADULTS WITH PRADER-WILLI SYNDROME}

Sinnema M, Einfeld SL, Schrander-Stumpel CTRM, Maaskant MA, Boer H, Curfs LMG

Res Dev Dis 2011;32:604-612 


\section{ABSTRACT}

\section{Introduction}

Prader-Willi syndrome (PWS) is characterized by temper tantrums, impulsivity, mood fluctuations, difficulty with change in routine, skinpicking, stubbornness and aggression. Many studies on behaviour in PWS are limited by sample size, age range, a lack of genetically confirmed diagnosis of PWS and inconsistent assessment of behaviour. The aim of this study was to explore systematically the relation between behavioural problems and age groups, genetic subtypes and $\mathrm{BMI}$ categories in an adult PWS population.

\section{Method}

Participants were contacted via the Dutch Prader-Willi Parent Association and through physicians specialized in persons with intellectual disabilities (ID). Behaviours were studied using the Developmental Behaviour Checklist for Adults (DBC-A). The forms were completed by the main caregivers of 98 adults with a genetically confirmed diagnosis of PWS.

\section{Results}

Differences between age groups were statistically significant (ANOVA, $p=0.03$ ). DBC-A total scores were higher in the consecutive age groups, with the most behavioural problems in the oldest age groups. Differences between genetic subtypes were also statistically significant (ANOVA, $p<0.01$ ). Persons with mUPD had higher total scores on the DBC-A than persons with a deletion. Those with a Type I deletion showed higher total DBC-A scores than persons with a Type II deletion. There were no statistically significant differences in DBC-A total scores between the different BMI categories. Individuals with a $\mathrm{BMI}<25$ had higher scores on the self-absorbed subscale compared to persons with a BMI between 25 and 30 .

\section{Discussion}

Unlike previous descriptions of the behavioural phenotype in adults with PWS, we did not find a reduction in behavioural problems in older adults. Therefore, special attention should be paid to behavioural problems as part of general management of adults with PWS. Longitudinal studies are warranted to gain more insight into the natural history and course of behavioural problems in adults and older people with PWS over the long term and possible risk and preventive factors. 


\subsection{INTRODUCTION}

Prader-Willi syndrome (PWS) is characterized by neonatal hypotonia with feeding problems, global developmental delay, small hands and feet, hypogonadism, small stature and facial features ${ }^{1,2}$. Later on, childhood onset hyperphagia results - without dietary restrictions - in marked obesity and secondary medical complications ${ }^{3}$. The majority of persons with PWS $(70 \%)$ have a paternal deletion of $15 q 11-q 13^{4}$, and approximately $25 \%$ have a maternal UPD ${ }^{5}$. The remaining cases $(5 \%)$ have imprinting center defects or translocations ${ }^{6}$.

Individuals with a paternal deletion can be further divided according to deletion size $^{7}$. Both subtypes share a breakpoint at BP3, but differences are present at breakpoints at BP1 and BP2. Deletions between BP3 and BP1 are classified as Type I deletions. Deletions between BP3 and BP2 are classified as Type II deletions ${ }^{8}$. The larger Type I deletions are seen in approximately $40 \%$ of the persons with PWS due to a deletion ${ }^{7}$.

Besides the physical and eating problems, PWS is characterized by behaviour including temper tantrums, impulsivity, mood fluctuations, difficulty with changes in routine, skinpicking, stubbornness and aggression ${ }^{9-14}$. Not only developmental life stage, but also genetic status and weight issues may influence behavioural characteristics ${ }^{15}$.

The majority of behavioural studies in PWS have focused on childhood and adolescence. Hyperphagia and food-seeking behaviour usually start between 2 and 6 years of age, along with temper tantrums and self-injurious behaviour ${ }^{16}$. During childhood under-activity, excessive sleeping, obsessiveness, argumentativeness, compulsive behaviour and talking too much are more frequent relative to persons with Down syndrome or ID in general ${ }^{17}$. Sadness and low self-worth are also seen during childhood development ${ }^{18}$. An increase in behavioural problems such as overeating, skinpicking, stubbornness, hoarding and temper tantrums are described during adolescence and young adulthood $^{\text {9,19-21. }}$.

Greenswag $^{22}$ found the following behaviours to be relatively frequent in adults with PWS compared to youngsters: slow moving, good natured, belligerent (related and non-related to food), irritable, impulsive, lazy, antisocial with peers and family, moody and physically aggressive. However, research on behaviour of older adults, above the age of 30 , with PWS is scarce. In a study regarding adults with $\mathrm{PWS}{ }^{20}$ only 5 out 30 adults were in their thirties. Dykens et al. ${ }^{21}$ also included only 6 (out of 21) participants in their thirties. In these studies the older 
adults were described as much less destructive and impulsive than participants in younger age groups, and had higher rates of underactivity, fatigue and withdrawal. In a larger study ${ }^{12}$ maladaptive and compulsive behaviours in 45 older adults with PWS (30-50 years) were compared to children, adolescents and young adults. It was concluded that young adults were at the highest risk for behavioural problems, and that maladaptive and compulsive behaviours were considerably less in older adults.

Differences in behavioural profiles have also been suggested for the different genotypes. Persons with mUPD have been found to have less skinpicking and maladaptive behaviour ${ }^{23,24}$, but to have heightened vulnerability for psychiatric disorders, such as atypical psychosis and affective disorders in young adulthood ${ }^{14,25,26}$. Reports on behavioural differences between those with Type I and Type II deletions have been contradictory ${ }^{27-31}$. Research showed ${ }^{27}$ that individuals with Type I deletions generally have more behavioural and psychological problems than individuals with Type II deletion or mUPD. Milner et al. ${ }^{31}$ and Varela et al. ${ }^{30}$ found that differences between the deletion types were minimal, although persons with Type I deletion performed worse on all measures of ability ${ }^{31}$. Hartley et al. $^{28}$ reported higher physical depression scores in persons with Type I deletions than in persons with Type II deletions. In another study ${ }^{29}$ more washing/cleaning compulsions were found in those with Type I deletions and more rereading/rewriting compulsions in those with Type II deletions. In a recent study ${ }^{32}$, no statistically significant differences between deletion subtypes were found, but within subtype analyses showed a relationship between age and behaviour. Although age did not emerge as a significant correlate of behaviour in the Type II and mUPD group, in the Type I group older age was associated with lower problem behaviours, adaptive skills and externalizing symptoms ${ }^{32}$.

A negative correlation between worsening behavioural problems and increasing BMI has been suggested in the literature. Dykens and Cassidy ${ }^{18}$ reported that adolescents and adults with lower BMls had significantly more maladaptive behaviours, specifically confused thinking, delusions, hallucinations, anxiety, fear, sadness and dependency relative to persons with higher BMls. Most of these features represented internal affective states and problems in thinking as opposed to overt behaviour. Other authors ${ }^{19}$ found a non-significant trend of more psychiatric concerns among subjects with more weight control. Another study ${ }^{22}$ showed that adults with a higher BMI were viewed as more lazy, slow-moving and anti-social with their families relative to PWS subjects with a lower BMI. Increased irritability, agitation, hyperactivity and non-compliance were found to be associated with increased $\mathrm{BMI}^{20}$. 
Many of these studies on behaviour in PWS are limited by sample size, age range, and lack of genetically confirmed diagnosis of PWS (e.g. ${ }^{18,20,22,28}$ ). Moreover, not all studies used standardized methods for assessing behaviour. The aim of this study was to explore systematically the relation between behavioural problems and age groups, genetic subtypes and BMI categories in an adult PWS population through a standardized method for measuring behaviour.

\subsection{METHODS}

\section{Study population}

Participants were contacted via the Dutch Prader-Willi Parent Association and through physicians specializing in persons with ID. The current study on behaviour was part of a larger study in The Netherlands on "Ageing in PWS". The individuals with PWS and their main caregivers (family and/or professional caregivers), were visited at home. They were interviewed using a semistructured interview that included questions about physical and mental health problems, and behaviour experienced over the participant's lifetime. The caregivers were asked to complete the Developmental Behaviour Checklist for Adults (DBC-A) before the interview. Current height and weight were measured. Medical files were retrieved from treating physicians. The level of intellectual disability was reported by the main caregivers.

\section{Participants}

In total 149 nominees with a (possible) diagnosis of PWS were notified to us. At time of contacting the participants, two nominees had died and two parents informed us that genetic testing had revealed that the candidates did not have PWS. Hence, 145 possible participants were left. Of these, 108 agreed to participate in the study. Detailed genetic test results were available in 68 patients, and in 40 patients the diagnosis and genetic subtype were confirmed during the study. The genetic diagnosis of PWS was confirmed in 102 out of 108 participants. The caregivers of 98 participants completed the DBC-A (response rate: $96 \%$ ). Four age groups were formed: $<25$ years, $25-34$ years, $35-44$ years, $45+$ years.

\section{Genetic diagnosis}

During the interviews, parents were asked whether genetic tests on PWS including genetic subtype were undertaken previously. Written confirmation on genetic diagnoses was retrieved from genetic centers, with the permission of the legal representatives. Genetic testing was undertaken in participants who 
did not have a confirmed genetic diagnosis $(n=40)$. Cytogenetic analysis and molecular analysis using the SALSA MLPA kit P245 (MRC Holland, Amsterdam) were performed to establish whether deletions were present. A diagnosis of PWS was confirmed by DNA methylation studies on the SNURF/SNRPN loci. mUPD was confirmed with microsatellite analysis at various loci on chromosome 15, when blood of parents was available. All 98 participants were genetically confirmed as having PWS: 54 (55\%) had paternal deletion, $42(43 \%)$ had mUPD and two (2\%) participants had an imprinting defect. Within the deletion subtype, 23 persons had a Type I deletion, 22 persons had a Type II deletion and six persons had an atypical deletion (larger than Type I or smaller than Type II deletions). In three persons, a deletion had been confirmed in the past, but there was no blood available to distinguish between a Type I and Type II deletion for this study.

\section{BMI}

The weight status was determined by the Body Mass Index, BMI (weight in kilograms / [height in meters] ${ }^{2}$ ). Height and weight of the participants were measured by the first author. Three different BMI categories were formed: $\mathrm{BMl}<25$, BMI 25-30, BMI 30+. Mean body mass index $\left(\mathrm{BMl}=\mathrm{kg} / \mathrm{m}^{2}\right)$ was 32.5 $(S D=7.9$, range $=16.8$ to 51.9$)$.

\section{Developmental Behaviour Checklist for Adults (DBC-A)}

The DBC-A ${ }^{33}$ was used to assess behavioural problems. The 107 -item questionnaire was completed by the participants' main caregiver (family and/or professional caregivers). It measures psychopathology at three levels: severity of overall behaviour and emotional disturbance (total behaviour problem score; TBPS); disturbance in six particular dimensions of psychopathology (six subscale scores derived from factor analysis); and level of disturbance of particular individual behaviours (107 items or symptoms). The questionnaire employs a 3-point rating scale $(0=$ not true; $1=$ somewhat or sometimes true; $3=$ very true or often true). The DBC-A consists of the following subscales (with examples of relevant items):

1. Disruptive: tantrums, irritable, impatient, whines, jealous;

2. Self absorbed: pica, hums, bites, hits, screams, chews, bangs head;

3. Communication disturbance: talks fast, thoughts, stands, not capable, hallucinations;

4. Anxiety/ antisocial: lights fires, panics, nightmares, inappropriate sexual activity, hides things, steals;

5. Social relating: loner, shy, arranges objects, distressed over small changes in routine, resists being cuddled, aloof; 
6. Depressive: withdrawn, lost enjoyment, lost self-care, depressed.

The caregiver-completed DBC-A has satisfactory psychometric properties ${ }^{34}$. The intraclass correlations for test-retest and inter-rater reliability ranged from 0.72 to 0.85 . Concurrent validity with the Aberrant Behaviour Checklist $(A B C)^{35}$ and the Psychiatric Assessment Schedule for Adults with Developmental Disabilities Checklist (PAS-ADD) ${ }^{36}$ was satisfactory. Normative data were collected in a large representative population in South Australia of adults with ID. The population covered the age span of late adolescence (16 years) through the transition to adult life then through to the elderly.

\section{Statistical analyses}

Differences between age groups, genetic subtypes, and weight status on the TBPS, DBC-A subscales and DBC-A items were analyzed. The following statistical tests were used: ANOVA to compare means of three or more groups, independent sample t-tests to compare means of two independent groups, Chisquare to compare frequencies of nominal data, and Kendall's tau to compare frequencies of ordinal data. SPSS (version 16.0) was used to analyze the data. A $P$-value of 0.05 or less was taken as significance level for all statistical tests.

\subsection{RESULTS}

\section{Study population}

The DBC-A was completed for 98 participants and consequently this report is based on these 98 individuals. Forty-eight $(49 \%)$ participants were male. The mean age of the participants was 36.4 years (SD 12.4, range 18 to 66 years). Seventy-eight $(78 \%)$ participants lived in an institutional residential or community residential facility, while $19(19 \%)$ participants lived at home with their parents or family; one (1\%) participant lived almost independently. The level of ID was mild $(48 \%, n=47)$ or moderate $(29 \%, n=28)$ in most participants. Eight $(8 \%, n=8)$ participants had severe ID. The other participants were functioning on a borderline ID level $(10 \%, n=10)$ or did not have ID $(5 \%, n=5)$. Five persons had a current prescription of growth hormone.

\section{DBC-A total score in PWS compared to persons with intellectual disabilities (ID) in general}

The mean item score (MIS) on the DBC-A in our sample (0.48) was high compared with the MIS of people with ID in general $(0.27)$ as retrieved from the DBC-A norms. The MIS score in our sample was on the 79 percentile. 


\section{DBC-A total score and DBC-A subscales}

Relation with age

Table 4.1 shows the mean total and mean subscale scores on DBC-A according to age groups. DBC-A total scores was higher in the consecutive age groups, with the highest scores in the oldest age groups. Differences between age groups were statistically significant (ANOVA, $p=0.03$ ). Further analyses showed that the differences between the age group $<25$ and $45+$ mostly counted for this statistical significance (t-test, $p=0.04$ ). Additional analyses of the subscales showed that only differences between the age groups on subscale 2 (self-absorbed) were statistically significant (ANOVA, $p<0.01$ ). Differences between individuals $<25$ years as compared to persons from age group 35-44 years and $\geq 45$ years counted most for these differences (t-test, $p \leq 0.03)$.

Table 4.1 Mean total and mean subscale scores on DBC-A according to age groups

\begin{tabular}{lcccccccc}
\hline $\begin{array}{l}\text { Age } \\
\text { groups }\end{array}$ & $\mathrm{N}$ & $\begin{array}{c}\text { Mean } \\
\text { Total }^{*}\end{array}$ & $\begin{array}{c}\text { Mean } \\
\text { subscale 1 }\end{array}$ & $\begin{array}{c}\text { Mean } \\
\text { subscale 2 }\end{array}$ & $\begin{array}{c}\text { Mean } \\
\text { subscale 3 }\end{array}$ & $\begin{array}{c}\text { Mean } \\
\text { subscale 4 }\end{array}$ & $\begin{array}{c}\text { Mean } \\
\text { subscale 5 }\end{array}$ & $\begin{array}{c}\text { Mean } \\
\text { subscale 6 }\end{array}$ \\
\hline$<25$ & 20 & 38.5 & 8.9 & 7.0 & 4.6 & 2.0 & 4.4 & 3.2 \\
$25-34$ & 27 & 50.5 & 11.0 & 9.9 & 6.1 & 2.7 & 4.8 & 5.0 \\
$35-44$ & 26 & 56.6 & 12.9 & 12.8 & 6.0 & 3.6 & 4.6 & 5.0 \\
$45+$ & 25 & 57.1 & 13.8 & 12.4 & 6.1 & 3.3 & 4.4 & 5.4 \\
Total & $\mathbf{9 8}$ & $\mathbf{5 1 . 3}$ & $\mathbf{1 1 . 8}$ & $\mathbf{1 0 . 7}$ & $\mathbf{5 . 8}$ & $\mathbf{2 . 9}$ & $\mathbf{4 . 6}$ & $\mathbf{4 . 7}$ \\
\hline
\end{tabular}

* statistically significant (ANOVA, $p \leq 0.05$ )

\section{Relation with genetic subtypes}

Table 4.2 shows the mean total and mean subscale scores on DBC-A according to genetic subtypes: the differences between genetic subtypes were statistically significant (ANOVA, $p<0.01$ ). Further analyses showed that the differences between persons with Type II deletions and mUPD accounted for most of this statistical significance (t-test, $p<0.01$ ). Additional analyses of the subscales showed that differences between the genetic subtypes on subscale 1 (disruptive), subscale 2 (self-absorbed), subscale 5 (social relating) and subscale 6 (depressive) were statistically significant (ANOVA, $p<0.05$ ). Differences between persons with a Type I deletion and persons with a mUPD accounted for most of this statistical significance on subscale 2 (self absorbed) and subscale 5 (social relating) (t-test, $p<0.05$ ). Differences between persons with a Type II deletion and persons with a mUPD accounted for most of this statistical significance on subscale 1 (disruptive) and subscale 6 (depressive) (t-test, $\mathrm{p}<0.05$ ). 
Table 4.2 Mean total and mean subscale scores on DBC-A according to genetic subtypes

\begin{tabular}{lccrrrrrc}
\hline $\begin{array}{l}\text { Genetic } \\
\text { subtype }\end{array}$ & $\mathrm{n}$ & $\begin{array}{c}\text { Mean } \\
\text { Total }\end{array}$ & $\begin{array}{c}\text { Mean } \\
\text { subscale }\end{array}$ & $\begin{array}{c}\text { Mean } \\
\text { subscale }\end{array}$ & $\begin{array}{c}\text { Mean } \\
\text { subscale 3 }\end{array}$ & $\begin{array}{c}\text { Mean } \\
\text { subscale 4 }\end{array}$ & $\begin{array}{c}\text { Mean } \\
\text { subscale }\end{array}$ & $\begin{array}{c}\text { Mean } \\
\text { subscale 6 }\end{array}$ \\
\hline Type I del & 23 & 45.3 & 9.5 & 7.4 & 5.6 & 2.2 & 5.4 & 4.6 \\
Type II del & 22 & 39.6 & 9.0 & 8.5 & 4.7 & 2.4 & 4.3 & 3.0 \\
mUPD & 42 & 58.0 & 13.4 & 13.2 & 6.1 & 3.5 & 4.1 & 5.4 \\
Total & $\mathbf{8 7}$ & $\mathbf{5 0 . 0}$ & $\mathbf{1 1 . 3}$ & $\mathbf{1 0 . 5}$ & $\mathbf{5 . 6}$ & $\mathbf{2 . 9}$ & $\mathbf{4 . 5}$ & $\mathbf{4 . 6}$ \\
\hline
\end{tabular}

* statistically significant (ANOVA, $p \leq 0.05$ )

\# 11 persons were excluded from this part of the study: 6 with an atypical deletion, 3 with a missing blood sample, 2 with an imprinting defect

\section{Relation with BMI categories}

Table 4.3 shows the mean total and mean subscale scores on DBC-A according to BMI categories. There were no statistically significant differences in DBC-A total scores between the different BMI categories. However, additional analyses of the subscales showed statistically significant differences on subscale 2 (self-absorbed), mainly due to differences between individuals with $\mathrm{B} B \mathrm{MI}<25$ and persons with a BMI between 25 and 30 (t-test, $\mathrm{p}=0.04$ ).

Table 4.3 Mean total and mean subscale scores on DBC-A according to BMI categories

\begin{tabular}{lcccccccc}
\hline BMI & $\mathrm{N}$ & $\begin{array}{c}\text { Mean } \\
\text { Total }\end{array}$ & $\begin{array}{c}\text { Mean } \\
\text { subscale 1 }\end{array}$ & $\begin{array}{c}\text { Mean } \\
\text { subscale 2* }\end{array}$ & $\begin{array}{c}\text { Mean } \\
\text { subscale 3 }\end{array}$ & $\begin{array}{c}\text { Mean } \\
\text { subscale 4 }\end{array}$ & $\begin{array}{c}\text { Mean } \\
\text { subscale 5 }\end{array}$ & $\begin{array}{c}\text { Mean } \\
\text { subscale 6 }\end{array}$ \\
\hline$<25$ & 17 & 54.3 & 12.1 & 14.4 & 5.8 & 2.9 & 4.0 & 3.9 \\
$25-30$ & 25 & 48.2 & 10.9 & 9.4 & 6.0 & 2.7 & 4.6 & 3.8 \\
$30+$ & 56 & 51.8 & 12.1 & 10.2 & 5.6 & 3.1 & 4.7 & 5.4 \\
Total & $\mathbf{9 8}$ & $\mathbf{5 1 . 3}$ & $\mathbf{1 1 . 8}$ & $\mathbf{1 0 . 7}$ & $\mathbf{5 . 8}$ & $\mathbf{2 . 9}$ & $\mathbf{4 . 6}$ & $\mathbf{4 . 7}$ \\
\hline
\end{tabular}

* statistically significant (ANOVA, $\mathrm{p} \leq 0.05)$

\section{Relation with other factors}

Gender and level of intellectual disabilities were not significantly related to mean total and mean subscale scores on the DBC-A.

\section{DBC-A item analysis}

Table 4.4 shows the DBC-A items in relation to age groups, genetic subtypes and $\mathrm{BMI}$ categories. 
Table 4.4 DBC-A items in relation to age groups, genetic subtypes, and BMI categories

\begin{tabular}{|c|c|c|c|c|}
\hline \multicolumn{2}{|c|}{ DBC-A Item (subscale) } & \multirow{2}{*}{$\begin{array}{c}\text { Age groups } \\
\mathrm{X}^{2}, \mathbf{p} \text {-value } \\
\text { n.s. }\end{array}$} & \multirow{2}{*}{$\begin{array}{c}\text { Genetic subtypes } \\
\mathbf{X}^{2}, \mathbf{p}_{\text {-value }}^{\#} \\
\mathbf{0 . 0 2}^{3}\end{array}$} & \multirow{2}{*}{$\begin{array}{c}\begin{array}{c}\text { BMI categories } \\
\mathbf{X}^{2}, \mathbf{p} \text {-value }\end{array} \\
\text { n.s. }\end{array}$} \\
\hline 1 & Unhappy $(1,6)$ & & & \\
\hline 2 & Eye contact & n.s. & n.s. & n.s. \\
\hline 3 & Aloof (5) & n.s. & n.s. & n.s. \\
\hline 4 & Abusive (1) & n.s. & $0.02^{3}$ & n.s. \\
\hline 5 & Routine (5) & n.s. & n.s. & n.s. \\
\hline 6 & Bangs head (2) & n.s. & n.s. & $0.02^{1}$ \\
\hline 7 & Excited $(1,2)$ & n.s. & n.s. & $0.03^{1}$ \\
\hline 8 & Bites (2) & $0.05^{1}$ & n.s. & $<0.01^{1}$ \\
\hline 9 & Bizarre speech & n.s. & n.s. & n.s. \\
\hline 10 & Attention & n.s. & $0.03^{3}$ & n.s. \\
\hline 11 & Mouths (2) & n.s. & n.s. & n.s. \\
\hline 12 & Cries (1) & n.s. & n.s. & n.s. \\
\hline 13 & Sounds & n.s. & n.s. & n.s. \\
\hline 14 & Pronouns (3) & n.s. & n.s. & n.s. \\
\hline 15 & Runs away & n.s. & n.s. & n.s. \\
\hline 16 & Delusions & n.s. & n.s. & n.s. \\
\hline 17 & Alone & n.s. & n.s. & n.s. \\
\hline 18 & Affection & n.s. & n.s. & n.s. \\
\hline 19 & Feelings (2) & n.s. & n.s. & n.s. \\
\hline 20 & Distracted (3) & n.s. & n.s. & n.s. \\
\hline 21 & Easily led (3) & n.s. & n.s. & n.s. \\
\hline 22 & Non food (2) & n.s. & n.s. & n.s. \\
\hline 23 & Familiar & n.s. & n.s. & n.s. \\
\hline 24 & Fears & n.s. & n.s. & n.s. \\
\hline 25 & Twitches (2) & n.s. & $0.01^{3}$ & n.s. \\
\hline 26 & Flicks (2) & n.s. & $<0.01^{3}$ & n.s. \\
\hline 27 & Food fads & n.s. & n.s. & n.s. \\
\hline 28 & Gorges (2) & $<0.01^{4 *}$ & n.s. & n.s. \\
\hline 29 & Obsessed & n.s. & n.s. & n.s. \\
\hline 30 & Grinds (2) & n.s. & n.s. & n.s. \\
\hline 31 & Confused (6) & n.s. & n.s. & n.s. \\
\hline 32 & Withdrawn (6) & n.s. & n.s. & n.s. \\
\hline 33 & Nightmares (4) & n.s. & n.s. & n.s. \\
\hline 34 & Tantrums (1) & n.s. & n.s. & n.s. \\
\hline 35 & Hides (4) & $0.04^{2}$ & n.s. & $0.04^{3 *}$ \\
\hline 36 & Hits self (2) & n.s. & n.s. & $0.05^{1}$ \\
\hline 37 & Hums (2) & n.s. & n.s. & n.s. \\
\hline 38 & Impatient (1) & n.s. & $0.01^{3}$ & n.s. \\
\hline 39 & Sexual (4) & n.s. & n.s. & n.s. \\
\hline 40 & Increase of appetite & $0.04^{3}$ & n.s. & n.s. \\
\hline 41 & Impulsive & n.s. & n.s. & n.s. \\
\hline 42 & Irritable (1) & n.s. & n.s. & n.s. \\
\hline 43 & Jealous (1) & n.s. & n.s. & n.s. \\
\hline 44 & Kicks (2) & n.s. & n.s. & n.s. \\
\hline 45 & Esteem & n.s. & n.s. & n.s. \\
\hline 46 & Laughs (2) & $0.05^{4 *}$ & n.s. & n.s. \\
\hline 47 & Fires (4) & n.s. & n.s. & n.s. \\
\hline 48 & Strings (2) & n.s. & n.s. & n.s. \\
\hline 49 & Loss of appetite (6) & n.s. & n.s. & n.s. \\
\hline 50 & Loss of enjoyment (6) & n.s. & n.s. & n.s. \\
\hline 51 & Loss of self-care (6) & n.s. & n.s. & n.s. \\
\hline 52 & Gloomy (4) & n.s. & n.s. & n.s. \\
\hline 53 & In public (4) & n.s. & n.s. & n.s. \\
\hline 54 & Mood (6) & $0.02^{2}$ & n.s. & n.s. \\
\hline
\end{tabular}




\begin{tabular}{|c|c|c|c|c|}
\hline \multicolumn{2}{|c|}{ DBC-A Item (subscale) } & \multirow{2}{*}{$\begin{array}{c}\begin{array}{c}\text { Age groups } \\
\mathrm{X}^{2}, \mathrm{p} \text {-value }\end{array} \\
0.03^{4}\end{array}$} & \multirow{2}{*}{$\begin{array}{c}\begin{array}{c}\text { Genetic subtypes } \\
\mathbf{X}^{2}, \mathbf{p} \text {-value }\end{array} \\
\text { n.s. }\end{array}$} & \multirow{2}{*}{$\begin{array}{c}\begin{array}{c}\text { BMl categories } \\
\mathrm{X}^{2}, \mathrm{p} \text {-value }\end{array} \\
\text { n.s. }\end{array}$} \\
\hline 55 & Underactive (6) & & & \\
\hline 56 & Noisy (2) & n.s. & n.s. & n.s. \\
\hline 57 & Communicating (6) & n.s. & n.s. & n.s. \\
\hline 58 & Overactive $(2,3)$ & n.s. & $<0.01^{3}$ & $0.05^{1 *}$ \\
\hline 59 & Overaffectionate (3) & n.s. & n.s. & n.s. \\
\hline 60 & Vomits & n.s. & n.s. & n.s. \\
\hline 61 & Attention seeking (1) & n.s. & n.s. & $0.01^{3}$ \\
\hline 62 & Mechanical & n.s. & n.s. & n.s. \\
\hline 63 & Panics (4) & $<0.01^{4 *}$ & n.s. & n.s. \\
\hline 64 & Danger (4) & n.s. & n.s. & n.s. \\
\hline 65 & Her own (5) & n.s. & n.s. & n.s. \\
\hline 66 & Preoccupied & n.s. & n.s. & n.s. \\
\hline 67 & Problems with cigarettes & n.s. & n.s. & n.s. \\
\hline 68 & Problems with drugs & n.s. & n.s. & n.s. \\
\hline 69 & Refuses to go (1) & n.s. & n.s. & n.s. \\
\hline 70 & Movements (2) & n.s. & n.s. & $0.04^{1}$ \\
\hline 71 & Cuddled (5) & n.s. & n.s. & n.s. \\
\hline 72 & Echo (3) & n.s. & n.s. & n.s. \\
\hline 73 & Repeats & n.s. & $0.04^{1}$ & n.s. \\
\hline 74 & Smells (2) & n.s. & n.s. & n.s. \\
\hline 75 & Scratches (2) & n.s. & n.s. & n.s. \\
\hline 76 & Screams (2) & n.s. & $<0.01^{3}$ & $0.05^{1}$ \\
\hline 77 & Sleeps little & n.s. & n.s. & n.s. \\
\hline 78 & Stares (2) & n.s. & n.s. & n.s. \\
\hline 79 & Sleeps much (6) & n.s. & n.s. & n.s. \\
\hline 80 & Soils (2) & $<0.01^{4 *}$ & $0.03^{3}$ & n.s. \\
\hline 81 & Whispers & n.s. & $0.03^{3}$ & n.s. \\
\hline 82 & Spits (2) & n.s. & n.s. & n.s. \\
\hline 83 & Lights (2) & n.s. & n.s. & n.s. \\
\hline 84 & Steals (4) & n.s. & n.s. & n.s. \\
\hline 85 & Stubborn (1) & $0.03^{2}$ & n.s. & n.s. \\
\hline 86 & Shy (5) & n.s. & n.s. & n.s. \\
\hline 87 & Clothes (2) & n.s. & $0.05^{3}$ & n.s. \\
\hline 88 & Not capable (3) & n.s. & n.s. & n.s. \\
\hline 89 & Stands (3) & n.s. & n.s. & n.s. \\
\hline 90 & Hallucinates (3) & n.s. & n.s. & n.s. \\
\hline 91 & Kill self & n.s. & n.s. & n.s. \\
\hline 92 & Talks fast (3) & n.s. & n.s. & n.s. \\
\hline 93 & Talks to self ( 3 ) & n.s. & n.s. & n.s. \\
\hline 94 & Lies $(2,3)$ & n.s. & $0.02^{3}$ & n.s. \\
\hline 95 & Thoughts (3) & n.s. & n.s. & n.s. \\
\hline 96 & Tense (1) & n.s. & n.s. & n.s. \\
\hline 97 & Throws (1) & n.s. & n.s. & n.s. \\
\hline 98 & Manipulates (1) & n.s. & n.s. & n.s. \\
\hline 99 & Pain & n.s. & n.s. & n.s. \\
\hline 100 & Elated & n.s. & n.s. & n.s. \\
\hline 101 & Posture & n.s. & n.s. & n.s. \\
\hline 102 & Changes $(1,5)$ & n.s. & n.s. & n.s. \\
\hline 103 & Urinates (2) & n.s. & n.s. & n.s. \\
\hline 104 & Bossy (1) & n.s. & n.s. & n.s. \\
\hline 105 & Wanders & n.s. & $0.05^{3}$ & n.s. \\
\hline
\end{tabular}

* Also statistical significance on Kendall's tau ( $p \leq 0.05)$; \# Highest scores in the group: Age groups: 1. $<25 \mathrm{yrs}, 2.25-34$ yrs, 3. 35-44 yrs, 4. 45+ yrs; Genetic subtypes: 1. Type I deletion, 2. Type II deletion, 3. mUPD; BMI categories: 1. $<25,2$. 25-30, 3. 30+ 


\section{Relation with age}

Persons $<25$ years scored highest on biting others (item \#8) $\left(x^{2}, p=0.05\right)$. Persons in the age group 25-34 showed highest scores on the items hiding things (\#35), rapid mood changes (\#54) and stubbornness $(\# 85)\left(x^{2}, p \leq 0.04\right)$. Increase in appetite (\#40) was most prominent in age group 35-44 years and over 45 years $\left(x^{2}, p=0.04\right)$. People above the age of 45 were most underactive $(\# 55)\left(x^{2}, p=0.03\right)$. The following items were related to age and most prominent in the oldest age group: gorges food (\#28), laughs for no obvious reason (\#46), panics (\#63) and soils outside the toilet (\#80) ( $x^{2}$ and Kendall's tau, $p \leq 0.05$ ).

\section{Relation with genetic subtypes}

Persons with mUPD scored significantly higher than persons with a Type I and Type II deletion on the following DBC-A items: unhappy (item \#1), abusive (\#4), poor attention span (\#10), facial twitches (\#25), flicks (taps and twirls objects repeatedly) (\#26), impatient (\#38), overactive (\#58), screams a lot (\#76), soils outside the toilet (\#80), whispers (\#81), strips of clothes (\#87), tells lies (\#94) and wanders aimlessly $(\# 105)\left(x^{2}, p \leq 0.05\right)$. Persons with Type I deletions scored the highest on repeating the same word/phrase (\#73).

\section{Relation with BMI categories}

Persons with $\mathrm{BMI}<25$ scored significantly higher than persons with higher BMI on the following DBC-A items: bangs the head (\#6), becomes over-excited $(\# 7)$, bites (\#8), hits oneself (\#36), repeated movements (e.g. of hands, head of body) (\#70) and screams a lot $(\# 76)\left(X^{2}, p \leq 0.05\right)$. Overactiveness (restless, unable to sit still) (\#58) is negatively related to BMI, with the highest scores in the BMI category $<25$ ( $x^{2}$ and Kendall's tau, $p \leq 0.05$ ). Hiding things (\#35) is positively related to BMI, with the highest scores in the BMI category $\geq 30$ ( $X^{2}$ and Kendall's tau, $p \leq 0.05)$. Attention seeking (\#61) was most prominent in the BMI category $\geq 30$ ( $X^{2}$ and Kendall's tau, $p=0.01$ ).

\section{Relationship to genetic subtype and age}

Two-tailed independent T-Tests were performed to test whether the differences between younger ( $<40$ years) and older ( $\geq 40$ years) adults within the genetic subtypes were statistically significant. Results showed that scores both on both the total DBC-A and the subscales did not differ significantly.

\subsection{DISCUSSION}

In this study, we assessed problem behaviour in a large group of genetically confirmed adults with PWS, with a valid and reliable questionnaire on 
behavioural problems (DBC-A). Our results show that adults with PWS have higher rates of maladaptive behaviours compared to people with ID due to other etiologies (non-specified ID, Down syndrome or fragile $\mathrm{X}$ syndrome). This is in line with other studies ${ }^{9,17,20}$.

Previous studies have noted a sequence of distinct behavioural "epochs" in $\mathrm{PWS}^{19,37}$. For a broader view of how maladaptive behaviour might change over the entire lifespan, the information of older adults with PWS has to be linked to the behavioural characteristics in childhood and young adulthood. Most studies described an increase in behavioural problems during adolescence and young adulthood $^{19,20}$. We found biting, hiding things, rapid mood changes and stubbornness to be more frequent under the age of 35 . Young adulthood may be a period of psychosocial adjustments and consequently heightened behavioural problems, compared to childhood and adolescence. Graduation from school and starting to work, out of home placement (in a residential facility) and the awareness of their differences in abilities and dependency compared with siblings, may contribute to an increase in maladaptive behaviour. First psychiatric episodes in persons with PWS are also frequently associated with young adulthood ${ }^{25}$.

Unlike previous descriptions of the behavioural phenotype in adults with PWS, we did not find reductions in behavioural problems in older adults. To the contrary, we found that behavioural problems were more prevalent in older adults. This behaviour included underactivity, gorging food, laughing for no obvious reason, panicking and soiling outside the toilet. These behaviours may be refractory to behavioural and dietary interventions. Behavioural problems in older age may also be a result of increasing physical morbidity, functional decline or behavioural problems of other residents in the house.

We found most behavioural problems in adults with the mUPD subtype. In contrast, other studies reported that persons with a mUPD have less skinpicking and maladaptive behaviour than persons with a deletion ${ }^{23,24}$, but heightened vulnerabilities in young adulthood for psychiatric disorders, such as atypical psychosis and affective disorders ${ }^{14,25,26}$.

Psychiatric symptoms are frequent in adults with PWS and are associated with psychosis and affective disorders ${ }^{38-41}$. Persons with mUPD are at increased risk to develop a first episode of psychopathology in young adulthood ${ }^{25}$. Results from our study on psychopathology in this same cohort ${ }^{42}$ revealed nine out of 53 persons with a 15q11-q13 deletion and 28 out of 44 persons with mUPD with a current or previous psychiatric illness. It is likely that there is an overlap between behavioural symptoms and psychiatric disorders, attributing to 
higher problem behaviour scores in persons with mUPD. Many adults with PWS need psychiatric support, including psychotropic medication and sometimes hospitalization, during several periods of their lives. It is important for professionals to be aware of any increases in behavioural problems, as these may be early indicators of underlying medical or psychiatric disorders.

Individuals with a $\mathrm{BMI}<25$ had higher scores on the self-absorbed scale (e.g. biting, screaming, and banging of the head) compared to persons with a BMI between 25 and 30. Both psychological and physiological mechanisms may be implicated in these BMl findings. Very strict dietary control to achieve a healthy weight status may cause more frustration and internal stress in persons with PWS, resulting in an increase of behavioural problems. Our results are in line with the literature ${ }^{18,19}$. It was suggested ${ }^{12}$ that achieving adequate weight control is inherently stressful for most individuals with PWS and that they are often in a state of denial. Weight loss does not seem to be a cure for all aspects of the disorder. A lower BMI may influence the physiological and hormonal status which contributes to specific behaviour. This may be an argument to balance the need for weight loss and the increased risk of behavioural problems.

Our results on the relation between problem behaviour and age and genetic subtype, differed from results from other studies ${ }^{12,23,27,32}$. This may be explained by the use of different behavioural measurements and a possible different focus of interest (e.g. obsessive-compulsive behaviour or depressive symptomatology). Moreover, the study population in this study differed from other study groups $s^{12,20,23,27,32}$. Our study population is characterized by a predominance of older persons with PWS. We also found a different distribution of genetic subtypes ${ }^{43}$. Genetic testing showed $55 \%$ with a paternal deletion, $43 \%$ with a mUPD and $2 \%$ with a defect of the imprinting center. The observed distribution in our study differed significantly from the classic distribution in the literature $(70 \% \text { deletion, } 30 \% \mathrm{mUPD})^{43}$. This difference was mainly due to a higher proportion of mUPD in the advanced age groups. The mUPD subtype is associated with higher prevalence of psychiatric and, presumably, co-occurring behavioural problems. These unique characteristics of our study population probably contribute to different findings on behavioural problems.

Behavioural issues often impact on individuals with PWS and their families and caregivers more than any other aspect of the disorder ${ }^{44}$. Compared to reported stress levels in families of children with mixed etiologies of ID, parents of children with PWS showed higher levels of parent and family problems, and comparable levels of pessimism. Families experienced greater levels of stress 
when the child showed more behaviour problems overall ${ }^{45}$. Therefore, parents and professional caregivers should be supported in dealing with behavioural problems, not only in childhood, but also during the entire lifespan.

General management of adults with PWS should include attention for behavioural problems. Persons in the older age groups as well as persons with PWS due to mUPD and individuals with low BMI may be at increased risk of certain behavioural problems. Further research is needed in older adults and should among other things focus on the relationship between behavioural problems and psychiatric episodes. Longitudinal studies are warranted to gain more insight into the natural history and course of behavioural problems in adults and older people with PWS over the long term and possible risk and preventive factors. 


\section{REFERENCES}

1. Cassidy SB: Prader-Willi syndrome. J Med Genet 1997; 34: 917-923.

2. Holm VA, Cassidy SB, Butler MG, Hanchett JM, Greenswag LR, Whitman BY, Greenberg F: Prader-Willi syndrome: consensus diagnostic criteria. Pediatrics 1993; 91: 398-402.

3. Goldstone AP, Holland AJ, Hauffa BP, Hokken-Koelega AC, Tauber M: Recommendations for the diagnosis and management of Prader-Willi syndrome. $J$ Clin Endocrinol Metab 2008; 93: 4183-4197.

4. Ledbetter DH, Riccardi VM, Airhart SD, Strobel RJ, Keenan BS, Crawford JD: Deletions of chromosome 15 as a cause of the Prader-Willi syndrome. N Engl J Med 1981; 304: 325-329.

5. Nicholls RD, Knoll JH, Butler MG, Karam S, Lalande M: Genetic imprinting suggested by maternal heterodisomy in nondeletion Prader-Willi syndrome. Nature 1989; 342: 281-285.

6. Buiting K, Saitoh S, Gross S, Dittrich B, Schwartz S, Nicholls RD, Horsthemke B: Inherited microdeletions in the Angelman and Prader-Willi syndromes define an imprinting centre on human chromosome 15. Nat Genet 1995; 9: 395-400.

7. Bittel DC, Butler MG: Prader-Willi syndrome: clinical genetics, cytogenetics and molecular biology. Expert Rev Mol Med 2005; 7: 1-20.

8. Christian SL, Robinson WP, Huang B, Mutirangura A, Line MR, Nakao M, Surti U, Chakravarti $\mathrm{A}$, Ledbetter $\mathrm{DH}$ : Molecular characterization of two proximal deletion breakpoint regions in both Prader-Willi and Angelman syndrome patients. Am J Hum Genet 1995; 57: 40-48.

9. Einfeld SL, Smith A, Durvasula S, Florio T, Tonge BJ: Behavior and emotional disturbance in Prader-Willi syndrome. Am J Med Genet 1999; 82: 123-127.

10. Clarke DJ, Boer H, Whittington J, Holland A, Butler J, Webb T: Prader-Willi syndrome, compulsive and ritualistic behaviours: the first population-based survey. Br J Psychiatry 2002; 180: 358-362.

11. Dykens EM, Leckman JF, Cassidy SB: Obsessions and compulsions in PraderWilli syndrome. J Child Psychol Psychiatry 1996; 37: 995-1002.

12. Dykens EM: Maladaptive and compulsive behavior in Prader-Willi syndrome: new insights from older adults. Am J Ment Retard 2004; 109: 142-153.

13. Curfs LM, Verhulst FC, Fryns JP: Behavioral and emotional problems in youngsters with Prader-Willi syndrome. Genet Couns 1991; 2: 33-41.

14. Beardsmore A, Dorman T, Cooper SA, Webb T: Affective psychosis and PraderWilli syndrome. J Intellect Disabil Res 1998; 42: 463-471.

15. Ho AY, Dimitropoulos A: Clinical management of behavioral characteristics of Prader-Willi syndrome. Neuropsychiatr Dis Treat 2010; 6: 107-118.

16. Dimitropoulos A, Feurer ID, Butler MG, Thompson T: Emergence of compulsive behavior and tantrums in children with Prader-Willi syndrome. Am J Ment Retard 2001; 106: 39-51.

17. Dykens EM, Kasari C: Maladaptive behavior in children with Prader-Willi syndrome, Down syndrome, and nonspecific mental retardation. Am J Ment Retard 1997; 102: 228-237.

18. Dykens EM, Cassidy SB: Correlates of maladaptive behavior in children and adults with Prader-Willi syndrome. Am J Med Genet 1995; 60: 546-549.

19. Whitman BY, Accardo P: Emotional symptoms in Prader-Willi syndrome adolescents. Am J Med Genet 1987; 28: 897-905. 
20. Clarke DJ, Boer H, Chung MC, Sturmey P, Webb T: Maladaptive behaviour in Prader-Willi syndrome in adult life. J Intellect Disabil Res 1996; 40: 159-165.

21. Dykens EM, Hodapp RM, Walsh K, Nash LJ: Adaptive and maladaptive behavior in Prader-Willi syndrome. J Am Acad Child Adolesc Psychiatry 1992; 31: 1131-1136.

22. Greenswag LR: Adults with Prader-Willi syndrome: a survey of 232 cases. Dev Med Child Neurol 1987; 29: 145-152.

23. Dykens EM, Cassidy SB, King BH: Maladaptive behavior differences in Prader-Willi syndrome due to paternal deletion versus maternal uniparental disomy. Am J Ment Retard 1999; 104: 67-77.

24. Symons FJ, Koppekin A, Wehby JH: Treatment of self-injurious behavior and quality of life for persons with mental retardation. Ment Retard 1999; 37: 297-307.

25. Boer H, Holland A, Whittington J, Butler J, Webb T, Clarke D: Psychotic illness in people with Prader Willi syndrome due to chromosome 15 maternal uniparental disomy. Lancet 2002; 359: 135-136.

26. Vogels A, Matthijs G, Legius E, Devriendt K, Fryns JP: Chromosome 15 maternal uniparental disomy and psychosis in Prader-Willi syndrome. J Med Genet 2003; 40: 72-73.

27. Butler MG, Bittel DC, Kibiryeva N, Talebizadeh Z, Thompson T: Behavioral differences among subjects with Prader-Willi syndrome and type I or type II deletion and maternal disomy. Pediatrics 2004; 113: 565-573.

28. Hartley SL, Maclean WE, Jr., Butler MG, Zarcone J, Thompson T: Maladaptive behaviors and risk factors among the genetic subtypes of Prader-Willi syndrome. Am J Med Genet A 2005; 136: 140-145.

29. Zarcone J, Napolitano D, Peterson C, Breidbord J, Ferraioli S, Caruso-Anderson M, Holsen L, Butler MG, Thompson T: The relationship between compulsive behaviour and academic achievement across the three genetic subtypes of PraderWilli syndrome. J Intellect Disabil Res 2007; 51: 478-487.

30. Varela MC, Kok F, Setian N, Kim CA, Koiffmann CP: Impact of molecular mechanisms, including deletion size, on Prader-Willi syndrome phenotype: study of 75 patients. Clin Genet 2005; 67: 47-52.

31. Milner KM, Craig EE, Thompson RJ, Veltman MW, Thomas NS, Roberts S, Bellamy M, Curran SR, Sporikou CM, Bolton PF: Prader-Willi syndrome: intellectual abilities and behavioural features by genetic subtype. J Child Psychol Psychiatry 2005; 46: 1089-1096.

32. Dykens EM, Roof E: Behavior in Prader-Willi syndrome: relationship to genetic subtypes and age. J Child Psychol Psychiatry 2008; 49: 1001-1008.

33. Einfeld SL, Tonge BJ, Mohr C: The Developmental Behaviour Checklist for Adults (DBC-A). School of Psychiatry, University of New South Wales, and Centre of Developmental Psychiatry and Psychology, Monash University, Sydney and Melbourne 2002.

34. Mohr C, Tonge BJ, Einfeld SL: The development of a new measure for the assessment of psychopathology in adults with intellectual disability. J Intellect Disabil Res 2005; 49: 469-480.

35. Aman MG, Singh NN, Stewart AW, Field CJ: Psychometric characteristics of the aberrant behavior checklist. Am J Ment Defic 1985; 89: 492-502.

36. Moss S, Prosser H, Costello H, Simpson N, Patel P, Rowe S, Turner S, Hatton C: Reliability and validity of the PAS-ADD Checklist for detecting psychiatric disorders in adults with intellectual disability. J Intellect Disabil Res 1998; 42: 173-183.

37. Butler MG, Lee PDK, Whitman BY: Management of Prader-Willi syndrome, Third edition edn, New York: Springer, 2006. 
38. Soni S, Whittington J, Holland AJ, Webb T, Maina E, Boer H, Clarke D: The course and outcome of psychiatric illness in people with Prader-Willi syndrome: implications for management and treatment. J Intellect Disabil Res 2007; 51: 32-42.

39. Soni S, Whittington J, Holland AJ, Webb T, Maina EN, Boer H, Clarke D: The phenomenology and diagnosis of psychiatric illness in people with Prader-Willi syndrome. Psychol Med 2008; 38: 1505-1514.

40. Vogels A, De Hert M, Descheemaeker MJ, Govers V, Devriendt K, Legius E, Prinzie P, Fryns JP: Psychotic disorders in Prader-Willi syndrome. Am J Med Genet A 2004; 127A: 238-243.

41. Verhoeven WM, Tuinier S, Curfs LM: Prader-Willi syndrome: the psychopathological phenotype in uniparental disomy. J Med Genet 2003; 40: e112.

42. Sinnema M, Boer $H$, Collin $P$, Maaskant MA, van Roozendaal KEP, SchranderStumpel CTRM, Curfs LMG: Psychiatric illness in a cohort of adults with PraderWilli syndrome. Res Dev Disabil 2011.32: 1729-1735

43. Sinnema M, van Roozendaal KE, Maaskant MA, Smeets HJ, Engelen JJ, JonkerHouben N, Schrander-Stumpel CT, Curfs LM: Different distribution of the genetic subtypes of the Prader-Willi syndrome in the elderly. Eur J Hum Genet 2010; 18: 993-998.

44. van den Borne HW, van Hooren RH, van Gestel M, Rienmeijer P, Fryns JP, Curfs LM: Psychosocial problems, coping strategies, and the need for information of parents of children with Prader-Willi syndrome and Angelman syndrome. Patient Educ Couns 1999; 38: 205-216.

45. Hodapp RM, Dykens EM, Masino LL: Families of children with Prader-Willi syndrome: stress-support and relations to child characteristics. J Autism Dev Disord 1997; 27: 11-24. 


\section{CHAPTER 5}

\section{PSYCHIATRIC ILLNESS IN A COHORT OF ADULTS WITH PRADER-WILLI SYNDROME}

Sinnema M, Boer H, Collin Ph, Maaskant MA, van Roozendaal KEP, Schrander-Stumpel CTRM, Curfs LMG

Res Dev Disabil 2011;32:1729-1735 


\section{ABSTRACT}

\section{Background}

Previous studies have suggested an association between PWS and comorbid psychiatric illness. Data on prevalence rates of psychopathology is still scarce. This paper describes a large-scale, systematic study investigating the prevalence of psychiatric illness in a Dutch adult PWS cohort.

\section{Methods}

102 individuals were screened for psychiatric illness. Case vignettes were written by the first author on 63 individuals with a positive screening on psychopathology according to the interviews, medical history, medication use and behavioural questionnaires. These case vignettes were rated by two psychiatrists specializing in Intellectual Disability (ID). Psychopathology was divided into four diagnostic categories: bipolar disorder with psychotic symptoms, psychotic illness, depressive illness with psychotic symptoms and depressive illness without psychotic symptoms.

\section{Results}

Nine out of 53 persons (17\%) with a 15q11-13 deletion and 28 out of $44(64 \%)$ persons with maternal uniparental disomy (mUPD) were diagnosed with a current or previous psychiatric illness. Depressive illness with psychotic symptoms was the cause of psychiatric problems in the majority of persons with PWS due to deletion (56\%). In the case of mUPD, almost all individuals with histories of psychopathology suffered from psychotic symptoms (85\%) with or without affective component.

\section{Conclusion}

Psychiatric examination should be part of general management of adults with PWS, especially when caused by mUPD. More attention should be paid to the presence of precursor symptoms, indicating a developing psychiatric episode. Longitudinal studies are needed to gain more insight into the natural history of psychiatric illness in adults with PWS. 


\subsection{INTRODUCTION}

Prader-Willi syndrome (PWS) is a neurodevelopmental disorder caused by the absence of paternal expression of imprinted genes in the critical region at 15q11-13. The main mechanisms causing PWS include a paternal deletion at $15 \mathrm{q} 11-13(70 \%)^{1}$ and a maternal uniparental disomy (mUPD) of chromosome $15(25-30 \%)^{2}$. Translocations and imprinting defects account for $1-5 \%$ of the cases $^{3}$. The main phenotypic features include neonatal hypotonia and feeding problems, short stature, hypogonadism, hyperphagia and obesity, characteristic facial appearances and mild to moderate intellectual disability ${ }^{4}$. Besides typical physical features, persons with PWS are characterized by behavioural phenotypes including temper tantrums, skin picking, lability of mood, stubbornness and compulsive and ritualistic behaviours ${ }^{5}$.

Previous studies have suggested associations between PWS and comorbid psychiatric illness. The first reports on psychotic episodes consisted of individual case reports ${ }^{6-11}$. In other studies psychotic symptoms were mentioned as part of the clinical picture of PWS, without detailed descriptions ${ }^{12}$. Two studies estimated the prevalence of psychotic symptoms associated with PWS by administering questionnaires to the parents and caregivers ${ }^{13,14}$. Boer et al. ${ }^{15}$ first indicated that the risk of developing psychotic episodes with increasing age was associated with the mUPD subtype of PWS. Of those aged over 27 years, $100 \%$ had developed at least one psychotic episode. These findings were supported by subsequent studies ${ }^{16,17}$. The development of psychiatric illness in PWS is influenced by genetic, biological and environmental factors ${ }^{18}$.

Soni et al. ${ }^{18}$ systematically studied psychiatric illness in a large cohort of persons with PWS ( $n=119)$ within the UK. They confirmed that those with mUPD had a higher rate of psychiatric illness than those with a deletion. A history of psychiatric illness was present in $24 / 85(28.2 \%)$ individuals with a deletion and 22/34 (64.7\%) with a mUPD. The profile of psychiatric illness in both genetic subtypes resembled an atypical affective disorder with or without psychotic symptoms. Those with PWS due to a deletion were more likely to have developed a non-psychotic depressive illness and those with mUPD a bipolar disorder with psychotic symptoms. Prevalence rates from this UK study have not previously been confirmed in other large PWS cohorts.

Here, we describe a large-scale, systematic study investigating the prevalence of psychiatric illness in a Dutch adult PWS cohort. Because of a predominance of older people (40+) with PWS in our cohort, the results are likely to give more insight in the natural history of psychopathology in the syndrome. Our aims 
were: firstly, to describe the prevalence of psychopathology in adults with PWS; secondly, to confirm or refute previous findings of the prevalence of psychiatric illness in adults with PWS; thirdly, to specify the relation of psychiatric illness in relation to the genetic subtypes, age and psychopathology in first degree relatives in more detail.

\subsection{METHODS}

\section{Procedure}

The current study was part of a large study in the Netherlands on psychiatry and ageing in PWS and was approved by the Medical Ethics Committee Maastricht. Persons with possible PWS were contacted through the Dutch Prader-Willi Parent Association and through intellectual disability physicians. In total 149 nominees with (possible) diagnoses of PWS were notified to us. After eliminating four nominees who had died $(n=2)$ or whose parents told us that PWS had been excluded by genetic testing $(n=2), 145$ possible participants were left. Of these, 108 agreed to participate in the study (a response rate of $75 \%$ ). Detailed genetic test results were available on 68 participants, and 40 participants were genetically tested during the study. For 102 patients, the genetic diagnosis of PWS was confirmed and therefore this study is based on these 102 individuals. Genetic testing revealed that the six remaining persons did not suffer from PWS. Non-response analyses showed that there was no statistical difference between the non-respondents and the 102 participants with regard to age and gender.

\section{Genetic diagnosis}

Parents were asked whether genetic testing on PWS including genetic subtype had been undertaken previously. With permission of the carers, written confirmation on genetic diagnoses was requested from genetic centres and for all cases received. For participants who did not have a confirmed genetic diagnosis $(n=40)$, genetic testing was undertaken. Cytogenetic analysis and molecular analysis using the SALSA MLPA kit ME028-A1 (MRC Holland, Amsterdam) were performed to establish whether deletions were present. Diagnosis of PWS was confirmed by DNA methylation studies on the SNURF/SNRPN locus and mUPD was confirmed with microsatellite analysis at various loci on chromosome 15 , when blood of parents was available.

\section{Screening for psychiatric illness}

Data on physical, behavioural and psychiatric characteristics were collected by the first author (M.S.) through semi-structured interviews with the individuals 
with PWS and their main carers (family and/or professional carers). All 102 individuals were screened for current or previous psychiatric illness. A number of questionnaires were used for additional information on psychiatric symptoms including the Developmental Behaviour Checklist for Adults (DBC-A $)^{19}$ and the Psychiatric Assessment Schedule for Adults with Developmental Disabilities (PAS-ADD) checklist ${ }^{20}$. We also established if there was a history of psychiatric illness or psychiatric symptoms in the first degree relatives of persons with PWS. Medical files on psychopathology were retrieved from general practitioners, intellectual disability physicians, and psychiatrists.

Case vignettes, were written by the first author on all people with PWS who had a history of psychiatric treatment or diagnosis, all those presently receiving psychotropic drugs, and any who scored positively on the behavioural questionnaires $(n=63)$. These case vignettes (including a mental state examination and the additional questionnaires) were independently rated according to ICD-10 criteria by two senior consultant psychiatrists specializing in ID (H.B. and P.C.) who were blind to the participants' genetic status. A number of cases $(n=24)$, in which initial rating by the two consultant psychiatrists resulted in different diagnostic categories, were further discussed during a consensus meeting with the two consultant psychiatrists. This resulted in consensus diagnoses in all patients.

Case vignettes were rated into following diagnosis groups: non-psychotic depressive illness, depressive psychosis, bipolar illness with psychotic symptoms and psychotic illness where affective symptoms were not prominent. We used the same diagnostic groups as Soni et al. ${ }^{18}$ to enable comparison. We added a category of bipolar illness without psychotic symptoms, because one case could not be classified in any of the other diagnostic groups.

\section{Statistical analyses}

SPSS (version 16.0) was used to analyze the data. To test whether differences in genetic subtype were statistically significant, Chi-square tests were performed. A $p$-value of 0.05 or less was regarded as statistically significant for all statistical tests. Via Cohen's kappa ${ }^{21}$, the level of agreement between the psychiatrists for the psychiatric diagnoses (inter-rater reliability) was investigated. The kappa values were rated as follows: $k<0.40$ 'poor', $0.40<\mathrm{k}<0.59$ 'moderate', $0.60<\mathrm{k}<0.75$ 'good', en $\mathrm{k}>0.75$ 'excellent ${ }^{22,23}$. 


\subsection{RESULTS}

\section{Participants}

A total of 108 adults with PWS were initially included in the study. Six individuals were found not to have PWS following genetic testing. Therefore, in total 102 participants were genetically confirmed as having PWS: $55(54 \%)$ had paternal deletion of the $15 q 11-13$ region, $44(43 \%)$ had mUPD and three $(3 \%)$ participants had imprinting centre defect. In persons with imprinting centre defect, the paternal chromosome 15 is hypermethylated, giving apparent uniparental disomy. In the following analyses, those with an imprinting centre defect are subsumed into the mUPD group because genetic configuration is the same in both mechanisms. Analyses showed that 49 individuals (48\%) were male. The mean age was 36.2 years $(S D=12.4$, range $=18$ to 66 years).

Five persons were excluded from this part of the study (leaving 97 respondents), because the first author was not able to assess these persons with PWS in person. Interviews only took place with the caregivers. The psychiatric diagnoses could therefore not be established in the same way as the other cases. However, in all these five persons, current psychiatric problems were the main reason why the interviews could not take place. Based on information from parents, professional caregivers and medical files, the diagnosis of bipolar disorder with psychotic symptoms would have been made in three persons (two persons with mUPD, one with deletion) and the diagnosis of depression in two persons (one person with mUPD, one person with deletion).

The initial inter-rater reliability between the psychiatrists on the presence of psychopathology in general was excellent $(\mathrm{k}=0.88)$, and on specific psychiatric diagnosis was moderate $(\mathrm{k}=0.52)$.

\section{Prevalence of psychopathology}

Individuals with mUPD were significantly more likely to have a history of psychopathology in general $(28 / 44 ; 64 \%)$ than those with a deletion $(9 / 53$; $17 \%)($ Chi square $p<0.01$ ) (Table 5.1). Specific histories of psychotic symptoms were present in 24 out of $44(55 \%)$ persons with mUPD and 7 out of $53(13 \%)$ with deletion (Table 5.1). Differences in the presence of psychotic symptoms, between the genetic subtypes were statistically significant (Chi square $\mathrm{p}<0.001)$. 
Table 5.1 Presence/absence of psychiatric diagnosis in general and psychosis according to genetic subtypes

\begin{tabular}{lccc}
\hline Diagnosis / subtype & Deletion & mUPD & Total \\
\hline Psychiatric diagnosis in general & ${ }^{*}$ & & \\
Present & 9 & 28 & 37 \\
Absent & 44 & 16 & 60 \\
Psychosis & & & \\
Present & 7 & 24 & 31 \\
Absent & 46 & 20 & 66 \\
Total & $\mathbf{5 3}$ & $\mathbf{4 4}$ & $\mathbf{9 7}$ \\
\hline
\end{tabular}

* Chi square: $20.3 ; \mathrm{df}=1 ; \mathrm{p}<0.01 ;{ }^{\#}$ Chi square: $17.0 ; \mathrm{df}=1 ; \mathrm{p}<0.01$

\section{Types of psychiatric diagnoses}

Table 5.2 shows the distribution of consensus psychiatric diagnoses according to genetic subtypes. Non-psychotic depressive illness, depressive psychosis, bipolar illness with psychotic symptoms and psychotic illness were prevalent in persons with mUPD as well as persons with PWS due to deletion. However, all psychiatric diagnoses were more prevalent in individuals of the mUPD subtype. Because observed cell values were too small for statistical analyses, these were not performed. Depressive illness with psychotic symptoms was the cause of psychiatric problems in the majority of persons with PWS due to deletion $(n=5 ; 56 \%)$. In case of mUPD, almost all individuals with histories of psychopathology, suffered from psychotic symptoms with or without affective components $(n=24 ; 85 \%)$.

Table 5.2 Distribution of psychiatric diagnosis according to genetic subtypes

\begin{tabular}{lllc}
\hline Diagnosis / subtype & $\begin{array}{c}\text { Deletion } \\
(\mathrm{n}=53)\end{array}$ & $\begin{array}{c}\mathrm{mUPD} \\
(\mathrm{n}=44)\end{array}$ & $\begin{array}{c}\text { Total } \\
(\mathrm{n}=97)\end{array}$ \\
\hline Bipolar disorder with psychotic symptoms & $1(2 \%)$ & $9(20 \%)$ & $10(10 \%)$ \\
Bipolar disorder & $0(0 \%)$ & $1(2 \%)$ & $1(1 \%)$ \\
Depressive illness with psychotic symptoms & $5(9 \%)$ & $8(18 \%)$ & $13(13 \%)$ \\
Depressive illness without psychotic symptoms & $2(4 \%)$ & $3(7 \%)$ & $5(5 \%)$ \\
Psychotic illness & $1(2 \%)$ & $7(16 \%)$ & $8(8 \%)$ \\
Total & $\mathbf{9 ( 1 7 \% )}$ & $\mathbf{2 8 ( 6 4 \% )}$ & $\mathbf{3 7 ( 3 8 \% )}$ \\
\hline
\end{tabular}

\section{Age at onset}

The mean age at onset of the first psychiatric episode was 21.9 years and did not differ between persons with a deletion ( $n=9$; mean: 21.3years; range 11-34 years) and persons with mUPD ( $n=24$; mean 22.1 years; range 13-38 years). Table 5.3 shows the mean age at onset of the specific psychiatric diagnoses. Differences between the diagnoses were not statistically significant. Age at onset was not known in 4 persons. 
Table 5.3 Age at onset of different psychiatric diagnoses

\begin{tabular}{lrcc}
\hline Consensus psychiatric diagnosis & N & Mean (yrs) & Range (yrs) \\
\hline Bipolar disorder with psychotic symptoms & 9 & 20,4 & $14-31$ \\
Bipolar disorder & 1 & 13,0 & 13 \\
Depressive illness with psychotic symptoms & 11 & 21,8 & $11-34$ \\
Depressive illness without psychotic symptoms & 5 & 28,2 & $16-38$ \\
Psychotic illness & 7 & 20,6 & $14-29$ \\
Total & $\mathbf{3 3}$ & $\mathbf{2 1 , 8 8}$ & $\mathbf{1 1 - 3 8}$ \\
\hline
\end{tabular}

\section{History of psychotic symptoms in relation with age groups and genetic subtype}

There was no statistically significant difference in the prevalence of psychosis between the age groups within the genetic subtypes (Table 5.4).

Table 5.4 History of psychotic symptoms in relation with age groups and genetic subtype
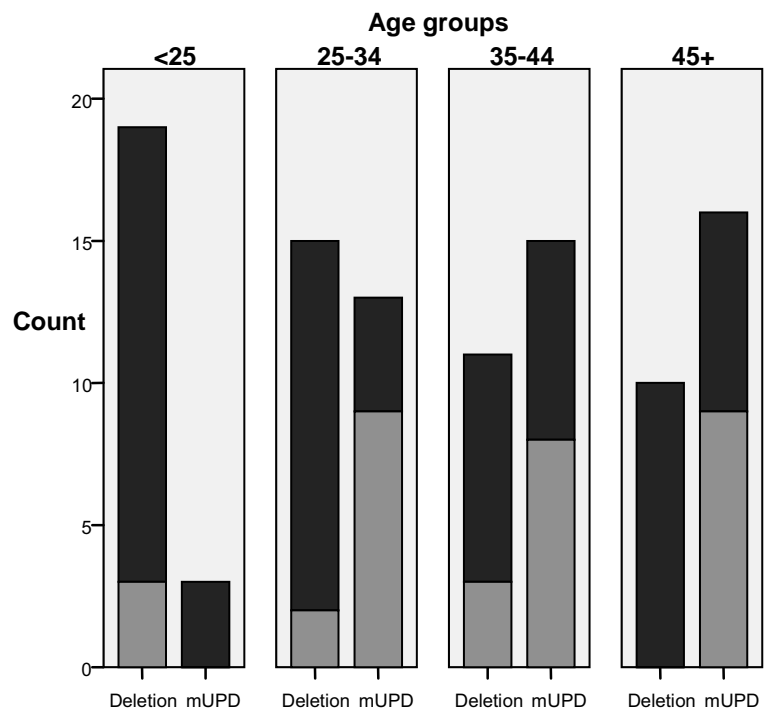

History of psychotic symptoms

Genetic subtypes

\section{Rates of psychopathology in first-degree relatives}

Table 5.5 shows the rates of psychopathology in first-degree relatives (FDR) of persons with PWS. Twelve FDR of persons with PWS had a history of psychopathology. We did not find a relationship between a specific diagnosis of the FDR and the specific diagnosis of the person with PWS or the genetic subtype. 
Table 5.5 Presence of psychopathology in first-degree relatives of persons with PWS

\begin{tabular}{llll}
\hline & $\begin{array}{l}\text { Psychopathology } \\
\text { FDR }\end{array}$ & $\begin{array}{l}\text { Psychopathology } \\
\text { PWS }\end{array}$ & $\begin{array}{l}\text { Genetic } \\
\text { subtype of } \\
\text { PWS }\end{array}$ \\
\hline Father & $\begin{array}{l}\text { Alcohol abuse } \\
\text { Alcohol abuse }\end{array}$ & Depression & $\begin{array}{l}\text { Deletion } \\
\text { Deletion }\end{array}$ \\
& Burn-out & None & Deletion \\
& Depression/alcohol abuse & None & Deletion \\
Mother & Burn-out/depression & Bipolar disorder with psychotic symptoms & mUPD \\
& Bipolar disorder & None & mUPD \\
& Burn-out & None & mUPD \\
& Depression & None & mUPD \\
Sibling & Bipolar disorder & Depression & mUPD \\
& Autism & Bipolar disorder with psychotic symptoms & Deletion \\
& ADHD & None & Deletion \\
& ADHD & None & Deletion \\
\hline
\end{tabular}

FDR $=$ first degree relative

\subsection{DISCUSSION}

The aim of the present study was to gain a better insight in psychiatric illness in a new large cohort of adults with a genetically confirmed diagnosis of PWS. Our results confirm previous findings that psychiatric illness is highly prevalent in adults with PWS. Individuals with mUPD are at higher risk of developing psychiatric illness, and psychosis in particular, than individuals with a deletion. The prevalence of psychopathology in general $(64 \%)$ and psychotic symptoms specifically $(55 \%)$ in persons with mUPD was strikingly high.

We compared our results with the results of Soni et al. ${ }^{18}$. In individuals with deletion, we found a similar prevalence of psychotic symptoms as Soni et al. ${ }^{18}$ $(13 \%$ vs. $17 \%)$. However, the prevalence of psychopathology in general in this subgroup was slightly higher in their study ( $17 \%$ vs. $28 \%)$, mainly due to more persons with depressive illness without psychotic symptoms. Bipolar disorder with psychotic symptoms was more prevalent in Soni's mUPD group compared with our results $(50 \%$ vs. $32 \%)$. The absolute numbers in both studies are unfortunately too small for testing the observed differences on statistical significance. Boer et al. ${ }^{15}$ found psychosis in $100 \%$ of the mUPD goup above the age of 28 in his initial sample. Soni et al. ${ }^{24}$ found some mUPD individuals without psychotic symptoms. We found an even higher percentage of people with mUPD above the age of 35 without a history of psychosis $(13 / 28 ; 46 \%)$.

The different results in our study may be due to limitations of small sample size, lack of genetically confirmed diagnosis in older age groups or selection bias in recruitment of participants in previous reports. The UK is one of the few 
countries in the world with dedicated psychiatrists for people with ID. Therefore, people with psychosis may have had a higher chance of having been known to services in the UK studies ${ }^{15,18}$. Another explanation may also be that persons with psychosis are at higher risk of having died at a younger age, resulting in a higher prevalence of non-psychotic older people. However, our results are not in line with this hypothesis (see Table 5.4).

Our study indicates that PWS caused by mUPD is associated with a high risk of developing psychosis in early adulthood. In contrast, only about $13 \%$ of people with a deletion were found to have psychotic symptoms. The prevalence in both genetic subtypes is higher than the prevalence of psychotic illness in persons with ID in general (Soni et al. 2008). Several genetic mechanisms have been suggested which could play a role in the development of psychotic problems. There could be insufficient expression of a nonimprinted gene in the PWS region in persons with a deletion. On the other hand, an excess of expression of maternally expressed genes could contribute to a greater vulnerability for psychosis in individuals with mUPD. It is possible that any gene associated with psychosis is located in the more distal part of the PWS/AS critical region where individuals with MUPD would have two active copies of any paternally imprinted genes while those with a deletion would have only a single copy.

Any exception to the risk of psychosis at adult age in individuals with mUPD, could provide clues to the underlying aetiological mechanisms. In our cohort, a total of 20 persons with mUPD did not have a history of psychotic symptoms. Thirteen out of twenty individuals were above the age of 35 . Five out of thirteen were diagnosed with affective disorders. We presume that the 7 persons under 35 without a history of psychotic symptoms may still be at risk of developing a psychotic episode. In more than half of these cases there were symptoms suggestive of a prodromal phase, characterized by an increase in lability of mood, destructiveness, aggression, ritualistic and compulsive behaviour, automutilation, increased irritability and explosiveness.

In contrast, seven persons with deletion of $15 q 11-q 13$ in our cohort $(n=53)$ had a history of psychotic illness. This is consistent with prevalence found by Soni et al. ${ }^{18}$ and lends support to their hypothesis that there is a genetic cause for the higher number of psychosis in persons with a deletion compared with people with ID in general. Webb et al. $^{25}$, using microsatellite markers, investigated 12 persons with a deletion who suffered psychotic episodes. All these individuals were found to have two maternally derived copies of a narrow region between D15S975 and D15S661, making them effectively disomic for these loci. They suggested that this causes dysregulation of a gene(s) within 
the region which may contribute to psychosis. We could not confirm these findings using MLPA analysis. All seven patients with a deletion and psychosis displayed loss of the paternal allele up to breakpoint 3 (BP3), thus also including loss of copy number of the OCA2 gene. Further research is needed to explain these differences.

We could not confirm the finding of Soni et al. ${ }^{24}$ on a relationship between depression on the maternal side and development of psychosis in persons with a deletion of 15q11-q13. In our series, family history of psychiatric illness was of very little influence in the development of psychiatric illness in adults with PWS. In addition to the genetic vulnerability, psychosocial stressors are known to be triggers for the development of first psychotic episodes ${ }^{24,26}$. Stressors in our participants included for example changes in living circumstances, graduation from school and starting to work or death of a family member. Whitman and Accardo ${ }^{13}$ hypothesized that starting a strict diet and good control of weight may also be a stressor in the onset of psychotic symptoms in PWS persons with a genetic predisposition for psychotic illness

There is no consensus regarding the psychiatric diagnoses associated with PWS in the literature. Diagnostic labels include schizophrenia, bipolar disorder, cycloid psychosis, florid psychotic states, paranoid-hallucinatory psychosis, depressive psychosis and depressive episodes ${ }^{7-11,27}$. In general, mood swings are common amongst both those with deletions and mUPD. These appear not to be related to the risk of psychotic illness, but may represent a shift in liability threshold ${ }^{28}$. PWS caused by mUPD is associated with psychotic disorder, and it is argued that in many patients a diagnosis of atypical bipolar disorder is appropriate ${ }^{17}$. It is known that the presence of mixed psychotic and affective symptoms, a combination which is often found in people with PWS, can lead to diagnostic disagreement ${ }^{29,30}$.

There are a number of limitations to this study. The cohort is large in terms of an adult PWS cohort, however the sample size remains small. Participants for this study were recruited from a larger study on ageing in PWS. Five persons with current psychiatric illness were excluded from this part of the study because the first author was not able to assess the persons with PWS in person. Hence, we suggest that the actual prevalence rates of psychopathology are even higher than reported in our results. For our retrospective data collection, we had to rely on information from parents and caregivers. To make data more objective, we combined the data of the caregivers, with interviews with the persons with PWS themselves and retrieved information from medical files. 
Despite these limitations, this study has provided information about the nature of psychiatric illness in a large Dutch cohort of adults with PWS and confirmed genetic diagnoses. During the screening phase, we used broad selection criteria for psychopathology, to be over-inclusive rather than overlooking symptoms. Our study population had a much broader age range compared to other studies, because of a predominance of older people (40+) with PWS. The observed distribution in our study ( $54 \%$ deletion; $46 \%$ mUPD) was significantly different $(z$-score: $p<0.05)$ from the classic distribution in the literature $(70 \%$ deletion, $30 \% \mathrm{mUPD})^{31}$. This was mainly caused by a higher proportion of mUPD in the advanced age groups ${ }^{32}$. The different age ranges of the study population may have affected the outcome. Ageing in PWS (40+) is an area which has not been researched before.

The results of this study are largely supportive of previous studies, and confirm that psychiatric assessment should be part of general management of adults with PWS, especially when caused by mUPD. In contrast to previous studies, we firstly found fewer adults with mUPD and psychotic episodes ${ }^{24}$. Secondly, we could not confirm the relationship between a family history of psychiatry and development of psychosis in persons with a deletion ${ }^{24}$. And thirdly, we did not find two maternally derived copies of a narrow region between D15S975 and D15S661 in people with a deletion and psychotic symptoms, which Webb et al. ${ }^{25}$ associated with the risk of developing psychosis. However, the rarity of the syndrome and the need to control for different variables such as genetic subtype, age and gender, limits clinical studies of sufficient size in any one country $^{33}$. There is thus a need for international collaborative studies to reach larger sample sizes of persons with confirmed genetic diagnoses. More attention should be paid to the presence of precursor symptoms, indicating a developing psychiatric episode. Longitudinal studies are warranted to gain more insight into the natural history and course of psychiatric illness in adults and older people with PWS over the long term. 


\section{REFERENCES}

1. Ledbetter DH, Riccardi VM, Airhart SD, Strobel RJ, Keenan BS, Crawford JD: Deletions of chromosome 15 as a cause of the Prader-Willi syndrome. N Engl J Med 1981; 304: 325-329.

2. Nicholls RD, Knoll JH, Butler MG, Karam S, Lalande M: Genetic imprinting suggested by maternal heterodisomy in nondeletion Prader-Willi syndrome. Nature 1989; 342: 281-285.

3. Buiting K, Saitoh S, Gross S, Dittrich B, Schwartz S, Nicholls RD, Horsthemke B: Inherited microdeletions in the Angelman and Prader-Willi syndromes define an imprinting centre on human chromosome 15. Nat Genet 1995; 9: 395-400.

4. Holm VA, Cassidy SB, Butler MG, Hanchett JM, Greenswag LR, Whitman BY, Greenberg F: Prader-Willi syndrome: consensus diagnostic criteria. Pediatrics 1993; 91: 398-402.

5. Clarke DJ, Boer $\mathrm{H}$, Whittington J, Holland A, Butler J, Webb T: Prader-Willi syndrome, compulsive and ritualistic behaviours: the first population-based survey. Br J Psychiatry 2002; 180: 358-362.

6. Clarke DJ: Prader-Willi syndrome and psychoses. $\mathrm{Br} J$ Psychiatry 1993; 163: 680-684.

7. Kollrack HW, Wolff D: Paranoid-hallucinatory psychosis in the Prader-Labhart-WilliFanconi syndrome. Acta Paedopsychiatr 1966; 33: 309-314.

8. Descheemaeker MJ, Vogels A, Govers V, Borghgraef M, Willekens D, Swillen A, Verhoeven W, Fryns JP: Prader-Willi syndrome: new insights in the behavioural and psychiatric spectrum. J Intellect Disabil Res 2002; 46: 41-50.

9. Beardsmore A, Dorman T, Cooper SA, Webb T: Affective psychosis and PraderWilli syndrome. J Intellect Disabil Res 1998; 42: 463-471.

10. Clarke D, Boer H, Webb T, Scott P, Frazer S, Vogels A, Borghgraef M, Curfs LM: Prader-Willi syndrome and psychotic symptoms: 1 . Case descriptions and genetic studies. J Intellect Disabil Res 1998; 42: 440-450.

11. Verhoeven WM, Curfs LM, Tuinier S: Prader-Willi syndrome and cycloid psychoses. J Intellect Disabil Res 1998; 42: 455-462.

12. Bray GA, Dahms WT, Swerdloff RS, Fiser RH, Atkinson RL, Carrel RE: The Prader-Willi syndrome: a study of 40 patients and a review of the literature. Medicine 1983; 62: 59-80.

13. Whitman BY, Accardo P: Emotional symptoms in Prader-Willi syndrome adolescents. Am J Med Genet 1987; 28: 897-905.

14. Clarke D: Prader-Willi syndrome and psychotic symptoms: 2. A preliminary study of prevalence using the Psychopathology Assessment Schedule for Adults with Developmental Disability checklist. J Intellect Disabil Res 1998; 42: 451-454.

15. Boer H, Holland A, Whittington J, Butler J, Webb T, Clarke D: Psychotic illness in people with Prader Willi syndrome due to chromosome 15 maternal uniparental disomy. Lancet 2002; 359: 135-136.

16. Vogels A, Matthijs G, Legius E, Devriendt K, Fryns JP: Chromosome 15 maternal uniparental disomy and psychosis in Prader-Willi syndrome. J Med Genet 2003; 40: $72-73$.

17. Verhoeven WM, Tuinier S, Curfs LM: Prader-Willi syndrome: the psychopathological phenotype in uniparental disomy. J Med Genet 2003; 40: e112. 
18. Soni S, Whittington J, Holland AJ, Webb T, Maina E, Boer H, Clarke D: The course and outcome of psychiatric illness in people with Prader-Willi syndrome: implications for management and treatment. J Intellect Disabil Res 2007; 51: 32-42.

19. Einfeld SL, Tonge BJ, Mohr C: The Developmental Behaviour Checklist for Adults (DBC-A). School of Psychiatry, University of New South Wales, and Centre of Developmental Psychiatry and Psychology, Monash University, Sydney and Melbourne 2002.

20. Moss SC, Prosser H, Costello H, Simpson N, Patel P: PAS-ADD Checklist. Hester Adrian Research Centre, University of Manchester, Manchester 1996.

21. Cohen JA: Coefficient for agreement for nominal scales. Educational and psychological measurement 1960; 20: 37-46.

22. Cicchetti DV, Sparrow SS: Development of criteria for establishing the interrater reliability of specific items in a given inventory: applications to assessment of adaptive behavior. American Journal of Mental Deficiency 1981; 86: 127-137.

23. Landis JR, Koch GG: The measurement of observer agreement for categorical data. Biometrics 1977; 33: 159-174.

24. Soni S, Whittington J, Holland AJ, Webb T, Maina EN, Boer H, Clarke D: The phenomenology and diagnosis of psychiatric illness in people with Prader-Willi syndrome. Psychol Med 2008; 38: 1505-1514.

25. Webb T, Maina EN, Soni S, Whittington J, Boer H, Clarke D, Holland A: In search of the psychosis gene in people with Prader-Willi syndrome. Am J Med Genet $A$ 2008; 146: 843-853.

26. Vogels A, De Hert M, Descheemaeker MJ, Govers V, Devriendt K, Legius E, Prinzie P, Fryns JP: Psychotic disorders in Prader-Willi syndrome. Am J Med Genet A 2004; 127A: 238-243.

27. Bartolucci G, Younger J: Tentative classification of neuropsychiatric disturbances in Prader-Willi syndrome. J Intellect Disabil Res 1994; 38: 621-629.

28. Holland A, Whittington J, Hinton E: The paradox of Prader-Willi syndrome: a genetic model of starvation. Lancet 2003; 362: 989-991.

29. Roy MA, Lanctot G, Merette C, Cliche D, Fournier JP, Boutin P, Rodrigue C, Charron L, Turgeon M, Hamel M, Montgrain N, Nicole L, Pires A, Wallot H, Ponton AM, Garneau Y, Dion C, Lavallee JC, Potvin A, Szatmari P, Maziade M: Clinical and methodological factors related to reliability of the best-estimate diagnostic procedure. Am J Psychiatry 1997; 154: 1726-1733.

30. van Os J, Gilvarry C, Bale R, van Horn E, Tattan T, White I, Murray R: Diagnostic value of the DSM and ICD categories of psychosis: an evidence-based approach. UK700 Group. Soc Psychiatry Psychiatr Epidemiol 2000; 35: 305-311.

31. Whittington JE, Butler JV, Holland AJ: Changing rates of genetic subtypes of Prader-Willi syndrome in the UK. Eur J Hum Genet 2007; 15: 127-130.

32. Sinnema M, van Roozendaal KE, Maaskant MA, Smeets HJ, Engelen JJ, JonkerHouben N, Schrander-Stumpel CT, Curfs LM: Different distribution of the genetic subtypes of the Prader-Willi syndrome in the elderly. Eur J Hum Genet 2010; 18: 993-998.

33. Holland A, Whittington J, Cohen O, Curfs L, Delahaye F, Dudley O, Horsthemke B, Lindgren AC, Nourissier C, Sharma N, Vogels A: The European Prader-Willi Syndrome Clinical Research Database: an aid in the investigation of a rare genetically determined neurodevelopmental disorder. J Intellect Disabil Res 2009; 53: $538-547$. 


\title{
CHAPTER 6
}

\author{
DEMENTIA IN A WOMAN WITH \\ PRADER-WILLI SYNDROME
}

Sinnema M, Schrander-Stumpel CTRM, Verheij HEG, Meeuwsen M, Maaskant MA, Curfs LMG

Eur J Med Genet 2010;53:145-148 


\section{ABSTRACT}

We report on a 58-year-old woman with Prader-Willi syndrome (PWS) and dementia. This case report illustrates a new research area in older adults with PWS. Dementia might be associated with PWS. In the case of dementia, more clinical studies are warranted to observe whether premature Alzheimer changes or indications of other dementia forms indeed occur more prevalent in people with PWS. 


\subsection{INTRODUCTION}

Prader-Willi syndrome (PWS) is a genetic disorder and results from the absence of the paternal part of the chromosome 15q11-q13 region. Several mechanisms can cause this absence. About $75 \%$ of the people with PWS have a deletion in the paternally derived 15q11-q13 region, the remaining subjects have a maternal uniparental disomy (UPD; $20-25 \%$ ) or an imprinting defect $(1 \%)^{1,2}$.

The ageing process in people with intellectual disabilities (ID) has been topic of interest in the recent years. Compared to people without intellectual disabilities ageing specific conditions occur more often and, in general, they appear earlier in life ${ }^{3-8}$. Dementia is one of these ageing specific conditions. Persons with Down syndrome are known to have an increased risk to develop dementia of Alzheimer's type ${ }^{6,9-12}$. Less attention has been paid, however, to the risk of dementia in other specific genetic syndromes associated with ID such as PWS.

We report on a case of an older woman with PWS who presented with findings highly suggestive of dementia.

\subsection{CLINICAL REPORT}

The 58 year-old woman had a genetically confirmed diagnosis of PWS due to a uniparental disomy of chromosome 15. She has moderate ID. She used to have good verbal capacities and even had writing and reading skills. Although she already had an obsession for food as a child, she had a normal weight in her youth because the food access was closely supervised. She became obese from the age of 17 . At that time she had a first psychosis and after hospitalization for two years, because of these psychiatric problems, she went to a residential home. Severe mood fluctuations and psychotic episodes were present all her further life, for which she used several sorts of psychiatric medication: antipsychotics, antidepressants and mood stabilizing agents.

Psychotic episodes during her adult life were characterized by optic and acoustic hallucinations, delusions (related to insufficiency, religion and fear), aggression, increase of obsessive behavior, increase of food obsession, motor agitation. She was also diagnosed with a bipolar disorder. She suffered from mood swings. On the one hand she could be good-tempered, adorable, humoristic, interested in other people. On the other hand, in bad times, she could be depressed, compelling, fierce and accusatory.

From the age of 40 , physical and mental deterioration seemed to start. Her movements became slower and she had less energy during the days. At the 
age of 50 , both of her parents and an older sister died within a couple of months. At that time her ageing process accelerated. She started dragging her left leg and walking more slowly. More and more she needed help in her ADL (Activities of Daily Living). Her interest in food became less obvious and she showed less compulsive behaviour. From the age of 56 , she became almost completely dependent of professional support. She became urinary and fecal incontinent and lost the ability to walk. She developed contractures of her fingers. She was restless during nights and sleepy during the day. She showed periods of maladaptive behaviour like screaming, irritability and aggression. At present (early 2009) she is wheelchair bound and sleeps frequently during the day. Her behaviour calmed down. She only uses single words when speaking. Most of the time she is unresponsive to her environment.

\subsection{METHODS AND RESULTS}

Diagnosis of dementia in people with ID is complex. Evidence of progressive deterioration in an individual's level of functioning is needed in order to diagnose dementia ${ }^{13}$. Thereby, other treatable explanations for changes in functioning, like sensory impairments, depression, intoxications and delirium, have to be excluded.

\section{Medical evaluation}

A thorough medical evaluation was performed in order to find possible treatable causes for her decline. Visus controls revealed a high myopia and mild cataract. Her glasses seemed to be sufficient. She is known to have mild hearing loss on both sides. Hypothyroidia, diabetes mellitus and dehydration were excluded by laboratory testing. A CT-scan of the brain revealed no abnormalities. All psychiatric medication has been phased out at present, except for a low dosage of pipamperone (Dipiperon ${ }^{\circledR}$ ) a day, without restart of the psychotic episodes. Neurological and psychiatric consultations did not reveal new diagnoses to explain her decline in functioning like depression or delirium.

\section{Decline in functioning was measured on the following scales}

$S R Z$

The Social Functioning Scale for ID, $(S R Z)^{14}$ is a validated Dutch scale for the level of social functioning. The SRZ consists of 31 items, divided into four subscales: Self Help, Communication, Persistence, and Social Skills. Possible SRZ standard scores are 3-, 3, 4, 5, 6, 7, 8, 9, 9+, indicating poor to good 
social functioning. Table 6.1 shows gradual decline on all SRZ subscales between the ages 47 and 58 years.

Table 6.1 Standard scores of the client on SZR subscales at consecutive ages

\begin{tabular}{lccccccc}
\hline $\begin{array}{l}\text { Age at testing/ } \\
\text { SRZ-standard scores }\end{array}$ & 47 years & 52 years & 53 years & 55 years & 56 years & 57 years & 58 years \\
SRZ subscale & 7 & 6 & 5 & $3-$ & 3 & $3-$ & 3 \\
\hline Self Help & 9 & 7 & 7 & 6 & 7 & 5 & 5 \\
Communication & 6 & 5 & 4 & 3 & 3 & 3 & 3 \\
Persistence & 7 & 6 & 5 & 3 & 3 & 4 & 3 \\
Social Skills & $\mathbf{8}$ & $\mathbf{6}$ & $\mathbf{5}$ & $\mathbf{4}$ & $\mathbf{4}$ & $\mathbf{3}$ & $\mathbf{3}$ \\
Total & & &
\end{tabular}

\section{VABS}

The Vineland Adaptive Behaviour Scales (VABS) ${ }^{15}$ is used to measure adaptive behaviour. The subscales include Communication, Daily Living Skills, Socialisation and Motor. The VABS scores (Table 6.2) show that the woman deteriorated substantially on Communication skills, Daily living skills, Socialization and Motor skills between the age of 53 and 58 .

Table 6.2 VABS scores of the client at consecutive ages

\begin{tabular}{lrc}
\hline Age at testing/VABS-scores & 53 years & 58 years \\
VABS subscale & & \\
\hline Communication & $4 ; 10$ years & $1 ; 9$ years \\
Daily Living Skills & $1 ; 6$ years & 0,8 years \\
Socialisation & $4 ; 7$ years & $1 ; 4$ years \\
Motor & $1 ; 2$ years & $0 ; 8$ years \\
\hline
\end{tabular}

\section{Signs of dementia was rated on the following scale}

\section{$D S D S$}

The Dutch revision of the Dementia Scale for Down Syndrome of Gedye ${ }^{16}$, was used $^{17}$. Validity and reliability of this scale are sufficient. The DSDS consists of 60 items, and is a diagnostic instrument for dementia in persons with ID. The scores indicate absence or presence of dementia, and gives qualitative indications for the four stages of dementia (early, middle, late, very late). It also focuses on differential diagnoses of dementia e.g. depression, hypothyroidism, visual and hearing impairment. 
Dementia is likely if the number of present features in questions of dementia stage 1 is $\geq 8$, or score on dementia stage 1 and 2 is $\geq 10$. Indicative for early dementia is a score of $\geq 17$ on dementia stage 1 and 2 domains. Indicative for middle stage dementia is a score of $\geq 7$ on dementia stage 3 domain. Indicative for late stage dementia is a score of 3 items on dementia stage on dementia stage 4 domain.

The scores of the woman on the DSDS also indicate dementia (Table 6.3). In conclusion functional deterioration on all domains of the SRZ and VABS was assessed. Scores on the DSDS were indicative for the presence of dementia in the very late stage. Possible differential diagnoses were excluded.

Table 6.3 Scores on DSDS of the client at age 58

\begin{tabular}{lc}
\hline DSDS stages (number of items) & Number of positive scores \\
\hline Dementia stage 1 (20 items) & 12 \\
Dementia stage 2 (20 items) & 11 \\
Dementia stage 3 (15 items) & 7 \\
Dementia stage 4 (5 items) & 3 \\
Total (60 items) & 33 \\
\hline
\end{tabular}

\subsection{DISCUSSION}

We report on a case of an older woman with PWS who presented with findings highly suggestive of dementia.

\section{Ageing in persons with ID}

Life expectancy of persons with ID has increased substantially during the last decades due to improvements in medical care and living circumstances. This results in increasing numbers of elderly adults with $\mathrm{ID}^{18,19}$. Ageing is related to age-related problems like sensory impairments, heart and vascular diseases, joint problems and dementia.

\section{Dementia}

Dementia is a clinical state characterized by loss of function in multiple cognitive domains. The most commonly used criteria for diagnoses of dementia is the DSM-IV-TR ${ }^{20}$ and the ICD-10 ${ }^{21}$. Diagnostic features include: memory impairment and at least one of the following: aphasia, apraxia, agnosia, disturbances in executive functioning. In addition, the cognitive impairments must be severe enough to cause impairment in social and occupational functioning. Importantly, the deterioration must represent a decline from a 
previously higher level of functioning. Finally, the diagnosis of dementia should not be made if the cognitive deficits occur exclusively during the course of a delirium. There are many different types of dementia. Some of the major disorders causing dementia are: degenerative diseases (e.g., Alzheimer's Disease, Pick's Disease), vascular dementia, anoxic dementia, traumatic dementia, infectious dementia (e.g., Creutzfeldt-Jakob Disease), toxic dementia.

In the general European population $6,4 \%$ of the people suffer from dementia. The prevalence of dementia increases with age (0.8\% in the group age 65-69 years and $28.5 \%$ at age 90 years and older). Alzheimer's disease is the most prevalent cause of dementia ${ }^{22}$. Risk factors for developing dementia include age, positive family history and risk factors associated with cardiovascular diseases like hypertension, atherosclerosis, type II diabetes mellitus and smoking.

\section{Dementia in persons with ID}

In persons with ID, dementia is as prevalent as it is in the general population ${ }^{23}$ but presentation can be very different. Information on dementia in specific syndromes is scarce ${ }^{6}$. In people with Down's syndrome dementia is more prevalent and presents at a relatively young age. At obduction the neuropathological changes of Alzheimer's disease are present in almost 100\% of the older $(40+)$ persons with Down syndrome. However, only about $17 \%$ of the people with Down syndrome above the age of 45 show signs of Alzheimer dementia in daily life ${ }^{24}$.

There are indications that dementia presentation may differ in those with and without Down Syndrome (DS) ${ }^{25}$. Therefore it is important to consider the population with and without DS separately. In a UK study, 26 non-DS dementia cases were reported by caregivers ${ }^{26}$. The most common presenting symptoms were general deterioration in functioning $(50 \%)$, followed by behavioural or emotional change $(15 \%)$. Deterioration in memory and other cognitive functions were less prominent in the early stages of the disorder. Other signs include symptoms of depression such as lack of energy, low mood and disturbed sleep, persecutory delusions and auditory hallucinations, or delirium; while late stage symptoms such as urinary incontinence, difficulty in walking and faecal incontinence were common ${ }^{25,27}$.

\section{Diagnostic evaluations}

In practice, the first evidence of decline in persons with ID is usually noticed by the caregivers ${ }^{28}$. In general, caregivers provide most of the information for the detailed diagnostic assessment. Ideally information from multiple caregivers 
from a variety of situations (e.g. living, working) should be gathered for a complete overview of the person's functioning. Diagnosis of dementia in adults with ID requires changes of baseline functioning, which exceeds that of normal ageing. Normative ageing results in certain sensory, physical and behavioural changes. To understand pathological changes it is important to know the differences between these normative changes in person with ID and changes that result from disease or other pathological processes ${ }^{29}$. The clinical presentation of dementia may be confused with other conditions such as visual and hearing problems, hypothyroidia, medicine intoxications, delirium, depression, normal pressure hydrocephalus and internal diseases like feeding deficiencies, diabetes mellitus and dehydration. These reasons for decline might be treatable and reversible ${ }^{29}$. Significant life events such as bereavement or changes in living or work circumstances may also result in cognitive or behaviour changes that could be wrongly attributed to dementia. Diagnostic evaluation should therefore include a medical, cognitive and functional assessment.

In our patient we should also distinguishing the clinical characteristics of dementia from chronic psychosis. Our patient suffered from psychiatric problems during adult age (bipolar disorder and psychosis). Symptoms of these psychiatric episodes differed from the clinical picture of decline from the age of 50 years. During psychoses she showed, besides the typical hallucinations and delusions, an increased interest in food and increased obsessive-compulsive behavior. During the decline from the age of 50 years her interest in food became less obvious and she showed less obsessive-compulsive behavior. The main characteristic of this process was her functional decline in ADL and physical well-being (e.g. losing continence and ability to walk). She became more and more dependent of professional support. Besides, during recent years almost all psychiatric medication has been faded out, without a restart of psychotic symptoms like hallucinations, delusions, aggression and increase of obsessive behavior which she showed before. The functional decline continued continuously. In our opinion this underlines the diagnosis of dementia instead of chronic psychosis.

To get insight in the possible causes of changes in behaviour, it is necessary to compare the present and previous level of functioning. A baseline screening, including cognitive, health and functional assessment, is advisable. International guidelines advice to start screening in persons with ID beginning at the age of 40 years in individuals at increased risk for premature ageing (i.e., Down syndrome, severe/profound ID), and beginning at age of 50 years in others. Longitudinal follow-up of these assessments (at least yearly) are important to monitor the ageing process or the stage of dementia ${ }^{29}$. 


\section{Ageing in Prader-Willi syndrome}

The knowledge regarding PWS and age-related characteristics is mainly focused on child- and young adulthood. PWS is characterized by severe hypotonia and feeding problems in early infancy. In later childhood and adolescence this is followed by hyperphagia and, without any dietary instructions, extreme obesity ${ }^{1}$. In general, individuals have mild to moderate $I \mathrm{I}^{30}$. Adolescence and adulthood are dominated by health problems secondary to obesity, including diabetes mellitus, respiratory problems, obstructive sleep apnoea, hypertension and cardiovascular problems ${ }^{2,31,32}$. Individuals with PWS can show significant maladaptive behaviour and emotional characteristics including temper tantrums, inappropriate social behaviour, automutilation (skin picking), stubbornness, mood lability, impulsivity, depression, anxiety, obsessive-compulsive symptoms and autism spectrum disorder ${ }^{2,33-35}$. About $10 \%$ of the adult subjects develop major psychiatric problems, ranging from depression to obsessive-compulsive and psychotic episodes ${ }^{33,36-38}$.

Young adults in their twenties show the highest levels of maladaptive and compulsive behaviour ${ }^{39}$. Subjects in their thirties however, seem to 'mellow' behaviourally and show much less destructive, food-seeking, impulsive behaviour than younger adults, and they also have higher rates of under activity, fatigue and withdrawal ${ }^{39,40}$. So far, not much is known about characteristics of older adults with PWS and the ageing process. Dementia in PWS has not been reported in literature.

\section{Future recommendations}

The presently reported woman illustrates a new research area in older adults with PWS. In order to get a better understanding of the ageing process, possible premature ageing and the prevalence of dementia in persons with PWS, more studies are necessary. The association between PWS and dementia could of course be coincidental. However, nowadays some persons with PWS will reach their fifties, sixties or even seventies. We hypothesize deterioration in many elderly from the age of about 40 years.

Yearly dementia screening in the PWS population is advisable and should start at latest from the age of 50 years. In the case of dementia, study of brain material is warranted to observe whether premature Alzheimer changes or indications of other dementia forms indeed occur more prevalent in people with PWS. 


\section{REFERENCES}

1. Holm VA, Cassidy SB, Butler MG, Hanchett JM, Greenswag LR, Whitman BY, Greenberg F: Prader-Willi syndrome: consensus diagnostic criteria. Pediatrics 1993; 91: 398-402.

2. Cassidy SB: Prader-Willi syndrome. J Med Genet 1997; 34: 917-923.

3. Maaskant MA: Mental handicap and ageing. Thesis Maastricht University. Dwingeloo: Kavanah. 1993.

4. Van Schrojenstein Lantman-de Valk HM, Metsemakers JF, Haveman MJ, Crebolder HF: Health problems in people with intellectual disability in general practice: a comparative study. Fam Pract 2000; 17: 405-407.

5. Van Schrojenstein Lantman-de Valk HMJ: Health problems in people with intellectual disability. Aspects of morbidity in residential settings and in primary health care. Thesis Maastricht University. Maastricht: UPM. 1998.

6. Strydom A, Shooshtari S, Lee L, Raykar V, Torr J, Tsiouris J, Jokinen N, Courtenay K, Bass N, Sinnema M, Maaskant M: Dementia in older adults with Intellectual Disabilities - epidemiology, presentation and diagnosis. Retrieved on March 18 2010 from: http://www.iassid.org/pdf/dementia_iassid_report_fin[1].pdf.

7. Janicki MP, Davidson PW, Henderson CM, McCallion P, Taets JD, Force LT, Sulkes SB, Frangenberg E, Ladrigan PM: Health characteristics and health services utilization in older adults with intellectual disability living in community residences. J Intellect Disabil Res 2002; 46: 287-298.

8. Lifshitz $\mathrm{H}$, Merrick J: Aging among persons with intellectual disability in Israel in relation to type of residence, age, and etiology. Res Dev Disabil 2004; 25: 193-205.

9. Schupf N, Sergievsky GH: Genetic and host factors for dementia in Down's syndrome. Br J Psychiatry 2002; 180: 405-410.

10. Tyrrell J, Cosgrave M, McCarron M, McPherson J, Calvert J, Kelly A, McLaughlin M, Gill M, Lawlor BA: Dementia in people with Down's syndrome. Int J Geriatr Psychiatry 2001; 16: 1168-1174.

11. Burt DB, Loveland KA, Primeaux-Hart S, Chen YW, Phillips NB, Cleveland LA, Lewis KR, Lesser J, Cummings E: Dementia in adults with Down syndrome: diagnostic challenges. Am J Ment Retard 1998; 103: 130-145.

12. Zigman WB, Schupf N, Devenny DA, Miezejeski C, Ryan R, Urv TK, Schubert R, Silverman W: Incidence and prevalence of dementia in elderly adults with mental retardation without down syndrome. Am J Ment Retard 2004; 109: 126-141.

13. Aylward EH, Burt DB, Thorpe LU, Lai F, Dalton A: Diagnosis of dementia in individuals with intellectual disability. J Intellect Disabil Res 1997; 41: 152-164.

14. Kraijer DW, Kema GN: Sociale redzaamheidsschaal voor zwakzinnigen : SRZ (SRZ), Lisse: Swets Test Services (STS), 1994.

15. Sparrow SS, Balla DA, Cicchetti DV: The Vineland adaptive behavioral scales Circle Pines, MN: America Guidance Service, 1984.

16. Gedye A: Dementia Scale for Down Syndrome, Vancouver, 1995.

17. Maaskant M, Hoekman J, Lansbergen M: Assessing validity and reliability of the Dementia Scale for Down Syndrome (abstract). Journal of Intellectual Disability Research 2008; 52: 647.

18. Patja K, livanainen M, Vesala H, Oksanen H, Ruoppila I: Life expectancy of people with intellectual disability: a 35-year follow-up study. J Intellect Disabil Res 2000; 44: 591-599. 
19. Maaskant MA, Gevers JPM, Wierda H: Mortality and life expectancy in Dutch residential centres for individuals with intellectual disability, 1991-1995. Journal of Applied Research in Intellectual Disabilities 2002; 15: 202-212.

20. DSM-IV-TR. Diagnostic and statistical Manual of Mental Disorders, American Psychiatric Association 2000.

21. ICD-10. International Statistical Classification of Diseases and Related Health Problems World Health Organisation, 1994.

22. Lobo A, Launer LJ, Fratiglioni L, Andersen K, Di Carlo A, Breteler MM, Copeland JR, Dartigues JF, Jagger C, Martinez-Lage J, Soininen H, Hofman A: Prevalence of dementia and major subtypes in Europe: A collaborative study of populationbased cohorts. Neurologic Diseases in the Elderly Research Group. Neurology 2000; 54: S4-9.

23. Janicki MP, Dalton AJ: Prevalence of dementia and impact on intellectual disability services. Ment Retard 2000; 38: 276-288.

24. Coppus A, Evenhuis H, Verberne GJ, Visser F, van Gool P, Eikelenboom P, van Duijin C: Dementia and mortality in persons with Down's syndrome. J Intellect Disabil Res 2006; 50: 768-777.

25. Cooper SA, Prasher VP: Maladaptive behaviours and symptoms of dementia in adults with Down's syndrome compared with adults with intellectual disability of other aetiologies. J Intellect Disabil Res 1998; 42: 293-300.

26. Strydom A, Livingston G, King M, Hassiotis A: Prevalence of dementia in intellectual disability using different diagnostic criteria. Br J Psychiatry 2007; 191: 150-157.

27. Evenhuis HM: The natural history of dementia in ageing people with intellectual disability. J Intellect Disabil Res 1997; 41: 92-96.

28. Aylward EH, Burt DB, Thorpe LU, Lai F, Dalton AJ. Diagnosis of Dementia in Individuals with Intellectual Disability. Washington, American Association on Mental Retardation, 1995.

29. Janicki MP, Heller T, Seltzer GB, Hogg J: Practice guidelines for the clinical assessment and care management of Alzheimer's disease and other dementias among adults with intellectual disability. AAMR-IASSID Workgroup on Practice Guidelines for Care Management of Alzheimer's Disease among Adults with Intellectual Disability. J Intellect Disabil Res 1996; 40: 374-382.

30. Curfs LM, Fryns JP: Prader-Willi syndrome: a review with special attention to the cognitive and behavioral profile. Birth Defects Orig Artic Ser 1992; 28: 99-104.

31. Butler JV, Whittington JE, Holland AJ, Boer H, Clarke D, Webb T: Prevalence of, and risk factors for, physical ill-health in people with Prader-Willi syndrome: a population-based study. Dev Med Child Neurol 2002; 44: 248-255.

32. O'Donoghue FJ, Camfferman D, Kennedy JD, Martin AJ, Couper T, Lack LD, Lushington K, McEvoy RD: Sleep-disordered breathing in Prader-Willi syndrome and its association with neurobehavioral abnormalities. J Pediatr 2005; 147: 823-829.

33. Descheemaeker MJ, Vogels A, Govers V, Borghgraef M, Willekens D, Swillen A, Verhoeven W, Fryns JP: Prader-Willi syndrome: new insights in the behavioural and psychiatric spectrum. J Intellect Disabil Res 2002; 46: 41-50.

34. Greaves N, Prince E, Evans DW, Charman T: Repetitive and ritualistic behaviour in children with Prader-Willi syndrome and children with autism. J Intellect Disabil Res 2006; 50: 92-100.

35. Veltman MW, Craig EE, Bolton PF: Autism spectrum disorders in Prader-Willi and Angelman syndromes: a systematic review. Psychiatr Genet 2005; 15: 243-254. 
36. Vogels A, De Hert M, Descheemaeker MJ, Govers V, Devriendt K, Legius E, Prinzie P, Fryns JP: Psychotic disorders in Prader-Willi syndrome. Am J Med Genet A 2004; 127A: 238-243.

37. Steinhausen HC, Eiholzer U, Hauffa BP, Malin Z: Behavioural and emotional disturbances in people with Prader-Willi Syndrome. J Intellect Disabil Res 2004; 48: 47-52.

38. Boer H, Holland A, Whittington J, Butler J, Webb T, Clarke D: Psychotic illness in people with Prader Willi syndrome due to chromosome 15 maternal uniparental disomy. Lancet 2002; 359: 135-136.

39. Dykens EM: Maladaptive and compulsive behavior in Prader-Willi syndrome: new insights from older adults. Am J Ment Retard 2004; 109: 142-153.

40. Descheemaeker MJ, Govers V, Vermeulen P, Fryns JP: Pervasive developmental disorders in Prader-Willi syndrome: the Leuven experience in 59 subjects and controls. Am J Med Genet A 2006; 140: 1136-1142. 


\title{
CHAPTER 7
}

\author{
AGEING IN PRADER-WILLI SYNDROME: \\ TWELVE PERSONS OVER THE AGE OF 50 YEARS
}

Sinnema M, Schrander-Stumpel CTRM, Maaskant MA, Boer H, Curfs LMG Submitted 


\section{ABSTRACT}

\section{Introduction}

The life expectancy of persons with Prader-Willi syndrome (PWS) has increased in recent years. Because of the paucity of reports on older persons with PWS, the natural history, the onset and type of age related problems are poorly understood. Knowledge of the syndrome specific age related health risk factors can lead to enhanced prevention or early diagnosis of potentially impairing conditions.

\section{Method}

Twelve persons with a genetically confirmed diagnosis of PWS aged over 50 years are described (4 deletion; 8 mUPD). Data on physical, behavioural, psychiatric and ageing characteristics were collected through semi-structured interviews with the individuals with PWS and their main carers.

\section{Results}

Cardiovascular diseases, diabetes, dermatological and orthopedic problems were common physical complaints in older people with PWS. Functioning in ADL (Activities of Daily Living), psychological functioning, physical functions and care dependence were substantially worse in the older age group (50+) compared to the control group (18-49 years). Seven out of eight persons with mUPD had a history of psychiatric illness. The behaviour in the older age group was characterized by more bizarre speech, gorging food, exposing oneself in public, hallucinating and poor self-esteem when compared with the control group. Behavioural problems were not less reported in the older age group.

\section{Discussion}

Given the combination of age related physical morbidity, physical appearance, behavioural and psychiatric problems and functional decline in our cohort, we hypothesize that premature ageing occurs in PWS. The care for older people with PWS requires a lifespan approach that recognizes the presence, progression and consequences of specific morbidity. Special medical surveillance of people with PWS from 40 years onwards would ensure that intervention and support is offered with respect to specific areas of decline at the earliest possible time. 


\subsection{INTRODUCTION}

The life expectancy of people with intellectual disabilities (ID) in general, has increased substantially in recent years, resulting in increasing numbers of older adults with $I D^{1,2}$. Some specific syndromes have risks related to ageing, e.g. the increased risk for Alzheimer disease in people with Down syndrome ${ }^{3}$ and increased incidence of schizophrenia, infections, scoliosis and hernias in 22q11 deletion syndrome ${ }^{4}$. Information regarding ageing or longevity in other syndromes is difficult to find ${ }^{5}$.

The average age of people with Prader-Willi syndrome (PWS) is getting older. PWS is characterized by neonatal hypotonia, impaired sexual development, short stature, a propensity to severe obesity, and intellectual disabilities. Research on PWS has mainly focused on clinical characteristics in child- and early adulthood. Little is known about PWS at older age.

High morbidity in adults with PWS results in high mortality rates and a lower life expectancy than the general population ${ }^{6,7}$. Until recently, survival past the $5^{\text {th }}$ or $6^{\text {th }}$ decade was thought to be very unusual for persons with PWS. Reports on people with PWS above the age of 50 years are scarce. Greenswag ${ }^{8}$ reported on a 64-year-old person, Goldman ${ }^{9}$ on two individuals, aged 54 and 69 years, Carpenter ${ }^{10}$ on a 71 -year-old woman and Butler ${ }^{11}$ on a person of 68 years old.

Because of the paucity of reports on older persons with PWS, the natural history, onset and type of age related problems are not well known. However, knowledge of the syndrome specific age related health risk factors can lead to enhanced prevention or early diagnosis of potentially impairing conditions and thus may lead to improved quality of life of those concerned. Therefore we report data on twelve individuals aged 50 years and older with genetically confirmed diagnoses of PWS, specifically regarding physical and mental health, behaviour, skills and food related issues.

\subsection{METHOD}

\section{Procedure}

Persons with possible PWS were contacted through the Dutch Prader-Willi Parent Association and through intellectual disability physicians. Twelve individuals with a genetically confirmed diagnosis of PWS were 50 years and older. 


\section{Data collection}

Data on physical, behavioural and psychiatric characteristics were collected through semi-structured interviews with the individuals with PWS and their main carers (family and/or professional carers).

\section{Physical health problems and ageing characteristics}

The semi-structured interview included questions about physical health experienced over the participants' lifetime. If health problems were reported this led to further inquiries as to age at onset and treatment. No physical examinations were carried out apart from recordings of current height and weight. Medical data were retrieved from treating physicians.

\section{Observational Questionnaire Elderly Residents with ID}

The Observational Questionnaire Elderly Residents with ID (Observatielijst Ouderwordende Bewoners, $O O B)^{12}$ was used. The OOB is an instrument that assesses functioning, behaviour and care dependency; it has to be completed by a caregiver familiar with the client. The OOB has four subscales: (1) activities of daily living (ADL), (2) psychological functioning, (3) (inappropriate) reactions, and (4) physical functions and care dependence. The range for the scale is $0 / 1$ to 4 : the higher the score the better the functioning. The reliability and validity of the OOB have been demonstrated to be satisfactory to good ${ }^{12}$.

\section{Individual deterioration}

To determine decline in functioning at an individual level, questions about deterioration in functioning were added. We also asked at what age any changes started.

\section{Screening for psychiatric illnesses}

All individuals were screened for current or previous psychiatric illness (see Sinnema et al. $2011^{26}$ ). A number of questionnaires were used for additional information on psychiatric symptoms including the Developmental Behaviour Checklist for Adults (DBC-A $)^{13}$ and the Psychiatric Assessment Schedule for Adults with Developmental Disabilities (PAS-ADD) $)^{14}$. Medical data on psychopathology were retrieved from general practitioners, intellectual disability physicians, and psychiatrists. Case vignettes were independently rated according to ICD-10 criteria by two senior consultant psychiatrists specializing in ID who were blind to the participants' genetic status. Case vignettes were rated into the following diagnosis groups: non-psychotic depressive illness, depressive psychosis, bipolar illness with psychotic symptoms and psychotic illness where affective symptoms were not prominent. 


\section{Developmental Behaviour Checklist for Adults (DBC- $A ;^{13}$ )}

This 107-item questionnaire was used to measure problem behaviour and to screen for psychiatric symptoms. It measures psychopathology at three levels: severity of overall behaviour and emotional disturbance (total behaviour problem score; TBPS); disturbance in six particular dimensions of psychopathology (six subscale scores derived from factor analysis); and level of disturbance of particular individual behaviours (107 items or symptoms). The questionnaire employs a 3 -point rating scale $(0=$ not true; $1=$ somewhat or sometimes true; $3=$ very true or often true). The carer-completed DBC-A has satisfactory psychometric properties ${ }^{15}$.

\section{Food Related Problem Questionnaire (FRPQ)}

The $F R P Q^{16}$ is a 16 -item questionnaire on food related problems, with three subscales (preoccupation with food, impairment of satiety and other foodrelated "challenging" behaviour). Each item is rated on a 7-point scale with responses ranging from $0=$ "never" to $6=$ "always". The FRPQ has sufficiently robust psychometric properties ${ }^{16}$.

\section{Genetic diagnosis}

Parents were asked whether genetic testing on PWS including genetic subtype had been undertaken previously. With permission of the carers, written confirmation on genetic diagnoses were requested from genetic centres and were received in all cases. In participants who did not have a confirmed genetic diagnosis $(n=5 / 12)$, genetic testing was performed.

\section{Control group}

The current study was part of a large study in the Netherlands on adults with PWS and ageing. Individuals aged 18 to 49 years were used as a control group.

\section{Statistical analyses}

SPSS (version 16.0) was used to analyze the data. To test whether differences in scores between the age group $<50$ years and the age group $\geq 50$ years were statistically significant, ANOVA and t-tests were performed. Differences within the 50-plus group were tested non-parametrically (Mann Whitney $U$ test), because of the small numbers. A $p$-value of 0.05 or less was regarded as statistically significant for all statistical tests. 


\subsection{RESULTS}

\section{Study population}

A total of 12 adults with PWS were included in this study, of whom five were male. Their mean age was 57.8 years (SD 6.2 years, range 50 to 66 years). All participants were genetically confirmed as having PWS: Four had paternal deletion and eight had mUPD. The mean age at which the genetic diagnosis of PWS was confirmed was 47.2 (SD 13.7, range 17 to 65). Eleven participants lived in institutional residential or community residential facilities; one participant lived with his elderly mother. The level of ID was: mild $(n=4)$, moderate $(n=6)$, severe $(n=2)$. The mean BMI was 31.5 (SD 5.0, range 23.4 to 37.1). The mean BMI in persons with a deletion (mean 35.5) was significantly higher than in persons with a mUPD (mean 29.5) (Mann-Whitney $U$ test: $p=0.03$ ). The mean maximum BMI they had reached during their lives was 36.5 (SD 5.5, range 23.6 to 44.4). Most persons $(n=7)$ were currently at their maximum BMI. Three persons smoked cigarettes, pipe or cigars. One woman died shortly after the data-collection of this study at the age of 65 because of pulmonary insufficiency and sputum stasis.

\section{Physical health problems}

Half of the study group $(n=6)$ suffered from diabetes mellitus. The mean age at time of the diagnosis was 41.6 years. The present mean BMI of the persons with and without diabetes mellitus did not differ significantly. Three persons also had a clinical diagnosis of hypertension. The mean age at time of the diagnosis of high bloodpressure was 51.5 years. Three individuals had a history of stroke at a mean age of 55.0 years. One man had severe kidney problems because of a congenital abnormality (bilateral duplication of the kidney and ureter system). One woman had a primary amenorrhoea. The remaining women had their menarche at a mean age of 23.8 years (range 18-31 years) and menopause at a mean age of 49.0 years (range $40-56$ years). Estrogen or growth hormone therapy was not used by participants in this cohort. One man was treated with testosterone injections. There were no reports of epilepsy or cancer in this study group. The prevalence of these and other physical morbidity is summarized in Table 7.1. Table 7.2 shows individual characteristics of the participants in relation with chronic conditions. 
Table 7.1 Prevalence of physical health problems in the older PWS-participants $(n=12)$

\begin{tabular}{llc}
\hline Tract & Physical health problems & Total prevalence $(\mathrm{n})$ \\
\hline Cardiovascular & Hypertension & $3 / 12$ \\
& Stroke & $3 / 12$ \\
Respiratory and sleep & Diabetes & $6 / 12$ \\
& Pneumonia & $3 / 12$ \\
Gastro-intestinal & Excessive daytime sleepiness & $8 / 12$ \\
& Constipation & $5 / 12$ \\
Genito-urinary & Reflux & $2 / 12$ \\
Endocrine & Anemia of unknown origin & $2 / 12$ \\
& Kidney problems & $1 / 12$ \\
Neurologic & Osteoporosis & $2 / 12$ \\
Orthopedic & History of any fracture & $6 / 12$ \\
& Primary amenorrhoea & $1 / 7$ \\
Dermatologic & Epilepsy & $0 / 12$ \\
& Scoliosis & $5 / 12$ \\
& Foot problems & $10 / 12$ \\
& Hip problems & $2 / 12$ \\
& Oedema & $9 / 12$ \\
& Erysipelas & $6 / 12$ \\
& Varices & $3 / 12$ \\
\hline
\end{tabular}

Table 7.2 Individual characteristics of the older PWS- participants in relation with chronic conditions $(n=12)$

\begin{tabular}{|c|c|c|c|c|c|c|c|c|c|c|c|c|c|}
\hline $\begin{array}{l}\text { Case } \\
\text { Characteristic }\end{array}$ & 1 & 2 & 3 & 4 & 5 & 6 & 7 & 8 & 9 & $10 \dagger$ & 11 & 12 & \\
\hline Age & 50 & 51 & 51 & 51 & 55 & 55 & 58 & 59 & 62 & 65 & 65 & 66 & \\
\hline Gender & q & $\hat{0}$ & $\hat{\sigma}$ & q & q & $\hat{\sigma}$ & q & q & $\hat{\jmath}$ & $q$ & q & $\hat{\jmath}$ & \\
\hline Genotype & UPD & UPD & Del & Del & Del & UPD & UPD & UPD & UPD & UPD & Del & UPD & \\
\hline BMI & 37.1 & 23.6 & 33.3 & 37.1 & 34.4 & 24.9 & 32.4 & 31.1 & 23.4 & 30.2 & 37.0 & 32.9 & \\
\hline No. drugs ${ }^{*}$ & 1 & 3 & 13 & 2 & 8 & 7 & 2 & 5 & 8 & 13 & 7 & 2 & \\
\hline Condtion & & & & & & & & & & & & & Total \\
\hline Diabetes & & & $x$ & & $x$ & $x$ & & $x$ & & $x$ & $x$ & & 6 \\
\hline Hypertension & & & $x$ & & $x$ & & & & & & $x$ & & 3 \\
\hline Stroke & & $x$ & & & & & & & $x$ & & $x$ & & 3 \\
\hline Pneumonia & & & $x$ & & & & & & $x$ & & $x$ & & 3 \\
\hline Mobility & & & & $x$ & & $x$ & $x$ & & & $x$ & $x$ & & 5 \\
\hline Psychiatry & $x$ & $x$ & & & & & $x$ & $x$ & $x$ & $x$ & & $x$ & 7 \\
\hline Kidney & & & $x$ & & & & & & & & & & 1 \\
\hline Total & 1 & 2 & 4 & 1 & 2 & 2 & 2 & 2 & 3 & 3 & 5 & 1 & \\
\hline
\end{tabular}

$\mathrm{X}=$ chronic condition is present in an individual; *No. drugs= number of prescribed drugs they are taking

\section{Observational Questionnaire Elderly Residents with ID (OOB)}

Functioning, behaviour and care dependency as measured by the OOB revealed worse functioning in the older than the younger group. The mean total 
score on the $O O B$ was significantly lower in the age group $\geq 50$ years (mean 93.6) compared with the control group $<50$ years (mean 106.2) (T-test; $p<0.01$ ). Differences between the age groups $<50$ years and $\geq 50$ years were statistically significant on the following subscales: ADL, psychological functioning, physical functions and care dependence (ANOVA, $p<0.05$ ), those in the older group scoring less favorable. Scores in the older group were significantly lower on the following items: personal hygiene (e.g. taking a bath or shower), dressing, eating, being ambulant, mobility, grooming, memory, orientation, sleeping difficulties, physical complaints, hearing, vision, dependency on medical care and care dependency (ANOVA, $p<0.05$ ). Table 7.3 shows the scores on the OOB items. Table 7.4 shows deterioration at individual level and age at which the decline in function started.

Table 7.3 Scores on OOB of the older PWS-study group $(n=12)$

\begin{tabular}{|c|c|c|c|}
\hline Subscales & Item & Severity & $\mathrm{n}$ \\
\hline \multirow[t]{25}{*}{$\mathrm{ADL}^{*}$} & \multirow[t]{3}{*}{ Personal hygiene* } & By caregivers & 7 \\
\hline & & By themselves, with control & 4 \\
\hline & & By themselves & 1 \\
\hline & \multirow[t]{3}{*}{ Toilet use } & By caregivers & 4 \\
\hline & & By themselves, with control & 2 \\
\hline & & By themselves & 6 \\
\hline & \multirow[t]{4}{*}{ Incontinence } & Urine and faeces incontinence & 1 \\
\hline & & Periods of incontinence & 2 \\
\hline & & Is placed on toilet regularly & 4 \\
\hline & & Continent & 6 \\
\hline & \multirow[t]{3}{*}{ Dressing* } & By caregivers & 3 \\
\hline & & By themselves, with little help & 4 \\
\hline & & By themselves & 5 \\
\hline & \multirow[t]{3}{*}{ Eating* } & By caregivers & 1 \\
\hline & & By themselves, with little help & 5 \\
\hline & & By themselves & 6 \\
\hline & \multirow[t]{4}{*}{ Ambulance* } & Wheelchair bound & 1 \\
\hline & & Walks with walking aids or rollator & 3 \\
\hline & & Walks with little help (e.g. walking stick) & 2 \\
\hline & & Walks without help & 6 \\
\hline & \multirow[t]{3}{*}{ Mobility* } & Does not transfer without others & 5 \\
\hline & & Transfer only inside living/working situation & 5 \\
\hline & & Transfer in- and outside living/working situation & 2 \\
\hline & \multirow{2}{*}{ Grooming* } & Does not care about appearance & 10 \\
\hline & & Cares about appearance & 2 \\
\hline \multirow{14}{*}{$\begin{array}{l}\text { Psychological } \\
\text { functioning* }\end{array}$} & \multirow[t]{2}{*}{ Communication } & Can mostly make something clear by spoken/sign language & 3 \\
\hline & & Can always make something clear by spoken/sign language & 9 \\
\hline & \multirow{2}{*}{ Accomplishing tasks } & Accomplishes tasks, sometimes with stimulation & 2 \\
\hline & & Accomplishes tasks without stimulation & 10 \\
\hline & \multirow[t]{4}{*}{ Memory* } & Not known & 1 \\
\hline & & Regularly problems with short-term memory & 2 \\
\hline & & Sometimes problems with short-term memory & 3 \\
\hline & & No problems with short- or long-term memory & 6 \\
\hline & \multirow[t]{3}{*}{ Reaction time } & Mostly slow and thoughtless & 3 \\
\hline & & Sometimes slow and thoughtless & 6 \\
\hline & & Never slow and thoughtless & 3 \\
\hline & \multirow{3}{*}{$\begin{array}{l}\text { Purposeful } \\
\text { behaviour }\end{array}$} & Behaviour seems frequently not purposeful & 2 \\
\hline & & Behaviour seems sometimes not purposeful & 5 \\
\hline & & Behaviour seems always purposeful & 5 \\
\hline
\end{tabular}




\begin{tabular}{|c|c|c|c|}
\hline Subscales & Item & Severity & $\mathrm{n}$ \\
\hline \multirow{20}{*}{$\begin{array}{l}\text { Inappropriate } \\
\text { behaviour }\end{array}$} & \multirow[t]{4}{*}{ Orientation* } & Does not move without help & 2 \\
\hline & & Orientates only in living situation & 6 \\
\hline & & Orientates in not daily situations & 1 \\
\hline & & Orientates in new situations & 3 \\
\hline & \multirow{3}{*}{$\begin{array}{l}\text { Interest in the } \\
\text { environment }\end{array}$} & Is sometimes interested in the environment & 2 \\
\hline & & Is frequently interested in the environment & 7 \\
\hline & & Is always interested in the environment & 3 \\
\hline & \multirow[t]{2}{*}{ Understanding } & Understands mostly what is made clear to him/her & 7 \\
\hline & & Understands always what is made clear to him/her & 5 \\
\hline & Inconsistent & Regularly shows inconsistent behaviour & 3 \\
\hline & \multirow[t]{2}{*}{ behaviour } & Sometimes shows inconsistent behaviour & 1 \\
\hline & & Never shows inconsistent behaviour & 8 \\
\hline & \multirow[t]{4}{*}{ Apathy } & Passive, without initiative & 1 \\
\hline & & Frequently passive, without initiative & 5 \\
\hline & & Sometimes passive, without initiative & 3 \\
\hline & & Active, shows initiative & 3 \\
\hline & \multirow[t]{4}{*}{ Adaptability } & Always difficulties in adapting to other caregivers & 2 \\
\hline & & Frequently difficulties in adapting to other caregivers & 4 \\
\hline & & Sometimes difficulties in adapting to other caregivers & 2 \\
\hline & & Never difficulties in adapting to other caregivers & 4 \\
\hline & \multirow[t]{3}{*}{ Irritation } & Frequently reacts irritated & 2 \\
\hline & & Regularly reacts irritated & 6 \\
\hline & & Sometimes reacts irritated & 4 \\
\hline & \multirow[t]{3}{*}{ Fear } & Frequently seems anxious/insecure & 1 \\
\hline & & Sometimes seems anxious/insecure & 7 \\
\hline & & Never seems anxious/insecure & 4 \\
\hline & \multirow[t]{3}{*}{ Restlessness } & Frequently seems restless & 1 \\
\hline & & Sometimes seems restless & 8 \\
\hline & & Never seems restless & 3 \\
\hline & \multirow[t]{3}{*}{ Agitation at night } & Mostly shows agitation at night & 1 \\
\hline & & Sometimes shows agitation at night & 5 \\
\hline & & Never shows agitation at night & 6 \\
\hline & \multirow{4}{*}{$\begin{array}{l}\text { Sleeping problems } \\
\text { at night* }\end{array}$} & Always sleeping problems at night & 2 \\
\hline & & Frequently sleeping problems at night & 1 \\
\hline & & Sometimes sleeping problems at night & 2 \\
\hline & & Never sleeping problems at night & 7 \\
\hline \multirow{19}{*}{$\begin{array}{l}\text { Physical } \\
\text { functioning* }\end{array}$} & \multirow[t]{2}{*}{ Appetite } & Regularly a bad appetite & 2 \\
\hline & & Good appetite & 10 \\
\hline & \multirow[t]{4}{*}{ Physical complaints } & Regularly & 3 \\
\hline & & Sometimes & 4 \\
\hline & & Occasionally & 2 \\
\hline & & Seldom or never & 3 \\
\hline & \multirow[t]{4}{*}{ Constipation } & Always & 2 \\
\hline & & Frequently & 3 \\
\hline & & Sometimes & 1 \\
\hline & & Never & 6 \\
\hline & Epilepsy & None & 12 \\
\hline & \multirow[t]{2}{*}{ Hearing* } & Minor hearing loss & 3 \\
\hline & & No hearing loss & 9 \\
\hline & \multirow[t]{3}{*}{ Vision* } & Poor vision & 4 \\
\hline & & Minor vision problems, compensated by glasses & 5 \\
\hline & & No vision problems & 3 \\
\hline & Dependency on & Monthly visits MD & 5 \\
\hline & medical care* & Periodical controls by MD & 5 \\
\hline & & Never/hardly visits MD & 2 \\
\hline Care & Care dependency* & Need for intense help and nursing & 2 \\
\hline dependence* & & Need for control, care and/or treatment & 9 \\
\hline & & Almost independent & 1 \\
\hline
\end{tabular}

* Statistically siginificant compared with age group $<50$ years (ANOVA, $p<0.05$ ) 
Table 7.4 Prevalence of deterioration characteristics and age at start of the older PWS-study group $(n=12)$

\begin{tabular}{lccc}
\hline Characteristic & $\mathrm{n}$ & $\begin{array}{r}\text { Mean age at start } \\
\text { deterioration }(\mathrm{yrs})\end{array}$ & Age range (yrs) \\
\hline Mobility & 10 & 48 & $30-60$ \\
Hearing & 0 & - & - \\
Vision & 2 & 50 & $47-53$ \\
Coordination & 3 & 48 & $40-55$ \\
Dressing self & 4 & 54 & $47-60$ \\
Feeding self & 2 & 51 & $40-61$ \\
Washing/grooming self & 4 & 55 & $47-61$ \\
Memory & 2 & 57 & $50-64$ \\
Thought processes & 1 & 40 & - \\
Understanding other people & 1 & 40 & - \\
Making decisions or planning & 1 & 40 & - \\
Social behaviour & 2 & 49 & $45-53$ \\
Orientation & 1 & 53 & - \\
Continence & 4 & 59 & $53-64$ \\
\hline
\end{tabular}

\section{Psychiatric illness}

No psychopathology was present in the persons with PWS due to a deletion $(n=4)$. In individuals with mUPD the following consensus psychiatric diagnoses were established: bipolar disorder with psychotic symptoms $(n=3)$, psychotic illness $(n=2)$, depressive illness without psychotic symptoms $(n=1)$ and bipolar disorder $(n=1)$. One person with a mUPD did not have a history of psychopathology. All persons with PWS due to mUPD $(n=8)$ used psychotropic medication. One woman presented with symptoms highly suggestive of dementia ${ }^{17}$.

\section{Behaviour (DBC-A)}

Problem behaviour as measured by the DBC-A was frequent in elderly with PWS. The differences between age $<50$ years and age $\geq 50$ years on total score of the DBC-A and the subscales however, were not statistically significant. On item level, the older individuals (50+ years) scored significantly higher on bizarre speech, gorging food, masturbating or exposing oneself in public and hallucinating. Scores on lack of self-confidence or poor self-esteem on the other hand were statistically significant lower.

\section{Eating behaviour (FRPQ)}

The differences between age $<50$ years (mean 41.3 ) and age $\geq 50$ years (mean 38.9) on total score of the FRPQ and the subscales on preoccupation with food, impairment of satiety and composite negative behaviour, were not statistically significant. 


\subsection{DISCUSSION}

We present the first cohort ever published of older people with PWS (50 years and older). Information on various health aspects were collected systematically. More research is needed on older people with PWS, because of the recognition that age-related health problems of later life stages are of particular significance. The results of this study can be helpful in the health care management of older individuals with PWS.

\section{Characteristics of the study group and life expectancy}

The cause of death in adults with PWS is usually reported as "obesity related" ${ }^{\prime \prime, 18,19}$. The characteristics of the study population we describe could provide clues about factors influencing life expectancy in PWS. All previously published cases of PWS aged over 50 years until now $(n=5)$, have been female ${ }^{8-11}$. In our cohort, $5 / 12$ participants were male and we therefore hypothesize that the fact that all previously reported cases were female may have been a chance finding ${ }^{8-11}$. Compared with the younger age group in this cohort and other studies ${ }^{20,21}$ we found relatively more individuals in the moderate to severe ID range (mild $n=4$, moderate $n=6$ and severe $n=2$ ). We hypothesize that more severe ID may have resulted in a greater need for structured residential settings, and that this could have contributed to their longevity because of better weight management and prevention of serious medical complications. Most individuals in our cohort were obese $(n=9 / 12)$. People with mUPD had a lower mean BMI than persons with PWS due to a deletion. Obesity related morbidity however, like diabetes and hypertension, was prevalent in obese persons as well as in persons with a healthy weight status. Obesity and related morbidity seems to be an important factor in health at older age, but a healthy weight is not a safeguard for developing syndrome specific morbidity. Finally, there was a predominance of persons with PWS due to mUPD (8/12) in the age group $\geq 50$ years. This may be explained by a difference in survival of the genetic subtypes. Further studies on causes of death and on survival in relation with genetic subtypes of PWS are highly needed.

\section{Genetic diagnosis}

Older people with Prader-Willi syndrome may not have been recognized as having the disorder. In our study, 5 out of 12 older individuals had not been given a confirmed genetic diagnosis prior to the study. Although the definitive diagnosis of PWS is currently made by genetic testing, clinical diagnosis criteria continue to be of importance, not least in the identification of appropriate persons for testing. Diagnostic criteria were first proposed by Holm et al. ${ }^{22}$. The clinical diagnosis of PWS is based on core features such as 
hypotonia, failure to thrive and undescended testes in boys. However, this important clinical information is not always available later in life, due to the death of informants (family members). Therefore, clinical diagnosis criteria should be adjusted in the older age groups. Genetic testing for PWS in adults should also be considered in case of a less marked phenotype, characterized by behavioural and psychiatric problems in addition to obesity and delayed or incomplete puberty ${ }^{23,24}$. Health care professionals should be familiar enough with the characteristics of the syndrome to recognize it in adults.

\section{General health}

Ageing in people with ID, comes together with physical and mental changes ${ }^{5}$. Many of the changes are not caused by the ageing process, but by disease, the environment and lifestyles ${ }^{25}$. Some of the changes caused by these factors may be prevented or slowed down by taking action. Caregivers should be provided with ongoing information regarding healthy living, such as nutrition, oral hygiene and substance abuse ${ }^{23}$. People who live an inactive lifestyle, lose muscle mass and might gain weight as they age. In PWS it is particularly important to maintain mobility into older age.

\section{Physical health problems}

Health care providers for older adults with PWS should be aware that adult (and older) age onset medical conditions are common in this population. They should be alert for the presence of cardiovascular diseases, diabetes, dermatological and orthopedic problems. Sleep problems and osteoporosis are likely to be underreported and deserve special attention. Typical PWS characteristics such as temperature instability, the reduced ability to vomit and a high pain threshold may mask the initial symptoms of illness ${ }^{22}$. In case of unexplained serious illness, a respiratory infection should be ruled out. The diagnosis of pneumonia is frequently delayed in older adults with PWS because of the absence of fever and the course can be very detrimental. Low body temperature (e.g. after swimming), anemia, diabetic dysregulation and adverse reactions to medications should also be considered in case of medical problems in older people with PWS.

Presently, there is no research to suggest that preventative health practices that are recommended for the general population, throughout the lifespan, should be withheld from people with PWS ${ }^{25}$. Therefore, age appropriate screening protocols for conditions such as sensory impairment and various forms of cancer (with the possible exception of PAP smears in women without a history of sexual activity), should also be offered to adults with PWS. Based on our results, we have no indication that sensory impairment or cancer is 
more prevalent in PWS than in people with ID in general. However, the number of participants in our study was too small to draw robust conclusions.

\section{Functional decline}

In many adults with PWS, functional abilities deteriorated from the age of 40 years, as recalled by the participants' informants. Decline usually started with decrease in energy levels and lessening of mobility. They were in greater want of rest during the day. Deterioration on the domains of ADL, psychological functioning, physical functions and care dependence over the age of 50 are striking. Functional decline in older age warrants careful evaluation and followup over time. Undiagnosed psychopathology or physical morbidity can have an atypical presentation in people with PWS and should be ruled out or treated. Support in residential settings should be adjusted to fit the higher levels of care dependency, the different needs in the daycare program and diminishing mobility. Staff should be provided with knowledge on syndrome specific agerelated characteristics and should be trained on how to integrate this in existing practices.

\section{Behaviour and psychiatry}

Our results show that behavioural problems are major concerns in adults with PWS into old age. Psychiatric illness is common in our cohort and likewise there is an overlap between behavioural symptoms and psychiatric disorders. As expected, our results indicate that PWS caused by MUPD is associated with a high risk of developing psychiatric illness. Psychiatric symptoms usually started at young adult age and had a cycloid course through adulthood ${ }^{26-28}$. The chronic course of psychiatric illness and chronic use of psychotropic medication might have effects on the ageing process in PWS. For instance, changes in cognitive performance and functional outcomes have been reported in late life in people from the general population with schizophrenia ${ }^{29}$ and people with 22q11 deletion syndrome and psychiatric problems ${ }^{30}$.

Many in the older group (8/12) with PWS used more than one different psychotropic medication. Adverse effects to medication, and especially psychotropic medications, are frequently reported in $\mathrm{PWS}^{23,28}$. Sensitivity to psychotropic medication differs with age $^{31}$. Therefore, it is important to reassess the need for and dosage of psychotropic medication in older people with PWS, in order to find the lowest possible effective dose as well as minimal side effects ${ }^{32}$.

The association between PWS and dementia could of course be coincidental. Nevertheless, in order to achieve a better understanding of the prevalence of dementia in older people with PWS, more studies are necessary ${ }^{17}$. Annual 
dementia screening in the PWS population and follow up of functional decline is advisable and should start at latest from the age of 50 years.

\section{Social-economic changes}

Ageing is associated with more than just biological changes, cognitive decline and increasing risk of physical and psychiatric disorders. Ageing is also associated with significant social and economic changes. In older adults it is important to recognize when lifestyle should be changed (e.g. less time at work or day care centre) or retirement should be planned ${ }^{33}$. Increasing age for people with ID is also associated with the ageing and death of family members. Bereavement is frequently associated with behavioural disturbances and emotional distress ${ }^{34}$. Therefore caregivers should acknowledge the need for emotional support when family circumstances change. The loss of family members may also mean that important information about a person's (medical) past and the family is lost. Life story books are a way of trying to maintain at least some of this knowledge ${ }^{35}$.

\section{Premature ageing?}

Premature ageing can be defined as the early appearance of the signs of ageing before chronological old age. Given the combination of age related physical morbidity, physical appearance, behavioural and psychiatric problems and functional decline in our cohort, we hypothesize that premature ageing occurs in PWS. Therefore, age-related support needs to be put in place well in advance of conventional chronological age.

Premature ageing in PWS may be related to lower levels of estrogen, testosterone and growth hormone in adults with PWS. Replacement of sex hormones and growth hormone therapy is not very common in the Dutch adult PWS population. In the younger population (<18 years), these therapies have become common ${ }^{23,36,37}$. Only one person of the older group was treated with hormonal therapy. Hormone dependent ageing problems may include alterations on skin and hair, osteoporosis, coronary atherosclerosis and negative effects on body composition (e.g. lower muscle mass) in men ${ }^{38}$. Lower levels of estrogen (e.g. in women after menopause) are also associated with a higher risk of Alzheimer's disease and urinary incontinence ${ }^{39}$. These general ageing characteristics are prematurely prevalent in some adults with PWS. Further studies on the effect of hormone replacement therapy on ageing in PWS are recommended.

Ageing in people with PWS starts at 50 years or younger. Special medical surveillance of people with PWS from 40 years onwards will ensure that 
intervention and support is offered with respect to specific areas of decline at the earliest possible time.

\section{Potential bias of the study population}

The study of age-related changes in older people with PWS is complicated by the potential bias of the study population. Medical care and mortality rates were very different 50 years ago than they are today. Infant mortality would have been higher, neonatal care less advanced and the diagnosis of PWS would have been delayed. Those people who survived childhood are likely to have been self-selected on the on the basis of their ability to survive despite their disabilities. Therefore they may well have carried a strength with them into adult life, of which the effects may continue into old age.

\subsection{CONCLUSION}

As more people with PWS attain older age, it is important to note that excess functional impairment, morbidity and even mortality may result from the consequences of early age onset conditions, through their long-term progression or their interactions with older age onset conditions. The fact that people with PWS are more likely to reach old age requires a corresponding increase in training and preparation of physicians and other health care professionals to meet the needs of adults with PWS. Although more research needs to be done, it is clear that healthy ageing in PWS requires lifespan approaches that recognize the presence, progression and consequences of specific morbidity. Consequently, regularly scheduled preventive management following practical guidelines is recommended. 

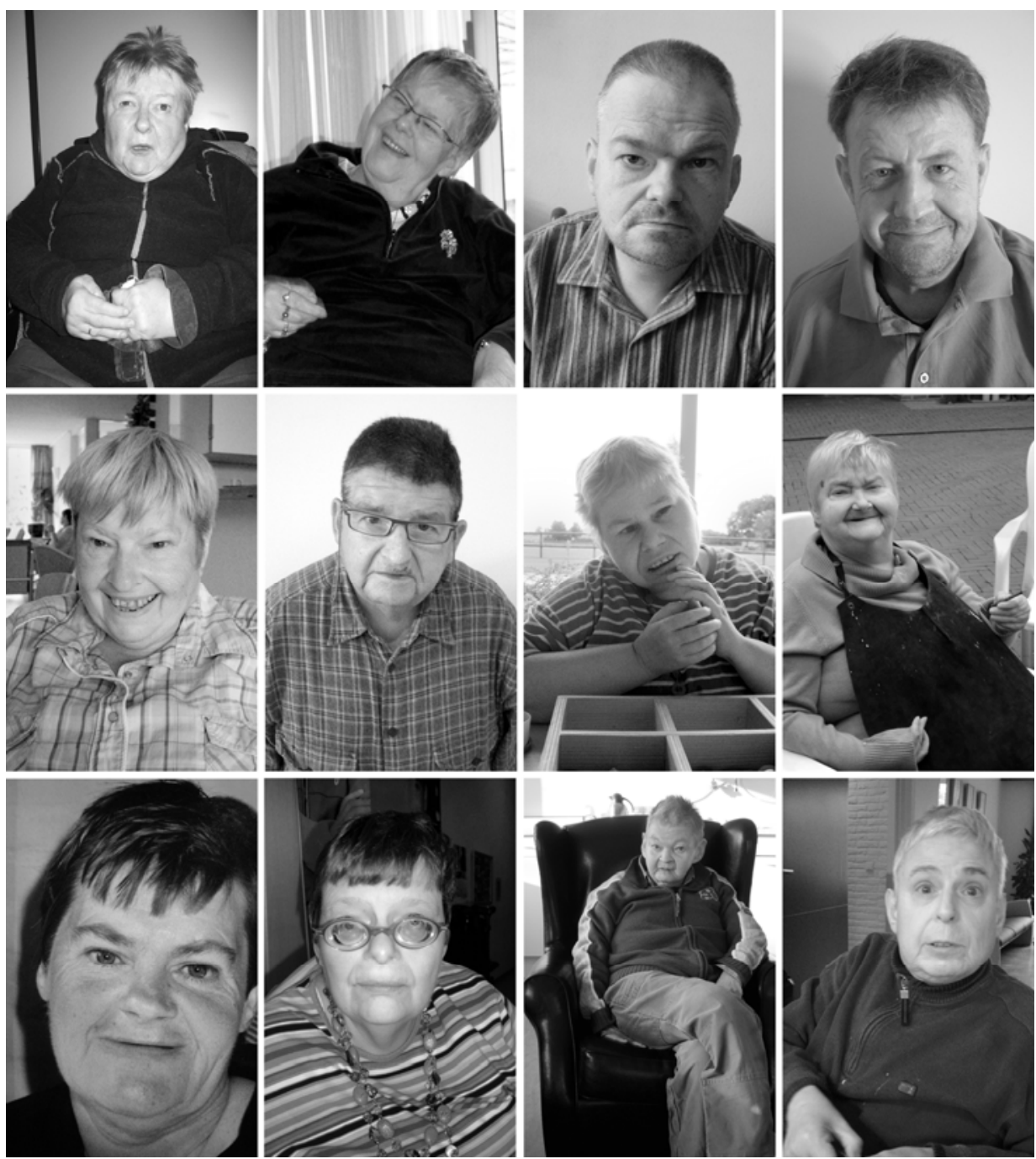

Figure 7.1: Twelve persons with PWS over the age of 50 years 


\section{REFERENCES}

1. Fisher K, Kettl P: Aging with mental retardation: increasing population of older adults with MR require health interventions and prevention strategies. Geriatrics 2005; 60: 26-29.

2. Maaskant MA, Gevers JPM, Wierda H: Mortality and life expectancy in Dutch residential centres for individuals with intellectual disability, 1991-1995. Journal of Applied Research in Intellectual Disabilities 2002; 15: 202-212.

3. Coppus A, Evenhuis H, Verberne GJ, Visser F, van Gool P, Eikelenboom P, van Duijin C: Dementia and mortality in persons with Down's syndrome. J Intellect Disabil Res 2006; 50: 768-777.

4. Bassett AS, Chow EW, Husted J, Weksberg R, Caluseriu O, Webb GD, Gatzoulis MA: Clinical features of 78 adults with 22q11 Deletion Syndrome. Am J Med Genet A 2005; 138: 307-313.

5. Haveman M, Heller T, Lee L, Maaskant M, Shooshtari S, Strydom A: Ageing and Health risks in Persons with Intellectual Disabilities: An overview of recent studies. Journal of Policy and Practice in Intellectual Disabilities 2010; 7: 59-69.

6. Whittington JE, Holland AJ, Webb T, Butler J, Clarke D, Boer H: Population prevalence and estimated birth incidence and mortality rate for people with PraderWilli syndrome in one UK Health Region. J Med Genet 2001; 38: 792-798.

7. Einfeld SL, Kavanagh SJ, Smith A, Evans EJ, Tonge BJ, Taffe J: Mortality in Prader-Willi syndrome. Am J Ment Retard 2006; 111: 193-198.

8. Greenswag LR: Adults with Prader-Willi syndrome: a survey of 232 cases. Dev Med Child Neurol 1987; 29: 145-152.

9. Goldman JJ: Prader-Willi syndrome in two institutionalized older adults. Ment Retard 1988; 26: 97-102.

10. Carpenter PK: Prader-Willi syndrome in old age. J Intellect Disabil Res 1994; 38: 529-531.

11. Butler MG: A 68-year-old white female with Prader-Willi syndrome. Clin Dysmorphol 2000; 9: 65-67.

12. Hoefnagel CWM: Oud en zwakzinnig: mentale retardatie vanuit psychologische optiek, Lisse: Swets en Zeitlinger, 1989.

13. Einfeld SL, Tonge BJ, Mohr C: The Developmental Behaviour Checklist for Adults (DBC-A). School of Psychiatry, University of New South Wales, and Centre of Developmental Psychiatry and Psychology, Monash University, Sydney and Melbourne 2002.

14. Moss S, Prosser H, Costello H, Simpson N, Patel P, Rowe S, Turner S, Hatton C: Reliability and validity of the PAS-ADD Checklist for detecting psychiatric disorders in adults with intellectual disability. J Intellect Disabil Res 1998; 42: 173-183.

15. Mohr C, Tonge BJ, Einfeld SL: The development of a new measure for the assessment of psychopathology in adults with intellectual disability. $J$ Intellect Disabil Res 2005; 49: 469-480.

16. Russell $\mathrm{H}$, Oliver $\mathrm{C}$ : The assessment of food-related problems in individuals with Prader-Willi syndrome. Br J Clin Psychol 2003; 42: 379-392.

17. Sinnema M, Schrander-Stumpel CT, Verheij HE, Meeuwsen M, Maaskant MA, Curfs LM: Dementia in a woman with Prader-Willi syndrome. Eur J Med Genet 2010; 53: 145-148.

18. Schrander-Stumpel CT, Curfs LM, Sastrowijoto P, Cassidy SB, Schrander JJ, Fryns JP: Prader-Willi syndrome: causes of death in an international series of 27 cases. Am J Med Genet A 2004; 124: 333-338. 
19. Vogels A, Van Den Ende J, Keymolen K, Mortier G, Devriendt K, Legius E, Fryns JP: Minimum prevalence, birth incidence and cause of death for Prader-Willi syndrome in Flanders. Eur J Hum Genet 2004; 12: 238-240.

20. Curfs LM, Fryns JP: Prader-Willi syndrome: a review with special attention to the cognitive and behavioural profile. Birth Defects Orig Artic Ser 1992; 28: 99-104.

21. Whittington J, Holland A, Webb T, Butler J, Clarke D, Boer H: Cognitive abilities and genotype in a population-based sample of people with Prader-Willi syndrome. J Intellect Disabil Res 2004; 48: 172-187.

22. Holm VA, Cassidy SB, Butler MG, Hanchett JM, Greenswag LR, Whitman BY, Greenberg F: Prader-Willi syndrome: consensus diagnostic criteria. Pediatrics 1993; 91: 398-402.

23. Goldstone AP, Holland AJ, Hauffa BP, Hokken-Koelega AC, Tauber M: Recommendations for the diagnosis and management of Prader-Willi syndrome. $J$ Clin Endocrinol Metab 2008; 93: 4183-4197.

24. Sinnema M, van Roozendaal KE, Maaskant MA, Smeets HJ, Engelen JJ, JonkerHouben N, Schrander-Stumpel CT, Curfs LM: Different distribution of the genetic subtypes of the Prader-Willi syndrome in the elderly. Eur J Hum Genet 2010; 18: 993-998.

25. Evenhuis $\mathrm{H}$, Henderson CM, Beange $\mathrm{H}$, Lennox N, Chicoine B. Healthy Ageing Adults with Intellectual Disabilities: Physical Health Issues. Geneva, Switserland, World Health Organization, 2000.

26. Sinnema M, Boer H, Collin P, Maaskant MA, van Roozendaal KEP, SchranderStumpel CTRM, Curfs LMG: Psychiatric illness in a cohort of adults with PraderWilli syndrome. Res Dev Disabil 2011; 32: 1729-1735.

27. Boer H, Holland A, Whittington J, Butler J, Webb T, Clarke D: Psychotic illness in people with Prader Willi syndrome due to chromosome 15 maternal uniparental disomy. Lancet 2002; 359: 135-136.

28. Soni S, Whittington J, Holland AJ, Webb T, Maina E, Boer H, Clarke D: The course and outcome of psychiatric illness in people with Prader-Willi syndrome: implications for management and treatment. J Intellect Disabil Res 2007; 51: 32-42.

29. Harvey PD, Reichenberg A, Bowie CR: Cognition and aging in psychopathology: focus on schizophrenia and depression. Annu Rev Clin Psychol 2006; 2: 389-409.

30. Evers LJ, De Die-Smulders CE, Smeets EE, Clerkx MG, Curfs LM: The velocardio-facial syndrome: the spectrum of psychiatric problems and cognitive deterioration at adult age. Genet Couns 2009; 20: 307-315.

31. Uchida H, Mamo DC: Dosing of antipsychotics in schizophrenia across the lifespectrum. Prog Neuropsychopharmacol Biol Psychiatry 2009; 33: 917-920.

32. Holden B, Gitlesen JP: Psychotropic medication in adults with mental retardation: prevalence, and prescription practices. Res Dev Disabil 2004; 25: 509-521.

33. Holland AJ: Ageing and learning disability. Br J Psychiatry 2000; 176: 26-31.

34. Hollins $S$, Esterhuyzen A: Bereavement and grief in adults with learning disabilities. Br J Psychiatry 1997; 170: 497-501.

35. Hewitt $\mathrm{H}$ : A life story approach for people with profound learning disabilities. $\mathrm{Br} \mathrm{J}$ Nurs 2000; 9: 90-95.

36. Festen DA, de Lind van Wijngaarden $R$, van Eekelen $M$, Otten BJ, Wit JM, Duivenvoorden HJ, Hokken-Koelega AC: Randomized controlled GH trial: effects on anthropometry, body composition and body proportions in a large group of children with Prader-Willi syndrome. Clin Endocrinol 2008; 69: 443-451. 
37. de Lind van Wijngaarden RF, Siemensma EP, Festen DA, Otten BJ, van Mil EG, Rotteveel J, Odink RJ, Bindels-de Heus GC, van Leeuwen M, Haring DA, Bocca G, Houdijk EC, Hoorweg-Nijman JJ, Vreuls RC, Jira PE, van Trotsenburg AS, Bakker B, Schroor EJ, Pilon JW, Wit JM, Drop SL, Hokken-Koelega AC: Efficacy and safety of long-term continuous growth hormone treatment in children with PraderWilli syndrome. J Clin Endocrinol Metab 2009; 94: 4205-4215.

38. Gooren LJ: Androgens and male aging: Current evidence of safety and efficacy. Asian J Androl 2010; 12: 136-151.

39. Jung $\mathrm{BH}$, Jeon $\mathrm{MJ}$, Bai SW: Hormone-dependent aging problems in women. Yonsei Med J 2008; 49: 345-351. 

CHAPTER 8

GENERAL DISCUSSION 
CHAPTER 8 


\section{GENERAL DISCUSSION}

The aim of this thesis is to contribute towards better understanding of PWS at adult age. Various aspects of PWS were evaluated, including the distribution of genetic subtypes, physical morbidity, behavioural phenotype, psychiatric illness and characteristics at older age. In this general discussion, the results will be discussed in a broader perspective. The methodological considerations of our studies will also be addressed. Finally, we make a number of suggestions for clinical implications. We consider future research opportunities in the light of the subject of the thesis.

\subsection{RESULTS IN A BROADER PERSPECTIVE}

\section{Distribution of genetics subtypes in an adult PWS cohort}

In the present study population, we found a different distribution of genetic subtypes across the age groups compared with previous population based studies $^{1-3}$. In our study, the number of people with mUPD was relatively high in the older age groups. We were not able to find a conclusive explanation of the differences in distribution of genetic subtypes across the age groups. A possible reason for the observed differences in distribution of genetic subtypes across the age groups may be differences in survival of the genetic subtypes into older age. Significant differences in BMI between the genetic subtypes were not found. Therefore we propose that a non obesity related factor, influencing the risk of dying in adults with PWS may explain the different distribution of genetic subtypes. This hypothesis needs to be evaluated in further studies on mortality and causes of death in the genetic subtypes.

\section{Physical characteristics of PWS at adult age}

Adults with PWS are frequent medical-care consumers. This high consumption was related to hospitalization rates, medication use, surgery and visits to the emergency department. Physical morbidity in adults with PWS included, amongst others, non-insulin dependent diabetes mellitus (NIDDM), hypertension, cerebrovascular accidents, respiratory infections, dermatologic and orthopedic problems. We hypothesize that the prevalence of physical morbidity in our cohort is an underestimate. Due to the setting of home visits in this study, we could not carry out further physical examinations and additional tests to screen for undiagnosed morbidity. Studies in the literature that focused on physical health problems were restricted by small sample sizes, limited age ranges and lack of genetically confirmed diagnoses ${ }^{2,4-7}$. These studies used widely different methods to collect data on physical morbidity, making it very difficult to compare prevalence rates with those in our study. 
The results on physical morbidity add new areas of interest for the care of and research in adults with PWS. For example:

- The prevalence of cardiovascular diseases was surprisingly low;

- Serious illness in the older age group was often triggered by pulmonary infections;

- Constipation was frequent and rectal ulcers occurred as a result of a regional skin picking and in some cases even caused anaemia;

- Surgery was mostly not performed in older men with cryptorchidism and this may carry risk of malignant degeneration;

- Sexual interests were not uncommon in adults with PWS;

- Oedema of the lower extremities was a very frequent characteristic in adults with PWS and the etiology was mostly not clear.

\section{Behavioural characteristics of PWS at adult age}

The results showed that adults with PWS had higher rates of maladaptive behaviours compared to people with ID due to other etiologies. Persons in the older age groups as well as persons with PWS due to MUPD and individuals with low BMI may be at increased risk of certain behavioural problems.

The results of this study on the relation between problem behaviour and age and genetic subtype, differed from results from other studies ${ }^{8-11}$. This may be explained by the use of different behavioural measurements. Moreover, the study population in this study differed from other study groups ${ }^{8-12}$. First, our study population was characterized by a predominance of older persons with PWS. Second, we also found a different distribution of genetic subtypes. The mUPD subtype was associated with higher prevalences of psychiatric and, presumably, co-occurring behavioural problems. The unique characteristics of the study population probably contributed to different findings on behavioural problems in this study.

Changes in behaviour could provide a signaling function. It is important for professionals to be aware of any increases in behavioural problems, as these may be early indicators of underlying medical or psychiatric disorders. Behavioural issues often impact on individuals with PWS and their families and caregivers more than any other aspect of the disorder ${ }^{13}$. The results underline that parents and professional caregivers should be supported in dealing with behavioural problems, not only in childhood, but during the entire lifespan.

\section{Psychiatric characteristics of PWS at adult age}

Results from this study confirmed previous findings that psychiatric illness is highly prevalent in adults with PWS. Individuals with mUPD were at higher risk of developing psychiatric illness, and psychosis in particular, than individuals with PWS due to a deletion. The prevalence of psychopathology in general 
(64\%) and psychotic symptoms specifically (55\%) in persons with mUPD was strikingly high.

Boer et al. ${ }^{14}$ found psychosis in $100 \%$ of the mUPD group above the age of 28 in their initial sample. Soni et al. ${ }^{15}$ reported some mUPD individuals without psychotic symptoms. In the present study, an even higher percentage of people with mUPD above the age of 35 without a history of psychosis (13/28; $46 \%$ ) was reported. In addition, about $13 \%$ of people with a deletion were found to have psychotic symptoms.

In contrast to previous studies, we firstly found fewer adults with mUPD and psychotic episodes ${ }^{15}$. Secondly, we could not confirm the relationship between a family history of psychiatry and development of psychosis in persons with a deletion ${ }^{15}$. And thirdly, we did not find two maternally derived copies of a narrow region on 15q11-q13 in people with a deletion and psychotic symptoms, which Webb et al. ${ }^{16}$ associated with the risk of developing psychosis.

This additional information contributes to a more detailed clinical picture of psychopathology in PWS. On the one hand, not all adults with mUPD develop psychiatric illness; on the other hand, the deletion subtype is not a safeguard against psychiatric episodes. Any exception to the risk of psychosis at adult age in individuals with mUPD and absence of psychosis in individuals with a deletion, could provide clues to the underlying aetiological mechanisms. The role of environmental factors and life events on the development of psychosis is still unclear and deserves further investigation besides research into the genetic mechanisms.

The treatment of psychiatric disease first requires that it is recognized. More attention should be paid to precursor symptoms. In view of the higher prevalence of psychosis in PWS, caregivers should be provided with information on how to recognize the early signs of a psychiatric episode. The management should both include a predictable and safe environment as well as the use of appropriate medication ${ }^{17}$.

\section{The relation between age, genetic subtype and BMI and the clinical characteristics}

Age, genetic subtype and BMI deserve special attention during general medical care because they might increase the risk of specific disorders.

Unlike previous descriptions of the behavioural phenotype in adults with PWS, we found in the present study that behavioural problems in older adults were not reduced. To the contrary, behavioural problems were more prevalent in older people with PWS. This behaviour included underactivity, gorging food, laughing for no obvious reason, panicking and soiling outside the toilet. On top of the behavioural problems, the results also show that psychiatric illness is a major concern in adults with PWS and frequently has a chronic course into 
older age. People in the older age groups also suffered more from diabetes and erysipelas.

Most behavioural problems were found in adults with the mUPD subtype. Persons with mUPD are also at increased risk to develop episodes of psychopathology. Regarding physical morbidity, individuals with the mUPD subtype were significantly more often diagnosed as suffering from pneumonia (at adult age), excessive daytime sleepiness, disturbed sleep, anaemia (mostly due to rectal skin-picking), ear problems and urinary incontinence age. The deletion subtype was associated with osteoporosis, knee problems and oedema.

More than half $(56 \%)$ of those in study population were obese $(\mathrm{BMI}>30)$. In the present study, obesity was related to diabetes, hypertension, excessive daytime sleepiness, snoring and erysipelas. Obesity management in people with PWS still includes environmental control with an early introduction of a lowcalorie, well-balanced diet, with regular exercise, rigorous supervision, restriction of access to food and money to buy food ${ }^{17}$. However, the results of our study also stress that weight loss does not seem to be a cure for all aspects of the disorder. Individuals with a BMI of less than 25 had higher scores on the self-absorbed scale (e.g. biting, screaming, banging of the head) of the DBC-A compared to persons with a BMI between 25 and 30 . Very strict dietary control to achieve a healthy weight status may cause more frustration and internal stress in persons with PWS, resulting in an increase of behavioural problems. A lower BMI was also associated with more cerebrovascular accidents.

\section{Linking genotype and phenotype}

The subtypes of PWS have similar genetic effects: for different genetic reasons, the normally active genes in the 15q11-q13 region are not expressed. However, there is a marked clinical variability between adults with PWS. In order to explain these observations, features that appear to be universally present (the core features) should be distinguished from those that appear to have a lower, but still high, prevalence rate ${ }^{18}$. Core features for example include hypotonia, feeding difficulties, hypogonadism and excessive eating behaviour. Skinpicking, psychiatric illness and scoliosis are not universal, but more prevalent than in the general population or in people with ID.

Phenotypic variations between the different genetic subtypes could provide clues to the underlying aetiological mechanisms. Persons with mUPD or imprinting defects lack expression of all maternally imprinted genes on chromosome 15 and also express both alleles of any paternally imprinted genes. They also have two copies of the non-imprinted genes in the PWS region. Those with a deletion lack paternally expressed alleles in the PWS region; however they have a (normal) single copy of maternally expressed 
genes on the maternal chromosome and only a single copy of non-imprinted genes within the PWS region. Phenotypic differences between the deletion sizes may yield information about the function of single genes in the region between BP1 en BP2.

The effects of the genotype on the phenotype of an individual may also be either direct or indirect. Some direct links can already be explained. For example, people with a deletion of the paternal chromosome 15 show higher rates of "fair for family"19. They only have a single copy of the non-imprinted pigmentation OCA2 gene, and the recessive allele is more likely to be expressed. Indirect links have also been proposed, in which the absence of expression of a gene sets a threshold or results in arrested development at a certain age. In case of such an indirect link, one would predict that the phenotypic feature would not be universal and that other environmental or biological factors would also influence the development of a certain characteristic ${ }^{18}$. Examples of these influencing factors may be age, life events, family history, BMI and living circumstances.

These indirect mechanisms are likely to play a crucial role in characteristics that develop during adulthood. Most of these characteristics are not universally present in all adults with PWS. In some behavioural characteristics, e.g. obsessive behaviour and temper tantrums, arrested brain development may play a role ${ }^{20}$. The observation that psychiatric illness is more prevalent in persons with mUPD, has led to the hypothesis that psychosis can be explained by double expression of a paternally imprinted gene on chromosome $15^{16,21}$.

\section{Characteristics of PWS at older age}

In many adults with PWS, functional abilities deteriorate from the age of 40 years. We found that decline in abilities usually started with a decrease in energy level and a recuction of their mobility. The deterioration on the domains of $A D L$, of psychological functioning, of physical functions and the increased dependence on care over the age of 50 were striking. Morbidity in the elderly included cardiovascular diseases, diabetes, dermatological complaints, orthopedic problems and psychiatric illness. We should take into account that the persons in the older age groups may be the "healthy survivors" of the cohort.

We hypothesized that people with PWS may age prematurely. Signs of ageing, such as the appearance of age related physical morbidity, physical appearance, behavioural and psychiatric problems and functional deline, appear earlier than expected. Lower levels of estrogen, testosterone and growth hormone in adults with PWS may play a role in premature ageing. The chronic course of psychiatric illness and chronic use of psychotropic medication might also have effects on the ageing process in PWS. 
We also considered whether the behavioural changes in older people with PWS may be associated with dementia. Therefore, we described a case of a woman with PWS and dementia. The association between PWS and dementia could of course be coincidental. In order to get a better understanding of the prevalence of dementia in older people with PWS, more longitudinal studies are needed using larger cohorts. Moreover, study of brain material is warranted to observe whether premature Alzheimer changes or indications of other causes of dementia indeed occur in people with PWS. Annual dementia screening in the PWS population and follow up of functional decline is advisable in our opinion and should start at latest from the age of 50 years.

\subsection{CLINICAL IMPLICATIONS}

This study is an example of scientific research performed in close collaboration with the Dutch Prader-Willi Parent Association. Crucial information given by the parents and individuals with PWS themselves provided the first clues that required further investigation. Families that were involved in the research contributed to what is known about adults with PWS. The results from this study were communicated directly to the parents and other caregivers. This exchange of information provided results that meet the needs of families. Prader-Willi parent associations have now been established in many countries and are linked in the International Prader-Willi Syndrome Organization (IPWSO). These organizations help to bridge the gap between knowledge and interest of both parents and professionals.

Few of the studies described in the literature included older persons with PWS. Almost half of the participants in our study (44\%) were aged 40 years or older. It is possible that in previous studies older people with PWS are underrepresented as PWS had not been diagnosed. The clinical diagnosis of PWS is based on core features such as hypotonia, failure to thrive and undescended testes in boys. However, this important clinical information is not always available in later life, due to the death of family members. Therefore, clinical diagnostic criteria should be adjusted in the older age groups. Genetic testing for PWS in adults should also be considered in case of a less marked phenotype, characterized by behavioural and psychiatric problems in addition to obesity and delayed or incomplete puberty.

As with any condition, making a diagnosis is merely the beginning. Ongoing management and support trough the lifespan, tailored to the needs of persons with PWS and their families are essential. Clinical symptoms and signs of early disease are easily missed in persons with PWS, because of their limited 
communicative skills. Moreover, typical characteristics of PWS such as a high pain threshold, temperature instability and decreased ability to vomit may mask early symptoms. As a result, health problems may remain undetected and thereby increasing the morbidity and early mortality over time. There thus is a need for guidelines for routine preventive management, adjusted to the adult PWS population.

In Appendix 1 we suggest an approach for preventive management in adults with PWS. These recommendations for preventive management in adults with PWS are based on the results of our study and data from the literature. It is not possible to develop evidence based guidelines based on the results of this study $^{22}$. However, the results serve as an important starting point for developing guidelines. For the future, we recommend a systematic review of the evidence in the literature and a multidisciplinary consensus meeting by experts in PWS, in order to produce validated guidelines on the optimum management of specific conditions.

Emergency situations deserve special attention in people with PWS. It is important that peopled involved in the care of adults with PWS are well informed about the possible health hazards surrounding acute disorders. Symptoms, which in people without PWS would be evident, are not always clear in adults with PWS. Healthcare professionals providing care during emergency situations are mostly not familiar with the syndrome. A decreased ability to vomit, abnormal pain awareness and an unpredictable fever response can lead to underreporting of pain and missed diagnoses of serious conditions that would otherwise be expected to produce severe pain or fever. Characteristics of the syndrome that could cause complications during acute or routine medical care or hospitalization include respiratory infections, acute gastrointestinal episodes, anesthesia, water intoxications, psychiatric episodes and adverse reactions to medication. We listed the characteristics of PWS in general and possible complications during acute illness in the wallet-sized booklet Medical Alerts. This publication is based on the results of this study and the Medical Alerts booklet of the PWSAUSA. The booklet provides parents and caregivers with syndrome specific information and can be given to medical professionals in case of emergency. The Medical Alerts booklet is attached in Appendix 2.

The care for older people with PWS needs to be put into place at a relatively young age because we suggest that people with PWS suffer from premature ageing. Special medical surveillance of people with PWS of 40 years and older will ensure that intervention and support is offered with respect to specific areas of decline at the earliest possible opportunity. Efforts are needed to 
ensure that health care professionals are better at recognizing and treating PWS related morbidity. Support in older people with PWS may need to be adjusted to higher levels of care dependency, decreased energy during the day and diminished mobility.

\subsection{METHODOLOGICAL CONSIDERATIONS}

This thesis describes research findings obtained from a large cohort of adults with PWS. Information was gathered in semi-structured interviews with persons with PWS, family members and professional caregivers. The interview included questions about physical health problems experienced over the participants' lifetime. A number of questionnaires were used for additional information on behavioural and psychiatric symptoms including the Developmental Behaviour Checklist for Adults (DBC-A) (Einfeld et al. 2002) and the Psychiatric Assessment Schedule for Adults with Developmental Disabilities (PAS-ADD) checklist (Moss et al. 1996). Medical files were retrieved from general practitioners, intellectual disability physicians, psychiatrists and other medical specialists.

This study is one of the largest cohort studies of adults with PWS. The study has a number of strengths compared to previous research. First, all participants had a genetically confirmed diagnosis of PWS. Second, the age range of the study population was relatively broad. The results of this study show a substantial number $(n=45)$ of persons above the age of 40 and even up to the age of 66 years. Third, the total number of participants was high, as well as the response rate of the study (75\%). Fourth, we investigated not only one aspect of the adult PWS population, but combined the assessment of physical illness, behaviour and psychiatry.

There are however limitations of the current research project. Awareness of these limitations can be used to improve future studies. First, we (at least partly) had to rely on retrospective and self-reported data from the caregivers. Self-reported data contain several potential sources of bias: selective memory (remembering or not remembering experiences or events that occurred sometime in the past); telescoping (recalling events that occurred at one time as if they had occurred at another time); and attribution bias (attributing positive events and outcomes to one's own agency but attributing negative outcomes to external forces). While these problems are difficult to overcome, medical files were also collected from physicians to provide relatively independent information about the presence and severity of medical conditions. 
A second limitation of the study is the absence of a comparison or control group. In future studies a control group with a non-specific cause for ID is recommended to obtain more specific information on the ageing process in people with PWS. This control group should at least be matched for level of functioning, BMl and age.

Third, the study of age-related changes in older people with PWS is complicated by the potential bias of the study population. The results in this report relate to cross-sectional data. Medical care and mortality rates were very different 50 years ago than they are at present. Infant mortality would have been higher, neonatal care less advanced and the diagnosis of PWS would have been delayed. Those people who survived childhood are likely to have been self-selected on the on the basis of their ability to survive despite their disabilities. Therefore, they may well have carried strengths into adult life, the effects of which could continue into old age. Therefore care has to be taken when extrapolating current findings to the future.

\subsection{FUTURE RESEARCH OPPORTUNITIES}

There has been significant progress in the understanding of PWS in recent years. However, there are still major gaps in our knowledge. Because of major advances in care and medical treatment, there appears to be an improvement in life expectancy for persons with PWS. This increased life expectancy has given rise to additional medical and social concerns related to ageing. Surprisingly little information is available on health care issues of older persons with PWS and determinants of morbidity and mortality at older age remain far from being understood. The challenge will be to gain insight in the prevalence of medical problems in adults with PWS and unravel the contributing factors. Future research should focus on characteristics in the later stages of life in larger study populations.

The unique characteristics of this study population open opportunities for ongoing research. Over time the GKC - Clinical Genetics Maastricht database will accumulate data of the participants with PWS, which enables testing of novel hypotheses using both cross-sectional and longitudinal research designs, and also the investigation of influences on development of people with PWS over their lifespan. Longitudinal measurements, in large cohorts, are necessary for separating the effects of ageing (changes over time within individuals) from cohort effects (differences between subjects at baseline). Longitudinal studies are also warranted to gain more insight into the natural history and changing characteristics in adults and older people with PWS over the long term and 
possible risk and preventive factors. Fixed data, such as genetic status and information about the neonatal period, should be stored once collected. This reduces the repetitive collection of the same data and thereby reduces demands on participants and their caregivers.

Any study that involves people with ID should ideally include people with ID in the research team. In planning further research, opportunities to do "nothing about us without us" should be strived for. Adults with PWS may, for example, identify research problems with which they need help, work with researchers to analyse problems, collect data and help designing accessible study information materials.

We chose to evaluate a broad spectrum of clinical characteristics of PWS in this study. Consequently, we could not dwell at length on every single aspect. Due to the setting of home visits, we could not screen for unrevealed illness. Extensive physical examinations and additional tests such as blood analysis, bone density measurements, metyrapone stress tests for adrenal insufficiency, polysomnography or ultrasound were not part of the current study. Due to this approach, medical disorders may be more common than our findings suggest. Based on the results of this study, it would be useful to focus more in detail on the topics such as sleep apnea, osteoporosis and cardiovascular diseases in this cohort in the future. Screening for these conditions was by and large not part of general care of the participants of the study and the prevalence of health problems is therefore likely to be underestimated in our results.

Physical illness is often only diagnosed in advanced stages of disease or when severe complications have developed in adults with PWS. Strategies are needed to increase effective early detection and treatment of medical disorders. The development of guidelines for preventive management, including the use of standardized screening instruments at clinic visits, may assist healthcare professionals in the care for adults with PWS. We recommend to investigate the prevalence of medical disorders in a cohort of adults with PWS, monitored and managed following these clinical guidelines.

In this thesis we describe the association of PWS with behavioral and physical characteristics. The next step in further research is to try to explain the mechanisms underlying these associations. Because not all characteristics in PWS are universal, the PWS phenotype is likely to result from the the action of different mechanisms, as for example proposed by Holland et al. ${ }^{20}$ for the behavioral phenotype. 
The relatvely rarity of people with particular syndromes is often such that researchers depend upon just a few people in their country to take part in research. Moreover in many studies, like our study, there is a need to investigate the influence of different variables such as genetic subtype, age and BMI. Study populations are often too small to answer such specific research questions. Therefore research into rare disorders requires collaborative approaches and the ability to combine data from different countries in databases. Specific aspects of the phenotype should be assessed using valid and reliable instruments in order to standardize assessments and make the combining of data across studies feasible. These databases also enable investigations on different health care policies between countries. The practical development and management of such a database is very complex. Recently, databases are being set up in e.g. USA, Europe, France and Australia \& New Zealand ${ }^{23,24}$.

\subsection{FINAL REMARKS}

In the current adult PWS population as described in this thesis, people were frequently diagnosed relatively late in their lives. Nowadays, the diagnosis is generally made during the neonatal period. This early diagnosis, combined with new therapeutic options, may reduce morbidity and improve quality of life in adult age in the next generation. So far, no studies are available on the clinical characteristics of PWS individuals who had been diagnosed early in life by genetic testing and who where treated from infancy onwards, with diet, exercise and hormonal substitution.

We studied a cohort of adults with PWS and can only make general recommendations. The presence of PWS brings a predisposition for certain disorders and other outcomes. However, there is a marked clinical variability throughout life between individuals. Support and medical care of adults with PWS should not only be based on scientific knowledge, but should also consist of individual assessments to gain insight in the particular threats and needs in individuals.

It is often difficult to distinguish physical and psychiatric morbidity in people with PWS. Instead of somatic complaints, physical problems can manifest themselves as challenging behaviour or loss of daily functioning. Some challenging behaviour or side effects of psychotropic medication may be so intense that this adversely affects the physical health of persons. Mental health problems may also occur as a response to physical disorders. Physical characteristics may be present in the early stages of psychiatric episodes, such 
as the occurrence of urine incontinence, weight loss and skin-picking in the first phase of a psychosis. Therefore, in case of any physical complaint, psychiatric causes for the complaints should also be taken into account and vice versa.

The results from this study contribute to the knowledge on adults with PWS and the ageing process. This knowledge is very important for persons with PWS, their families, (professional) caregivers, physicians and other healthcare professionals. Ongoing research in PWS may also provide important insights into factors leading to overeating, obesity and psychiatric illness in the general population ${ }^{21}$. Early diagnosis, education and support of caregivers, routine monitoring of health and timely treatment of co-morbidity, are the key to a better quality of life for people with PWS. However, this thesis only serves as a starting point for new research, rather than as an endpoint. Understanding the factors that contribute to healthy ageing in PWS will be a major challenge for clinical multidisciplinary research in the coming years. 


\section{REFERENCES}

1. Smith A, Egan J, Ridley G, Haan E, Montgomery P, Williams K, Elliott E: Birth prevalence of Prader-Willi syndrome in Australia. Arch Dis Child 2003; 88: 263-264.

2. Vogels A, Van Den Ende J, Keymolen K, Mortier G, Devriendt K, Legius E, Fryns JP: Minimum prevalence, birth incidence and cause of death for Prader-Willi syndrome in Flanders. Eur J Hum Genet 2004; 12: 238-240.

3. Whittington JE, Holland AJ, Webb T, Butler J, Clarke D, Boer H: Population prevalence and estimated birth incidence and mortality rate for people with PraderWilli syndrome in one UK Health Region. J Med Genet 2001; 38: 792-798.

4. Greenswag LR: Adults with Prader-Willi syndrome: a survey of 232 cases. Dev Med Child Neurol 1987; 29: 145-152.

5. Laurance BM, Brito A, Wilkinson J: Prader-Willi Syndrome after age 15 years. Arch Dis Child 1981; 56: 181-186.

6. Thomson AK, Glasson EJ, Bittles AH: A long-term population-based clinical and morbidity review of Prader-Willi syndrome in Western Australia. $J$ Intellect Disabil Res 2006; 50: 69-78.

7. Butler JV, Whittington JE, Holland AJ, Boer H, Clarke D, Webb T: Prevalence of, and risk factors for, physical ill-health in people with Prader-Willi syndrome: a population-based study. Dev Med Child Neurol 2002; 44: 248-255.

8. Butler MG, Bittel DC, Kibiryeva N, Talebizadeh Z, Thompson T: Behavioral differences among subjects with Prader-Willi syndrome and type I or type II deletion and maternal disomy. Pediatrics 2004; 113: 565-573.

9. Dykens EM: Maladaptive and compulsive behavior in Prader-Willi syndrome: new insights from older adults. Am J Ment Retard 2004; 109: 142-153.

10. Dykens EM, Cassidy SB, King BH: Maladaptive behavior differences in Prader-Willi syndrome due to paternal deletion versus maternal uniparental disomy. Am J Ment Retard 1999; 104: 67-77.

11. Dykens EM, Roof E: Behavior in Prader-Willi syndrome: relationship to genetic subtypes and age. J Child Psychol Psychiatry 2008; 49: 1001-1008.

12. Clarke DJ, Boer H, Chung MC, Sturmey $\mathrm{P}$, Webb T: Maladaptive behaviour in Prader-Willi syndrome in adult life. J Intellect Disabil Res 1996; 40: 159-165.

13. van den Borne HW, van Hooren RH, van Gestel M, Rienmeijer P, Fryns JP, Curfs LM: Psychosocial problems, coping strategies, and the need for information of parents of children with Prader-Willi syndrome and Angelman syndrome. Patient Educ Couns 1999; 38: 205-216.

14. Boer H, Holland A, Whittington J, Butler J, Webb T, Clarke D: Psychotic illness in people with Prader Willi syndrome due to chromosome 15 maternal uniparental disomy. Lancet 2002; 359: 135-136.

15. Soni S, Whittington J, Holland AJ, Webb T, Maina EN, Boer H, Clarke D: The phenomenology and diagnosis of psychiatric illness in people with Prader-Willi syndrome. Psychol Med 2008; 38: 1505-1514.

16. Webb T, Maina EN, Soni S, Whittington J, Boer H, Clarke D, Holland A: In search of the psychosis gene in people with Prader-Willi syndrome. Am J Med Genet $A$ 2008; 146: 843-853.

17. Goldstone AP, Holland AJ, Hauffa BP, Hokken-Koelega AC, Tauber M: Recommendations for the diagnosis and management of Prader-Willi syndrome. $J$ Clin Endocrinol Metab 2008; 93: 4183-4197. 
18. Whittington J, Holland A: Neurobehavioral phenotype in Prader-Willi syndrome. Am J Med Genet C Semin Med Genet 2010; 154C: 438-447.

19. Spritz RA, Bailin T, Nicholls RD, Lee ST, Park SK, Mascari MJ, Butler MG: Hypopigmentation in the Prader-Willi syndrome correlates with $\mathrm{P}$ gene deletion but not with haplotype of the hemizygous P allele. Am J Med Genet 1997; 71: 57-62.

20. Holland AJ, Whittington JE, Butler J, Webb T, Boer H, Clarke D: Behavioural phenotypes associated with specific genetic disorders: evidence from a populationbased study of people with Prader-Willi syndrome. Psychol Med 2003; 33: 141-153.

21. Ingason A, Kirov G, Giegling I, Hansen T, Isles AR, Jakobsen KD, Kristinsson KT, le Roux L, Gustafsson O, Craddock N, Moller HJ, McQuillin A, Muglia P, Cichon S, Rietschel M, Ophoff RA, Djurovic S, Andreassen OA, Pietilainen OP, Peltonen L, Dempster E, Collier DA, St Clair D, Rasmussen HB, Glenthoj BY, Kiemeney LA, Franke B, Tosato S, Bonetto C, Saemundsen E, Hreidarsson SJ, Nothen MM, Gurling H, O'Donovan MC, Owen MJ, Sigurdsson E, Petursson H, Stefansson H, Rujescu D, Stefansson K, Werge T: Maternally Derived Microduplications at 15q11-q13: Implication of Imprinted Genes in Psychotic Illness. Am J Psychiatry 2011; 168(4):408-17.

22. Grol R, Cluzeau FA, Burgers JS: Clinical practice guidelines: towards better quality guidelines and increased international collaboration. Br J Cancer 2003; 89: S4-8.

23. Molinas C, Cazals L, Diene G, Glattard M, Arnaud C, Tauber M: French database of children and adolescents with Prader-Willi syndrome. BMC Med Genet 2008; 9: 89.

24. Holland A, Whittington J, Cohen O, Curfs L, Delahaye F, Dudley O, Horsthemke B, Lindgren AC, Nourissier C, Sharma N, Vogels A: The European Prader-Willi Syndrome Clinical Research Database: an aid in the investigation of a rare genetically determined neurodevelopmental disorder. J Intellect Disabil Res 2009; 53: 538-547. 


\section{CHAPTER 9}

SUMMARY 


\section{SUMMARY}

Prader-Willi syndrome (PWS) is a neurodevelopmental disorder caused by the absence of paternal expression of imprinted genes in the critical region at 15q11-13. The main mechanisms causing PWS include a paternal deletion at $15 q 11-13(70 \%)$ and a maternal uniparental disomy (mUPD) of chromosome $15(25-30 \%)$. Translocations and imprinting defects account for $1-5 \%$ of the cases. Characteristics of PWS differ in the different life stages. At birth, neonates with PWS have severe hypotonia and feeding problems. During childhood, the original feeding problems improve and excessive appetite with hyperphagia develops. Without dietary restrictions this may result in extreme obesity. Research in Prader-Willi syndrome (PWS) has mainly focused on clinical characteristics in childhood, adolescence and early adulthood. Little is known about PWS at older age. The aim of this thesis is to contribute towards better understanding of PWS at adult age.

The studies described in this thesis were embedded in the project "Ageing in Prader-Willi syndrome" and were carried out at The Governor Kremers Centre and Department of Clinical Genetics, Maastricht University Medical Centre, the Netherlands. The study cohort consisted of 102 adult (18 years and older) persons with a genetically confirmed diagnosis of PWS. The individuals with PWS and their main caretakers (family and/or professional carers) were visited at home for semi-structured interviews. Data were collected on physical, behavioural and psychiatric characteristics.

The distribution of the genetic subtypes was discussed in Chapter 2. The frequencies of different subtypes in PWS are usually given in literature as $70 \%$ deletion, $25-30 \%$ mUPD and $3-5 \%$ others (IC defects and translocations). In our study population, a different distribution of genetic subtypes across the different age groups was found when compared with previous population based studies. This was mainly caused by a relatively high proportion of mUPD in the older age groups. Differences in maternal age and BMI of the persons with PWS could not explain the differences in distribution across the age groups. However, our study population had a much broader age range, compared to other studies, because of a predominance of older people (forty years and older) with PWS. Therefore, the results underline both the need for correct genetic diagnosis in all persons with PWS and the need for adjustments to the guidelines for preventive management in adulthood.

Chapter 3 describes the physical characteristics of PWS at adult age. We reported on the consequences of high morbidity such as increased numbers of hospital admissions, medication use and surgery. Special attention was paid to 
causes and symptoms of serious illness, and recovery from illness. Physical health problems included non-insulin dependent diabetes mellitus (NIDDM), hypertension, cerebrovascular accidents, respiratory infections, dermatologic and orthopedic problems. At adult age, hospitalization results from inguinal hernia surgery, diabetes mellitus, psychosis, erysipelas, water and drug intoxications. In older individuals, respiratory infections are the main reason for hospital admissions. Frequently used medication included psychotropics, laxatives, anti-diabetic medication and dermatologic preparations. Signs and symptoms of illness are not always easy to interpret in people with PWS. Abnormal drinking patterns, problems with anesthesia, decreased ability to vomit, abnormal pain awareness and unpredictable fever response was common and lead to delayed diagnosis of serious conditions. The results underline the importance of developing monitoring programmes which would help to recognize physical health problems in an early stage.

In Chapter 4, we reported on the behavioural phenotype, using the Developmental Behavior Checklist for Adults (DBC-A). Adults with PWS had higher rates of maladaptive behaviors compared to people with ID due to other etiologies. Persons with mUPD had higher total scores on the DBC-A than persons with a deletion. Those with a Type I deletion showed higher total DBCA scores than persons with a Type II deletion. There were no statistically significant differences in DBC-A total scores between the different BMI categories. Unlike previous descriptions of the behavioral phenotype in adults with PWS, behavioral problems were not less prevalent in older adults compared with younger adults.

The prevalence of psychiatric illness in the cohort was evaluated in Chapter 5. The results confirm previous findings that psychiatric illness is highly prevalent in adults with PWS. Nine out of 53 persons (17\%) with a 15q11-13 deletion and 28 out of $44(64 \%)$ persons with mUPD were diagnosed with a current or previous psychiatric illness. Depressive illness with psychotic symptoms was the cause of psychiatric problems in the majority of persons with PWS due to deletion (56\%). In the case of mUPD, almost all individuals with a history of psychopathology suffered from psychotic symptoms (85\%) with or without an affective component.

A specific psychiatric illness related to older age is dementia. The first case of a woman with PWS and symptoms highly suggestive of dementia was reported in Chapter 6. The association between PWS and dementia could of course be coincidental. In order to get a better understanding of the prevalence of dementia in elderly with PWS, more studies are necessary in larger cohorts. Moreover, study of brain material is warranted to observe whether premature 
Alzheimer changes or indications of other dementia forms do occur in people with PWS.

In Chapter 7, the focus was on characteristics of older age in PWS. In many adults with PWS, functional abilities deteriorated from the age of 40 years. This usually started with a decrease in energy level and lessening of mobility. Deterioration on the domains of activities of daily living (ADL), psychological functioning, physical functions and care dependence over the age of 50 were striking. Physical health problems in the older individuals included cardiovascular diseases, diabetes, dermatological complaints, orthopedic problems and psychiatric illness. Premature ageing occurs in persons with PWS. Lower levels of estrogen, testosterone and growth hormone in adults with PWS were suggested to play a role in premature ageing. The chronic course of psychiatric illness and chronic use of psychotropic medication might also affect the ageing process.

In Chapter 8, the general discussion, the results were placed in a broader perspective and methodological considerations were discussed. We made recommendations for clinical implementation and future research opportunities were made. Early diagnosis, education of and support by caregivers, routine monitoring of health and timely treatment of co-morbidity, are the key to a better quality of life for people with PWS. In Appendix 1 we suggest an approach for preventive management in adults with PWS. Emergency situations in people with PWS deserve special attention. Characteristics of the syndrome in general and possible complications during acute illness are listed in the Medical Alert booklet, attached in Appendix 2. Understanding the factors that contribute to healthy ageing in PWS will be a major challenge for clinical multidisciplinary research in the coming years.

In Appendix 3-7 specific topics, such as gastric dilatation, lymphedema, sleep disturbances \& behavioural problems, urinary incontinence and the GH/IGF-I axis \& pituitary function \& size were addressed more in detail. 
SAMENVATTING 


\section{SAMENVATTING}

Het Prader-Willi syndroom (PWS) is een genetische aandoening en is het gevolg van het ontbreken van expressie van genen uit de paternale chromosoom 15q11-13 regio. Verschillende mechanismen kunnen hieraan ten grondslag liggen, namelijk een deletie in de paternale 15q11-q13 regio $(70 \%)$, een maternale uniparentele disomie (mUPD; 25-30\%) of een defect in het imprintings centrum (3-5\%). In de diverse levensfasen van mensen met het PWS komen verschillende kenmerken voor. Bij pasgeborenen staan spierslapte en voedingsproblemen op de voorgrond. Tijdens de kindertijd ontstaat een onverzadigbare eetlust en, zonder dieetmaatregelen, overgewicht. Onderzoek naar PWS heeft zich tot op heden met name gericht op de klinische kenmerken van kinderen en jong volwassenen. $\mathrm{Er}$ is weinig bekend over PWS op oudere leeftijd. Het doel van dit onderzoek was om de specifieke kenmerken van mensen met PWS op volwassen leeftijd in kaart brengen.

De studies beschreven in dit proefschrift zijn uitgevoerd binnen het project "Gezond ouder worden met Prader-Willi syndroom" dat plaatsvond vanuit het Gouverneur Kremers Centrum en de afdeling klinische genetica van het Maastricht Universitair Medisch Centrum. De studiepopulatie bestond uit 102 volwassenen (18 jaar en ouder) met een genetisch bevestigde diagnose van PWS. De mensen met PWS zelf en hun belangrijkste verzorgers (familie en/of professionele begeleiders) werden thuis bezocht voor semi-gestructureerde interviews. Hierbij werd informatie verzameld over lichamelijke, gedrags- en psychiatrische kenmerken.

De verhouding tussen het voorkomen van de verschillende genetische subtypen van PWS kwam aan bod in Hoofdstuk 2. In de literatuur wordt veelal gesproken over $70 \%$ deletie, $25-30 \%$ mUPD en $3-5 \%$ andere oorzaken (imprintings centrum defecten en translocaties). In onze studie populatie werd een andere verdeling gevonden: $54 \%$ deletie, $43 \%$ mUPD en 3\% imprintings centrum defecten en translocaties. In vergelijking met andere studies, kende onze studiepopulatie een grotere leeftijdsspreiding en relatief veel oudere mensen met PWS. De afwijkende verdeling bleek met name veroorzaakt te worden door relatief veel mensen met mUPD in de oudste leeftijdsgroepen. Verschillen in leeftijd van de moeder bij geboorte van hun kind met PWS en gewichtsstatus (BMI) van de mensen met PWS vormden geen verklaring voor de andere verhouding tussen de genetische subtypen in de verschillende leeftijdsgroepen. De resultaten van deze studie onderstrepen het belang van een correcte genetische diagnose bij alle mensen met PWS en de behoefte om de richtlijnen voor preventieve zorg aan te passen aan de volwassen leeftijd. 
In Hoofdstuk 3 werden de lichamelijke kenmerken van PWS op volwassen leeftijd beschreven. We gaven een overzicht van de consequenties van de hoge morbiditeit in deze groep zoals het aantal ziekenhuisopnames, gebruik van medicatie en operaties. Speciale aandacht werd hierbij besteed aan medische spoedsituaties. Lichamelijke problemen bij volwassenen met PWS omvatten onder meer diabetes mellitus, hypertensie, CVA's, luchtweginfecties, dermatologische- en orthopedische problemen. Ziekenhuisopnames waren onder andere nodig in verband met met liesbreuk operaties, diabetes mellitus, psychoses, erysipelas, watervergiftigingen en bijwerkingen van medicatie. Bij de ouderen met PWS waren luchtweginfecties de belangrijkste reden voor opname in het ziekenhuis. Psychofarmaca, laxantia, antidiabetica en dermatologische preparaten waren de meest gebruikte medicijnen. Ziektesymptomen zijn niet altijd gemakkelijk te herkennen bij mensen met PWS. Omdat mensen met PWS vaak een verminderde mogelijkheid hebben om over te geven, een hoge pijngrens en een onvoorspelbare koorts reactie, werden ernstige aandoeningen vaak verlaat gediagnosticeerd. De resultaten van het onderzoek ondersteunen het belang om signaleringsprogramma's te ontwikkelen om lichamelijke problemen al in een vroeg stadium te herkennen.

In Hoofdstuk 4 bespraken we het gedragsfenotype van PWS op volwassen leeftijd. Hiervoor gebruikten we de Developmental Behavior Checklist for Adults (DBC-A). Volwassenen met PWS lieten meer probleemgedrag zien dan mensen met een verstandelijke beperking in het algemeen. Ons onderzoek liet tevens zien dat gedragsproblemen niet alleen vaker voorkwamen bij mensen met mUPD, maar ook bij degenen met Type I deleties ten opzichte van Type II deleties. Er bleek geen significant verschil in gedragsproblemen tussen de diverse gewichtsklassen. In tegenstelling tot eerdere beschrijvingen van het gedragsfenotype van volwassenen met PWS, kwamen gedragsproblemen in de oudere leeftijdsgroepen niet minder voor dan in de jongere leeftijdsgroepen.

Het vóórkomen van psychiatrische problemen in het cohort werd geëvalueerd in Hoofdstuk 5. Psychiatrische problemen komen veel voor bij volwassenen met PWS. Hiermee werden resultaten van eerder onderzoek bevestigd. Negen van de 53 mensen met een deletie (17\%) en 28 van de 44 van de mensen met een mUPD (64\%) werden gediagnosticeerd met een psychiatrische aandoening ten tijde van het onderzoek of in het verleden. Bij de meeste mensen met PWS ten gevolge van een deletie (56\%) bleek er sprake te zijn van een depressie met psychotische kenmerken. Bij mensen met PWS op basis van een mUPD, bleek er bij bijna alle mensen (85\%) sprake te zijn van psychotische symptomen met of zonder affectieve component.

Een specifiek psychiatrisch probleem op de latere leeftijd is dementie. De 
eerste casus van een vrouw met PWS en dementie, werd beschreven in Hoofdstuk 6. Het is echter niet bekend of mensen met PWS een grotere kans hebben om dement te worden. Om meer inzicht te krijgen in het vóórkomen van dementie bij ouderen met PWS, is onderzoek in grotere onderzoeksgroepen noodzakelijk. Tevens is het van belang om door middel van obductie op hersenmateriaal te bekijken of er (voor)tekenen van de ziekte van Alzheimer of andere vormen van dementie worden gevonden bij mensen met PWS.

Hoofdstuk 7 richtte zich op de kenmerken van PWS op oudere leeftijd. Vroegtijdige veroudering werd gezien bij mensen met PWS: bij velen van hen namen de functionele vaardigheden af vanaf de leeftijd van 40 jaar. Dit proces startte meestal met een afname energie en vermindering van de mobiliteit. Vanaf de leeftijd van 50 jaar werd een forse achteruitgang op het gebied van ADL (Activiteiten van het Dagelijks Leven), psychisch functioneren, lichamelijk functioneren en zorgafhankelijkheid gezien. Lichamelijke problemen van de oudere mensen met PWS omvatten hart- en vaatziekten, diabetes mellitus, huidproblemen, orthopedische en psychiatrische problemen. Lagere spiegels van oestrogenen, testosteron en groeihormoon zouden een rol kunnen spelen bij het proces van vroegtijdige veroudering. Ook het chronische verloop van psychiatrische problemen en het chronische gebruik van psychofarmaca zou van invloed kunnen zijn op het verouderingsproces.

In Hoofdstuk 8, de algemene discussie, werden de resultaten van het onderzoek in een breder perspectief geplaatst en methodologische kanttekeningen bij het onderzoek geplaatst. We hebben aanbevelingen gedaan voor het klinisch implementeren van de resultaten en voor toekomstige onderzoeksmogelijkheden. Een vroege diagnose, scholing van begeleiders, het routinematige vervolgen van de gezondheid en tijdige behandeling van bijkomende aandoeningen, zijn essentieel voor een betere kwaliteit van bestaan van mensen met PWS. In Bijlage 1 doen we een voorstel voor het signaleren van gezondheidsproblemen bij volwassenen met PWS. Medische spoedsituaties verdienen daarbij bijzondere aandacht. Een eerste aanzet daarvoor is beschreven in de publicatie Medical Alerts (zie Bijlage 2). Daarin zijn de algemene kenmerken van het syndroom en mogelijke complicaties bij acute aandoeningen samengevat. Het is essentieel om de factoren die bijdragen aan gezond ouder worden met Prader-Willi syndroom de komende jaren in klinisch multidisciplinair verband verder te ontrafelen. Dit werk zal uiteraard moeten worden ondersteund door wetenschappelijk onderzoek.

In Bijlage 3-7 wordt een aantal specifieke onderwerpen zoals maagdilataties, lymfoedeem, verstoorde slaap \& gedragsproblemen, urine incontinentie en de GH/IGF-I as \& hypofyse functie \& grootte, nader uitgewerkt. 
LIST OF PUBLICATIONS 


\section{PUBLICATIONS}

Schrander-Stumpel CTRM, Sinnema $M$, van den Hout $L$, Maaskant MA, van Schrojenstein Lantman-de Valk HMJ, Wagemans A, Schrander JJP, Curfs LMG. Healthcare transition in persons with intellectual disabilities. General issues, the Maastricht model and Prader-Willi syndrome. Am J Med Genet C Semin Med Genet. 2007; 145C: 241-247.

Sinnema M, Maaskant M, van Schrojenstein Lantman-de Valk HMJ, Schrander-Stumpel CTRM, Curfs LMG. Gezond ouder worden ondanks het Prader-Willi syndroom. Tijdschrift voor Artsen voor Verstandelijk Gehandicapten 2007; 3: 74-75

Heitink $M V^{*}$, Sinnema $M^{*}$, van Steensel MA, Schrander-Stumpel CT, Frank $J^{\S}$, Curfs $\mathrm{LM}^{\S}$. Lymphedema in Prader-Willi syndrome. Int J Dermatol 2008; 47 Suppl1: 42-44.

Strydom A, Shooshtari S, Lee L, Raykar V, Torr J, Tsiouris J, Jokinen N, Courtenay K, Bass N, Sinnema M, Maaskant, M. Dementia in older adults with Intellectual Disabilities - epidemiology, presentation and diagnosis. JPPID 2010; 7: 96-110.

Von Gontard A, Didden R, Sinnema M, Curfs M. Urinary incontinence in persons with Prader-Willi Syndrome. BJU Int. 2010 ; 106: 1758-1762.

Maas APHM*, Sinnema $M^{*}$, Didden R, Maaskant MA, Smits MG, Schrander-Stumpel CTRM, Curfs LMG. Sleep disturbances and behavioural problems in adults with PraderWilli syndrome. J Intellect Disabil Res 2010; 54: 906-917

Sinnema M, van Roozendaal KEP, Maaskant MA, Smeets HJM, Engelen JJM, JonkerHouben N, Schrander-Stumpel CTRM, Curfs LMG. Different distribution of genetic subtypes of Prader-Willi syndrome in elderly. Eur J Hum Genet 2010; 18: 993-998

Sinnema M, Schrander-Stumpel CTRM, Verheij HEG, Meeuwsen M, Maaskant MA, Curfs LMG. Dementia in a woman with Prader-Willi syndrome. Eur J Med Genet 2010; 53: $145-148$.

Sinnema M, Einfeld SL, Schrander-Stumpel CTRM, Maaskant MA, Boer H, Curfs LMG. Behavioural phenotype in adults with Prader-Willi syndrome. Res Dev Dis 2011; 32: 604-612.

Van Nieuwpoort IC*, Sinnema $\mathrm{M}^{*}$, Castelijns JA, Twisk JWR, Curfs LMG, Drent ML. The GH/IGF-I axis and pituitary function and size in adults with Prader-Willi syndrome. Horm Res Paediatr 2011; 75: 403-411.

Sinnema M, Boer H, Collin Ph, Maaskant MA, Schrander-Stumpel CTRM, Curfs LMG. Psychiatric illness in a cohort of adults with Prader-Willi syndrome. Res Dev Dis 2011; 32: $1729-1735$

Sinnema M, Maaskant MA, van Schrojenstein Lantman-de Valk HMJ, van Nieuwpoort IC, Drent ML, Curfs LMG ${ }^{\S}$, Schrander-Stumpel CTRM ${ }^{\S}$. Physical health problems in adults with Prader-Willi syndrome. Am J Med Genet Part A 2011. 155:2112-2124 
Sinnema M, Maaskant MA, van Schrojenstein Lantman-de Valk HMJ, Boer $\mathrm{H}$, Curfs $\mathrm{LMG}^{\S}$, Schrander-Stumpel CTRM ${ }^{\S}$. The use of medical care and prevalence of serious illness in a Dutch Prader-Willi cohort. 2011. Submitted

Sinnema M, Schrander-Stumpel CTRM, Maaskant MA, Boer H, Curfs LMG. Ageing in Prader-Willi syndrome: Twelve persons over the age of 50 years. 2011. Submitted

Sinnema M, Curfs LMG, Louisse AC, Calamé JJ, Stehouwer CDA, Schrander-Stumpel CTRM. Acute gastric dilatation as a cause of death in Prader-Willi syndrome: two cases. 2011. Submitted

${ }^{*}$ Equal contribution by both authors

$\S$ Authors share senior authorship 



\section{Appendix 1}

CHECKLIST FOR PREVENTIVE MANAGEMENT IN ADULTS WITH PRADER-WILLI SYNDROME 
APPENDIX 1 


\section{Checklist for preventive management in adults with PWS}

\begin{tabular}{|c|c|}
\hline Category & Evaluation \\
\hline \multirow[t]{6}{*}{ General } & Evaluate general well-being \\
\hline & Evaluate working and living circumstances \\
\hline & Assess relationships and sexuality \\
\hline & Assess use of tobacco and alcohol \\
\hline & $\begin{array}{l}\text { Consider general (ID) population screening programmes (e.g. for } \\
\text { sensory impairment, PAP smear, breast cancer) }\end{array}$ \\
\hline & Evaluate medication use and possible side effects \\
\hline Genetics & Confirm clinical diagnosis of PWS by genetic tests* \\
\hline \multirow[t]{2}{*}{ Feeding and weight } & Measure and plot weight and body mass index \\
\hline & Assess diet, exercise and management for obesity prevention \\
\hline \multirow[t]{3}{*}{ Cardiovascular } & Assess for hypertension \\
\hline & Evaluate for type II diabetes mellitus \\
\hline & Assess for cardiac complaints. Consider ECG, cardiac ultrasound \\
\hline Respiratory & Evaluate history of respiratory infections \\
\hline \multirow[t]{2}{*}{ Gastro-intestinal } & Assess constipation \\
\hline & Assess rectal bleeding (and rectal picking) \\
\hline \multirow[t]{7}{*}{ Endocrine } & Assess menstrual cycle \\
\hline & Evaluate for osteoporosis and obtain bone densometry \\
\hline & Consider the need for vitamin $D$ and calcium supplementation \\
\hline & Consider the need for sex hormone replacement \\
\hline & Consider the need and possibilities for growth hormone replacement \\
\hline & Consider evaluation of adrenal insufficiency \\
\hline & Assess thyroid function \\
\hline \multirow[t]{3}{*}{ Genito-urinary } & $\begin{array}{l}\text { Evaluate testicular descent. Consider referral for orchidopexy if } \\
\text { undescended }\end{array}$ \\
\hline & Assess for inguinal hernia \\
\hline & Assess urinary incontinence \\
\hline \multirow[t]{5}{*}{ Skeletal } & Assess scoliosis/kyphosis \\
\hline & Assess for arthrosis in any joint \\
\hline & Assess for hip dysplasia* \\
\hline & Assess for knee problems \\
\hline & Assess for feet abnormalities \\
\hline \multirow[t]{2}{*}{ Sleep } & Obtain sleep history \\
\hline & Consider referral for polysomnography \\
\hline Ophtalmologic & Opthalmologic evaluation for strabismus and visual acuity \\
\hline Skin & Evaluate the skin for signs of skinpicking, oedema and erysipelas \\
\hline Dental & Refer for dental care \\
\hline Behavior and & Assess behavioural problems, changes and management \\
\hline psychiatric & Assess for affective disorders and psychosis (and possible precursors) \\
\hline \multirow{3}{*}{$\begin{array}{l}\text { Development and } \\
\text { function }\end{array}$} & Evaluate physical fitness (physical therapy evaluation) \\
\hline & Perform IQ test \\
\hline & Assess functional decline and signs of dementia (50+ yrs) \\
\hline
\end{tabular}

* if not done previously 



\section{Appendix 2}

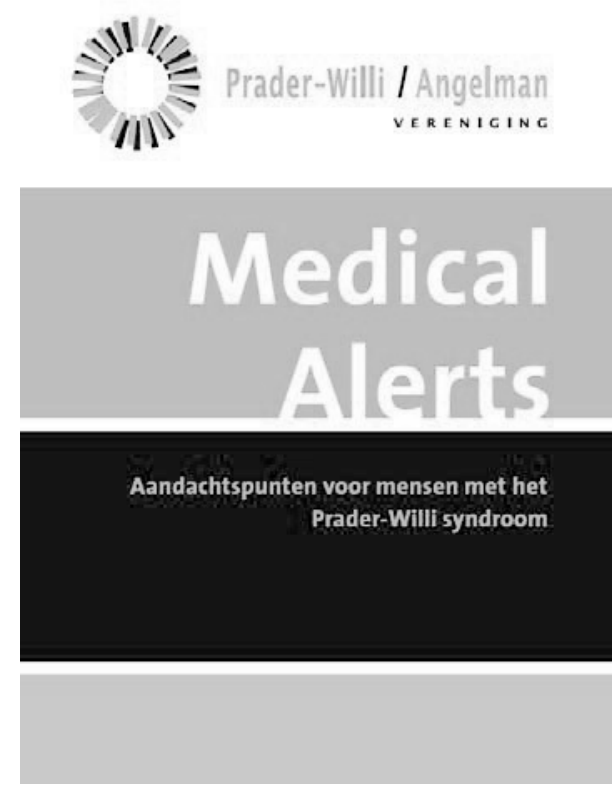

Sinnema M, Schrander-Stumpel CTRM, Curfs LMG

Medical Alerts; aandachtspunten in spoedsituaties voor mensen met PraderWilli syndroom. Utrecht/Maastricht, April 2009. 


\section{VOORWOORD}

Mensen met Prader-Willi syndroom (PWS) hebben specifieke zorgbehoeften. Het is van het grootste belang dat ook in noodsituaties rekening gehouden wordt met bepaalde kenmerken die samengaan met het PWS. Dit boekje kan hierbij helpen. Het is bedoeld voor ouders/verzorgers en kan in spoedeisende situaties op de eerste hulp, aan ambulancepersoneel of behandelend artsen worden gegeven.

Het boekje bestaat uit drie hoofdstukken. In het eerste hoofdstuk is informatie weergegeven die van belang is met betrekking tot spoedeisende medische situaties. Aandachtspunten rond specifieke problemen komen aan de orde in hoofdstuk twee. In het derde hoofdstuk worden de risico's besproken die anesthesie met zich meebrengt.

\section{PRADER-WILLI SYNDROOM}

\section{Inleiding}

Prader-Willi syndroom (PWS) is een complexe genetische aandoening, veroorzaakt door een verandering op chromosoom 15. PWS komt zowel bij mannen als vrouwen voor en bij verschillende bevolkingsgroepen. De incidentie onder pasgeborenen is ca. 1:30.000, de populatie prevalentie ca. 1:50.000.

PWS wordt gekenmerkt door spierslapte, kleine gestalte (indien niet behandeld met groeihormoon), ontwikkelingsachterstand, onvolledige puberteitsontwikkeling, gedragsproblemen en een chronisch hongergevoel dat, tezamen met een metabolisme dat veel minder calorieën verbruikt dan normaal, kan leiden tot overmatig eten en levensbedreigende obesitas.

Kinderen met PWS worden geboren met een laag geboortegewicht, hypotonie en voedingsproblemen door verminderde spierkracht ("failure to thrive"). De tweede fase ("thriving too well") ontstaat vanaf de leeftijd van 2-5 jaar en houdt de rest van het leven aan. In de tweede fase staan een toegenomen eetlust, beheersen van het gewicht, motorische ontwikkelingsachterstand en gedragsproblemen op de voorgrond.

Andere factoren die problemen kunnen veroorzaken zijn negatieve reacties op medicatie, hoge pijngrens, gastro-intestinale en respiratoire problemen, onvermogen tot braken en een onstabiele temperatuur.

Medische complicaties kunnen een onverwacht en ernstig beloop hebben bij mensen met PWS. 


\section{HOOFDSTUK 1}

\section{MEDISCHE ALARMSIGNALEN: BELANGRIJKE OVERWEGINGEN IN SPOED SITUATIES}

\section{Bijnierinsufficiëntie}

Uit onderzoek is gebleken dat $60 \%$ van de personen met PWS een bijnierinsufficiëntie heeft tijdens stress. Een adequaat functionerende bijnier is belangrijk in geval van ziekte en stress. Mogelijk houdt de bijnierinsufficiëntie verband met het hogere sterftecijfer bij kinderen met PWS.

Voor de behandelend arts:

Om deze reden wordt geadviseerd om PWS patiënten tijdens stress/ziekte te behandelen met een stressdosering hydrocortison. Een voorbeeld van een dergelijk stressschema is bijgevoegd (zie bijlage 1).

\section{Slaap- en ademhalingsproblemen}

Een aantal slaapgerelateerde ademhalingsproblemen wordt gezien bij mensen met PWS. Soms stopt de ademhaling even tijdens het slapen. Dit wordt een apneu genoemd. Tijdens de apneu wordt er te weinig zuurstof in het bloed opgenomen. Dit kan tot benauwdheid leiden waardoor iemand wakker wordt. Als dit vaak gebeurd kan iemand 's nachts meerdere malen per uur wakker worden. Deze onderbroken slaap leidt tot slaperigheid overdag en afname van de lichamelijke conditie. En verder kan het ook leiden tot een toename van gedragsproblemen en een afname van leer- en prestatiemogelijkheden.

De oorzaak van de apneu is meestal een tijdelijke obstructie (blokkade) ergens in de luchtpijp: Obstructief Slaap Apneu Syndroom (OSAS). Dit kan gerelateerd zijn aan het overgewicht, dik speeksel, een zijwaartse kromming van de rug of vergroting van de amandelen in combinatie met nauwe bovenste luchtwegen bij mensen met PWS. Slapte van de ademhalingsspieren kan hierbij ook een rol spelen.

Maar er zijn ook mensen met PWS die te weinig ademen door een verstoring in de aansturing van de ademhaling vanuit de hersenen: centrale slaap apneus. Jongere kinderen zonder overgewicht blijken geen OSAS te hebben, maar wel vaker centrale slaap apneus. 
Voor de behandelend arts:

De slaapgerelateerde ademhalingsproblemen worden vaak gediagnosticeerd zoals slaap apneu (obstructief (OSAS), centraal of gemixt) of hypoventilatie met hypoxie.

Cardiorespiratoire responsen op een snel ontwikkelende hypoxie en hypercapnie zijn vaak afwezig, afgenomen of vertraagd bij mensen met PWS. Zuurstof dient met zorg toegediend te worden. Sommige mensen met PWS hebben hypoxemie als hun enige ventilatoire drive en zuurstoftherapie kan de ademhaling gedurende de nacht verslechteren.

OSAS kan tot ernstige complicaties leiden zoals hypertensie, cardiovasculaire problemen en cor pulmonale. Cor pulmonale speelt een belangrijke rol in de morbiditeit en mortaliteit van volwassenen met Prader-Willi syndroom.

\section{Maagproblemen}

Het uitzetten of opzwellen van de buik, pijn en/of braken kunnen een teken zijn van een levensbedreigend maagprobleem. Dit komt vaker voor bij mensen met PWS dan in de algemene bevolking. Deze tekenen dienen zeer serieus genomen te worden.

Voor de behandelend arts:

Een aandoening omschreven als acute idiopathische maagdilatatie is beschreven. Bij deze aandoening zet de maag van de persoon met PWS uit door voedsel, zonder dat zij een teken krijgen van vol zitten of pijn. Slanke mensen met PWS lopen mogelijk een hoger risico. De maag kan dusdanig uitzetten dat de bloedtoevoer wordt afgekneld en necrose ontstaat. Dit ziektebeeld moet beschouwd worden als een chirurgisch spoedgeval. Als een persoon met PWS deze symptomen laat zien, dient hij/zij scherp in de gaten gehouden te worden. Een buikoverzichtsfoto is een eerste stap in de diagnostiek. Het is van het grootste belang dan niets meer per os te geven.

Verslikken komt regelmatig voor bij mensen met PWS door snel eten indien tijdelijk geen toezicht aanwezig is. Dit kan levensbedreigende gevolgen hebben.

\section{Onvermogen tot braken}

Bij mensen met PWS komt braken weinig voor. Braken kan een eerste teken zijn van een levensbedreigende ziekte (zie bijvoorbeeld hierboven onder maagproblemen). 
Voor de behandelend arts:

Emetica zijn vaak niet effectief en herhaalde doses kunnen toxisch zijn. Met dit kenmerk dient rekening gehouden te worden in het licht van de hyperfagie en de mogelijke inname van ongekookt, bedorven of anderszins ongezond voedsel.

\section{Onstabiele lichaamstemperatuur}

Mensen met PWS hebben vaak een verstoorde temperatuurregulatie. Bij infectieziekten geeft de hoogte van de koorts veelal geen goede indruk van de mate van ziek-zijn. Vaak ontstaat er geen koorts. Dit kan ten onrechte de indruk geven dat het wel meevalt met de ernst van de ziekte. Omgekeerd kan juist een sterke stijging van de temperatuur ontstaan, terwijl er slechts sprake is van een lichte infectie.

\section{Voor de behandelend arts:}

Idiopathische hyper- en hypothermie zijn beschreven. Hyperthermie kan zich voordoen tijdens een onschuldige ziekte en tijdens procedures waarbij anesthesie noodzakelijk is. Bij ernstige infecties kan koorts afwezig zijn of zelfs een ondertemperatuur ontstaan.

\section{Hoge pijngrens}

Het ontbreken van pijnsignalen kan aanwezigheid van een infectie of letsel maskeren. Het is mogelijk dat een mensen met PWS pas pijn aangeven indien de infectie zich reeds in een gevorderd stadium bevindt of dat de pijn moeilijk te lokaliseren is. Aanwijzingen van ouders/verzorgers over subtiele veranderingen in toestand of gedrag dienen altijd eerst onderzocht te worden op medische oorzaken.

\section{Hyperfagie (overmatige eetlust)}

De onverzadigbare eetlust kan leiden tot een levensbedreigende gewichtstoename, die snel kan ontstaan, zelfs tijdens een dieet. Supervisie van mensen met PWS is noodzakelijk in alle omstandigheden waar voedsel toegankelijk is. Hier dient ook in situaties op de eerste hulp, opname op een afdeling of rondom operaties rekening mee gehouden te worden. Degenen met een normaal gewicht hebben dit bijna zonder uitzondering bereikt door strikte externe controle van hun dieet en voedselinname. 


\section{HOOFDSTUK 2}

\section{AANDACHTSPUNTEN BIJ SPECIFIEKE PROBLEMEN}

\section{Groeihormoonbehandeling}

Kinderen met PWS worden veelal behandeld met groeihormoon. Hiermee wordt niet alleen de lengtegroei bevorderd, maar bovenal de lichaamssamenstelling verbeterd.

Voor de behandelend arts:

Een recente studie geeft aan dat er mogelijk extra risico op acute respiratoire problemen bestaat in de eerste 9 maanden na de start van groeihormoon therapie (o.a. door een vergroting van de amandelen). Om deze reden worden extra controles geadviseerd.

\section{Luchtweginfecties}

Relatief milde luchtweginfecties kunnen bij kinderen met PWS een onverwacht en/of gecompliceerd verloop hebben.

Voor de behandelend arts:

Opname ter observatie en behandeling met antibiotica worden laagdrempelig aanbevolen.

\section{Slaperigheid overdag}

Slaperigheid overdag wordt als kenmerk van PWS beschouwd. Het bestaan van slaapgerelateerde ademhalingsproblemen (OSAS) kan hierbij mede een rol spelen. Verstoringen in de slaap architectuur (moeilijk in slaap vallen, vaak wakker worden) komen ook voor.

Met het risico van slaperigheid overdag dient in het bijzonder rekening gehouden te worden bij het in bad gaan. Een aantal mensen met PWS is (bijna) verdronken nadat zij in bad in slaap waren gevallen. Goede begeleiding bij baden is dan ook aangewezen.

Soms wordt gedacht dat slaperigheid overdag bij mensen met PWS te wijten is aan narcolepsie. Dit zijn aanvallen van slaap, gewoonlijk samengaand met forse spierverslapping (kataplexie) tijdens dat in slaap vallen. Dit blijkt meestal niet het geval te zijn, met name kataplexie verschijnselen komen weinig voor. 
Bij een toename van slaperigheid overdag wordt nader onderzoek naar slaap apneu of een andere oorzaak voor de slaperigheid geadviseerd.

\section{Negatieve reacties op bepaalde medicatie}

Mensen met PWS kunnen ongebruikelijke reacties laten zien op standaarddoseringen van medicijnen (zoals psychiatrische medicatie of middelen die gebruikt worden bij de anesthesie).

Voor de behandelend arts:

Voorzichtigheid is zeker geboden bij medicatie die sedatie veroorzaakt; langer aanhoudend en meer uitgesproken effect bij gebruik van deze middelen is gerapporteerd.

\section{Watervergiftiging}

Een watervergiftiging kan ontstaan als iemand een abnormale hoeveelheid water drinkt zonder daarbij te eten. De nare gevolgen ontstaan doordat het natrium (zout) gehalte in het lichaam daalt. Watervergiftigingen komen soms voor bij mensen met PWS. Dit kan te maken hebben met het gebruik van bepaalde medicatie, psychiatrische problemen of met de afwezigheid van een verzadigingsgevoel.

\section{Voor de behandelend arts:}

Een abnormale water inname kan leiden tot een hyponatriëmie. Symptomen kunnen hoofdpijn, misselijkheid, verwardheid, insulten en bewustzijnsdaling omvatten. Behandeling bestaat uit het wegnemen van de oorzaak en herstellen van de hyponatriëmie.

\section{Diabetes mellitus}

Ongeveer een kwart van de volwassenen met PWS ontwikkelt diabetes mellitus type II als gevolg van obesitas.

Voor de behandelend arts:

Behandeling omvat stimuleren van gewichtsafname en lichaamsbeweging. Zoals bij obesitas gerelateerde diabetes in de algemene populatie wordt deze behandeld met orale anti-diabetica, indien nodig aangevuld met insuline.

\section{Huidproblemen}

Skin-picking, het peuteren en krabben aan oneffenheden van de huid, is een van de gedragskenmerken van PWS. Dit kan het genezen van infuus- en/of 
chirurgische wonden vertragen (zie verder het hoofdstuk over anesthesie). Wondroos komt frequent voor. Mensen met PWS uiten hierover vaak weinig klachten waardoor de problemen pas in een gevorderd stadium aan het licht komen. Personen met PWS krijgen ook sneller blauwe plekken. De wondjes en blauwe plekken leiden soms onterecht tot de verdenking van mishandeling.

\section{Gedrag en psychiatrie}

Door de bijzondere en ingrijpende emotionele en gedragsproblemen en de verhoogde kwetsbaarheid voor het ontwikkelen van psychiatrische stoornissen kunnen mensen met PWS onder de aandacht van psychiaters komen. Er is een typerend gedragsprofiel dat samenhangt met de genetische basis van PWS. De psychiatrische en gedragsproblematiek bij PWS bestaat uit:

- Koppigheid, prikkelbaarheid, agressief gedrag en verhoogde afleidbaarheid. Een verstoord verzadigingsgevoel leidt vaak tot conflictueus gedrag met betrekking tot excessief eten.

- Obessies, compulsies en stereotiep zelfdestructief gedrag zijn kenmerkend voor personen met PWS. Ook worden angststoornissen en depressies beschreven. Stoornissen uit het autisme spectrum stoornissen worden nogal eens verward met de obessies en compulsies die kenmerkend zijn voor het gedragsfenotype van PWS.

- Psychotische symptomen: de symptomatologie wordt veelal gekenmerkt door achterdocht, waanideeën, agitatie, angst en een verstoord slaappatroon. Uitgebreide stemmingswisselingen, die soms geduid worden als bipolaire stemmingsstoornis, komen vaak voor.

Voor de behandelend arts:

Het is van groot belang deze problemen vroegtijdig te onderkennen en te behandelen. Succesvolle behandeling met antipsychotica in lage doseringen zijn beschreven. Andere auteurs gebruikten stemmingsstabilisatoren omwille van het cyclisch beloop. Deze problematiek kan zich ook ontwikkelen op jonge leeftijd.

\section{Orthopedische problemen}

In geval van trauma dient rekening gehouden te worden met de hoge pijngrens van mensen met PWS. Er bestaat een kans dat ze te lang blijven doorlopen met een fractuur.

Scolioses komen frequent voor, ook op zeer jonge leeftijd. Het is van belang het ontstaan en beloop hiervan goed te volgen. Het risico op complicaties bij scoliosechirurgie is verhoogd. 


\section{HOOFDSTUK 3}

\section{ANESTHESIE}

Bij mensen met PWS kunnen de volgende gezondheidsaspecten van invloed zijn op het toedienen van anesthesie.

- Instabiele glucosestofwisseling

Grote schommelingen van de glucosespiegel zijn mogelijk.

- Obesitas

Mensen met PWS en fors overgewicht hebben meer kans op obstructieve apneu, longaandoeningen en diabetes.

- Dysmorfe aangezichtsafwijkingen/ intubatieproblemen

Ook bij niet-obese mensen met PWS moet men bedacht zijn op een moeilijke intubatie vanwege het smalle midden gelaat en nauwere luchtwegen.

- Hoge pijndrempel

Mensen met PWS reageren minder op pijn dan anderen.

- Instabiele temperatuur

Vanwege een stoornis in de hypothalamus kunnen mensen met PWS hypo- danwel hyperthermisch zijn.

- Dik speeksel

Een veelvoorkomend probleem bij PWS is bijzonder dik speeksel.

- Zoeken naar voedsel/nuchter zijn

Mensen met PWS kennen geen of weinig verzadigingsgevoel en vertellen wellicht niet de waarheid wanneer gevraagd wordt of ze vlak voor de operatie hebben gegeten. Van iemand met PWS moet dus aangenomen worden dat hij of zij recent gegeten heeft, tenzij ouder/verzorger zeker is van het tegendeel.

- Hypotonie

Het merendeel van de kinderen met PWS heeft een significant lagere spierspanning (hypotoon). Vanaf het tweede levensjaar verbetert dat. Toch hebben de meeste volwassenen met PWS ook nog een zekere mate van hypotonie.

- $\quad$ Skin picking (het krabben en peuteren aan oneffenheden van de huid) Skin picking kan het genezen van infuus- en/of incisiewonden bemoeilijken. Meestal is het voldoende om de wonden goed te verbinden. Afhankelijk van iemands cognitieve vaardigheden zijn beperkende maatregelen of handschoenen nodig om het genezingsproces van chirurgische wonden niet te vertragen. 
- Hypothyreoidie

Hypothyreoidie kan voorkomen bij mensen met PWS.

- Moeilijke toegang tot de aderen bij infuus en bloed prikken

Door obesitas en gebrek aan spiermassa kan het prikken van een infuus of bloed bij mensen met PWS soms moeilijkheden veroorzaken.

- Gedragsproblemen

Mensen met PWS hebben vaker emotionele uitbarstingen, obsessiefcompulsief gedrag en psychosen. Bij behandeling met psychofarmaca moet men rekening houden met de mogelijke interactie van deze medicijnen met anesthetica.

- Groeihormoon tekort

Het PWS gaat gepaard met een groeihormoondeficiëntie. Mensen met PWS, die geen groeihormoon behandeling krijgen, kunnen smallere luchtwegen hebben dan verwacht zou worden op basis van hun lichaamsbouw of leeftijd.

- Epilepsie

Incidenteel komt ook epilepsie voor bij mensen met PWS.

- Bijnierinsufficiëntie

$60 \%$ van de mensen met PWS heeft een bijnierinsufficiëntie tijdens stress. Om deze reden wordt tijdens stress, ziekte en operaties een behandeling met een stressdosering hydrocortison geadviseerd (tenzij bijnierinsufficiëntie is uitgesloten met een recente metyrapontest). Voor een dergelijk stress schema: zie bijlage 1.

- Cardiorespiratoire responsen

Cardiorespiratoire responsen op een snel ontwikkelende hypoxie en hypercapnie zijn vaak afwezig,afgenomen of vertraagd in mensen met PWS.Zuurstof dient met zorg toegediend te worden. Sommige mensen met PWS hebben hypoxemie als hun enige ventilatoire drive.

\section{Ontwaken na anesthesie/ademhalingsproblemen}

Zoals al eerder opgemerkt is een groot deel van de problemen te wijten aan obesitas, hypothalame dysfunctie, centrale en obstructieve apneus. Een lagere spierspanning en chronische aspiraties (met als gevolg luchtweginfecties) kunnen ook een rol spelen bij ademhalingsproblemen na anesthesie. Slaperigheid na anesthesie kan veroorzaakt worden door onderliggende slaperigheid en/of een component van centrale apneu. Observatie gedurende de nacht moet overwogen worden. 


\section{INFORMATIE}

De Prader-Willi/Angelman Vereniging

Mevr. T. Stranders

Postbus 1223

3500 BE Utrecht

Telefoon: $\quad$ 030-2727316

Bereikbaar: maandag $\mathrm{t} / \mathrm{m}$ donderdag van 09:30-16:00

E-mail: $\quad$ t.stranders@platformvg.nl

Nederlandse Vereniging Artsen voor Verstandelijk Gehandicapten (NVAVG)

Secretariaat NVAVG

Postbus 545

7500 AM Enschede

Telefoon: 0878 - 759338

e-mail: secretariaat@nvavg.nl

Website: $\quad$ www.nvavg.nl (o.a. lijst met AVG poliklinieken)

Afdeling Klinische Genetica - Gouverneur Kremers Centrum

Maastricht Universitair Medisch Centrum

Postbus 5800

6202 AZ Maastricht

Telefoon: $\quad$ 043-3875855

Website: $\quad$ www.genetica.azm.nl

www.gkc-um.nl

Stichting Kind en Groei

Westzeedijk 106

3016 AH Rotterdam

Telefoon: $\quad$ 010-2251533

Website: $\quad$ www.kindengroei.nl

Nuttige websites

Nederlandse Prader-Willi/Angelman vereniging: www.praderwillisyndroom.nl International Prader-Willi Syndrome association: www.ipwso.org 


\section{Bij overlijden}

Onderzoek naar de oorzaken van overlijden van mensen met PWS is in het belang van iedereen die nu of in de toekomst deze aandoening heeft. Indien $\mathrm{u}$, in geval van overlijden, bereid bent (medische) gegevens beschikbaar te stellen, dan kunt u contact opnemen met de Prader-Willi/Angelman Vereniging, Postbus 1223, 3500 BE Utrecht. Telefoon 030-2727316, email: t.stranders@platformvg.nl

\section{Colofon}

Tekst:

Drs. M. Sinnema, arts-onderzoeker, Maastricht

Prof. dr. C.T.R.M. Schrander-Stumpel, hoogleraar klinische genetica, Maastricht

Prof. dr. L.M.G. Curfs, hoogleraar verstandelijke handicap, Maastricht

Met financiële steun van de Prader-Willi oudervereniging, het Prader-Willi fonds en ZonMw

Met dank voor het kritisch doorlezen aan:

T. Stranders (oudervereniging), Dr. J. Weterings (anesthesist), Prof. dr. H.M.J. van Schrojenstein Lantman-de Valk (AVG), Dr. W. Braam (AVG), Drs. M. Tonino (AVG), Dr. R. de Lind van Wijngaarden (Stichting Kind en Groei), Drs. P.J.L. Collin (kinder- en jeugdpsychiater)

Gebaseerd op een uitgave van:

Prader-Willi Syndrome Association (USA)

5700 Midnight Pass Road, Suite 6

Sarasota, Florida 34242

Telephone: (800)926-4797 or (941)312-0400

Email: national@pwsausa.org

www.pwsausa.org 
Bijlage Medical Alerts:

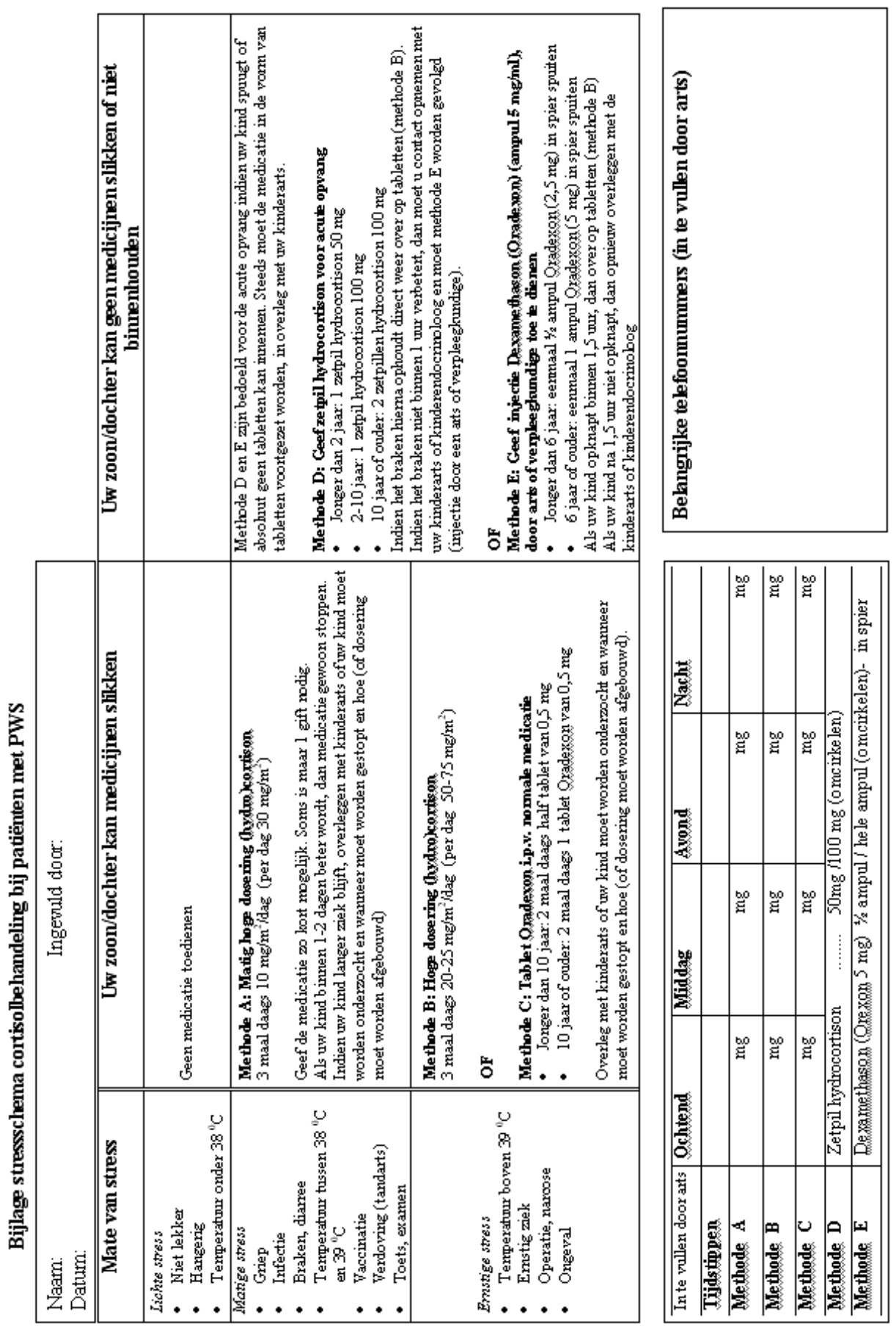





\title{
Appendix 3
}

\author{
ACUTE GASTRIC DILATATION AS A CAUSE OF \\ DEATH IN PRADER-WILLI SYNDROME: TWO CASES
}

Sinnema M, Curfs LMG, Louisse AChr, Calamé JJ, Stehouwer CDA, Schrander-Stumpel CTRM.

Submitted 


\section{ABSTRACT}

Prader-Willi syndrome (PWS) is a genetic condition due to loss of the expression of paternally derived genes located in the critical chromosome 15q11-q13 region, resulting in hypotonia, hypogonadism, intellectual disabilities, typical facial appearance, behavioural problems and hyperphagia. Besides the medical problems secondary to obesity, there is another risk in adults with PWS: acute gastric dilatation. We present two cases of death due to massive gastric dilatation in PWS. In these cases, the mild symptoms rapidly evolved to critical illness and death. The pathophysiologic mechanisms underlying these events are discussed. These cases illustrate the need for increased awareness of gastric dilatation in persons with PWS as a rare but rapidly progressive and possibly fatal condition. Most important in the treatment is early recognition. 


\subsection{INTRODUCTION}

Prader-Willi syndrome (PWS) is a genetic condition due to loss of the expression of paternally derived genes located in the critical chromosome 15q11-q13 region, resulting in hypotonia, hypogonadism, intellectual disabilities, typical facial appearance, behavioral problems and hyperphagia ${ }^{1}$. The mechanisms of the hyperphagia in PWS are still largely unknown. A dysfunction of the satiety system is suggested to be one of the major problems $^{2-4}$. Excessive eating behaviour, in combination with lower caloric requirements, growth and sex hormone deficiencies, short stature and hypotonia contribute, without adequate dietary restrictions, to serious obesity. In adult life, this leads to obesity-related medical complications like diabetes mellitus, cardiopulmonary disease and possibly early death ${ }^{5-9}$. Besides the medical problems secondary to obesity, there appears to be another risk in persons with PWS: acute gastric dilatation.

Although more attention is being paid to gastro-intestinal problems in PWS, reports in the literature on gastric problems in persons with PWS are still limited ${ }^{6,10-12}$. Wharton et al. ${ }^{10}$ described six PWS patients with acute dramatic gastric dilatation. Three young adult women presented with signs of vomiting and apparent gastroenteritis. The course rapidly progressed to gastric dilatation and gastric necrosis. These three women were morbidly obese and one died. Another patient died of sepsis and disseminated intravascular coagulation after gastric dilatation without necrosis. In the last two young girls the gastric dilatation resolved without surgical intervention. In a recent study, Stevenson et al. ${ }^{11}$ reported another four cases of unexpected death due to gastric perforation and necrosis. Four additional individuals were suspected to have gastric rupture and/or necrosis, but autopsy was not done. Finally, data from a parent support group bereavement program show that gastric perforation/necrosis was the cause of mortality in 3-6\% of individuals in the cohort who were known to the Prader-Willi Association (USA) ${ }^{11}$.

We present two cases of death, presumably due to acute gastric dilatation in PWS. The first patient has been reported briefly before ${ }^{6}$. The possible mechanisms causing gastric dilatation are discussed.

\subsection{CLINICAL REPORTS}

\section{Case 1}

A 38-year-old man presented with abdominal pain, heavy transpiration and diarrhea. He had genetically confirmed PWS due to uniparental disomy or an 
imprinting defect. In addition, he had a small marker chromosome 9. He also suffered from perinatal hypoxic encephalopathy. On examination, his temperature was $37.8^{\circ} \mathrm{C}$; earlier that day he had had a low temperature. His heart rate was 120 beats/minute and he was tachypnoeic with an oxygen saturation of $95 \%$. His BMl was $30 \mathrm{~kg} / \mathrm{m}^{2}$. Bowel sounds were hyperactive. He had a distended and tympanitic abdomen with tenderness in the left lower quadrant without peritoneal signs. Findings on rectal examination were normal. $\mathrm{He}$ was given analgesic medication. Some hours later (during the night) the man was found dead on the ground. His abdomen was grossly distended. He had vomited a large amount with a sanguinolent color. Three hours before he had still been approachable and had drunk some water.

At autopsy, the stomach, small intestines and the proximal part of the colon showed a considerable dilatation without signs of mechanical obstruction. There were no signs of gastric infarction or necrosis. The submucosal myenteric plexus appeared intact. The liver showed central steatosis and tissue loss with several bleedings, probably due to stasis. There was no apparent microscopic infarction of other organs. The wall of the left heart ventricle showed hypertrophy without areas of infarction. There was some ascites without peritonitis or perforation. Both lungs contained some aspirates of vegetable origin. The wall of the intestines showed multifocal areas with dysplasia of the inner circular muscle layer.

\section{Case 2}

A 21-year-old woman had received a diagnosis of PWS genetically confirmed by an abnormal methylation test. Her BMI was $21 \mathrm{~kg} / \mathrm{m}^{2}$. She went to a wedding party after a holiday with her residential group. At the wedding, she ate a lot. During the evening she complained of constipation and sat on the toilet for over half an hour. At home, she went to bed and, after 1.5 hours, she went to the toilet again after which the caregivers found some slimy substance in the basin. The next morning she said she was feeling a little better, although she was still tired and looked pale. She had lunch at a fast-food restaurant. Afterwards some slimy substance came out of her mouth like she was ruminating without swallowing. In the evening, she refused the regular dinner, but preferred bread over pasta, which was remarkable in her case. After dinner she started burping, ruminating and skin-picking. She did not like the cake that came with her cup of tea and she complained about severe abdominal pain and constipation. She asked for a bowl because she was nauseous and went to bed. The next morning she said that everything was alright because she wanted to visit her mother. After an hour, she called that she had fallen down. The caregivers found her vomiting. When they cleaned her mouth, they noticed that her jaw was broken and some of her teeth had fallen out. They put her on the bed. Her abdomen was distended enormously. She managed to say: "I 
want to go to my mum and I want to eat...", and then she died. No autopsy was performed.

\subsection{DISCUSSION}

We report the clinical history of two persons with PWS that presumably died from gastric dilatation.

The mortality rate of people with PWS in all age groups is higher than in the normal population ${ }^{13}$. Death in adults with PWS is usually due to cardiovascular complications of obesity or sleep apnea ${ }^{6,14-16}$. There is also an increased risk of choking due to rapid consumption of food ${ }^{17}$.

Gastric perforation/necrosis was the cause of mortality in 3-6\% of individuals in the cohort who were known to the Prader-Willi Association (USA) ${ }^{11}$. Causes of death in adults with PWS and a healthy weight status might be different. Because of the younger age at diagnosis, the use of growth-hormone therapy and improvement in care and support, the new adult population of persons with PWS is likely to be less obese. These slim individuals with PWS are suggested to be especially at risk of gastric dilatation and necrosis ${ }^{10,11}$. Although they are not obese, they still have an obsession with food and a single binge episode can result in a serious life threatening situation.

The two persons in our clinical reports had no history of morbid obesity. The persons had lived in a residential home for some years where their food intake was closely supervised. The weight status of both had been stable in the years before they died. The man in case 1 had a BMI around $30 \mathrm{~kg} / \mathrm{m}^{2}$, the woman in case 2 around $21 \mathrm{~kg} / \mathrm{m}^{2}$. In case 2 there was binge eating in the period before the complaints started. In both persons the mild abdominal complaints rapidly evolved to severe illness and death. The fluid loss by mouth in case 2 has, in combination with abdominal distention, been described as a typical characteristic of gastric dilatation ${ }^{18}$. The small amounts of fluid are not expelled forcefully like in ordinary vomiting, but seem to flow slowly through the esophagus to well up in the pharynx.

Acute gastric dilatation has been described in a range of conditions including anorexia nervosa and bulimia, trauma, the postoperative state, volvulus, some medications, electrolyte abnormalities, debilitating chronic illnesses, diabetes mellitus, acute infections, diaphragmatic herniation, psychogenic polyphagia, emotional stress and spinal deformities ${ }^{19-21}$. 
To develop a gastric dilatation there is a need for a source of air, fluid or food on the one hand, and an obstructive factor which limits this content to the stomach on the other hand ${ }^{19}$. The obstructive factor could be either mechanical or related to muscular, neural or humoral abnormalities ${ }^{22}$. In people with PWS, an episode of binge eating seems a reasonable source of a large stomach content. Because the distention can develop very quickly, it is also suggested that air sucked through the esophagus into the stomach causes dilatation ${ }^{18,19}$. Secondary to the distention of the stomach, fluid may leak from dysfunctional capillaries and/or gastric and pancreatic juices cannot be reabsorbed anymore ${ }^{19}$. People with PWS generally have the ability to ingest large amounts of food without abdominal complaints. In studies evaluating appetite behavior, people with PWS had unlimited access to food for one hour ${ }^{23-26}$. The subjects in all the studies continued to eat for the full hour, whereas the obese and normal weight controls had generally finished their meal after 15 minutes. The longer duration of consumption also resulted in a greater total food intake than in the control groups. There were no cases reported of abdominal discomfort, gastric distention or vomiting in people with PWS after these large meals. This suggests that, in persons with PWS, there might be an additional factor in gastric dilatation than binge eating alone.

In our first case a muscular abnormality seemed to be the cause of the ileus and distention of the stomach and intestines. A muscular abnormality as a cause for gastric dilatation in Prader-Willi syndrome has not been described before. The woman in case 2 was seriously suspected to have gastric dilatation, but without autopsy evidence. The underlying cause was not clear in this case.

Acute dilatation of the stomach has hemodynamical consequences. Secondary mechanical obstruction of the intra-abdominal inferior vena cava by the distended stomach seems to attribute to a decrease in venous return and arterial hypotension ${ }^{18}$. This, together with third space fluid loss, contributes to shock, electrolyte dysregulation and possible failure of perfusion of other organs ${ }^{27,28}$. In one case even compression of the aorta with ischemic injury of the bowels and lower extremities was reported ${ }^{29}$. Gastric necrosis is the most severe consequence of acute gastric dilatation ${ }^{21}$. Acute gastric necrosis is a rare condition because of the rich blood supply of the stomach. About half of the cases of gastric necrosis seem to be related to excessive food intake and acute gastric dilatation due to psychogenic polyphagia, anorexia nervosa, bulimia and $\mathrm{PWS}^{27}$.

The diagnosis of acute gastric dilatation is often delayed because of its rarity. In people with PWS, this delay may be even more likely because of typical 
Prader-Willi characteristics, like high pain threshold, decreased propensity to vomit and different temperature sensitivity ${ }^{1}$. Initially, the symptoms of gastric dilatation and/or necrosis include mild epigastric tenderness, vomiting or diarrhea, which can easily be misinterpreted as viral gastroenteritis. Symptoms can, however, progress rapidly to acute peritonitis, septic shock and death. Awareness of parents and other caregivers of this potential sequence of events in individuals with PWS is extremely important. A thorough medical evaluation should take place as soon as possible.

Diagnostics rely on physical examinations, plain abdominal films and CT scans 30. Endoscopy is important because this shows the general status of the gastric mucosa. First line treatment of acute gastric dilatation consists of nasogastric decompression, and fluid resuscitation ${ }^{19,21}$. Decompression and fluid resuscitation may easily lead to bleedings of necrotic lesions in the gastric mucosa $^{31}$. If conservative measures do not suffice or if gastric necrosis or perforation is suspected, surgical intervention is mandatory ${ }^{32}$. Treatment depends on the findings at laparotomy and may include surgical decompression and partial or complete gastric resection $20,21,27,33,34$.

The presently reported cases illustrate the need for increased awareness of gastric dilatation in persons with PWS as a rare, but rapidly progressive and possibly fatal condition. Early recognition is most important in the treatment of gastric dilatation. Especially in persons with PWS, physicians should have a high index of suspicion to diagnose this rare condition. Complaints of abdominal discomfort, nausea/regurgitating/vomiting, dyspnea and a distended abdomen, especially after a known episode of binge eating, should cause alarm bells to ring. Tools such as the "Medical Alerts" book of the PWSA (Prader-Willi Syndrome Association USA) can help parents and other caregivers to stress the possible life-threatening situation to physicians who are not familiar with PWS. 


\section{REFERENCES}

1. Holm VA, Cassidy SB, Butler MG, Hanchett JM, Greenswag LR, Whitman BY, Greenberg F: Prader-Willi syndrome: consensus diagnostic criteria. Pediatrics 1993; 91: 398-402.

2. Shapira NA, Lessig MC, He AG, James GA, Driscoll DJ, Liu Y: Satiety dysfunction in Prader-Willi syndrome demonstrated by fMRI. J Neurol Neurosurg Psychiatry 2005; 76: 260-262.

3. Hinton EC, Holland AJ, Gellatly MS, Soni S, Owen AM: An investigation into food preferences and the neural basis of food-related incentive motivation in Prader-Willi syndrome. J Intellect Disabil Res 2006; 50: 633-642.

4. Holland A, Whittington J, Hinton E: The paradox of Prader-Willi syndrome: a genetic model of starvation. Lancet 2003; 362: 989-991.

5. Goldstone AP: Prader-Willi syndrome: advances in genetics, pathophysiology and treatment. Trends Endocrinol Metab 2004; 15: 12-20.

6. Schrander-Stumpel CT, Curfs LM, Sastrowijoto P, Cassidy SB, Schrander JJ, Fryns JP: Prader-Willi syndrome: causes of death in an international series of 27 cases. Am J Med Genet A 2004; 124: 333-338.

7. Einfeld SL, Kavanagh SJ, Smith A, Evans EJ, Tonge BJ, Taffe J: Mortality in Prader-Willi syndrome. Am J Ment Retard 2006; 111: 193-198.

8. Nixon GM, Brouillette RT: Sleep and breathing in Prader-Willi syndrome. Pediatr Pulmonol 2002; 34: 209-217.

9. Goldstone AP, Holland AJ, Hauffa BP, Hokken-Koelega AC, Tauber M: Recommendations for the diagnosis and management of Prader-Willi syndrome. $J$ Clin Endocrinol Metab 2008; 93: 4183-4197.

10. Wharton RH, Wang T, Graeme-Cook F, Briggs S, Cole RE: Acute idiopathic gastric dilation with gastric necrosis in individuals with Prader-Willi syndrome. Am J Med Genet 1997; 73: 437-441.

11. Stevenson DA, Heinemann J, Angulo M, Butler MG, Loker J, Rupe N, Kendell P, Cassidy SB, Scheimann A: Gastric rupture and necrosis in Prader-Willi syndrome. J Pediatr Gastroenterol Nutr 2007; 45: 272-274.

12. De Peppo F, Di Giorgio G, Germani M, Ceriati E, Marchetti P, Galli C, Ubertini MG, Spera S, Ferrante G, Cuttini M, Cappa M, Castelli Gattinara G, Rivosecchi M, Crino A: BioEnterics intragastric balloon for treatment of morbid obesity in Prader-Willi syndrome: specific risks and benefits. Obes Surg 2008; 18: 1443-1449.

13. Whittington JE, Holland AJ, Webb T, Butler J, Clarke D, Boer H: Population prevalence and estimated birth incidence and mortality rate for people with PraderWilli syndrome in one UK Health Region. J Med Genet 2001; 38: 792-798.

14. Stevenson DA, Anaya TM, Clayton-Smith J, Hall BD, Van Allen MI, Zori RT, Zackai EH, Frank G, Clericuzio CL: Unexpected death and critical illness in Prader-Willi syndrome: report of ten individuals. Am J Med Genet A 2004; 124: 158-164.

15. Nagai $T$, Obata K, Tonoki $H$, Temma S, Murakami N, Katada $Y$, Yoshino A, Sakazume S, Takahashi E, Sakuta R, Niikawa N: Cause of sudden, unexpected death of Prader-Willi syndrome patients with or without growth hormone treatment. Am J Med Genet A 2005; 136: 45-48.

16. Smith A, Loughnan $G$, Steinbeck $\mathrm{K}$ : Death in adults with Prader-Willi syndrome may be correlated with maternal uniparental disomy. J Med Genet 2003; 40: e63.

17. Stevenson DA, Heinemann J, Angulo M, Butler MG, Loker J, Rupe N, Kendell P, Clericuzio CL, Scheimann AO: Deaths due to choking in Prader-Willi syndrome. Am J Med Genet A 2007; 143: 484-487. 
18. Engler HS, Kennedy TE, Ellison LT, Purvis JG, Moretz WH: Hemodynamics of experimental acute gastric dilatation. Am J Surg 1967; 113: 194-198.

19. Byrne JJ, Cahill JM: Acute gastric dilation. Am J Surg 1961; 101: 301-309.

20. Saul SH, Dekker A, Watson CG: Acute gastric dilatation with infarction and perforation. Report of fatal outcome in patient with anorexia nervosa. Gut 1981; 22: 978-983.

21. Todd SR, Marshall GT, Tyroch AH: Acute gastric dilatation revisited. Am Surg 2000; 66: 709-710.

22. Zarate N, Mearin F, Wang XY, Hewlett B, Huizinga JD, Malagelada JR: Severe idiopathic gastroparesis due to neuronal and interstitial cells of Cajal degeneration: pathological findings and management. Gut 2003; 52: 966-970.

23. Holland AJ, Treasure J, Coskeran P, Dallow J, Milton N, Hillhouse E: Measurement of excessive appetite and metabolic changes in Prader-Willi syndrome. Int $\mathrm{J}$ Obes Relat Metab Disord 1993; 17: 527-532.

24. Zipf WB, Berntson GG: Characteristics of abnormal food-intake patterns in children with Prader-Willi syndrome and study of effects of naloxone. Am J Clin Nutr 1987; 46: 277-281.

25. Fieldstone A, Zipf WB, Schwartz HC, Berntson GG: Food preferences in PraderWilli syndrome, normal weight and obese controls. Int $J$ Obes Relat Metab Disord 1997; 21: 1046-1052.

26. Lindgren AC, Barkeling B, Hagg A, Ritzen EM, Marcus C, Rossner S: Eating behavior in Prader-Willi syndrome, normal weight, and obese control groups. $J$ Pediatr 2000; 137: 50-55.

27. Turan M, Sen M, Canbay E, Karadayi K, Yildiz E: Gastric necrosis and perforation caused by acute gastric dilatation: report of a case. Surg Today 2003; 33: 302-304.

28. Idowu J, Razzouk AJ, Georgeson K: Visceral ischemia secondary to gastric dilatation: a rare complication of Nissen fundoplication. J Pediatr Surg 1987; 22: 939-940.

29. Gyurkovics E, Tihanyi B, Szijarto A, Kaliszky P, Temesi V, Hedvig SA, Kupcsulik P: Fatal outcome from extreme acute gastric dilation after an eating binge. Int $\mathrm{J}$ Eat Disord 2006; 39: 602-605.

30. Barada KA, Azar CR, Al-Kutoubi AO, Harb RS, Hazimeh YM, Abbas JS, Khani MK, Al-Amin HA: Massive gastric dilatation after a single binge in an anorectic woman. Int J Eat Disord 2006; 39: 166-169.

31. Cogbill TH, Bintz M, Johnson JA, Strutt PJ: Acute gastric dilatation after trauma. J Trauma 1987; 27: 1113-1117.

32. Abdu RA, Garritano D, Culver O: Acute gastric necrosis in anorexia nervosa and bulimia. Two case reports. Arch Surg 1987; 122: 830-832.

33. Holtkamp K, Mogharrebi R, Hanisch C, Schumpelick V, Herpertz-Dahlmann B: Gastric dilatation in a girl with former obesity and atypical anorexia nervosa. Int $J$ Eat Disord 2002; 32: 372-376.

34. Lunca S, Rikkers A, Stanescu A: Acute massive gastric dilatation: severe ischemia and gastric necrosis without perforation. Rom J Gastroenterol 2005; 14: 279-283. 



\section{Appendix 4}

\section{LYMPHOEDEMA IN PRADER-WILLI SYNDROME}

Heitink $\mathrm{MV}^{*}$, Sinnema $\mathrm{M}^{*}$, van Steensel MAM, Schrander-Stumpel CTRM, Curfs LMG ${ }^{\S}$, Frank $\mathrm{J}^{\S}$.

Int J Dermatol 2008; 47:42-4

* Equal contribution of both authors; ${ }^{\S}$ Authors share senior authorship 


\section{ABSTRACT}

A 20-year-old woman with Prader-Willi syndrome presented with heaviness and swelling in the lower legs and feet, which had developed after a fall. Lymphoscintigraphy showed a disturbed lymphatic drainage pattern in both lower extremities. Based on the clinical findings and the results of lymphoscintigraphic examination we made the diagnosis of lymphoedema. The patient was successfully treated with manual lymphatic drainage in combination with multilayer compressive bandaging. After oedema reduction, elastic compressive stockings were fit. To the best of our knowledge, this is the first report on lymphoedema in a patient with Prader-Willi syndrome, an association that is probably often missed. 


\subsection{INTRODUCTION}

Prader-Willi syndrome (PWS) (OMIM 176270), also known as Prader-LabhartWilli syndrome, is a genetic disorder that was first described in 1956 by Prader, Labhart, and Willi ${ }^{1}$. The disease is equally common in males and females and its incidence ranges from 1:10 000 to 120.000 births $^{2}$.

With few exceptions, PWS almost always occurs sporadically ${ }^{3}$. In up to $70 \%$ of affected individuals partial or complete deletion of paternal 15q11-q13 is the cause of PWS. Maternal uniparental disomy (mUPD) of chromosome 15 accounts for approximately $25 \%$ of all cases. Between 1 to $5 \%$ of the patients harbor a mutation in the imprinting center, which causes abnormal gene expression. In the latter, there may a $50 \%$ risk of familial recurrence ${ }^{3,4}$.

Clinically, PWS is characterized by muscular hypotonia, hypogonadism, growth deficiency, small hands and feet, mild mental retardation, behavioral abnormalities, hyperphagia leading to obesity, and diabetes ${ }^{5-7}$. A specific cutaneous feature of the disease is skin picking ${ }^{8}$. By contrast, lymphoedema has not yet been observed in the context of the disorder.

In this article, to our knowledge, we report, for the first time, a patient with PWS who developed lymphoedema in both legs.

\subsection{CASE REPORT}

A 20-year-old Dutch woman was referred to our outpatient clinic with a progressive feeling of heaviness and both swollen lower legs and feet. These symptoms had developed approximately one year earlier after she fell on her knees.

Shortly after birth, hypotonia and failure to thrive was noted. During the following 8 months she received enteral nutrition and at the age of 2.5 years she developed hyperphagia. Her further medical history revealed short stature, small hands and feet, mild mental retardation, strabismus, severe kyphoscoliosis, primary amenorrhea, and skin picking. The presumptive diagnosis of PWS was confirmed by demonstration of a paternal deletion on the long arm of chromosome 15. There was no previous history of varicosis, erysipelas or leg surgery. None of her relatives had a skin disease or lymphoedema.

On physical examination, the patient was an obese woman (height $144 \mathrm{~cm}$; weight $98.7 \mathrm{~kg}$ ) with bilateral both pitting and nonpitting oedema of the lower 
legs, feet, and toes. Stemmer's sign, a diagnostic criterion for lymphoedema, was positive. Clinical signs of chronic venous insufficiency were not observed.

Venous ultrasonography was normal. Lymphoscintigraphic examination revealed an insufficient lymphatic drainage in both legs. Uptake in the left groin was $2.9 \%$ and in the right groin $3.6 \%$ (normal values $>10 \%$ ). Anterior lymphoscintigrams obtained 45 minutes and 2 hours after radionuclide injection showed (i) a decreased number of inguinal lymph nodes, (ii) absence of lymphatic channels in both upper and lower legs and (iii) no signs of dermal backflow.

On the basis of these findings, a diagnosis of lymphoedema was made. Subsequently, the patient was referred to a specialized lymphoedema therapist for manual lymphatic drainage and multilayer compressive bandaging. After oedema resolution, class III elastic compression stockings were prescribed.

\subsection{DISCUSSION}

The clinical symptoms encountered in PWS guide the path to the molecular confirmation of the diagnosis. These symptoms are manifested at different points of life, and characteristic features can be observed perinatally, during infancy and childhood, and in adolescence and adulthood ${ }^{9}$. At birth, infants with PWS exhibit severe hypotonia that is reflected by problems with suckling and swallowing as well as delayed psychomotoric development. In addition, a dysmorphic face and small hands and feet are frequently observed. Later, these children develop hyperphagia that can lead to striking obesity already in patients as young as 2 years ${ }^{5}$. During adolescence, endocrine abnormalities associated with a hypothalamic-pituitary dysfunction result in incomplete pubertal development, growth retardation, and short stature due to growth hormone deficiency ${ }^{10}$. The degree of cognitive dysfunction and emotional lability varies widely between affected individuals ${ }^{5}$. In contrast to these welldocumented and regularly observed clinical characteristics, other clinical signs might easily escape attention, in particular lymphoedema that may be masked by the prevailing increase in body fat with subsequent overweight, which is invariably seen in almost all PWS patients.

Lymphoedema results from an abnormal accumulation of interstitial protein rich fluid. Insufficient transport and drainage of lymph result in swelling of the respective body parts ${ }^{11}$. The onset of clinical signs can be either spontaneous without preceding trigger or associated with previous eliciting factors such as erysipelas, trauma or surgery ${ }^{12}$. All aforementioned events can lead to 
decompensation of the lymphatic system, either by themselves or in combination. Most frequently, lymphoedema manifests in the lower extremities, but can also develop in the face, upper extremities, trunk, and external genitals ${ }^{13}$.

The disease can be divided into primary and secondary lymphoedema. The latter usually manifests in adulthood and can be caused by (i) destruction of lymphatic vessels, e.g. after erysipelas, filariasis or other infections; (ii) obstruction of lymphatic vessels, e.g. by tumors; (iii) disruption of lymphatic transport, e.g. during surgical procedures or after lymph node resection; and (iv) overload of a normally developed lymphatic system, e.g. due to chronic venous insufficiency or immobility ${ }^{12}$. By contrast, primary lymphoedema can already present at birth or later in life and arises from a genetically determined and mostly inherited developmental defect of lymph vessels and/or lymph nodes. Its prevalence is increased in various syndromes, including Noonan syndrome $^{14}$, Irons Bianchi syndrome ${ }^{15}$, Hennekam syndrome ${ }^{16}$, and yellow nail syndrome ${ }^{17}$. Primary lymphoedema can be associated with mutations in genes that are important for the normal development of the lymphatic system such as, e.g. FLT4, FOXC2, and SOX18 $8^{18,19}$.

In previous reports, oedema of the lower extremities in patients with PWS has always been attributed to obesity that is regularly observed in this disorder. ${ }^{3,5}$ Surprisingly, lymphoedema has not yet been suspected or reported as a possible cause. In the patient described here, lymphoedema could certainly have developed secondary to decreased mobility in an obese individual or after her fall 1 year earlier. Interestingly, however, lymphoscintigraphic examination revealed complete absence of lymph vessels. These findings are consistent with lymphatic aplasia of the legs as encountered in primary lymphoedema and suggest a genetic developmental defect underlying the clinical symptoms observed in our patient. Irrespective of its origin, however, oedema therapy should involve life-long use of individually fitted compression stockings to prevent possible sequelae, such as ulcus crusis or erysipelas ${ }^{20}$.

Whether the diagnosis of primary lymphoedema in our patient with PWS is a coincidental finding or a frequently overlooked and important clinical sign needs to be studied in bigger cohorts of adult individuals with PWS. 


\section{REFERENCES}

1. Prader A, Labhart A, Willi H. Ein Syndrom von Adipositas Kleinwuchs, Kryptorchismus und Oligophrenie nach myatonieartigen Zustand im Neugeborenalter. Schwei Zmed Wochenschr 1956; 86: 1260-1261.

2. Whittington JE, Holland AJ, Webb T, et al. Population prevalence and estimated birth incidence and mortality rate for people with Prader-Willi syndrome in one UK Health Region. J Med Genet 2001; 38: 792-798.

3. Benarroch F, Hirsch HJ, Genstil L, et al. Prader-Willi syndrome: medical prevention and behavioral challenges. Child Adolesc Psychiatr Clin N Am 2007; 16: 695-708.

4. Camprubí C, Coll MD, Villatoro $S$, et al. Imprinting center analysis in Prader-Willi and Angelman syndrome patients with typical and atypical phenotypes. Eur J Med Genet 2007; 50: 11-20.

5. Chen C, Visootsak J, Dills S, Graham JM jr. Prader-Willi Syndrome: an Update and review for the primary paediatrician. Clin Pediatr 2007; 46: 580-591.

6. Gunay-Aygun M, Schwartz S, Heeger S, et al. The changing purpose of PraderWilli syndrome clinical diagnostic criteria and proposed revised criteria. Pedriatics 2001; 108: E92.

7. Torrado M, Araoz V, Baialardo E, et al. Clinical-etiologic correlation in children with Prader-Willi syndrome (PWS): an interdisciplinary study. Am J Med Genet A 2007; 143: $460-468$.

8. Schepis C, Failla P, Siragusa M, Romano C. Skin-picking: the best cutaneous feature in the recognization of Prader-Willi syndrome. Int J Dermatol 1994; 33: 866-867.

9. Holm VA, Cassidy SB, Butler MG, et al. Prader-Willi syndrome: consensus diagnostic criteria. Pediatrics 1993; 91: 398-402.

10. Partsch CJ, Lämmer C, Gilissen-Kaesbach G, Pankau R. Adult patients with Prader-Willi syndrome: clinical characteristics, life circumstances and growth hormone secretion. Growth Horm IGF Res 2000; 10: S81-85.

11. Mortimer PS. American Cancer Society Lymphedema Workshop: the pathophysiology of lymphedema. Cancer 1998; 83: 2798-2802.

12. Kerchner K, Fleischer A, Yosipovitch G. Lower extremity lymphedema Update: pathophysiology, diagnosis, and treatment guidelines. J Am Acad Dermatol 2008; 59: 324-331

13. Szuba A, Rockson SG. Lymphedema: classification, diagnosis and therapy. Vasc Med 1998; 3: 145-156.

14. Witt DR, Hoyme HE, Zonana J, et al. Lymphedema in Noonan syndrome: clues to pathogenesis and prenatal diagnosis and review of the literature. Am J Med Genet 1987; 27: 841-856.

15. Irons $\mathrm{MB}$, Bianchi DW, Geggel RL, et al. Possible new autosomal recessive syndrome of lymphedema, hydroceles, atrial septal defect, and characteristic facial changes. Am J Med Genet 1996; 66: 69-71.

16. Van Balkom ID, Alders M, Allanson J, et al. Lymphedema-lymphangiectasia-mental retardation (Hennekam) syndrome: a review. Am J Med Genet 2002; 112: 412-421.

17. Szolnoky G, Lakatos B, Husz S, Dobozy A. Improvement in lymphatic function and partial resolution of nails after complex decongestive physiotherapy in yellow nail syndrome. Int J Dermatol 2005; 44: 501-503.

18. Mäkinen T, Norrmén C, Petrova TV. Molecular mechanisms of lymphatic vascular development. Cell Mol Life Sci 2007; 64: 1915-1929. 
19. Karpanen T, Mäkinen T. Regulation of lymphangiogenesis--from cell fate determination to vessel remodeling. Exp Cell Res 2006; 312: 575-583.

20. Liu R, Kwok YL, Li Y, et al. Skin pressure profiles and variations with body postural changes beneath medical elastic compression stockings. Int J Dermatol 2007; 46: 514-523. 



\section{Appendix 5}

\section{SLEEP DISTURBANCES AND BEHAVIOURAL PROBLEMS IN ADULTS WITH PRADER-WILLI SYNDROME}

Maas APHM*, Sinnema M*, Didden R, Maaskant MA, Smits MG, SchranderStumpel CTRM, Curfs LMG

J Intellect Disabil Res 2010; 54(10):906-917

* Equal contribution of both authors 


\section{ABSTRACT}

\section{Background}

Individuals with Prader-Willi syndrome (PWS) are at risk of sleep disturbances, such as excessive daytime sleepiness (EDS) and sleep apnea, and behavioural problems. Sleep disturbances and their relationship with other variables had not been researched extensively in adults with PWS.

\section{Method}

Sleep disturbances and behavioural problems were investigated in adults with genetically confirmed PWS using standardized questionnaires. Results of adults with paternal deletion (Del; $n=45$ ) were compared with those of adults with maternal uniparental disomy (mUPD; $n=33$ ).

\section{Results}

Eleven adults with PWS (i.e. 15\%) had a current sleep problem, mostly night waking problems. Twenty-six adults with PWS (i.e. 33\%) suffered from severe EDS. No differences in prevalence of sleep disturbances between genetic subtypes were found. Seventeen adults with deletion (i.e. 38\%) and seventeen adults with mUPD (i.e. 52\%) had behavioural problems. No significant relationships were found between sleep disturbances and behavioural problems.

\section{Conclusions}

In adults with PWS, EDS is the most common type of sleep disturbance. Men and individuals with relative high BMls are at increased risk for EDS. More research, aimed at developing a suitable screening instrument for sleep apnea in adults with PWS, is necessary. Clinical implications of the findings are discussed. 


\subsection{INTRODUCTION}

Prader-Willi syndrome (PWS) is characterized by infantile hypotonia, hyperphagia, intellectual disability (ID), short stature and hypogonadism ${ }^{1-4}$. PWS results from the abnormal or absent expression of the paternal copy of a maternally imprinted gene region at chromosome 15q11-q13. This can arise from four different mechanisms: a paternal deletion (70\%), a maternal uniparental disomy (mUPD) $(25 \%)$, an imprinting centre defect $(<5 \%)$ or an unbalanced chromosomal translocation $(<1 \%)^{3-8}$.

Temper tantrums, insistence on routine, skin-picking, obsessive traits, mood swings and stubbornness are characteristic behaviour problems often observed among individuals with $\mathrm{PWS}^{9-12}$. Also sleep disturbances, more specifically excessive daytime sleepiness (EDS) and sleep apnea, are common in individuals with $\mathrm{PWS}^{13}$.

Early prevalence studies in adults with PWS revealed that daytime sleepiness was observed in more than $95 \%$ of samples ${ }^{14,15}$. Validity of outcomes of these studies is limited because no standardized sleep questionnaires were used and data on other types of sleep disturbances (e.g., difficulty falling asleep, night waking and breathing disturbances during sleep; see Vela-Bueno et al. ${ }^{16}$ ) than those indicating hypersomnia were lacking. Furthermore, in both studies diagnosis was not genetically confirmed for all participants. A decade later Richdale et al. ${ }^{17}$ performed a study on sleep disturbances in children and adults with PWS using standardized sleep questionnaires to screen for EDS, sleep apnea and narcolepsy. They found sleep disturbances including EDS, snoring and night waking to be present in adults. The number of adults in their sample was rather small (i.e. $n=7$ ).

In individuals with PWS, daytime sleepiness and poor sleep quality may be related to daytime irritability, temper tantrums and attention problems ${ }^{17-19}$. Richdale et al. ${ }^{17}$ found that in children with PWS, EDS was associated with behavioural problems in all domains of the Developmental Behaviour Checklist $\left(\mathrm{DBC} ;{ }^{20}\right)$. At present, studies on the relationship between sleep disturbance and behavioural problems in adults with PWS are lacking, except for Clarke et al.'s study ${ }^{15}$. In their study, reports of parents showed that adults who frequently slept during the day or slept longer at night did not have more temper tantrums during the day than adults who did not show symptoms of hypersomnia. However, according to $43 \%$ of the parents impaired night time sleep in these adults was followed by irritability or temper tantrums the day after. According to these findings behavioural problems were associated with insomnia rather than with hypersomnia. 
Other variables than behavioural problems may be associated with sleep disturbances in adults with PWS. In the general population obesity is related to EDS and sleep apnea ${ }^{21,22}$. Evidence supporting a positive relationship between EDS and BMI in individuals with PWS is mixed ${ }^{23}$. Breathing disturbances during sleep, including sleep apnea, may be exacerbated by obesity in individuals with $\mathrm{PWS}^{24,25}$. Other variables which have previously been found to be related with sleep disturbances in adults with ID (without PWS) are gender, age, living situation, epilepsy, medication use, evening caffeine consumption, nocturnal urinary incontinence and ability to communicate ${ }^{26,27}$. Up until now there have been no prevalence studies on different types of sleep disturbances in a large sample of adults with PWS who are genetically confirmed. Also, the relationship between sleep disturbances and other variables had not been researched extensively in adults with PWS.

This study replicates Richdale et al.'s ${ }^{17}$ study by using the same standardized sleep and behaviour questionnaires. It elaborates on their study by including only adults with PWS of whom the genetic subtype is confirmed. The aim of this study is threefold; it (a) investigates prevalence and nature of sleep disturbances in a Dutch cohort $(n=79)$ of adults with PWS across genetic subtypes, (b) explores the relationship between sleep disturbances and behavioural problems, and (c) explores associations between sleep disturbances and gender, age, BMI, living situation, medication use and behavioural problems in adults with PWS.

\subsection{METHOD}

\section{Procedure}

The study was approved by the Medical Ethics Committee of the Academic Hospital Maastricht and Maastricht University. Adults with PWS were approached through the Dutch Prader-Willi Parent Association and physicians specializing in people with ID. The legal representatives (mostly parents) gave their informed written consent. The individuals with PWS and their main caregivers (family and/or professional caregivers) were visited by the second author for a semi-structured interview. For each question an evaluation was made of the person who (either individual with PWS or main caregivers) would provide the most reliable information on sleeping behaviour. If the individual with PWS had moderate or severe ID and/or low verbal ability or if staff were present at night, information of main caregivers was considered more reliable than information of individuals with PWS. For most questions information was provided by main caregivers and this was more often than not in agreement with the information provided by individuals with PWS themselves. We are 
aware of the fact that orally administering standardized sleep questionnaires developed for the general population may threaten validity ${ }^{28}$. However, to our knowledge no self-report questionnaires for adults with ID assessing sleep disturbances have been developed so far. Information about behaviour problems was provided by main caregivers. Data on demographic information, including prescribed medication and physical conditions were collected. The level of intellectual disability was reported by the main caregivers. Results of IQ tests were available in $52 \%$ of the cases. If no results of IQ tests were available level of ID was estimated on the basis of information (e.g., results from adaptive skills questionnaires) in participants' files. Medical information was retrieved from physicians. Genetic testing was undertaken in case of participants who did not have a previously confirmed genetic diagnosis. DNA methylation studies on the SNURF/SNRPN locus were used to confirm the diagnosis of PWS. Cytogenetic analyses were performed to establish whether a deletion was present. Parental samples, whenever available, were used to confirm mUPD with microsatellite analysis at various loci on chromosome 15.

\section{Participants}

A total of 79 adults with PWS were included in this study, of whom $34(43 \%)$ were male. Their mean age was 34.4 yrs $(S D=11.8$, range $=18$ to 65$)$. All participants were genetically confirmed as having PWS: 45 (57\%) had paternal deletion, $33(42 \%)$ had mUPD and one (1\%) participant had an imprinting centre defect. Sixty-three (80\%) participants lived in an institutional residential or community residential facility while $16(20 \%)$ participants lived at home with their parents or family. Level of ID was mild $(47 \%, n=37)$ or moderate $(30 \%$, $\mathrm{n}=24)$ in most participants. Five (6\%) participants had severe ID. The other participants were functioning at a borderline ID level (IQ 70-80) $(10 \%, n=8)$ or did not have ID (IQ $\geq 80)(6 \%, n=5)$. Mean body mass index $(B M I=k g / m 3)$ was $33.2(S D=8.0$, range $=21.4$ to 51.9$)$. Forty-eight $(61 \%)$ participants were obese (BMI $\geq 30)$. Twenty-six (33\%) participants received (combinations of) psychotropic medication for behavioural and/or emotional problems. Six (8\%) participants received medication for sleep disturbances. See Table A5.1 for more information on demographic characteristics and information on medication use across genetic subtypes (paternal deletion vs. mUPD). 
Table A5.1 Number and percentage of participants' characteristics by genetic subtype (paternal deletion vs. mUPD)

\begin{tabular}{lcccc}
\hline & Del & mUPD & & \\
Characteristic & $n(\%)$ & $(n=33)$ & & $P^{\dagger}$ \\
Number of males & $21(47)$ & $12(36)$ & 0.83 & 0.36 \\
Living situation & & & 2.47 & 0.12 \\
Residential facility & $33(73)$ & $29(88)$ & & \\
Family & $12(27)$ & $4(12)$ & & 0.28 \\
Level of cognitive functioning & & & & \\
No ID (IQ>80) & $2(4)$ & $3(9)$ & & \\
Borderline (IQ70-80) & $6(13)$ & $2(6)$ & & \\
Mild ID & $23(51)$ & $13(39)$ & & \\
Moderate ID & $13(29)$ & $11(33)$ & & $<0.001^{* *}$ \\
Severe ID & $1(2)$ & $4(12)$ & & $0.001^{* *}$ \\
Medication use related to & & & & $0.002^{* *}$ \\
Psychopathology & $6(13)$ & $20(61)$ & 19.15 & 0.42 \\
Antipsychotics & $4(9)$ & $15(45)$ & 13.82 & 0.69 \\
Antidepressants & $1(2)$ & $6(18)$ & & 0.42 \\
Mood stabilizers & $3(7)$ & $11(33)$ & 9.19 & 1 \\
Anxiolytics & 0 & $1(3)$ & & 0.42 \\
Sleep disturbances & $3(7)$ & $3(9)$ & & 1 \\
Melatonin & 0 & $1(3)$ & & \\
Modiodal & $2(4)$ & $1(3)$ & & \\
Temazepam & 0 & $1(3)$ & & \\
Venlafaxine & $1(2)$ & 0 &
\end{tabular}

${ }^{*} p<0.05,{ }^{* *} p<0.01 ;{ }^{\dagger}$ In case no value for $x^{2}$ is depicted because of low cell frequencies, the $p$ value is a result of Fisher's exact test. Del, paternal deletion; mUPD, maternal uniparental disomy.

On average, participants with deletion subtype were somewhat younger $(M=32.1, S D=11.0$, range $=18$ to 65$)$ than participants with $m U P D(M=37.3$, $\mathrm{SD}=12.4$, range $=18$ to 65 ). Results of a t-test showed that this difference approached statistical significance (t $(76)=-1.98, p=0.051)$. Mean BMI scores were $33.7(\mathrm{SD}=8.2$, range $=21.4$ to 51.9$)$ for participants with deletion and 33.0 $(S D=7.7$. range $=23.1$ to 49.9$)$ for participants with mUPD. These differences were not statistically significant $(t(76)=0.38, p=0.71)$.

\section{Materials}

As part of the semi-structured interview data on settling problems, night waking and early waking were collected. Questions concerning settling, night waking and early waking were asked to determine if current sleep problems were present according to criteria established by Wiggs \& Stores $^{29}$ and Didden et al. ${ }^{30}$. Frequency of occurrence of sleep problems was assessed on a 7-point Likert-type scale from "Never" (1) to "Daily" (7). Questions about duration were measured on a 5-point Likert-type scale from "A few minutes" (1) to "More than two hours" (5). Settling problems were defined as severe if they occurred three or more nights a week, the individual took more than 1 hour to fall asleep and 
parents or other caregivers were disturbed during this time. Settling was considered a mild problem if it occurred one or two nights a week and falling asleep took more than 30 minutes but less than one hour. Night waking was defined as severe if it occurred three or more nights a week, and if the individual remained awake for more than a few minutes and disturbed parents or other caregivers during that time. Night waking was considered a mild problem if it occurred once or twice a week. Finally, early waking was defined as the individual waking up before 5 a.m. and staying awake. This was considered a severe problem if it occurred three or more nights a week and a mild problem if it occurred once or twice a week. Participants were diagnosed with current sleep problems if they had at least one of the three types of sleep problems mentioned above and if the level of these problems was mild or severe.

Furthermore, two standardized questionnaires were included in the interview to screen for the presence of EDS and sleep apnea. The Epworth Sleepiness Scale (ESS; ${ }^{31}$ ) was used to measure the participants' general level of daytime sleepiness. The ESS consists of 8 items, indicating a variety of circumstances, which are rated on a 4-point Likert-type scale, from "Would never doze" (0) to "High chance of dozing" (3) (range=0 to 24). ESS scores $\geq 16$ are indicative of a high level of daytime sleepiness (EDS). The ESS has good internal consistency (Cronbach's $\alpha=0.88)$ and test-retest reliability $(r=0.82)^{32}$ when administered to nondisabled individuals. ESS cut-off scores used by Richdale et al. ${ }^{17}$ were $7 \leq E S S<16$ and ESS $\geq 16$ in individuals with PWS. Therefore prevalence rates will be presented for $7 \leq E S S<16$ and $E S S \geq 16$.

The Sleep Apnea (SA) subscale of the Sleep Disorders Questionnaire $\left(\mathrm{SDQ} ;{ }^{33,34}\right)$ consists of 12 items that are rated on a 5-point Likert-type scale, from "Never" (1) to "Always" (5) (range=12 to 60). The SA-SDQ does not include questions about daytime sleepiness. Scores $\geq 36$ for men and $\geq 32$ for women are proposed as cut-off values above which sleep apnea becomes clinically probable with satisfactory specificity (76-81\%) and sensitivity $(85-88 \%)$. Internal consistency (Cronbach's $\alpha=0.86$ ) and test-retest reliability $(\mathrm{rho}=0.84)$ of the SA scale were good when administered to nondisabled individuals. A procedure for estimating a small number of missing data was as follows: a median value was calculated for each item on the basis of scores regarding that item by all respondents. Missing data were replaced by this median score.

To gather information about behavioural problems main caregivers completed a questionnaire prior to the interview. The Developmental Behaviour Checklist for Adults $\left(\mathrm{DBC}-\mathrm{A} ;{ }^{20}\right)$ is designed to assess problematic behaviour and 
emotional state in adults with ID. The main caregiver rated 107 items on a 3-point Likert-type scale, as "Not true" (0), "Sometimes or somewhat true" (1) or "Often true or very true" (2) (range=0 to 321). To derive a total behaviour problem score (TBPS) all item scores were summed. TBPS $\geq 51$ are proposed as cut-off with modest specificity $(50 \%)$ and high sensitivity $(87 \%)$ with regard to expert clinical judgement of psychiatric caseness. Furthermore six subscale scores were obtained: Disruptive (17 items), Self-Absorbed (28 items), Communication Disturbance (13 items), Anxiety/Antisocial (9 items), Social Relating (6 items) and Depressive (10 items). Internal consistency of the total scale (Cronbach's $\alpha=0.95$ ) was excellent and internal consistency of the subscales was substantial to good (Cronbach's $\alpha=0.61$ to 0.89 ) (Mohr et al. 2004). Intraclass correlations for test-retest $(I C C=0.75$ and $I C C=0.85)$ and inter-rater reliability $(I C C=0.72)$ were good, and concurrent validity of the DBC-A with the Aberrant Behavior Checklist $\left(\mathrm{ABC} ;{ }^{35}\right) \quad(r=0.63)$ and the Psychiatric Assessment Scale for Adults with Developmental Disability Checklist (PAS-ADD Checklist; $\left.{ }^{36}\right) \quad(r=0.61)$ revealed moderately positive relations ${ }^{33}$.

\section{Statistical analyses}

To test whether differences between genetic subtypes were statistically significant Chi-square tests/Fisher's exact tests and Independent Samples $t$-tests/Mann-Whitney $U$ tests were performed for nominal/ordinal and metric data, respectively. To test the relationship between sleep disturbances and behavioural problems Kendall's tau-b was used for ordinal data and bivariate correlation (Pearson correlation/ Kendall's tau-b/ Spearman's rank correlation when appropriate) for metric data. All variables which could possibly be associated with sleep disturbances in adults with PWS, i.e. gender, age, BMI, living situation, medication use related to psychopathology and TBPS, were included in a regression model to test their predictive value on the dependent sleep variables. SPSS (version 16.0) was used to analyze the data. A $P$-value of 0.05 or less was taken as significant for all statistical tests.

\subsection{RESULTS}

\section{Sleep disturbances}

\section{Settling problems, night waking and early waking}

Percentages of participants with a current sleep problem are shown in Table A5.2. Eleven participants $(15 \%, n=75)$ had a current sleep problem of which night waking problems were the most common. No participants with deletion and three (9\%) participants with mUPD had a problem with early waking. 
Differences between groups (deletion vs. mUPD) in percentage of participants with sleep problems were not statistically significant. Relationships between sleep problems and cut-off scores for EDS and sleep apnea were weak and not statistically significant (Kendall's tau-b range $=|<0.01|$ to $|0.09|$ ).

Table A5.2 Number and percentage of participants with sleep problems by genetic subtype

\begin{tabular}{ccccc}
\hline & $\begin{array}{c}\text { All } \\
(\mathrm{n}=79) \\
\mathrm{n}(\%)\end{array}$ & $\begin{array}{c}\text { Del } \\
(\mathrm{n}=45) \\
\mathrm{n}(\%)\end{array}$ & $\begin{array}{c}\mathrm{mUPD} \\
(\mathrm{n}=33) \\
\mathrm{n}(\%)\end{array}$ & $\mathrm{p}^{\dagger}$ \\
\hline Type of sleep problem & & & & \\
$\quad \begin{array}{l}\text { Settling problem } \\
\text { Night waking problem }\end{array}$ & $1(1)$ & 0 & $1(3)$ & 0.42 \\
$\quad \begin{array}{c}\text { Early waking problem } \\
\text { Current sleep problem }\end{array}$ & $10(13)$ & $6(14)$ & $4(13)$ & 1 \\
\hline, 5 & $3(4)$ & 0 & $3(9)$ & 0.07 \\
\hline
\end{tabular}

${ }^{\dagger}$ Fisher's exact test; ${ }^{\ddagger} \mathrm{n}$ all $=75 ; \mathrm{n}$ del $=42 ; \mathrm{n}$ mUPD $=32 ;{ }^{\zeta}$ Two participants with mUPD had a combination of sleep problems; Del, paternal deletion; mUPD, maternal uniparental disomy.

\section{Excessive daytime sleepiness (EDS)}

Twenty-six participants (33\%) had ESS scores of sixteen or higher, indicating that they suffered from EDS. The differences between groups in frequency of EDS were not statistically significant (See Table A5.3).

\section{Sleep apnea}

Only three participants (4\%) met criteria for sleep apnea on the SA-SDQ (See Table A5.3). In both groups (deletion and mUPD) none of the males $(n=33)$ met the criterion for sleep apnea. Of the women $(n=45)$, two $(8 \%, n=24)$ participants with deletion and one $(5 \%, n=21)$ participant with mUPD met the criterion for sleep apnea. These differences, however, were not statistically significant. SASDQ scores were significantly, but weakly correlated with ESS scores (rho $=0.38, p=0.001)$.

Table A5.3 Number and percentage of participants with Excessive Daytime Sleepiness (EDS) and sleep apnea by genetic subtype

\begin{tabular}{lcccccc}
\hline & $\begin{array}{c}\text { All } \\
(\mathrm{n}=79) \\
\mathrm{n}(\%)\end{array}$ & $\begin{array}{c}\text { Del } \\
(\mathrm{n}=45) \\
\mathrm{n}(\%)\end{array}$ & $\begin{array}{c}\mathrm{mUPD} \\
(\mathrm{n}=33) \\
\mathrm{n}(\%)\end{array}$ & $\mathrm{x}^{2}$ & $\mathrm{df}$ & $\mathrm{p}^{\dagger}$ \\
\hline EDS & & & & & & \\
ESS $<7(\%)$ & $25(32)$ & $13(29)$ & $11(33)$ & 0.78 & 2 & 0.68 \\
$7 \leq$ EDS $<16(\%)$ & $28(35)$ & $18(40)$ & $10(30)$ & & & \\
$\quad$ ESS $\geq 16(\%)$ & $26(33)$ & $14(31)$ & $12(36)$ & & & \\
Sleep apnea & & & & & & \\
$\quad$ SA-SDQ cut-off 32 (female) 36 (male) (\%) & $3(4)$ & $2(4)$ & $1(3)$ & & & 1 \\
\hline
\end{tabular}

${ }^{\dagger}$ In case no value for $x^{2}$ is depicted because of low cell frequencies, the $p$ value is a result of Fisher's exact test. Del, paternal deletion; mUPD, maternal uniparental disomy; ESS, Epworth Sleepiness Scale; SA-SDQ, Sleep Apnea subscale of the Sleep Disorders Questionnaire 


\section{Behavioural problems}

Thirty-five (44\%) participants, including the participant with an imprinting centre defect, had a TBPS of 51 or higher which is indicative of clinically significant behavioural problems. Seventeen (38\%) participants with deletion and 17 $(52 \%)$ participants with mUPD had a TBPS of at least 51 . This difference was not statistically significant $\left(X^{2}(1)=1.46, P=0.23\right)$. Results from the KolmogorovSmirnov test showed that the scores on three of the six subscales of the DBCA were not normally distributed. As a consequence, the Mann-Whitney $U$ test was used to test differences between genetic subtypes on the DBC-A subscales Self-Absorbed, Anxiety/Antisocial and Depressive (See Table A5.4). Differences between groups on DBC-A subscales Disruptive and SelfAbsorbed approached statistical significance, and on both subscales mean scores were higher for participants with mUPD than for participants with a deletion.

Table A5.4 Mean scores (SD) on the DBC-A and DBC-A subscales by genetic subtype

\begin{tabular}{lcccc}
\hline & $\begin{array}{c}\text { All } \\
(\mathrm{n}=79) \\
\text { Mean }(\mathrm{SD})\end{array}$ & $\begin{array}{c}\text { Del } \\
(\mathrm{n}=45) \\
\text { Mean (SD) }\end{array}$ & $\begin{array}{c}\text { mUPD } \\
(\mathrm{n}=33)\end{array}$ & \\
Mean (SD) & $\mathrm{p}^{\dagger}$ \\
\hline DBC-A TBPS & $50.2(23.7)$ & $46.3(20.7)$ & $55.4(27.0)$ & 0.10 \\
DBC-A Disruptive & $11.3(6.5)$ & $10.1(5.5)$ & $12.9(7.4)$ & 0.06 \\
DBC-A Self-Absorbed & $9.2(6.4)$ & $7.6(4.3)$ & $11.1(8.2)$ & 0.08 \\
DBC-A Communication Disturbed & $5.9(3.6)$ & $5.9(3.5)$ & $6.0(3.9)$ & 0.85 \\
DBC-A Anxiety/Antisocial & $1.7(2.2)$ & $1.4(2.0)$ & $1.9(2.5)$ & 0.41 \\
DBC-A Social relating & $4.8(2.4)$ & $4.9(2.5)$ & $4.6(2.1)$ & 0.50 \\
DBC-A Depressive & $4.6(3.4)$ & $4.3(3.0)$ & $5.1(3.8)$ & 0.53 \\
\hline
\end{tabular}

${ }^{\dagger}$ T-test except for Self-Absorbed, Anxiety/Antisocial and Depressive: Mann-Whitney U-test (scores were not normally distributed on this subscale). DBC-A, Developmental Behaviour Checklist for Adults, Del, paternal deletion; mUPD, maternal uniparental disomy; TBPS, Total Behaviour Problem Score.

\section{Sleep disturbances and behavioural problems}

Information on relationships between sleep measures and the DBC-A scales is given in Table A5.5. There were no significant relationships between sleep disturbances and behavioural problems. 
Table A5.5 Relationships (Kendall's tau-b, Pearson R or Spearman rho) between sleep variables and DBC-A scores $(n=79)$

\begin{tabular}{|c|c|c|c|c|c|c|c|c|}
\hline & $\begin{array}{c}\text { DBC-A } \\
T B P S \geq 51\end{array}$ & $\begin{array}{l}\text { DBC-A } \\
\text { TBPS }\end{array}$ & $\begin{array}{l}\text { DBC-A } \\
\text { Disruptive }\end{array}$ & $\begin{array}{c}\text { DBC-A } \\
\text { Self- } \\
\text { Absorbed }\end{array}$ & $\begin{array}{c}\text { DBC-A } \\
\text { Communication } \\
\text { Disturbed }\end{array}$ & $\begin{array}{l}\text { DBC-A } \\
\text { Anxiety/ } \\
\text { Antisocial }\end{array}$ & $\begin{array}{l}\text { DBC-A } \\
\text { Social } \\
\text { relating }\end{array}$ & $\begin{array}{c}\text { DBC-A } \\
\text { Depressive }\end{array}$ \\
\hline $\begin{array}{l}\text { Current sleep } \\
\text { problem }^{\ddagger}\end{array}$ & tau $-b=0.16$ & & & & & & & \\
\hline $\begin{array}{l}\text { Settling } \\
\text { problem }\end{array}$ & tau $-\mathrm{b}=0.13$ & & & & & & & \\
\hline $\begin{array}{l}\text { Night waking } \\
\text { problem }{ }^{\ddagger}\end{array}$ & tau $-\mathrm{b}=0.21$ & & & & & & & \\
\hline $\begin{array}{l}\text { Early waking } \\
\text { problem }\end{array}$ & tau $-b=0.09$ & & & & & & & \\
\hline ESS & & $R=0.19$ & $\mathrm{R}=0.17$ & rho $=0.05$ & $R=0.24^{*}$ & rho $=0.12$ & $R=0.15$ & rho $=0.18$ \\
\hline SA-SDQ & & $R=-0.02$ & $R=-0.02$ & rho $=-0.12$ & $R=0.04$ & rho $=0.31^{* *}$ & $R=0.02$ & rho $=0.13$ \\
\hline
\end{tabular}

${ }^{*} p<0.5 ;{ }^{*} \mathrm{p}<0.01 ;{ }^{\ddagger} \mathrm{n}=75$. DBC-A, Developmental Behaviour Checklist for Adults; TBPS, Total Behaviour Problem Score; ESS, Epworth Sleepiness Scale; SA-SDQ, Sleep Apnea subscale of the Sleep Disorders Questionnaire.

\section{Sleep disturbances and individual-related variables}

Logistic regression analyses to predict a current sleep problem and night waking could not be performed because of low prevalence rates of those problems. However, two regression analyses (method Enter) were performed to assess to what extent (a) gender, (b) age, (c) BMI, (d) living situation, (e) medication use (related to psychopathology) and (f) behavioural problems (TBPS) predict EDS and sleep apnea. Firstly, analysis of ESS scores (indicating EDS) resulted in a statistically significant predictive model $\left(F_{6,72}=3.52, p<0.01, R^{2}=0.23\right)$. Gender $(B=-3.40, p=0.03)$ and $B M I(B=0.29$, $p<0.01)$ had a statistically significant impact on ESS scores. It showed that females had lower ESS scores than males and participants with higher BMI scores had higher ESS scores. Age had no statistically significant impact $(p=0.70)$. Secondly, analysis of SA-SDQ scores (indicating sleep apnea) was performed with the above mentioned variables, but without age and BMI (because these variables are included in the SA-SDQ score). This did not result in a statistically significant predictive model $\left(F_{4,74}=2.25, p=0.07\right.$, $\left.R^{2}=0.11\right)$. Only living situation $(B=4.64, p=0.007)$ had a statistically significant impact on SA-SDQ scores. It showed that participants living in residential facilities had higher SA-SDQ scores than participants living at home with their family. See Table A5.6 for results of the regression models for ESS and SASDQ scores. 
Table A5.6 Summary of regression analyses for variables predicting scores on sleep questionnaires $(\mathrm{N}=79)$

\begin{tabular}{lcccccc}
\hline & \multicolumn{3}{c}{ ESS } & & \multicolumn{3}{c}{ SA-SDQ } \\
& $P$ & $\mathrm{~B}$ & $95 \% \mathrm{Cl}$ & $P$ & $\mathrm{~B}$ & $95 \% \mathrm{Cl}$ \\
\hline Gender (M/F) & $0.03^{*}$ & -3.40 & $-6.47--0.33$ & 0.56 & -0.75 & $-3.30-1.80$ \\
Age & 0.70 & -0.03 & $-0.17-0.11$ & - & - & - \\
BMl & $0.003^{* *}$ & 0.29 & $0.10-0.48$ & - & - & - \\
Living situation $^{\dagger}$ & 0.17 & 2.95 & $-1.34-7.25$ & $0.007^{* *}$ & 4.64 & $1.28-7.99$ \\
Medication use $^{\ddagger}(-/+)$ & 0.08 & -2.97 & $-6.34-0.40$ & 0.17 & -1.99 & $-4.82-0.84$ \\
TBPS & 0.09 & 0.06 & $-0.01-0.13$ & 0.44 & -0.02 & $-0.08-0.03$ \\
Constant term & 0.97 & 0.14 & $-8.05-8.33$ & 0.44 & -0.02 & $17.75-25.39$ \\
\hline
\end{tabular}

${ }^{*} p<0.05 ;{ }^{* *} p<0.01 .{ }^{\dagger}$ Family vs. Residential facility. ${ }^{\ddagger}$ Medication use related to psychopathology. ESS, Epworth Sleepiness Scale; SA-SDQ, Sleep Apnea subscale of the Sleep Disorders Questionnaire; $95 \% \mathrm{Cl}=95 \%$ confidence interval of B; TBPS, Total Behaviour Problem Score of the Developmental Behaviour Checklist for Adults; -, variables were not included in model.

\subsection{DISCUSSION}

This study reported sleep and behaviour in a sample of adults with confirmed PWS. No differences in prevalence of sleep disturbances and behavioural problems between genetic subtypes were found. However, adults with mUPD tended to have higher scores on the Disruptive and Self Absorbed subscales of the DBC-A compared to adults with paternal deletion $(p<0.10)$. Furthermore, no relationships between sleep variables and behaviour problems were found in adults with PWS. These findings do not corroborate those of Richdale et al. ${ }^{17}$ who found moderate correlations between different sleep variables and all DBC scales in children and adolescents with PWS. Differences in sample characteristics (i.e. sample size, age and BMI) and lack of information about genetic diagnosis, living situation, medication use related to psychopathology and medication use related to sleep disturbances in Richdale et al.'s ${ }^{17}$ study, render comparisons between studies impossible.

The results show that the overall prevalence rate of a current sleep problem was relatively low (i.e. 15\%). Considering the type of sleep problems, night waking problems were most often observed, i.e. in $13 \%$ of the sample. Further, EDS was found in a minority of our sample, which is in $33 \%$ of the participants. This is in contrast with other studies using parent reports and questionnaires. For example, Clarke et al. ${ }^{15}$ found EDS in $63 \%$ of adults with PWS. Differences in both definition and measurement of daytime sleepiness may account for the difference in prevalence rates. Greenswag ${ }^{14}$ and Clarke et al. ${ }^{15}$ did not use a standardized sleep questionnaire to measure daytime sleepiness. Richdale et al. ${ }^{17}$, also using the ESS to measure EDS, found a prevalence rate of $29 \%$ which is somewhat lower than the prevalence rate in our study. The origins of EDS in PWS remain unclear ${ }^{37}$. In this study EDS could be partly explained by 
gender and BMI. The model could only explain $23 \%$ of the variance. Other factors, not included in the model, such as breathing disturbances during sleep, hypothalamic dysfunction and lack of structured activities may contribute to $\operatorname{EDS}^{23,24,38}$.

Only few participants (4\%) met the cut-off score for sleep apnea. This is not in line with polysomnographic studies in individuals with $\mathrm{PWS}^{23}$ in which much higher rates of sleep apnea were found. The explanation for this difference could be twofold. Firstly, the relatively high rate of obstructive sleep apnea $(57 \%)$ mentioned by Camfferman et al. ${ }^{23}$ may not be representative. Polysomnography-based information on breathing disturbances during sleep in individuals with PWS described in literature is often limited to small groups of both children and adults. These samples are highly selected in that individuals are referred because of complaints of daytime sleepiness and/or loud snoring. However, high rates of obstructive sleep apnea have been found in a sample of unselected adolescents and adults with PWS ${ }^{25}$. Secondly, experience with the SA-SDQ scale in this study leads to the conclusion that it may not be an appropriate instrument for screening of sleep apnea in the population of adults with PWS. In this study, eight participants (four males) were previously diagnosed with sleep apnea (confirmed by PSG or observed during surgery) and none of them met the cut-off score on the SA-SDQ. Mean SA-SDQ score of the participants previously diagnosed with sleep apnea was 26 (range $=18$ to 31). Although Richdale et al. ${ }^{17}$ also have used this questionnaire with individuals with PWS, the SA-SDQ is not designed for measuring sleep apnea individuals with ID. Questions on sleeping position, snoring, audible apneas or awaking with a start were difficult to answer for both individuals with PWS themselves as well as their parents or caregivers. Development of cut-off scores for individuals with ID or more specifically for individuals with PWS is recommended. Specific (lower) cut-off scores on the SA-SDQ have already been developed for individuals with epilepsy ${ }^{39}$. Cut-off scores are important when it comes to referring individuals to a (sleep) clinic for additional evaluation of breathing disorders during sleep and therefore they should minimize false negatives. Treatment options are available for this serious morbidity and treatment may improve the health and the quality of life of the individuals affected.

Results of this study should be interpreted in the context of its methodological shortcomings. The first shortcoming relates to the use of informant based screening questionnaires to assess sleep disturbances. Although not as objective as measurements like polysomnography and the Multiple Sleep Latency Test (MSLT), this was the only way to collect data on sleep in a relatively large sample of adults with PWS. As mentioned before, sleep studies 
in PWS using polysomnography are frequently biased, because they include highly selected samples of participants. In this study there was no selection of participants based on sleep complaints. After administration of screening questionnaires, further assessment is necessary to determine if a sleep disorder is present. Based on high scores on the standardized questionnaires five participants of this study were studied more extensively with home polygraphy in order to determine if they should or should not be diagnosed with sleep apnea and one of them appeared to have sleep apnea. A second shortcoming is that we were not able to control for differences in age and use of psychotropic medication between groups. In this study, adults with mUPD were on average older and used psychotropic medication more often than those with deletion subtype. Overall age did not have an impact on ESS and SA-SDQ scores. However, medication use related to psychopathology tended to have some impact on ESS scores (See Table A5.6). Unfortunately, we were not able to predict the influence of age and use of psychotropic medication on settling problems, night waking and early waking, due to low rates of these sleep problems. Based on earlier reports ${ }^{15,27}$ and anecdotal remarks of parents and caregivers during the interviews we suspect a relationship between night waking and behavioural and emotional problems during the day. Future research should focus on the relationships between sleep disturbances, such as night waking and EDS and (development of) behavioural and emotional problems in adults with mUPD.

Despite these limitations, this study has provided information about sleep disturbances and behavioural problems which until now had not been examined with standardized questionnaires in adults with PWS across genetic subtypes.

Several clinical implications may be identified. We recommend that caregivers regularly look for sleep disturbances in adults with PWS. In our opinion, the ESS is a useful instrument that can easily be applied to determine the severity of daytime sleepiness in adults with PWS. In case of ESS scores $\geq 16$ or significant changes in ESS scores further assessment of sleep disturbances and associated variables is recommended. The SA-SDQ may not be suitable for screening breathing disturbances during sleep, and other ways to screen for these sleep disorders have to be developed. Furthermore, we advise caregivers to combine looking for sleep disturbances with looking for behavioural and emotional problems. Changes in sleep patterns, e.g. difficulty falling asleep and night waking, could be a first presenting sign of psychiatric illness and should be carefully monitored, specifically in young adults with PWS who are at risk of developing psychiatric illness ${ }^{40-42}$. We also recommend looking for sleep disturbances when daytime behaviour becomes disorganized. 
Regulation of the sleep pattern could prevent worsening of behavioural and emotional problems ${ }^{43}$. Once specific behavioural or psychiatric causes of the sleep disturbance have been identified, appropriate treatment can be undertaken ${ }^{44}$. An individual treatment plan for sleep disturbances in adults with PWS may consist of treatment of extreme obesity, treatment of sleep apnea, sleep hygiene measures (including activities during the day, especially in weekends) ${ }^{38}$, treatment of (night time) behaviour problems and/or psychiatric illness. Combined assessment and treatment ultimately lead to improvement of sleep quality, behaviour and daytime functioning. This could be of considerable benefit to the individuals with PWS themselves, their families and their professional caregivers. 


\section{REFERENCES}

1. Holm VA, Cassidy SB, Butler MG, Hanchett JM, Greenswag LR, Whitman BY, Greenberg F: Prader-Willi syndrome: consensus diagnostic criteria. Pediatrics 1993; 91: 398-402.

2. Prader A, Labhart A, Willi H: Ein syndrom von adipositas, kleinwuchs, kryptorchismus and oligophrenie nach myotonicartigen zustand im neugeborenenalter. Schweizerische Medizinische Wochenschrift 1956; 86: 1260-1261.

3. Goldstone AP, Holland AJ, Hauffa BP, Hokken-Koelega AC, Tauber M: Recommendations for the diagnosis and management of Prader-Willi syndrome. $J$ Clin Endocrinol Metab 2008; 93: 4183-4197.

4. Cassidy SB, Driscoll DJ: Prader-Willi syndrome. Eur J Hum Genet 2009; 17: 3-13.

5. Buiting K, Dittrich B, Gross S, Lich C, Farber C, Buchholz T, Smith E, Reis A, Burger J, Nothen MM, Barth-Witte U, Janssen B, Abeliovich D, Lerer I, van den Ouweland AM, Halley DJ, Schrander-Stumpel C, Smeets H, Meinecke P, Malcolm S, Gardner A, Lalande M, Nicholls RD, Friend K, Schulze A, Matthijs G, Kokkonen H, Hilbert P, Van Maldergem L, Glover G, Carbonell P, Willems P, GillessenKaesbach G, Horsthemke B: Sporadic imprinting defects in Prader-Willi syndrome and Angelman syndrome: implications for imprint-switch models, genetic counseling, and prenatal diagnosis. Am J Hum Genet 1998; 63: 170-180.

6. Ledbetter DH, Riccardi VM, Airhart SD, Strobel RJ, Keenan BS, Crawford JD: Deletions of chromosome 15 as a cause of the Prader-Willi syndrome. N Engl J Med 1981; 304: 325-329.

7. Nicholls RD, Knoll JH, Butler MG, Karam S, Lalande M: Genetic imprinting suggested by maternal heterodisomy in nondeletion Prader-Willi syndrome. Nature 1989; 342: 281-285.

8. Horsthemke B, Buiting K: Imprinting defects on human chromosome 15. Cytogenet Genome Res 2006; 113: 292-299.

9. Boer H, Clarke D: Development and behaviour in two genetic syndromes 1: Prader-Willi syndrome. Journal of Applied Research in Intellectual Disabilities 1999; 12: 294-301.

10. Clarke DJ, Boer $\mathrm{H}$, Whittington J, Holland A, Butler J, Webb T: Prader-Willi syndrome, compulsive and ritualistic behaviours: the first population-based survey. Br J Psychiatry 2002; 180: 358-362.

11. Holland AJ, Whittington JE, Butler J, Webb T, Boer H, Clarke D: Behavioural phenotypes associated with specific genetic disorders: evidence from a populationbased study of people with Prader-Willi syndrome. Psychol Med 2003; 33: 141-153.

12. Didden R, Korzilius H, Curfs L: Skin-picking in individuals with Prader-Willi syndrome: Prevalence, functional assessment, and its comorbidity with compulsive and self-injurious behaviours Journal of Applied Research in Intellectual Disabilities 2007; 20: 409-419.

13. Butler JV, Whittington JE, Holland AJ, Boer H, Clarke D, Webb T: Prevalence of, and risk factors for, physical ill-health in people with Prader-Willi syndrome: a population-based study. Dev Med Child Neurol 2002; 44: 248-255.

14. Greenswag LR: Adults with Prader-Willi syndrome: a survey of 232 cases. Dev Med Child Neurol 1987; 29: 145-152.

15. Clarke DJ, Waters J, Corbett JA: Adults with Prader-Willi syndrome: abnormalities of sleep and behaviour. J $R$ Soc Med 1989; 82: 21-24. 
16. Vela-Bueno A, Kales A, Soldatos CR, Dobladez-Blanco B, Campos-Castello J, Espino-Hurtado P, Olivan-Palacios J: Sleep in the Prader-Willi syndrome. Clinical and polygraphic findings. Arch Neurol 1984; 41: 294-296.

17. Richdale AL, Cotton S, Hibbit K: Sleep and behaviour disturbance in Prader-Willi syndrome: a questionnaire study. J Intellect Disabil Res 1999; 43: 380-392.

18. Boer $\mathrm{H}$ : Behavioural studies in Prader-Willi syndrome. Doctoral dissertation Maastricht University, Maastricht, The Netherlands., 2004.

19. O'Donoghue FJ, Camfferman D, Kennedy JD, Martin AJ, Couper T, Lack LD, Lushington K, McEvoy RD: Sleep-disordered breathing in Prader-Willi syndrome and its association with neurobehavioral abnormalities. J Pediatr 2005; 147: 823-829.

20. Einfeld SL, Tonge BJ, Mohr C: The Developmental Behaviour Checklist for Adults (DBC-A). School of Psychiatry, University of New South Wales, and Centre of Developmental Psychiatry and Psychology, Monash University, Sydney and Melbourne 2002.

21. Bixler EO, Vgontzas AN, Lin HM, Calhoun SL, Vela-Bueno A, Kales A: Excessive daytime sleepiness in a general population sample: the role of sleep apnea, age, obesity, diabetes, and depression. J Clin Endocrinol Metab 2005; 90: 4510-4515.

22. Shah N, Roux F: The relationship of obesity and obstructive sleep apnea. Clin Chest Med 2009; 30: 455-465.

23. Camfferman D, McEvoy RD, O'Donoghue F, Lushington K: Prader Willi Syndrome and excessive daytime sleepiness. Sleep Med Rev 2008; 12: 65-75.

24. Nixon GM, Brouillette RT: Sleep and breathing in Prader-Willi syndrome. Pediatr Pulmonol 2002; 34: 209-217.

25. Yee BJ, Buchanan PR, Mahadev S, Banerjee D, Liu PY, Phillips C, Loughnan G, Steinbeck K, Grunstein RR: Assessment of sleep and breathing in adults with prader-willi syndrome: a case control series. J Clin Sleep Med 2007; 3: 713-718.

26. Espie CA, Tweedie FM: Sleep patterns and sleep problems amongst people with mental handicap. J Ment Defic Res 1991; 35: 25-36.

27. Brylewski JE, Wiggs L: A questionnaire survey of sleep and night-time behaviour in a community-based sample of adults with intellectual disability. J Intellect Disabil Res 1998; 42: 154-162.

28. Finlay WM, Lyons E: Methodological issues in interviewing and using self-report questionnaires with people with mental retardation. Psychol Assess 2001; 13: 319-335.

29. Wiggs L, Stores G: Severe sleep disturbance and daytime challenging behaviour in children with severe learning disabilities. J Intellect Disabil Res 1996; 40: 518-528.

30. Didden R, Korzilius H, van Aperlo B, van Overloop C, de Vries M: Sleep problems and daytime problem behaviours in children with intellectual disability. $J$ Intellect Disabil Res 2002; 46: 537-547.

31. Johns MW: A new method for measuring daytime sleepiness: the Epworth sleepiness scale. Sleep 1991; 14: 540-545.

32. Johns MW: Reliability and factor analysis of the Epworth Sleepiness Scale. Sleep 1992; 15: 376-381.

33. Mohr C, Tonge BJ, Einfeld SL: The development of a new measure for the assessment of psychopathology in adults with intellectual disability. J Intellect Disabil Res 2005; 49: 469-480.

34. Douglass AB, Bornstein R, Nino-Murcia G, Keenan S, Miles L, Zarcone VP, Jr., Guilleminault C, Dement WC: The Sleep Disorders Questionnaire. I: Creation and multivariate structure of SDQ. Sleep 1994; 17: 160-167. 
35. Aman MG, Singh NN, Stewart AW, Field CJ: Psychometric characteristics of the aberrant behavior checklist. Am J Ment Defic 1985; 89: 492-502.

36. Moss SC, Prosser H, Costello H, Simpson N, Patel P: PAS-ADD Checklist. Hester Adrian Research Centre, University of Manchester, Manchester 1996.

37. Didden R, Braam W, De Weerd A, Smits M, Curfs L: Sleep and sleep problems in Angelman syndrome and Prader-Willi syndrome. In: Focus on Birth Defects Research (ed JF Engels), pp 81-104 Nova Science Publishers, Hauppauge, NY 2006.

38. Maas AP, Didden R, Bouts L, Smits MG, Curfs LM: Scatter plot analysis of excessive daytime sleepiness and severe disruptive behavior in adults with PraderWilli syndrome: a pilot study. Res Dev Disabil 2009; 30: 529-537.

39. Weatherwax KJ, Lin X, Marzec ML, Malow BA: Obstructive sleep apnea in epilepsy patients: the Sleep Apnea scale of the Sleep Disorders Questionnaire (SA-SDQ) is a useful screening instrument for obstructive sleep apnea in a disease-specific population. Sleep Med 2003; 4: 517-521.

40. Boer H, Holland A, Whittington J, Butler J, Webb T, Clarke D: Psychotic illness in people with Prader Willi syndrome due to chromosome 15 maternal uniparental disomy. Lancet 2002; 359: 135-136.

41. Dykens EM: Maladaptive and compulsive behavior in Prader-Willi syndrome: new insights from older adults. Am J Ment Retard 2004; 109: 142-153.

42. Soni S, Whittington J, Holland AJ, Webb T, Maina EN, Boer H, Clarke D: The phenomenology and diagnosis of psychiatric illness in people with Prader-Willi syndrome. Psychol Med 2008; 38: 1505-1514.

43. Wirz-Justice A: Biological rhythm disturbances in mood disorders. Int Clin Psychopharmacol 2006; 21: S11-15.

44. Costa e Silva JA: Sleep disorders in psychiatry. Metabolism 2006; 55: S40-44. 


\section{Appendix 6}

\section{URINARY INCONTINENCE IN PERSONS WITH PRADER-WILLI SYNDROME}

Von Gontard A, Didden R, Sinnema M, Curfs LMG

BJU Int. 2010 Dec; 106(11):1758-62 


\section{ABSTRACT}

\section{Objective}

To assess and identify the frequency and type of urinary incontinence (UI), as well as associated symptoms in persons with Prader-Willi syndrome (PWS). PWS is characterised by mental retardation, short stature, obesity and hypogonadism. The behavioural phenotype includes eating problems, temper outbursts, affective disorders, stereotypies and speech abnormalities. UI is common in children with mental retardation in general, but has not been reported systematically in children with PWS so far.

\section{Materials and methods}

The Dutch version of the "Parental Questionnaire: Enuresis/Urinary Incontinence" was completed by 118 parents of children with PWS. This questionnaire includes items referring to day- and nighttime wetting, toilet habits, observable voiding behaviours and reactions, urinary tract infections, stool habits and behavioural symptoms.

\section{Results}

The rate of nocturnal enuresis in persons with PWS was $13.6 \%(16)$ at a mean age of 15.1 years. $3.8 \%(5)$ had additional daytime urinary incontinence, and $3.3 \%$ (4) had faecal incontinence. Lower urinary tract symptoms were common indicative of overactive bladder, dysfunctional voiding and postponement. Also, the rate of internalising and externalising behavioural problems was high.

\section{Conclusion}

Urinary incontinence is more common in persons PWS than in typically developing children, adolescents and adults. As lower urinary tract symptoms are common, detailed assessment and specific treatment of UI should be part of the care of all persons with PWS. 


\subsection{INTRODUCTION}

Prader-Willi syndrome (PWS) is a genetically determined neurodevelopmental disorder with a prevalence of $1: 10000$ to $1: 24000$. In $70 \%$ of the cases, it is caused by a paternal deletion on chromosome 15 (15q11-13), in $29 \%$ by maternal disomy and in the remaining $1 \%$ by imprinting defects ${ }^{1}$. Clinically, the syndrome is characterised by early hypotonia with feeding problems, hyperphagia and obesity if not controlled, hypogonadism, short stature and developmental delay. The behavioural phenotype includes: eating problems, temper outbursts, affective disorders, stereotypies and speech abnormalities. $I Q$ is reduced, mostly in the range of mild intellectual disability (IQ of 50 to 70 ).

Urinary incontinence $(\mathrm{UI})$ is more common in children with intellectual disability in general than in typically developing children, but has not been reported systematically in children with PWS. According to the ICCS (International Children's Continence Society) standardisation document ${ }^{2}$, nocturnal enuresis (NE) is defined descriptively as any intermittent incontinence during sleep. Primary (never dry) and secondary (relapse after a dry interval of 6 months or more), as well as mono- (without) and non-monosymptomatic (with lower urinary tract symptoms) subtypes are differentiated. The more common types of daytime UI are overactive bladder, voiding postponement and dysfunctional voiding. Children with combined day- and nighttime $\mathrm{UI}$ are given dual diagnoses. According to the Rome-III classification ${ }^{3}$, functional constipation (with or without faecal incontinence - FI) as well as non-retentive faecal incontinence are differentiated. The prevalence of incontinence in 7-year-old typically developing children is approximately $10 \%$ for NE, $2-3 \%$ for daytime UI and $1-3 \%$ for $\mathrm{FI}^{4}$.

The prevalence rates of $\mathrm{NE}$, daytime $\mathrm{UI}$ and $\mathrm{FI}$ are higher in persons with intellectual disability, defined by an IQ of 70 or lower ${ }^{5}$. Results of a populationbased study showed that $38.1 \%$ of 7 -year-olds had NE and $39.0 \% \mathrm{UI}$ (at the age of 20 years the rates were $20.0 \%$ for NE and UI, respectively) ${ }^{6}$. Also, $35.5 \%$ of 7 -year-old and $19.0 \%$ of 20 -year-old persons with mental retardation had $\mathrm{FI}$. The rates of incontinence increase with decreasing $\mathrm{IQ}^{6}$.

Prevalence rates of incontinence have only rarely been examined in children whose ID is associated with a genetic disorder. Backes et al. showed that $27 \%$ of children with Fragile-X syndrome and $13 \%$ of children with tuberous sclerosis had $\mathrm{UI}$, while $20 \%$ and $6 \%$ had $\mathrm{FI}$, respectively ${ }^{7}$. Until now, the occurrence of incontinence in PWS has only been reported in case reports. For example, Webber and Udwin reported a case of a 4-year-old girl with PWS who had aggressive outbursts, skin-picking and enuresis ${ }^{8}$. Another girl with enuresis 
was treated with Desmopressin and developed water intoxication ${ }^{9}$. Occasional enuresis was reported in 17 patients with PWS who had excessive daytime sleepiness and sleep disturbances ${ }^{10}$. And finally, Carpenter reported a case study on a 20-year-old man with secondary functional encopresis and aggressive behaviour ${ }^{11}$.

It may be concluded that our knowledge on UI in PWS is very limited. As no systematic study on PWS and incontinence had been conducted so far, the aim of our study was to assess and identify the frequency and type of $\mathrm{UI}$, and associated symptoms, in persons with PWS.

\subsection{MATERIAL AND METHOD}

The "Parental Questionnaire: Enuresis/Urinary Incontinence" ${ }^{4,12}$ is a clinical, non-validated questionnaire which includes 57 items referring to day- and nighttime time wetting, toilet habits, observable voiding behaviours and reactions, urinary tract infections, stool habits and behavioural symptoms which are rated in a yes/no format. Additional data (such as voiding and wetting frequency) are noted numerically. The questionnaire is suitable for children who are at least 5 years of age. It has been used in a study on children with spinal muscular atrophy (SMA $)^{13}$.

A total of 189 parents of the Dutch Prader-Willi Association were contacted and 118 questionnaires were completed and returned (response rate of $62.4 \%$ ). The non-responders were not contacted. The mean age of persons with PWS was 20.5 years (SD 11.5) with a range from 5 to 45 years. $60.2 \%$ (43) lived at home. PWS was due to a deletion in $27.1 \%$ of cases, to disomy in $22.9 \%$ and to an imprinting defect in $2.5 \%$. The cause was not known in $25.4 \%$ of cases.

Descriptive statistics were calculated with the SSPS statistical package version 17.0.

\subsection{RESULTS}

Number (and percentages) of children with various types of incontinence are shown in Table A6.1. A total of 16 persons with PWS (13.6\%) with a mean age of 15.1 years wetted their bed at night. The distribution across age groups is presented in Table A6.2. NE and UI was most common among children and adolescents, while FI mainly affected young adults. All 5 persons with daytime $\mathrm{UI}$ also had NE, which implies that there was no case of isolated daytime UI. The mean age of this group was higher (21.4 years). Another 4 persons had Fl: 
one with isolated $\mathrm{FI}$, the others with combined UI ( 3 with NE and 2 with daytime UI). All 4 patients with FI soiled during the night (one during the day, as well).

Table A6.1 Rates and frequency of incontinence, age and sex ratio

\begin{tabular}{|c|c|c|c|c|}
\hline & $n(\%)$ & Frequency/week & Age (years) & $\begin{array}{c}\text { Sex ratio } \\
\text { Female:male }(n)\end{array}$ \\
\hline $\mathrm{NE}$ & $16(13.6)$ & $\begin{array}{c}5.2 \text { nights } \\
\text { (SD 2.3; range 1-7) }\end{array}$ & $\begin{array}{c}\text { Mean:15.1 } \\
\text { (SD 11.4; range 5-43) } \\
\text { Median: } 11\end{array}$ & $1: 1(8: 8)$ \\
\hline $\begin{array}{l}\text { Additional } \\
\text { daytime UI }\end{array}$ & $5(3.8)$ & $\begin{array}{c}5.2 \text { days } \\
\text { (SD } 2.2 ; 2-7)\end{array}$ & $\begin{array}{c}\text { Mean: } 21.4 \\
\text { (SD 14.8; range 7-43) } \\
\text { Median: } 14\end{array}$ & $1.5: 1(3: 2)$ \\
\hline $\mathrm{FI}$ & $4(3.3)$ & $\begin{array}{c}4.0 \text { nights } \\
\text { (SD 2.0; range 2-6) }\end{array}$ & $\begin{array}{c}\text { Mean: } 20.5 \\
\text { (SD 9.9; range } 7-30) \\
\text { Median: } 23\end{array}$ & $1: 1(2: 2)$ \\
\hline
\end{tabular}

$\mathrm{NE}=$ Nocturnal Enuresis $; \mathrm{UI}=$ Urinary Incontinence $; \mathrm{FI}=$ Faecal incontinence

Table A6.2 Age groups of total sample and persons with NE,UI and FI

\begin{tabular}{lcccc}
\hline & $\begin{array}{c}\text { Child: } \\
5-12 \text { years }\end{array}$ & $\begin{array}{c}\text { Teen: } \\
\text { 13-18 years }\end{array}$ & $\begin{array}{c}\text { Young adult: } \\
19-30 \text { years }\end{array}$ & $\begin{array}{c}\text { Adult: } \\
\text { 31-45 years }\end{array}$ \\
\hline $\begin{array}{l}\text { Total }(n=118) \\
\mathrm{n}(\%)\end{array}$ & $38(32)$ & $23(20)$ & $32(27)$ & $24(21)$ \\
$\begin{array}{l}\text { NE }(n=16) \\
\mathrm{n}(\%)\end{array}$ & $9(56)$ & $3(19)$ & $2(13)$ & $2(13)$ \\
$\begin{array}{l}\text { Additional } \\
\text { daytime UI }\end{array}$ & 1 & 2 & 1 & 1 \\
$(\mathrm{n}=5) \mathrm{n}$ & & & & \\
$\mathrm{FI}(\mathrm{n}=4) \mathrm{n}$ & 1 & 0 & 3 & 0 \\
\hline
\end{tabular}

The mean number of days/nights with incontinence was high: wetting (day and night) occurred on a mean of 5.2 days/nights per week and the soiling on a mean of 4 nights per week. Except for the daytime UI where there wqas a preponderance of females, the incontinence rates were the same for both sexes.

Descriptive data for all 16 persons with $\mathrm{NE}$, as well as for the subgroup with additional daytime UI are shown in Table A6.3. Most persons with PWS went to the toilet when they needed to. Although parents did not observe holding manoeuvres, a large percentage of persons had to strain $(40 \%)$, had an interrupted stream (38\%) and showed signs of urgency $(60 \%)$ and postponement $(38 \%)$. A third had a history of UTIs. Only a fifth of parents and persons with PWS were distressed by the incontinence and a minority was motivated for treatment. The artes of behavioural symptoms were high and 
included both internalizing (sad, anxious) as well as externalizing problems (conduct, hyperactivity, attention).

Table A6.3 Symptoms of nocturnal enuresis $(\mathrm{NE})^{*}$ and subgroup with additional daytime urinary incontinence (UI)

\begin{tabular}{|c|c|c|}
\hline & $\begin{array}{c}\mathrm{NE}(\mathrm{N}=16) \\
\mathrm{n}(\%)\end{array}$ & $\begin{array}{l}\text { Subgroup with additional daytime UI } \\
\qquad(\mathrm{n}=5) \mathrm{n}(\%)\end{array}$ \\
\hline \multicolumn{3}{|l|}{ Incontinence } \\
\hline Incontinence & $\begin{array}{l}\text { Mean of } 5.2 \text { nights/week } \\
\quad(\text { SD 2.3; range 1-7) }\end{array}$ & $\begin{array}{c}2.6 \text { days/week } \\
(\text { SD 2.2; range 2-7) }\end{array}$ \\
\hline Been dry before & $6(38)$ at night & 3 during day \\
\hline Dry at age & 8.0 years (SD 1.4; range $7-10$ ) & 4.3 years (SD 2.1; range $2-6$ ) \\
\hline Duration of dryness & 56 months (49.4; range $1-96)$ & 70 months (SD 39.0; range 30-108) \\
\hline Bed usually damp (night) & $11(69)$ & 4 \\
\hline Bed usually wet (night) & $11(69)$ & 4 \\
\hline Nocturia & $6(40)$ & 2 \\
\hline Wakes up after wetting & $4(25)$ & 1 \\
\hline Deep sleeper & $5(31)$ & 3 \\
\hline Clothes usually damp (day) & $3(19)$ & 3 \\
\hline Clothes usually wet (day) & 1 & 1 \\
\hline Urine dribbles constantly & 1 & 1 \\
\hline FI night & $3(19)$ & 2 \\
\hline FI day & 1 & 1 \\
\hline Daily bowel movements & $13(81)$ & 3 \\
\hline Constipation & $2(13)$ & 1 \\
\hline \multicolumn{3}{|l|}{ Micturition habits } \\
\hline Mean number voidings & 6.4/day (SD 2.6; range 2-12) & 6.8/day (SD 3.3; range 4-12) \\
\hline Mean duration w/o going to toilet & $\begin{array}{l}159 \text { minutes (SD 58.1; range 60- } \\
240)\end{array}$ & $\begin{array}{l}172 \text { minutes (SD 78.9; range 90- } \\
240 \text { ) }\end{array}$ \\
\hline Goes to the toilet if needs to & $15(94)$ & 4 \\
\hline Has to be sent to the toilet & $3(20)$ & 2 \\
\hline $\begin{array}{l}\text { Hurries and does not take time for } \\
\text { voiding }\end{array}$ & $4(25)$ & 2 \\
\hline Straining & $6(40)$ & 2 \\
\hline Interrupted stream & $6(38)$ & 2 \\
\hline Urgency & $9(60)$ & 3 \\
\hline Postponement & $6(38)$ & 1 \\
\hline Holding manoeuvres & 0 & 0 \\
\hline Urinary tract infections (history) & $5(32)$ & 2 \\
\hline UTI's with fever (history) & $2(13)$ & 1 \\
\hline \multicolumn{3}{|l|}{ Impact } \\
\hline Distressed by wetting & $3(19)$ & 1 \\
\hline Parent distressed & $3(19)$ & 1 \\
\hline Teased because of wetting & $1(6)$ & 1 \\
\hline Wets more often in stressful times & $4(25)$ & 2 \\
\hline $\begin{array}{l}\text { Cooperative and motivated for } \\
\text { treatment }\end{array}$ & $4(25)$ & 2 \\
\hline \multicolumn{3}{|l|}{ Behaviour } \\
\hline Sad, unhappy, withdrawn & $5(31)$ & 3 \\
\hline Anxious & $6(38)$ & 3 \\
\hline Difficulties in accepting rules & $5(36)$ & 3 \\
\hline $\begin{array}{l}\text { Restless, on the go, easily } \\
\text { distracted }\end{array}$ & $7(44)$ & 4 \\
\hline Difficulty concentrating & $10(63)$ & 4 \\
\hline
\end{tabular}

${ }^{*}$ missing values for individual items 
Because of the small size of the subgroup with additional daytime UI, no percentages were calculated. Descriptively, this group has similar rates of daytime micturition problems as the total group, but much higher rates of behavioural symptoms.

\subsection{DISCUSSION}

This is the first systematic report of prevalence of $\mathrm{UI}$ in a large group of persons with PWS. The results clearly show that $\mathrm{UI}$ is a common disorder associated with PWS. The rates of $\mathrm{UI}$ in this sample are much higher than in persons with an average IQ (in the range $85-115)^{4}$ - and possibly in those with intellectual disability in general. The IQ of the persons in this study was not ascertained, but approximately $40 \%$ of the persons with PWS have mild (IQ 5070 ) and $20 \%$ have moderate (IQ 35-50) intellectual disabilities, while $40 \%$ have an IQ higher than $70^{1}$. Comparable population-based rates of $\mathrm{UI}$ at a comparable mean age of 20 years was $0 \%$ for NE, $5.6 \%$ for daytime $\mathrm{UI}$ and $0 \%$ for $\mathrm{FI}$ in individuals with mild intellectual disability (incontinence is seldomly seen in the IQ-range of 50-70) ${ }^{6}$. By contrast, our results indicate that rates of UI among individuals with PWS are higher.

The study also shows that UI persists well beyond adolescence into adulthood, i.e. UI in PWS is not confined to childhood. Another finding is that most UI occurs mainly at night. It is noteworthy that $38 \%$ of the patients with UI had been dry before and had relapsed, indicative of secondary NE. It can be speculated that the associated behavioural disturbances might have acted as a trigger for these recurrences ${ }^{4}$.

Arousal difficulties were not a major problem, as many persons woke up spontaneously (nocturia) or after wetting - and only a third were considered to be deep sleepers. A high percentage had lower urinary tract symptoms possibly indicative of overactive bladder (urgency), dysfunctional voiding (straining, interrupted stream) or voiding postponement. Without daytime UI, this group would be classified as 'non-monosymptomatic' NE according to the ICCS terminology ${ }^{2}$. Dysfunctional voiding seems to be a special problem in children with intellectual disability, requiring urodynamic investigation ${ }^{14}$. Finally, the rate of $\mathrm{FI}$ was moderately increased compared to 20 -year-old persons with mild intellectual disability ${ }^{6}$, but occurring atypically only at night and not associated with constipation.

In contrast to most parents and typically developing children, the families were not highly distressed by the UI despite its high frequency of 5 nights/days per 
week $^{15,16}$. One can only speculate that due to the long course of the UI families might have resigned (parents might think that incontinence 'belongs' to ID) and have given up hopes for cure, or have not been offered professional help.

A limitation of the study is the reliance on parental report. Symptoms like holding manoeuvres might have been overlooked or misinterpreted by parents. Also, objective clinical and urodynamic assessment could have revealed specific functional disturbances and diagnoses ${ }^{14}$. The level of cognitive abilities (IQ) was not measured and a control group was not included which would have allowed direct comparisons with other studies ${ }^{6}$. Also, the non-responders were not assessed. One should view this study as a preliminary or pilot report, resulting in new research on the specific associations of urinary incontinence in PWS and in other genetic syndromes of intellectual disability.

In conclusion, $\mathrm{UI}$ is a common and neglected aspect in intellectual disability generally, and in PWS specifically. UI persist into adulthood, occurs mostly at night and occurs on most nights or days. Lower urinary tract and behavioural symptoms are common. Therefore, the care for children, adolescents and adults with PWS should include a detailed assessment and treatment for UI. Based on an exact diagnosis, the general guidelines for functional $\mathrm{UI}$ can be followed for some children ${ }^{4}$, while specific programmes for persons with intellectual disability will be needed for others ${ }^{17}$. 


\section{REFERENCES}

1. Cassidy SB, Driscoll DJ. Prader-Willi syndrome. Eur J Hum Genet 2009; 17: 3-13

2. Nevéus $T$, von Gontard $A$, Hoebeke $P$, Hjälmås K, Yeung $C K$, Vande Walle J, Rittig S, Jørgensen TM, Bower W, Bauer S, Djurhuus JC. The Standardisation of Terminology of Lower Urinary Tract Function in Children and Adolescents: Report from the Standardisation Committee of the International Children's Continence Society (ICCS). J Urol 2006; 176: 314-324

3. Rasquin A, Di Lorenzo C, Forbes D, Guiraldes E, Hyams JS, Staiano A, Walker LS. Childhood functional gastrointestinal disorders: child/adolescent. Gastroenterology 2006; 130: 1527-1537

4. von Gontard A, Neveus T. Management of disorders of bladder and bowel control in childhood. London, MacKeith Press, 2006

5. World Health Organization. Mental retardation division of health and prevention of substance abuse. International classification of Diseases. $10^{\text {th }}$ Edition. ICD-10. Geneva, 1996

6. on Wendt L, Similä S, Niskanen P, Järvelin MR. Development of bowel and bladder control in the mentally retarded. Dev Med Child Neurol 1990; 32: 515-518

7. Backes M, Genc B, Doerfler W, Schreck J, Lehmkuhl G, von Gontard A. Cognitive and behavioral profile of Fragile X boys - correlations to molecular data. Am J Med Genet 2000; 95: 150-156

8. Webber C, Udwin O Psychological intervention with a 4-year-old girl with PraderWilli syndrome. Genet Couns 1997; 8: 271

9. Robson WLM, Shashi V, Nagaryj S, Norgaard JP. Water intoxication in a patient with the Prader-Willi syndrome treated with Desmopressin for nocturnal enuresis. $J$ Urol 1997; 157: 646-647

10. Clift S, Dahlitz M, Parkes JD. Sleep apnoe in the Prader-Willi syndrome. J Sleep Res 1994; 3: 121-126

11. Carpenter SPC. Development of a young man with Prader-Willi syndrome and secondary functional encopresis. Can J Psychiatry 1989; 34: 123-127

12. Beetz $R$, von Gontard A, Lettgen B. Anamnese-Fragebogen: Einnässen/Harninkontinenz und Erläuterungen zum Anamnese-Fragebogen. Bad Homburg: Enuresis Informationszentrum, 1994.

13. von Gontard A, Laufersweiler-Plass C, Backes M, Zerres K, Rudnik-Schöneborn S. (2001b) Enuresis and urinary incontinence in children and adolescents with spinal muscular atrophy. BJU Int; 88: 409-413.

14. Van Laecke E, Golinveaux L, Raes A, Hoebeke P, Vande Walle J. Voiding disorders in severely mentally and motor disabled children. J Urol 2001; 166: 24042406

15. Butler RJ, Golding J, Heron J, Alspac study team: Nocturnal enuresis: a survey of parental coping strategies at $71 / 2$ years. Child Care Health Dev 2005; 31: 659-667

16. Butler R, Heron J. An exploration of children's views of bed-wetting at 9 years. Child Care Health Dev 2007; 34: 65-70

17. Smith L, Smith $P$, Lee SK. Behavioural treatment of urinary incontinence and encopresis in children with learning disabilities: transfer of stimulus control. Dev Med Child Neurol 2000; 42: 276-279 



\section{Appendix 7}

\section{THE GH/IGF-I AXIS AND PITUITARY FUNCTION AND SIZE IN ADULTS WITH PRADER-WILLI SYNDROME}

Van Nieuwpoort IC*, Sinnema M*, Castelijns JA, Twisk JWR, Curfs LMG, Drent $\mathrm{ML}$

Horm Res Paediatr 2011; 75: 403-411

* Equal contribution by both authors 


\section{ABSTRACT}

\section{Background}

In adults with PWS, limited information is available about pituitary function, more specifically the prevalence of growth hormone deficiency (GHD). The aim of this study was to gain more insight into endocrine function in PWS adults, with emphasis on $\mathrm{GH}$ secretion.

\section{Methods}

Fifteen randomly selected adult PWS individuals were included and fourteen healthy brothers and sisters served as a control group. Main outcome measures were IGF-I, IGFBP-3 and peak GH level after a combined GHRHArginine test. Other pituitary hormone deficits are diagnosed based on serum levels of the concerning hormones. The size of the pituitary gland was measured on MRI images.

\section{Results}

In PWS adults, IGF-I levels were low and IGFBP-3 levels normal when compared to healthy controls. GHD was diagnosed in $8-38 \%$ of the PWS patients, depending on the criteria used. Hypogonadism was present in $87 \%$ of the patients. Hypothyroidism and adrenal insufficiency could also be demonstrated. Anterior pituitary size was lower in PWS individuals when compared to healthy controls.

\section{Conclusion}

In this study, pituitary hormone deficiencies are demonstrated in a considerable number of adults with PWS, hypogonadism and GHD being most prominent. Furthermore, the anterior pituitary is smaller in comparison with healthy controls. 


\subsection{INTRODUCTION}

Prader-Willi syndrome (PWS), also known as Prader-Labhart-Willi syndrome, was originally described in 1956 by the Swiss physicians Prader, Labhart and Willi ${ }^{1}$. PWS is characterized by clinical features such as hyperphagia, morbid obesity, hypotonia, hypogonadism, dysmorphic features, short stature, mental retardation, behavioral abnormalities, high pain threshold and temperature instability ${ }^{1-3}$. Many of the clinical abnormalities seen in PWS are thought to be a result hypothalamic dysfunction ${ }^{1,2,4,5}$. Studies of pituitary size and structure are limited and contradictory. One study reports no significant difference in height of the anterior pituitary lobe in growth hormone deficient (GHD) PWS individuals compared with normal controls or children with isolated $\mathrm{GHD}^{6}$. In two other studies, however, a reduction of pituitary height was observed in $50-60 \%$ of the patients with $\mathrm{PWS}^{7,8}$. A remarkable finding in both studies was, that in some PWS subjects no posterior pituitary bright spot (PPBS) was present $^{6,7}$. The PPBS is thought to be a reflection of hypothalamic function, therefore a missing PPBS might be an indication for hypothalamic-pituitary dysfunction ${ }^{6}$.

Since the description of the syndrome, several studies have been performed in individuals with PWS to gain more information about endocrine function. Because some of the clinical features in PWS show similarities with symptoms seen in GHD patients, many of these studies focused on GH and IGF-I. Several studies showed a reduced GH secretion to provocative stimuli in a substantial amount of children with PWS and more recently also in adults ${ }^{2,9-14}$. The decreased GH secretion seen in PWS is not solely explained by obesity. In simple obesity, GH secretion after provocative stimuli is indeed decreased, but IGF-I levels are normal or even elevated. In PWS individuals on the other hand, IGF-I levels are lower in both obese and non-obese PWS individuals when compared to normal weight and obese controls $\mathrm{s}^{2,9-13,15-19}$.

Results from studies of the other pituitary axes have been conflicting and most of these studies have been conducted in PWS children. Normal function of the hypothalamic-pituitary-gonadal axis has been documented, but hypogonadism seems to be present in the majority of PWS subjects. This can be due to hypogonadotropic hypogonadism or primary gonadal failure as a results of cryptorchidism, but a combination of both primary and secondary hypogonadism seems to be present in most patients ${ }^{2,10,20-24}$. Published data on thyroid and adrenal function are limited. In most reports, thyroid and adrenal function are reported to be normal, although secondary hypothyroidism has been described ${ }^{2,10,23,25-28}$. Remarkably, in a recent study central adrenal insufficiency was demonstrated in $60 \%$ of the PWS children ${ }^{29}$. 
Since most studies of endocrine function have been performed in PWS children and not in adults, the aim of this study was to gain more insight in endocrine function in adults with PWS. Therefore, we investigated pituitary function, with emphasis on $\mathrm{GH}$ secretion, and pituitary size in adults with Prader-Willi syndrome. Healthy brothers and sisters were used as control group.

\subsection{SUBJECTS AND METHOD}

\section{Subjects}

PWS patients

Fifteen adult patients with PWS were included in this study, 4 males and 11 females, median age 22.0 years (range 19.2 - 42.9 years). Subjects were recruited via the Dutch Prader-Willi patients' association and the diagnosis was genetically confirmed. Patients were excluded if they received $\mathrm{GH}$-treatment within three months before enrolment. Written informed consent was obtained from the patients and their parents/caretakers. The study was approved by the Medical Ethics Review Committee of the VU University Medical Center and conducted according to the principles of the Helsinki declaration.

\section{Control group}

The control group consisted of 14 healthy brothers and sisters of the included PWS patients, 7 males and 7 females, median age 28.5 years (range 17.5 41.3 years). All control subjects had a good general health, no history of pituitary disease, surgery or radiotherapy of the head. IGF-I levels were determined to rule out abnormalities of the GH/IGF-I axis and IGF-I levels were normal for age and gender in all control subjects.

\section{Methods}

Medical history was taken in all PWS patients and a general physical examination was performed. Height $(\mathrm{m})$ was measured barefoot in the standing position with a wall stadiometer to the nearest of $0.1 \mathrm{~cm}$. Weight $(\mathrm{kg})$ was measured barefoot wearing only underwear on a calibrated balance scale with an accuracy of $0.1 \mathrm{~kg}$. BMI $\left(\mathrm{kg} / \mathrm{m}^{2}\right)$ was calculated as weight divided by square height. Waist circumference $(\mathrm{cm})$ was measured halfway between the lateral caudal costa and the iliac crest at the end of a normal expiration. Hip circumference was measured at the level of the trochanter major. In all analyses, the mean value of three measurements of waist and hip circumference was used. WHR was calculated by waist circumference divided by hip circumference. In PWS patients, fat mass was measured by Bioelectric 
Impedance Analysis (BIA; RJL 101/S/D, Akern-Rijl systems) and Dual Energy X-ray Absorptiometry (DXA; Hologic QDR-4500). In the control group, fat mass was only measured by BIA analysis. The method as described by Lukaski et al. ${ }^{30}$ was used for BIA calculations.

\section{Laboratory tests and assays}

In PWS patients, blood samples for laboratory tests were drawn in the morning (at approximately 08:00-10:00 h) after an overnight fast. Standard laboratory tests were done to rule out any underlying disease and no relevant abnormalities were found. Furthermore, blood samples for hormonal assessments were drawn and all laboratory analyses of hormonal parameters were performed altogether at the end of the study. The following laboratory assays were used: GH: Immunometric assay, Luminescence, Immulite 2500, Siemens Medical Solutions Diagnostics, USA. Reference range men $<10 \mathrm{mU} / \mathrm{l}$, women <20 mU/l. IGF-I: Immunometric assay, Luminescence, Immulite 2500, Siemens Medical Solutions Diagnostics, USA. Reference range gender and age specific. IGFBP-3: Immunometric assay, Luminescence, Immulite 2500, Siemens Medical Solutions Diagnostics, USA. Reference range gender and age specific. All other hormonal assessments were performed at the endocrine laboratory of the VU University Medical Center with commercially available, regularly internal and external quality controlled immunoassays.

\section{GHRH-Arginine test}

A combined GHRH-Arginine test was performed in PWS patients only. The GHRH-Arginine test was chosen over ITT since the latter is contra-indicated in patients with ischemic heart disease or seizure disorders and is known to have more side effects than the GHRH-Arginine test. During the GHRH-Arginine test an intravenous bolus of $1 \mu \mathrm{g} / \mathrm{kg} \mathrm{GHRH}$ is given at time $=0(\mathrm{~T} 0)^{31}$. For practical reasons, however, it was decided to standardize the dosing of GHRG by protocol as follows: patients with a body weight above $60 \mathrm{~kg}$ received a bolus of $100 \mu \mathrm{g} / \mathrm{kg} \mathrm{GHRH}$ and patients with a body weight just below $60 \mathrm{~kg}$ a bolus of $75 \mu \mathrm{g} \mathrm{GHRH}$. After this injection an intravenous infusion of arginine was given in a dose of $0.5 \mathrm{~g} / \mathrm{kg}$ body weight, with a maximum of 30 grams, over a time period of 30 minutes. Blood samples for serum growth hormone measurements were collected at T $-15, T 0, T 15, T 30, T 60$ and T 90 minutes. The criteria for GHD in adults in the Netherlands are defined as IGF-I level $\leq-2.0$ SD for age and gender combined with a peak GH level after GHRH-Arginine test $<9 \mu \mathrm{g} / /^{31}$, and are required for reimbursement of the $\mathrm{GH}$ treatment costs from the health insurer. However, also BMI-related cut-off points for the GHRH-Arginine test can be used to diagnose GHD in adults. Cut off levels for diagnosing GHD are defined by a peak $\mathrm{GH}$ of $11.5 \mu \mathrm{g} / \mathrm{l}$ if $\mathrm{BMl}<25 \mathrm{~kg} / \mathrm{m}^{2}$, a peak $\mathrm{GH}$ of $8.0 \mu \mathrm{g} / \mathrm{l}$ if BMl is $\geq 25$ and $<30$, and a peak GH of $4.2 \mu \mathrm{g} / \mathrm{l}$ if $\mathrm{BMI} \geq 30^{32}$. 


\section{Genetic analysis}

In all patients, the diagnosis of PWS was genetically confirmed at the Department of Clinical Genetics, Academic Hospital Maastricht, Maastricht University, The Netherlands. Cytogenetic and molecular analysis using the SALSA MLPA kit P245 (MRC Holland, Amsterdam) were performed to establish whether deletions were present. Diagnosis of PWS was confirmed by DNA methylation studies on the SNURF/SNRPN locus and maternal uniparental disomy (mUPD) was confirmed with microsatellite analysis at various loci on chromosome 15, when blood of parents was available.

\section{MRI}

In PWS patients and healthy controls, a MRI examination was performed at a 1.5-T Unit (Magnetom Sonata, Siemens Medical Systems, Erlangen, Germany) using a head coil. First, sagittal MPRAGE pulse sequence was used (T1weighted spin-echo images, repetition time $(T R)=2700 \mathrm{msec}$, echo time $(T E)$ $=5.17 \mathrm{msec}$, slice thickness $1.0 \mathrm{~mm}$, total of 176 slices, field-of-view $25 \times 25$ $\mathrm{cm}$, voxel 1x1x1 mm). After that, a T2-weighed coronal scan was obtained (T2weighted Turbo Spin Echo sequence, TR $=5260 \mathrm{msec}$, TE $=134 \mathrm{msec}$, slice thickness $3.0 \mathrm{~mm}$, gap $0.3 \mathrm{~mm}$, total of 15 slices, matrix $512^{\star} 384$, field-of-view $25 \times 25 \mathrm{~cm}$, voxel $0,6 \times 0,5 \times 3,0 \mathrm{~mm})$. Pituitary size was measured independently by two investigators (JC and ICVN) using IMS Centricity Enterprise Web V3. Size of the anterior pituitary was measured on both a sagittal (maximum anterior-posterior and cranio-caudal diameter) as well as a coronal (maximum left-to-right diameter) image at the level of the pituitary stalk. Maximum size of the posterior pituitary was measured on a sagittal image only, by measuring maximum anterior-posterior and cranio-caudal diameter. We used the mean of measurements of both observers for analysis.

\section{Statistical analysis}

This study is a cross-sectional observational study. All analyses were performed using the statistical software package SPSS version 15 (SPSS, Chicago, IL, USA). All data are presented as median with IQR (interquartile range) since most of the variables were not normally distributed. Area under the curve (AUC) for the GHRH-Arginine test was calculated by the trapezoidal method. Comparisons between groups were analyzed with the Mann-Whitney $\mathrm{U}$ test. Correlations between pairs of variables were assessed by Spearman's rank correlation analysis. A p-value below $<0.05$ was considered statistically significant. 


\subsection{RESULTS}

Baseline characteristics of both the PWS and control subjects are presented in Table A7.1. When compared to healthy controls, PWS subjects had a significantly lower height, IGF-I serum level and IGF-I SDS. BMI, waist circumference, WHR and fat mass measured by BIA were significantly higher in PWS subjects than in controls. There was no correlation between BMI and IGF-I SDS neither in healthy controls nor in PWS patients (data not shown). Fourteen PWS patients had a paternal deletion and one patient a mUPD. Since there was only one patient with a mUPD, we were not able evaluate differences between genetic subtypes.

\section{Thyroid function}

Two of the patients suffered from hypothyroidism (probably of hypothalamic/pituitary origin) and were using thyroxin in a stable dose. One patient suffered from hyperthyroidism, most likely as a result of thyroiditis caused by intake of high amounts of kelp in tablets which he received from an alternative healer. After stopping these tablets, patient became euthyroid within a few weeks. The twelve remaining subjects all had normal thyroid function.

\section{Adrenal function}

In one of the patients, adrenal function was insufficient since several years and this patient was treated with hydrocortisone in a stable dosage. Fasting morning cortisol and ACTH levels were normal in eight subjects. In six subjects, ACTH and/or cortisol levels were borderline and therefore these patients were advised to undergo further evaluation. In two patients a CRH test has been performed with a normal response in both patients.

\section{Gonadal function}

Two males and five females, had already been treated with sex steroids prior to this study. In the treated males, testosterone levels were just above the lower reference limit. Testosterone levels were low combined with low-normal $\mathrm{LH}$ and $\mathrm{FSH}$ levels in the untreated males $(n=2)$, indicating secondary hypogonadism. However, all four male subjects were treated with orchidopexy for cryptorchidism in the past, so a combination of primary and secondary hypogonadism was possible. Only two of the eleven females had a spontaneous regular menstrual cycle. Five females were treated with sex steroids, the remaining four were not, although they were clearly hypogonadal. In three of these patients, estradiol levels were even within the postmenopausal range. $\mathrm{LH}$ and $\mathrm{FSH}$ levels were low-normal. Considering the low estradiol levels, LH and FSH levels were too low, indicating a failing compensatory mechanism at the level of the pituitary gland. In conclusion, gonadal function was adequate in only two of the fifteen PWS adults (13\%). 


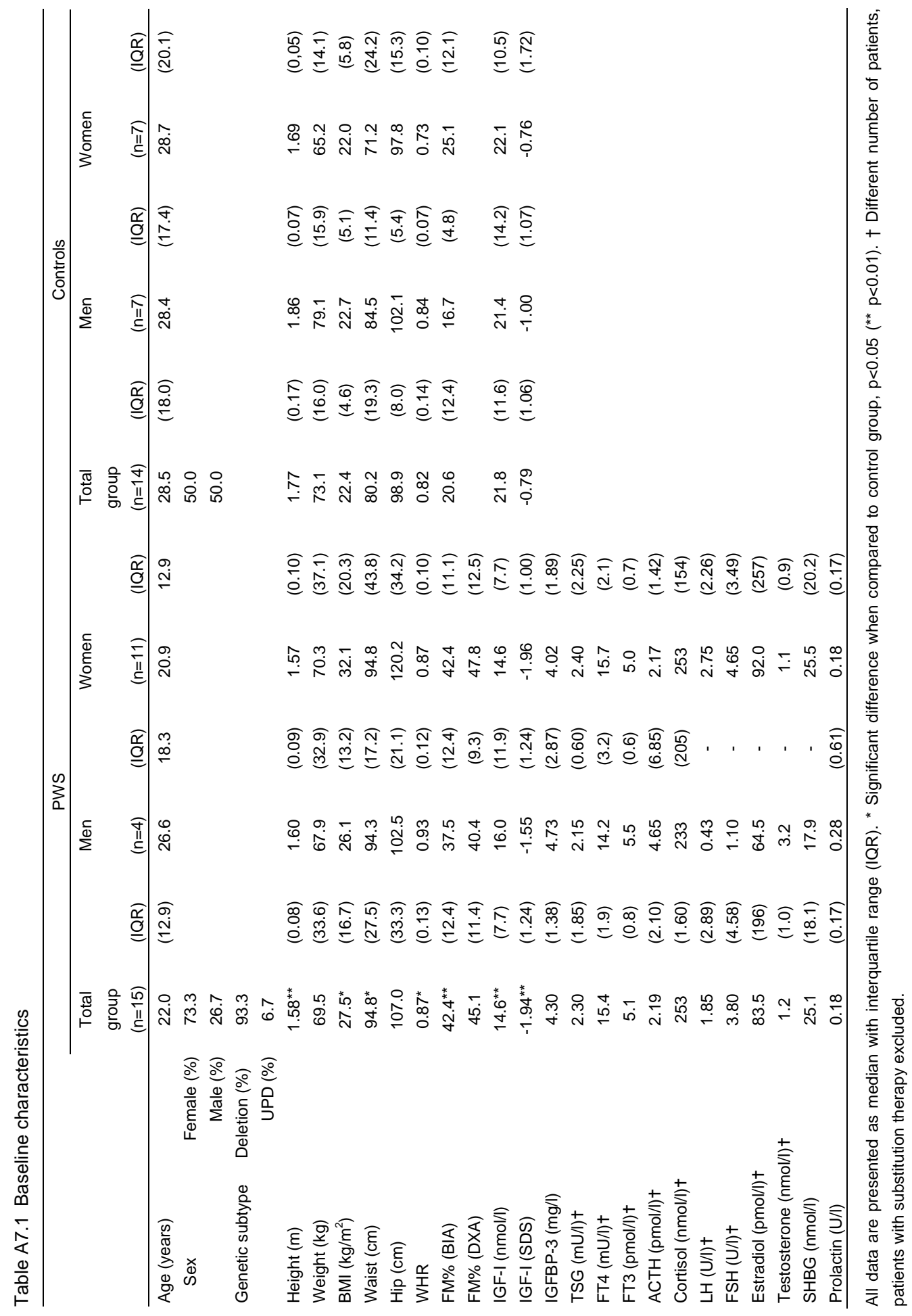




\section{GH/IGF-I axis}

Four of the PWS patients were treated with GH in the past (treatment duration 7-12 years), but all stopped treatment at least 5 months before the study. In the PWS individuals, median IGF-I level was $14.6 \mathrm{nmol} / \mathrm{l}$ and median IGF-I SDS 1.9 SD. Seven patients had a IGF-I SDS $\leq-2.0$ SD. Seven patients had an IGF-I SDS $\leq-2.0$ SD. IGFBP-3 was within the normal range in all participants. The results of the GHRH-Arginine tests are presented in Table A7.2 and Figure 7.1. Median peak GH was $40.6 \mathrm{mU} / \mathrm{l}$ and median AUC was $181.9 \mathrm{mU} / \mathrm{l}$ per 90 minutes. A striking problem we encountered during this study was the difficulty to place an intravenous cannula in an antecubital vein in some PWS patients. This is hardly mentioned in the literature, but according to most of the patients and their family or caretakers, it is always difficult to take blood samples for laboratory analyses. We were not able to perform a GH stimulation test in two patients, since we could not obtain an intravenous entrance. IGF-I levels were low in both patients (IGF-I SDS of -1.9 and -2.7 ). In the remaining thirteen patients, the percentage of patients with GHD depended on the criteria being used. Five participants had a peak GH level after GHRH-Arginine test $<9 \mu \mathrm{g} / \mathrm{l}$ $(38 \%)$. In four patients $(31 \%)$ the peak GH level was below the cut-off combined with an IGF-I level of $\leq-2.0$ SD. However, when BMI-related cut off points for the GHRH-Arginine test were used, stimulated $\mathrm{GH}$ levels were below the cut-off level in only 1 PWS patient (8\%).

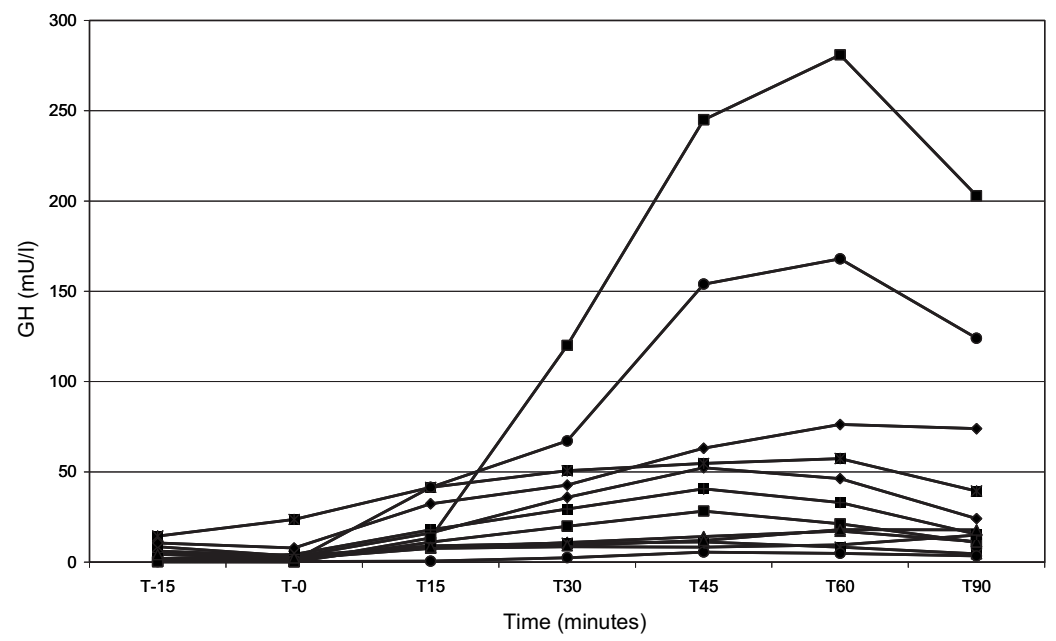

Figure 7.1 Individual peak GH responses to a GHRH-Arginine test in twelve adults with PWS 


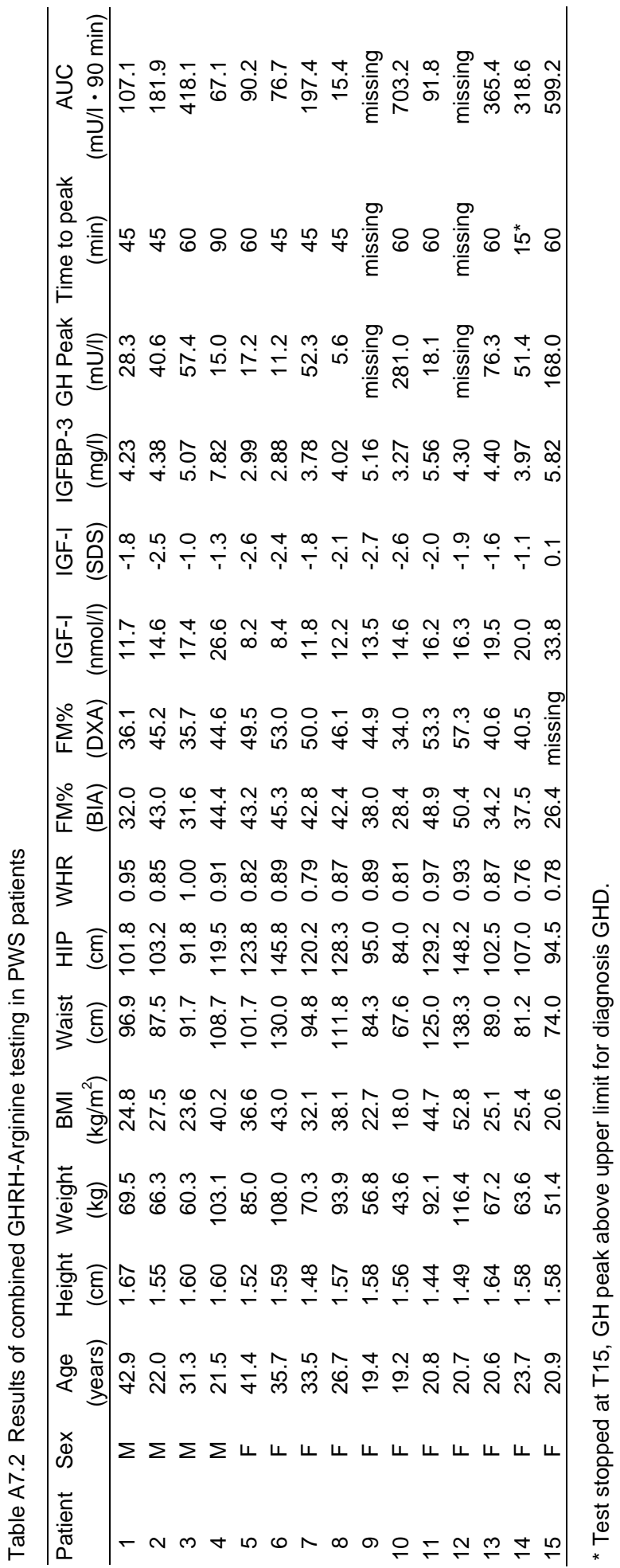




\section{Multiple pituitary deficiencies}

The number of PWS patients with multiple pituitary deficiencies depends on the criteria being used. For calculation of patients with multiple pituitary deficiencies, patients with borderline ACTH and cortisol levels were assumed to have adequate adrenal function. Patients with a decreased IGF-I level in whom a GHRH-Arginine test could not be performed were assumed not to be GHD. In five patients two pituitary deficiencies are present if GHD is defined by IGF-I level $\leq-2.0$ SD combined with a peak $\mathrm{GH}$ level $<9 \mu \mathrm{g} / \mathrm{l}$. When GHD is defined by BMI-related cut-off points alone, three patients had two pituitary deficiencies. However, it is possible that the number of patients with multiple pituitary deficiencies is underestimated by the before-mentioned assumptions.

\section{Correlations between measurements of adiposity and GHRH-Arginine test}

Peak GH and AUC were negatively correlated with weight, BMI, waist and fat mass measured by both BIA and DXA (Table A7.3). There was also a strong correlation between peak GH and AUC (correlation coefficient 0.984, $p<0.001$ ). Peak GH and AUC were not significantly correlated with IGF-I serum level or IGF-I SDS. Since gender might influence measurements of adiposity, we also investigated these correlations in female PWS subjects (not in male PWS subjects, because of the small number of male patients). We found approximately the same correlations in the female subjects as in the whole group, except that the correlations between peak GH and AUC with FM \% (DXA) were no longer significant, but this is more likely to be a power problem (data not shown).

Table A7.3 Correlation coefficients between measurements of body composition and peak GH and AUC in PWS patients

\begin{tabular}{lcc}
\hline & GH peak $(\mathrm{mU} / \mathrm{l})$ & AUC $(\mathrm{mmU} / \mathrm{l} \cdot 90 \mathrm{~min})$ \\
\hline Weight $(\mathrm{kg})$ & $-0.901^{* *}$ & $-0.934^{* *}$ \\
BMI $\left(\mathrm{kg} / \mathrm{m}^{2}\right)$ & $-0.846^{* *}$ & $-0.863^{* *}$ \\
Waist $(\mathrm{cm})$ & $-0.874^{* *}$ & $-0.874^{* *}$ \\
FM $(\%, \mathrm{BIA})$ & $-0.758^{* *}$ & $-0.775^{* *}$ \\
FM (\%, DXA) & $-0.608^{*}$ & $-0.636^{*}$ \\
IGF-I (nmol/l) & 0.440 & 0.418 \\
IGF-I (SDS) & 0.302 & 0.302 \\
\hline
\end{tabular}

* Significant correlation, $p<0.05\left({ }^{* *} p<0.01\right)$.

\section{Pituitary size}

The results of measurements of pituitary size are presented in Table A7.4. We were not able to perform a MRI scan in three PWS patients due to reluctance for the MRI examination in one patient and contra-indications for MRI in two other patients. Anterior pituitary size was significantly lower in all measured 
directions in PWS adults when compared to healthy controls. Size of the posterior pituitary did not differ significantly between both groups and we did not find absence of the PPBS in any of the patients. We also investigated whether size of the anterior pituitary was correlated to endocrine function. There was a significant correlation between the cranio-caudal diameter (as measured in the sagittal plane) of the anterior pituitary and ACTH levels (correlation coefficient $0.705, p=0.01$ ). TSH, LH, FSH, PRL, peak GH and AUC did not significantly correlate with anterior pituitary size (data not shown).

Table A7.4 Pituitary size

\begin{tabular}{lrrrr}
\hline & \multicolumn{2}{c}{$\begin{array}{c}\text { Controls } \\
(\mathrm{n}=14)\end{array}$} & \multicolumn{2}{c}{$\begin{array}{c}\text { PWS } \\
(\mathrm{n}=12)\end{array}$} \\
\hline Anterior pituitary in sagittal plane & & & & \\
A-P diameter (mm) & 8.3 & $(3.2)$ & $6.1^{*}$ & $(1.5)$ \\
C-C diameter (mm) & 6.7 & $(1.7)$ & $3.4^{* *}$ & $(1.3)$ \\
Anterior pituitary in coronal plane & & & & \\
L-R diameter (mm) & 14.4 & $(2.9)$ & $10.7^{* *}$ & $(3.0)$ \\
C-C diameter (mm) & 5.7 & $(1.3)$ & $4.0^{* *}$ & $(1.1)$ \\
Posterior pituitary in sagittal plane & & & & \\
A-P diameter (mm) & 3.2 & $(1.0)$ & 2.5 & $(1.1)$ \\
C-C diameter (mm) & 5.4 & $(2.1)$ & 4.8 & $(1.6)$ \\
\hline
\end{tabular}

All data are presented as median with interquartile range (IQR). * Significant difference when compared to control group, $\mathrm{p}<0.05\left({ }^{* *} \mathrm{p}<0.01\right)$. A-P $=$ Anterior-Posterior, $\mathrm{C}-\mathrm{C}=$ Cranio-Caudal, L-R=Left-Right.

\subsection{DISCUSSION}

As already known from literature, our PWS patients had a lower height and higher BMI, waist circumference, WHR and fat mass when compared to healthy controls. In this PWS group, BMI is in the overweight range, not in the obese range. However, percentage fat mass is more than twice as high when compared to the control group, once again indicating a different body composition in PWS adults ${ }^{33}$.

Since it is thought that hypothalamic dysfunction underlies PWS, it is interesting to know whether pituitary size is decreased and whether pituitary size and function are associated. In our patients, anterior pituitary size, measured by MRI, was significantly lower in all measured directions when compared to healthy controls. Although MRI studies of the size of the pituitary gland in individuals with PWS are scarce, this is in accordance with previous reports in children with PWS ${ }^{7,8}$. Except for ACTH levels, there was no significant correlation between measurements of pituitary size and endocrine function in PWS individuals. In their study, Miller et al. found no association 
between anterior pituitary hormone deficiencies and the presence of a hypoplastic pituitary gland ${ }^{34}$.

In accordance with previous studies, hypothyroidism is not very common in our group of PWS patients, with 2 out of 15 patients (13\%) being hypothyroid. This is a higher percentage than described in the general population or than reported in PWS by others ${ }^{25,27}$. However, the number of patients in our study was small, the prevalence we found could therefore be an overestimation of the real prevalence of hypothyroidism in PWS.

Recently, a high percentage of PWS children was reported to have central adrenal insufficiency $(\mathrm{CAI})^{29}$. In one of our adult PWS patients, the diagnosis CAl was already made several years before this study. Fasting morning ACTH and cortisol levels were borderline in six of the remaining fourteen patients. Two of them showed a normal response to CRH. Further testing needs to be done in the other four patients. The existence of CAI may have major therapeutic consequences and therefore further research is warranted, not only in children, but also in adults.

Hypogonadism was present in almost all of the PWS adults. However, only half of the patients were treated with sex steroids. Some of the PWS adults were not under standard medical control and hypogonadism was not diagnosed before. In others, there was reluctance to start hormonal substitution therapy for different reasons. In the view of the unusual body composition with a low lean body mass and a high fat mass, the lack of secondary sexual characteristics and the high prevalence of osteoporosis reported in PWS, treatment with sex steroids should be considered in PWS adults, although systematic studies are lacking ${ }^{21,35}$.

In this group of PWS patients, IGF-I serum levels and IGF-I SDS were significantly lower when compared to healthy controls, despite a significantly higher BMI in PWS patients. IGFBP-3 levels were within the normal range for healthy, normal-weight adults. Similar findings are previously reported by others ${ }^{13,14,16}$. The above described findings differ from observations in individuals with simple obesity, where peak $\mathrm{GH}$ at provocative tests is known to be low, but IGF-I levels are within the normal range or even elevated. It is therefore rather unlikely that GHD in PWS is solely explained by obesity $2,11,12,16$. This is also supported by the fact that we found no direct correlation between $\mathrm{BMI}$ and IGF-I SDS neither in PWS patients nor in healthy controls.

Although we used a shortened procedure of the GHRH-Arginine test, this has recently been proven to be a reliable test procedure for the diagnosis of GHD in adults $^{36}$. Depending on the criteria being used, peak $\mathrm{GH}$ levels after stimulation were low in $8-38 \%$ of the patients. Combined pituitary deficiencies were present in at least 3-5 of the patients. 
Although IGF-I SDS was below -2 SD in $47 \%$ of PWS patients, a decreased IGF level was not always accompanied by a low peak GH level after provocative testing. For example, one of the patients with an IGF-I SDS of 2.58 reached a peak $\mathrm{GH}$ of $281.0 \mathrm{mU} / \mathrm{l}$ after stimulation. The other way around also holds true, IGF-I was not always low when peak GH was low. In accordance with these findings, there was no direct correlation between IGF-I serum level and IGF-I SDS on the one hand and peak GH level and AUC on the other hand. Previous studies investigating a possible correlation between IGF-I and peak GH are conflicting ${ }^{12,14,37,38}$. Nevertheless, IGF-I levels alone do not seem to be a good predictor for the existence of GHD in adults with PWS. The percentage of PWS patients with severe GHD in this study is somewhat lower than reported previously ${ }^{12-14}$. This can be due to a limited number of patients in this study or to different stimulation tests or criteria for GHD used in other studies. Recently the percentage of PWS adults with GHD was described to be only $15 \%$ in a study also using the combined $\mathrm{GHRH}$-arginine test and BMI-related cut off points ${ }^{38}$. In another very recent study, the percentage of PWS patients with severe GHD was reported to be higher $(44 \%)$ and stimulated GH levels seemed to be different for the genetic subtypes of PWS, with higher $\mathrm{GH}$ responses in patients with a deletion when compared to mUPD patients ${ }^{39}$. Since there was only one patient with a mUPD in our study, we were not able to investigate differences in $\mathrm{GH}$ secretion between patients with a deletion or mUPD.

Peak GH and AUC were negatively correlated with weight, BMI, waist and fat mass in our study. These relationships are also described in healthy men ${ }^{40}$. In a very recent study Sode-Carlsen et al.$^{38}$ describe a strong negative correlation between subcutaneous and visceral fat fraction of the abdomen, thigh fat and muscle volume of the thigh on the one hand and peak $\mathrm{GH}$ on the other hand ${ }^{38}$. However, Grugni et al. found no correlations between peak GH levels and BMI or fat mass in adult patients with $\mathrm{PWS}^{37}$. Further research in this area is necessary, but since there is a strong correlation between peak GH and BMI in healthy individuals and probably also in PWS adults, it seems reasonable to use BMI-related cut off points in adult PWS patients until more knowledge is gained, although BMI might not be a good reflection of obesity in PWS subjects.

In conclusion, we found several pituitary hormone deficiencies in a significant number of adults with PWS, hypogonadism and growth hormone deficiency being most prominent, although the percentage of patients with GHD strongly depends on the criteria used. Furthermore, anterior pituitary size was significantly lower when compared to healthy controls. Studies of GH therapy are scarce in adults, but positive effects on body composition have been 
described ${ }^{13,41}$. Future studies of endocrine function and the effects of hormonal substitution, including GH therapy in large groups of adult PWS patients, are warranted. 


\section{REFERENCES}

1. Prader A, Labhart A, Willi H: Ein Syndrom von Adipositas, Kleinwuchs, Kryptorchismus und Oligophrenie nach myatonieartigem Zustand im Neugeborenenalter. Schweiz Med Wochenschr 1956; 86: 1260-1261.

2. Burman $P$, Ritzen EM, Lindgren AC: Endocrine dysfunction in Prader-Willi syndrome: a review with special reference to GH. Endocr Rev 2001; 22: 787-799.

3. Holm VA, Cassidy SB, Butler MG, Hanchett JM, Greenswag LR, Whitman BY, Greenberg F: Prader-Willi syndrome: consensus diagnostic criteria. Pediatrics 1993; 91: 398-402.

4. Cassidy SB: Prader-Willi syndrome. J Med Genet 1997; 34: 917-923.

5. Swaab DF: Prader-Willi syndrome and the hypothalamus. Acta Paediatr Suppl 1997; 423: 50-54.

6. Miller L, Angulo M, Price D, Taneja S: MR of the pituitary in patients with PraderWilli syndrome: size determination and imaging findings. Pediatr Radiol 1996; 26: 43-47.

7. lughetti L, Bosio L, Corrias A, Gargantini L, Ragusa L, Livieri C, Predieri B, Bruzzi P, Caselli G, Grugni G: Pituitary height and neuroradiological alterations in patients with Prader-Labhart-Willi syndrome. Eur J Pediatr 2008; 167: 701-702.

8. Tauber M, Barbeau C, Jouret B, Pienkowski C, Malzac P, Moncla A, Rochiccioli P: Auxological and endocrine evolution of 28 children with Prader-Willi syndrome: effect of GH therapy in 14 children. Horm Res 2000; 53: 279-287.

9. Beccaria L, Bosio L, Sanzari A, Aimaretti G, Ghigo E, Chiumello G: GH secretion in Prader-Labhard-Willi syndrome: somatotrope responsiveness to GHRH is enhanced by arginine but not by pyridostigmine. J Pediatr Endocrinol Metab 1996; 9: 577-583.

10. Bray GA, Dahms WT, Swerdloff RS, Fiser RH, Atkinson RL, Carrel RE: The Prader-Willi syndrome: a study of 40 patients and a review of the literature. Medicine 1983; 62: 59-80.

11. Corrias A, Bellone J, Beccaria L, Bosio L, Trifiro G, Livieri C, Ragusa L, Salvatoni A, Andreo M, Ciampalini P, Tonini G, Crino A: GH/IGF-I axis in Prader-Willi syndrome: evaluation of IGF-I levels and of the somatotroph responsiveness to various provocative stimuli. Genetic Obesity Study Group of Italian Society of Pediatric Endocrinology and Diabetology. J Endocrinol Invest 2000; 23: 84-89.

12. Grugni G, Marzullo P, Ragusa L, Sartorio A, Trifiro G, Liuzzi A, Crino A: Impairment of $\mathrm{GH}$ responsiveness to combined $\mathrm{GH}$-releasing hormone and arginine administration in adult patients with Prader-Willi syndrome. Clin Endocrinol 2006; 65: 492-499.

13. Hoybye C: Endocrine and metabolic aspects of adult Prader-Willi syndrome with special emphasis on the effect of growth hormone treatment. Growth Horm IGF Res 2004; 14: 1-15.

14. Partsch CJ, Lammer C, Gillessen-Kaesbach G, Pankau R: Adult patients with Prader-Willi syndrome: clinical characteristics, life circumstances and growth hormone secretion. Growth Horm IGF Res 2000; 10: S81-S85.

15. Davies PS: Growth hormone therapy in Prader-Willi syndrome. Int J Obes Relat Metab Disord 2001; 25: 2-7.

16. Eiholzer U, Stutz K, Weinmann C, Torresani T, Molinari L, Prader A: Low insulin, IGF-I and IGFBP-3 levels in children with Prader-Labhart-Willi syndrome. Eur $J$ Pediatr 1998; 157: 890-893. 
17. Eiholzer U, Bachmann S, I'Allemand D: Is there growth hormone deficiency in Prader-Willi Syndrome? Six arguments to support the presence of hypothalamic growth hormone deficiency in Prader-Willi syndrome. Horm Res 2000; 53: 44-52.

18. Goldstone AP: Prader-Willi syndrome: advances in genetics, pathophysiology and treatment. Trends Endocrinol Metab 2004; 15: 12-20.

19. Hoybye C, Frystyk J, Thoren M: The growth hormone-insulin-like growth factor axis in adult patients with Prader Willi syndrome. Growth Horm IGF Res 2003; 13: 269274.

20. Eiholzer U, l'Allemand D, Rousson V, Schlumpf M, Gasser T, Girard J, Gruters A, Simoni M: Hypothalamic and gonadal components of hypogonadism in boys with Prader-Labhart- Willi syndrome. J Clin Endocrinol Metab 2006; 91: 892-898.

21. Hirsch HJ, Eldar-Geva T, Benarroch F, Rubinstein O, Gross-Tsur V: Primary testicular dysfunction is a major contributor to abnormal pubertal development in males with Prader-Willi syndrome. J Clin Endocrinol Metab 2009; 94: 2262-2268.

22. Jeffcoate WJ, Laurance BM, Edwards CR, Besser GM: Endocrine function in the Prader-Willi syndrome. Clin Endocrinol 1980; 12: 81-89.

23. Lee PD: Disease management of Prader-Willi syndrome. Expert Opin Pharmacother 2002; 3: 1451-1459.

24. Muller J: Hypogonadism and endocrine metabolic disorders in Prader-Willi syndrome. Acta Paediatr Suppl 1997; 423: 58-59.

25. Butler MG, Theodoro M, Skouse JD: Thyroid function studies in Prader-Willi syndrome. Am J Med Genet A 2007; 143: 488-492.

26. Cassidy SB, Driscoll DJ: Prader-Willi syndrome. Eur J Hum Genet 2009; 17: 3-13.

27. Festen DA, Visser TJ, Otten BJ, Wit JM, Duivenvoorden HJ, Hokken-Koelega AC: Thyroid hormone levels in children with Prader-Willi syndrome before and during growth hormone treatment. Clin Endocrinol 2007; 67: 449-456.

28. Zipf WB: Prader-Willi syndrome: the care and treatment of infants, children, and adults. Adv Pediatr 2004; 51: 409-434.

29. de Lind van Wijngaarden RF, Otten BJ, Festen DA, Joosten KF, de Jong FH, Sweep FC, Hokken-Koelega AC: High prevalence of central adrenal insufficiency in patients with Prader-Willi syndrome. J Clin Endocrinol Metab 2008; 93: 1649-1654.

30. Lukaski HC, Johnson PE, Bolonchuk WW, Lykken GI: Assessment of fat-free mass using bioelectrical impedance measurements of the human body. Am J Clin Nutr 1985; 41: 810-817.

31. Drent ML, Delemarre-van de Waal HA, Wit JM: Once growth hormone, always growth hormone? Transition from growth hormone therapy in childhood to adulthood. Ned Tijdschr Geneeskd 2002; 146: 154-157.

32. Corneli G, Di Somma C, Baldelli R, Rovere S, Gasco V, Croce CG, Grottoli S, Maccario M, Colao A, Lombardi G, Ghigo E, Camanni F, Aimaretti G: The cut-off limits of the $\mathrm{GH}$ response to $\mathrm{GH}$-releasing hormone-arginine test related to body mass index. Eur J Endocrinol 2005; 153: 257-264.

33. Brambilla P, Bosio L, Manzoni P, Pietrobelli A, Beccaria L, Chiumello G: Peculiar body composition in patients with Prader-Labhart-Willi syndrome. Am J Clin Nutr 1997; 65: 1369-1374.

34. Miller JL, Goldstone AP, Couch JA, Shuster J, He G, Driscoll DJ, Liu Y, Schmalfuss IM: Pituitary abnormalities in Prader-Willi syndrome and early onset morbid obesity. Am J Med Genet A 2008; 146A: 570-577.

35. Goldstone AP, Holland AJ, Hauffa BP, Hokken-Koelega AC, Tauber M: Recommendations for the diagnosis and management of Prader-Willi syndrome. $J$ Clin Endocrinol Metab 2008; 93: 4183-4197. 
36. Aimaretti G, Bellone S, Baffoni C, Cornel G, Origlia C, Di VL, Rovere S, Arvat E, Camanni F, Ghigo E: Short procedure of GHRH plus arginine test in clinical practice. Pituitary 2001; 4: 129-134.

37. Grugni G, Crino A, Bertocco P, Marzullo P: Body fat excess and stimulated growth hormone levels in adult patients with Prader-Willi syndrome. Am J Med Genet $A$ 2009; 149A: 726-731.

38. Sode-Carlsen R, Farholt S, Rabben KF, Bollerslev J, Schreiner T, Jurik AG, Christiansen JS, Hoybye C: Body composition, endocrine and metabolic profiles in adults with Prader-Willi syndrome. Growth Horm IGF Res 2010; 20: 179-184.

39. Grugni G, Giardino D, Crino A, Malvestiti F, Ballarati L, Di GG, Marzullo P: Growth Hormone secretion among adult patients with Prader-Willi syndrome due to different genetic subtypes. J Endocrinol Invest 2010; in press.

40. Makimura H, Stanley T, Mun D, You SM, Grinspoon S: The effects of central adiposity on growth hormone $(\mathrm{GH})$ response to $\mathrm{GH}$-releasing hormone-arginine stimulation testing in men. J Clin Endocrinol Metab 2008; 93: 4254-4260.

41. Mogul HR, Lee PD, Whitman BY, Zipf WB, Frey M, Myers S, Cahan M, Pinyerd B, Southren AL: Growth hormone treatment of adults with Prader-Willi syndrome and growth hormone deficiency improves lean body mass, fractional bodv fat. and serum triiodothyronine without glucose impairment: results from th multicenter trial. J Clin Endocrinol Metab 2008; 93: 1238-1245. 


\section{DANKWOORD}




\section{DANKWOORD}

De berg is bedwongen, de top is bereikt! Nu ik de vlag heb geplant, is het goed om nog eens terug te kijken op hoe de reis hier naartoe is verlopen. De klim had ik niet op deze positieve en leerzame manier kunnen volbrengen zonder de hulp van vele reisgenoten die mij kortere of langere tijd hebben vergezeld. Graag gebruik ik deze gelegenheid om deze reisgenoten en iedereen die mij onderweg van de nodige proviand voor lichaam en geest heeft voorzien, te bedanken.

De bestemming van de reis werd bepaald door vragen van ouders. Hun kinderen met PWS werden ouder, bereikten volwassenheid en zelfs de oudere leeftijd. Ze wilden graag weten met welke kenmerken dit gepaard zou gaan en welke zorg hierbij gewenst zou zijn. De foto op de kaft van dit proefschrift staat voor mij symbool voor deze vragen. Het meisje staat toe te kijken op een feestje tijdens Koninginnedag. Aan haar houding en bouw is te zien dat het om een meisje met PWS gaat. Ze staart wat dromerig voor zich uit. Wellicht door de slaperigheid waar veel mensen met PWS ook overdag last van hebben, of doordat ze emotioneel niet mee komt met de andere spelende kinderen. Wat zal haar de rest van haar leven te wachten staan?

De routebeschrijving leidde mij allereerst kriskras door Nederland voor een kennismaking met de onderzoeksgroep en het verzamelen van de gegevens. De verkeerschaos door hevige sneeuwval, storingen in nieuwe tunnels en natuurlijk de dagelijkse files die altijd langer leken dan normaal, heb ik mogen trotseren, maar waren het meer dan waard. Na de lange reis volgde altijd een hartelijke en gastvrije ontvangst door deelnemers aan het onderzoek en hun familie en begeleiders. De verhalen waren vaak emotioneel, soms hilarisch, maar altijd uniek. Het was van grote toegevoegde waarde om iedereen in de thuissituatie te ontmoeten. Ik heb genoten van de slaapkamers: vaak bomvol verzamelingen van prullaria, met een grote puzzel op de tafel en soms een hometrainer in de hoek. Wat ik in mijn ooghoeken zag gebeuren tijdens de interviews was zeer illustratief voor wat het betekent om met het PWS te leven. Want wat gebeurt er als je dagprogramma opeens wijzigt doordat er een vreemde mevrouw aan de keukentafel zit als je uit je werk komt? En hoeveel kopjes koffie mag je als er iemand op bezoek is? Beste deelnemers, ouders en begeleiders: ik heb van dicht bij een kijkje mogen nemen in jullie levens, heel veel dank dat ik deze mogelijkheid heb gekregen!

De Prader-Willi/Angelman vereniging heeft een centrale rol gespeeld in mijn onderzoek. Ik wil de vereniging, en in het bijzonder Tamara en Gerard, danken voor de fijne samenwerking en hun inzet voor het onderzoek. Ook het Prader- 
Willi Fonds wil ik graag bedanken voor het in mij gestelde vertrouwen door de eerste subsidie die jullie als fonds verstrekten, in dit project te investeren. Ik heb grote bewondering voor de manier waarop jullie erin slagen om het onderzoek naar mensen met PWS te ondersteunen.

Ik wil graag mijn belangrijkste gidsen bedanken, mijn promotoren. Prof. dr. L.M.G. Curfs, beste Paul, dank voor de kans die je me hebt gegeven om dit onderzoek te kunnen uitvoeren. Jouw jarenlange inspanningen binnen de nationale en internationale PWS wereld waren van grote waarde voor het hele project. Dank dat je mij hierbinnen hebt geïntroduceerd. Prof. dr. C.T.R.M. Schrander-Stumpel, beste Connie, wij hebben met elkaar leren lezen en schrijven in de loop van de jaren. Inmiddels hebben we aan een half woord vaak genoeg. Ik wil je graag bedanken voor je persoonlijke betrokkenheid en je constructieve begeleiding. Ik heb veel geleerd van je ruime klinische ervaring en ben blij dat we dit in de komende jaren tijdens mijn opleiding kunnen voortzetten.

Vanaf het eerste moment dat ik aan onderzoek heb gesnuffeld zijn er nog twee mensen nauw bij betrokken geweest. Dr. M.A. Maaskant, beste Marian, jouw liefde voor cijfers en significantie doet mij elke keer versteld staan. Maar wat mij waarschijnlijk het meest heeft geholpen tijdens mijn promotie is jouw bijzondere vorm van humor. Wat hebben we gelachen toen we tegenover de nagelstudio sliepen, om de hysterische dia's van onze Aziatische vriendin en om jouw pogingen om alvast een geschikte jurk te scoren voor mijn promotiefeest. Dank voor je collegialiteit en vriendschap. Prof. dr. H.M.J. van Schrojenstein Lantman-de Valk, beste Henny, bedankt voor je opbouwende kritiek en persoonlijke interesse. Je hebt altijd oog voor de klinische relevantie van onderzoek en daar heb ik veel van geleerd. Ik bewonder je gedrevenheid en ambitie.

Mijn huisvesting tijdens mijn onderzoek is altijd nabij de unit algemeen van onze afdeling geweest. Prof. dr. J.P.M. Geraedts, beste Joep, bedankt voor je steun op cruciale momenten. Judith, Wies en Wilma, wat fijn dat jullie me vanaf dag 1 hebben geadopteerd! Dagelijkse beslommeringen, succesjes en frustraties heb ik met jullie kunnen delen. De lunches moeten we er vooral in blijven houden. Lieve Francis, bedankt voor je hulp bij de fotocollages en je betrokkenheid.

Uiteraard zijn er ook een aantal zijpaden, omwegen, en tweesprongen op weg naar de eindbestemming geweest. Graag dank ik de medeauteurs van de verschillende artikelen voor hun inbreng en prettige samenwerking. Jullie expertise op gebied van mensen met een verstandelijke beperking, slaap, 
genetica, psychiatrie, dermatologie, incontinentie en endocrinologie heeft mij geïnspireerd. Anneke en Caroline wil ik in het bijzonder danken voor het delen van het nodige onderzoekers-lief-en-leed. Ik wens jullie veel succes met het afronden van jullie proefschriften. Drs. P. Collin, beste Philippe, bedankt voor de stimulerende discussies over het onderzoek, de samenwerking in de patiëntenzorg en de gezelligheid tijdens congressen. Graag dank ik alle mensen van de units cytogenetica en DNA, en in het bijzonder drs. K. van Roozendaal, prof. dr. H.M.J. Smeets, dr. J.J.M. Engelen en dr. S. Stegmann, die hebben bijgedragen aan de genetische diagnostiek. Kees, door ons wekelijkse overleg hebben we de logistiek van het onderzoek goed op de rit kunnen houden. Dank voor je hulp! Dr. H. Boer, beste Harm, jij verdient een grote prijs voor het geven van stimulerende feedback. Door jouw aanwijzingen kon een tekst net van de juiste toon worden voorzien en daarmee heb je me in de laatste fase van mijn proefschrift enorm geholpen. Ik heb genoten van de inhoudelijke discussies die we hebben gehad. Je bescheidenheid siert je.

Beste collega's van de polikliniek klinische genetica. Bedankt voor alle lunches, koffiemomentjes, hulp bij secretariële problemen, uitleg over bloedbuisjes en speekselpotjes en betrokkenheid bij mijn onderzoek. Suzanne, mijn nieuwe roomie, bedankt voor de gezelligheid en collegialiteit. Dr. C.E.M. de DieSmulders, beste Christine en mijn huidige opleider, dank voor de ruimte en flexibiliteit om mijn promotie te voltooien. Ik kijk uit naar de rest van mijn opleiding. Nicky, partner in crime! We hebben heel wat life-time events mogen beleven in onze kelder. Een flinke dosis lachen en tranen hebben we gedeeld: van geaccepteerde publicaties, MEC protocollen, onderzoeksfrustraties tot relatie perikelen, kinderen en familie omstandigheden. Wat fijn dat je ook tijdens mijn promotie naast me staat. Tevens dank aan mijn collega's van het GKC voor het delen van onderzoekservaringen.

Ook buiten mijn werk hebben velen eraan bijgedragen dat mijn leven niet alleen uit wetenschap bestond en er voldoende ruimte was mijn hoofd af en toe leeg te maken. Sportmaatjes Mardoeka, Jeroen, Stefan, Richard, Roger, Pascal, Stephanie en jullie aanhang, het is bijzonder hoe een gemêleerde groep als deze elkaar kan vinden in zoveel meer dan alleen de uitlaatklep van de Body Attack. Bedankt voor jullie energie, geschreeuw en vriendschap. Maastrichtse vrienden, Mo, Niels, Brecht, Martijn, Anoek en velen meer, dank voor vertier in het weekend, stedentripjes, fietstochtjes, BBQ's en terrasjes. Mijn vriendschappen door heel Nederland vormden de uitgelezen logeermogelijkheid als ik tijdens mijn onderzoek met mijn grote koffer en weegschaal door het land trok. Wat fijn dat ik bij jullie terecht kon voor een bed, een maaltijd en een goed gesprek! Vrienden van de middelbare school, Maaike, Cathelijne, Marian, Bob, Dennis, Mathieu, Ferdi en Maarten, ook al 
zien we elkaar soms maar eens per jaar, binnen een kwartier zijn we weer 15 jaar terug in de tijd. Grappig om te merken dat er in essentie zo weinig verandert en we elkaar nog steeds zo goed kennen zonder dat we van elke dagelijkse beslommering op de hoogte zijn. Laten we snel weer wat plannen! KORT meiden, het blijft heerlijk om met jullie een theekransje te plannen en weer eens even de baby's, beste chocola, studietijd anecdotes, ideale vakantiebestemmingen, toekomst visies (is het oosten van het land nu echt de place-to-be nu we de dertig naderen?) en natuurlijk de mannen de revue te laten passeren. Sanne, Joris, Merijn, A-Sing, Rineke, Dirk-Jan, Evelyne, Tim, Bram, Frouke, Eric, Birgit en de kids, verspreid over het hele land zijn we ook na onze studie een hechte club gebleven in voor- en tegenspoed. Het is mooi om te zien hoe een ieder van ons zijn eigen weg in het artsenvak begint te vinden en deze is vaak anders dan jaren geleden voor ons is voorspeld. Lieve Jochen, bedankt voor je trouw, vriendschap en inspiratie. Hopelijk houdt het kleine Cals-Berkje zich een beetje aan de opdracht en zul je naast me staan tijdens mijn promotie!

Lieve Mark, dank voor alles wat je voor me hebt betekend tijdens mijn promotie en daarbuiten. Ik ben blij met wat we nu hebben. Ook veel dank aan de familie Kuipers voor de betrokkenheid.

Lieve schoonfamilie. Ik heb maar geboft met jullie. Ook al heb ik even moeten wennen aan jullie aantal, jullie ondernemingsdrift en jullie soms wat luidruchtige en stellige manier van communiceren.... inmiddels zijn pom en gele pesi mijn lievelingsgerechten, vind ik ook dat stoelverwarming standaard in iedere auto zou moeten zitten en geniet ik van jullie hechte band. Mijn fiets gaat alleen voorlopig de deur nog niet uit. Dank voor jullie steun op alle gebieden!

Lieve papa, mama en Bart. Dank voor alle mogelijkheden die jullie me hebben gegeven en voor de ruimte om mijn eigen weg te gaan. Door jullie ben ik geworden wie ik nu ben en hiermee hebben jullie de belangrijkste basis gelegd voor dit proefschrift. Lieve opa, het begin van mij promotie heb je nog heel bewust meegemaakt. Je kleindochter die een nieuwe stap in de wetenschappelijke wereld zette, je vond het razend interessant en bestookte me met het voor jou zo kenmerkende vragenvuur. Helaas vertroebelde je scherpe geest al snel daarna, maar ik weet dat je trots geweest zou zijn geweest op dit eindresultaat. Lieve opapa, je enige kleindochter is nu doctor. Ik besef me keer op keer dat het een voorrecht is om je grootouders zo lang van dichtbij mee te maken. Wat zou het een mooi moment zijn als ik jou op 101 jarige leeftijd mijn proefschrift kan komen overhandigen! Ook Daan, Joost, Hanneke, Hiske, Tjibbe, Wouter, Annelieke, Mieke en Kip, mijn kleine maar fijne familie, wil ik graag bedanken voor de interesse in mijn werk. 
Lieve Marco, jij gaf mij vleugels op het moment dat ik ze het hardst nodig had. Ik hou van je!

Dit dankwoord markeert het eind van deze reis. Wat was het een mooi avontuur...en wat ben ik blij dat ik de bestemming heb gehaald. Het is tijd voor een feestje! 
CURRICULUM VITAE 


\section{CURRICULUM VITAE}

Margje Sinnema werd op 23 oktober 1981 geboren in Utrecht. Zij groeide op in het landelijk gelegen dorpje Den Ham in Overijssel. Haar gymnasium opleiding volgde ze in Almelo (OSG Erasmus), waar zij in 2000 haar diploma behaalde. Ze verhuisde naar Maastricht om geneeskunde te gaan studeren. In 2006 behaalde ze cum-laude haar artsexamen.

Tijdens haar studie geneeskunde volgde ze twee keuzestages bij de afdeling Klinische Genetica in Maastricht. Naast een algemene kennismaking met het vakgebied, bracht zij tevens de in Maastricht bekende Neurofibromatose type I populatie in kaart. Zij volgde een extra keuzecoschap arts voor verstandelijk gehandicapten in Op de Bies te Landgraaf. Tijdens haar wetenschapsstage verrichte zij een vragenlijstonderzoek naar veroudering bij mensen met PraderWilli syndroom. Dit vooronderzoek kreeg een vervolg tijdens haar promotie onderzoek bij het Gouverneur Kremers Centrum en de afdeling Klinische Genetica van het Maastricht Universitair Medisch Centrum.

$\mathrm{Na}$ het behalen van het artsexamen, werkte zij van maart 2007 tot en met februari 2011 aan haar promotie onderzoek, onder leiding van Prof. dr. L.M.G. Curfs en Prof. dr. C.T.R.M. Schrander-Stumpel. Zij presenteerde de resultaten van haar onderzoek o.a. in mei 2010 op het congres van de Internationale Prader-Willi Syndroom Organisatie (IPWSO) in Taipei, Taiwan. Naast haar wetenschappelijke werk, leverde ze bijdrages aan de oudercontactdagen van de Nederlandse Prader-Willi/Angelman vereniging, was zij betrokken bij twee films over Prader-Willi syndroom en ontwikkelde zij mede het "Medical Alerts" boekje.

In maart 2011 startte zij met de opleiding tot klinisch geneticus in Maastricht (opleider: Dr. C.E.M. de Die-Smulders). Zij heeft een relatie met Marco Essed, met wie zij samenwoont in Maastricht. 
